\title{
Masters of Uncertainty: Social Scares and the Politics of Change in Energy Policy
}

\author{
by
}

Simon Langlois-Bertrand

A thesis submitted to the Faculty of Graduate and Postdoctoral Affairs in partial fulfillment of the requirements

for the degree of

Doctor of Philosophy

in

International Affairs

Carleton University

Ottawa, Ontario

(C) 2014

Simon Langlois-Bertrand 


\section{Abstract}

Social scares are periods triggered by a spectacular, deadly, traumatizing, or otherwise disruptive event. The event produces a sudden, broadly shared perception of insecurity that brings an area of activity to the forefront of public and political attention. In these instances, leading political figures must strike a balance between two objectives: appearing as good leaders to temper the insecurity felt by large segments of their population; and obtaining a policy outcome they are comfortable with. This balancing act is no easy task, as the scare context forces government actors to "do something", which may lead to policy changes unattractive to them. Nevertheless, political leaders who perform well regarding the first objective win a prize consisting of a bulk of symbolic capital, by being perceived as reducing the perception of insecurity. This is how social scares differ from the policy process during any other period: actors who capture a large such prize in the first days and weeks of a scare possess a formidable resource in the battle over potential policy changes, as this bulk of symbolic capital can tilt the balance to their favor, even if other coalitions and actors have substantial resources. Hence the form that the policy process takes in the aftermath of a scare results from the combination of the obligation for actors in power to act convincingly, of the constraints that this obligation imposes on them, and of the clashing sets of interests that the different groups have regarding the policy options.

Focusing on scares related to the energy sector, this dissertation shows how this two-dimensional battle is shaped by four aspects: the triggering event and the first prize that emerges from it; the strategies and actions of the actors regarding the two objectives; the framing of uncertainty and risk, and the role played by experts; and the impact of 
contextual factors, in particular the election timing and the regime type. By using these as broad investigative questions within the method of structured, focused comparison, the model allows for a better understanding of the political battles that occur while societies progressively return to a more normal state of affairs. 


\section{Acknowledgements}

This project would not have been possible without the help of several people at different stages. I would especially like to thank my two supervisors, Dr. James Meadowcroft and Dr. David Long, for their help and numerous suggestions and comments over the past few years.

I also want to thank Dr. Philippe Faucher, Dr. Jean Daudelin, Dr. Dane Rowlands, and Claire Woodside for their helpful comments in the early stages of the project. Finally, I want to thank Gaëlle Rivard-Piché and Eric Jardine for their extensive comments on later versions of the dissertation. 


\section{Table of Contents}

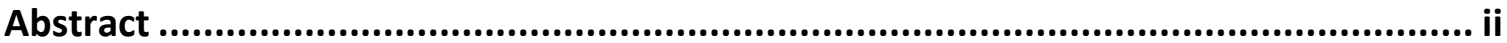

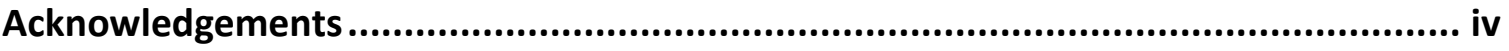

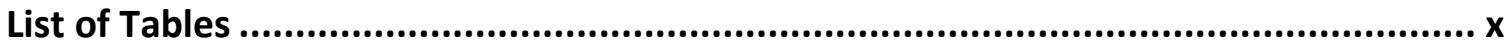

List of Figures ............................................................................................................. xi

Chapter 1. Introduction: uncertainty, insecurity, and social scares .......................... 1

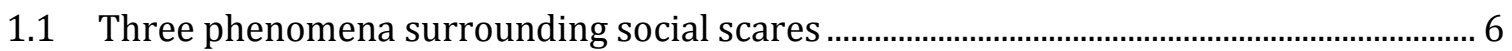

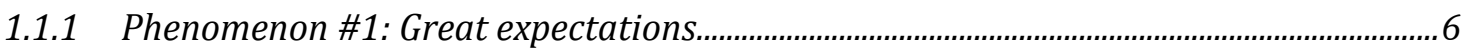

1.1.2 Phenomenon \#2: “Where were you, Mr. President?" ........................................................

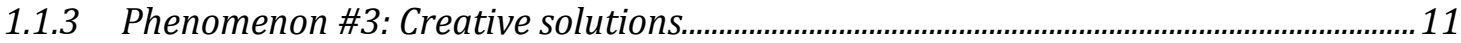

1.2 Social scares, uncertainty, and policy change

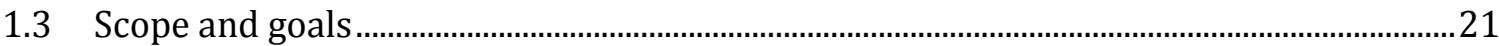

1.3.1 Scope of the study

1.3.2 Goals

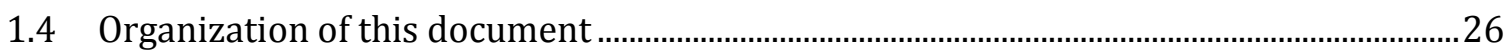

Chapter 2. Social scares and the policy process ................................................ 31

2.1 Social scares and theories of the policy process ….................................................................

2.2 From social scare to major policy change - or not.................................................................... 40

2.2.1 Causal chain: from social scare to policy change …............................................................ 41

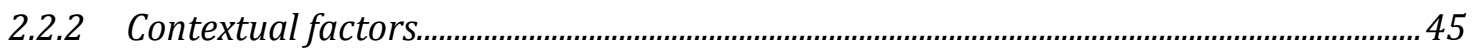

2.2.3 A political rent: the leadership curse and the resolution of the social scare ..................47

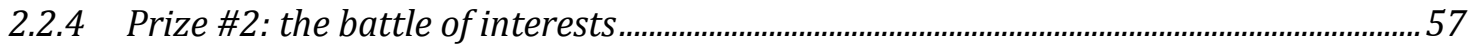


Chapter 3. Uncertainty, framing, and experts: additional theoretical considerations in

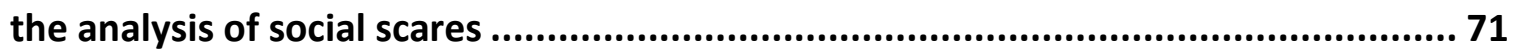

3.1 The social scare context: additional elements in the competition for the prizes ............72

3.1.1 Individual perception and social construction of risk and uncertainty ..........................77

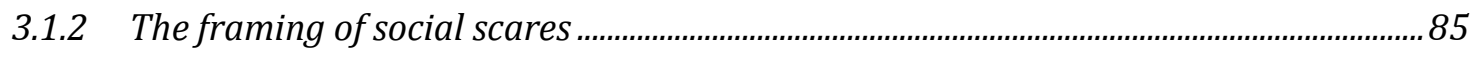

3.1.3 Science, knowledge, and politics: the competition for legitimacy and credibility...... 93

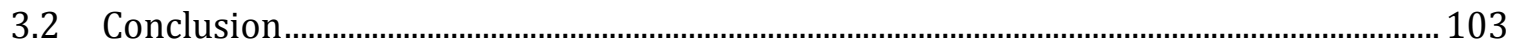

Chapter 4. Harnessing power: Investigating energy scares .................................. 105

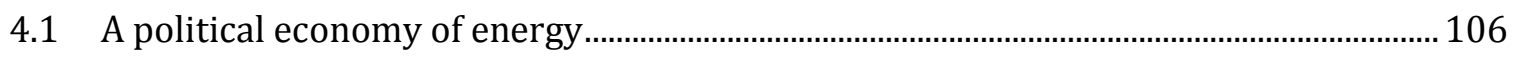

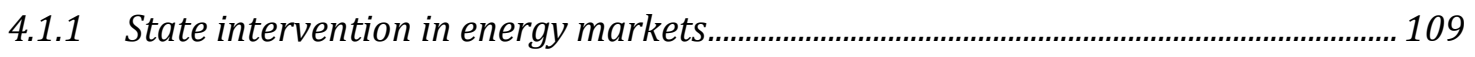

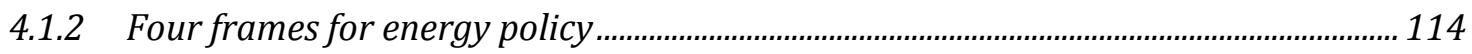

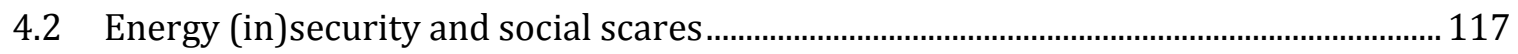

4.3 A model to study energy scares: methodological approach............................................. 121

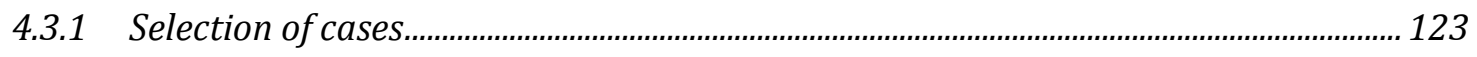

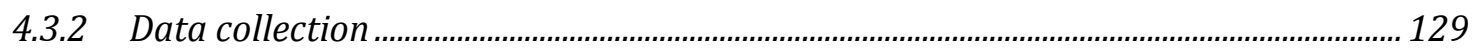

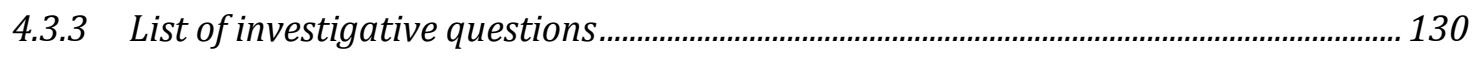

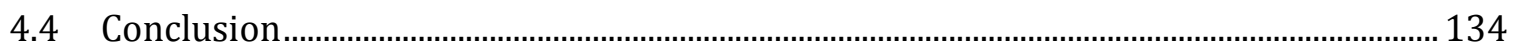

Chapter 5. Using the scare for different purposes: the Canadian National Energy

Program and the North American Ice Storm............................................... 135

5.1 Case \#1: the 1979-1980 oil shock and the passage of the National Energy Program in Canada 136 


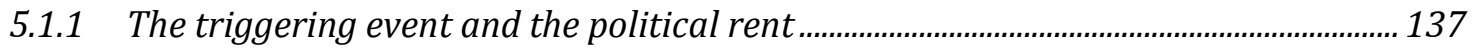

5.1.2 Strategies and actions of the actors regarding the two objectives ............................... 141

5.1.3 The framing of uncertainty and risk, and the role of experts........................................ 143

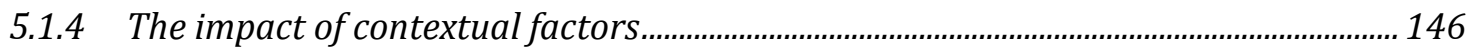

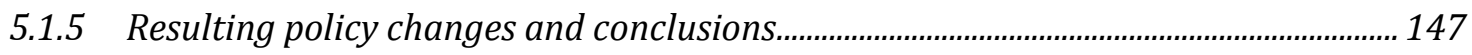

5.2 Case \#2: The 1998 Great Ice Storm in Quebec, Canada.................................................... 149

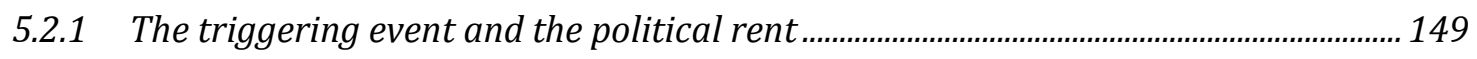

5.2.2 Strategies and actions of the actors regarding the two objectives ............................... 152

5.2.3 The framing of uncertainty and risk, and the role of experts.......................................... 156

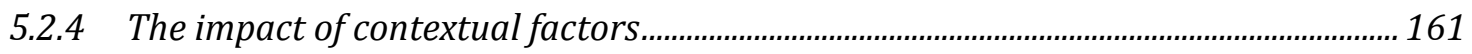

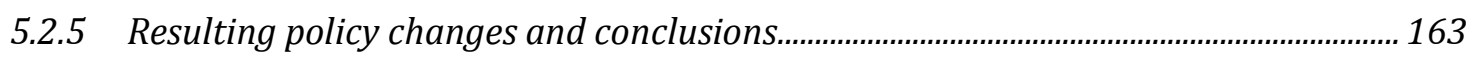

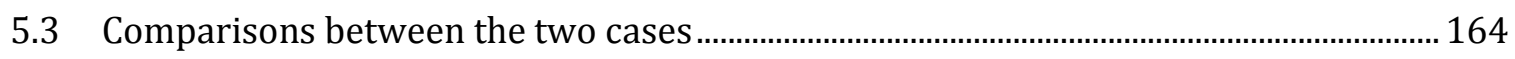

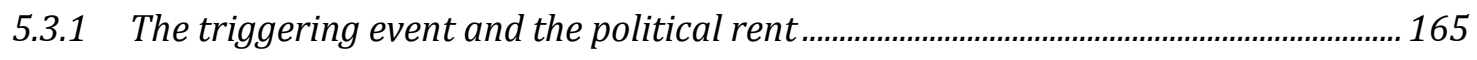

5.3.2 Strategies and actions of the actors regarding the two objectives ............................... 167

5.3.3 The framing of uncertainty and risk, and the role of experts....................................... 169

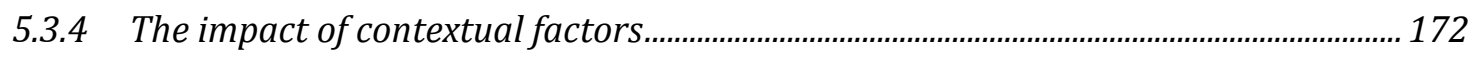

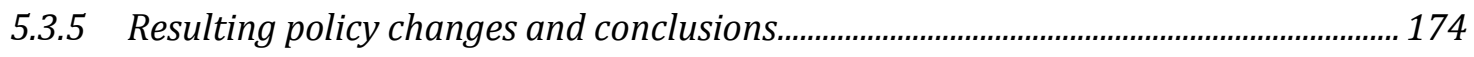

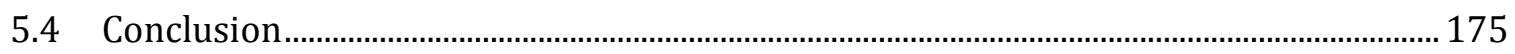

\section{Chapter 6. Forfeiting the rent: The impact of the Chernobyl nuclear disaster in West}

Germany and the Exxon Valdez oil spill in the United States ............................. 177

6.1 Case \#3: The 1986 Chernobyl accident and its impact in West Germany ...................... 177

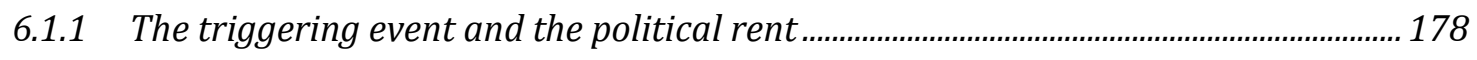

6.1.2 Strategies and actions of the actors regarding the two objectives ............................... 182

6.1.3 The framing of uncertainty and risk, and the role of experts.......................................186 


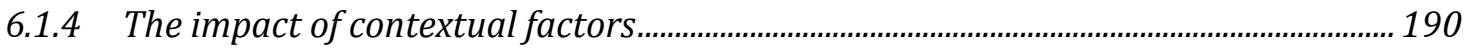

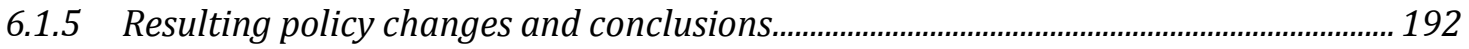

6.2 Case \#4: The 1989 Exxon Valdez oil spill in the United States........................................... 195

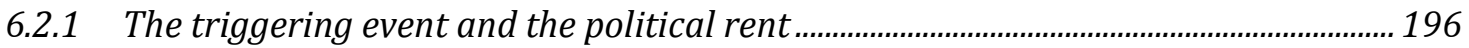

6.2.2 Strategies and actions of the actors regarding the two objectives ............................... 197

6.2.3 The framing of uncertainty and risk, and the role of experts........................................200

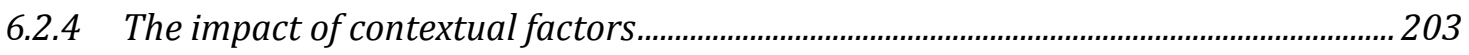

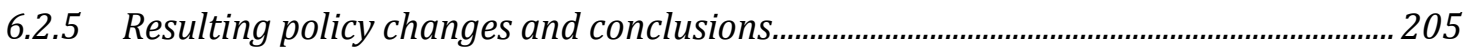

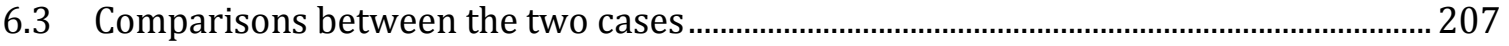

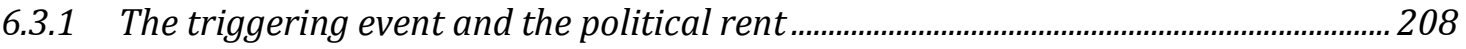

6.3.2 Strategies and actions of the actors regarding the two objectives ...............................210

6.3.3 The framing of uncertainty and risk, and the role of experts.......................................... 211

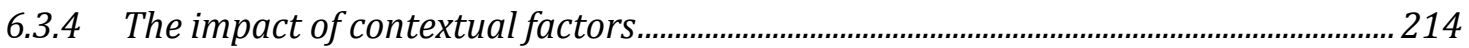

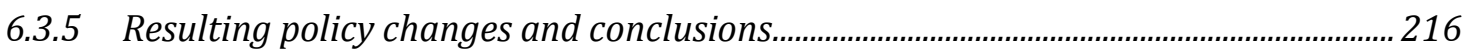

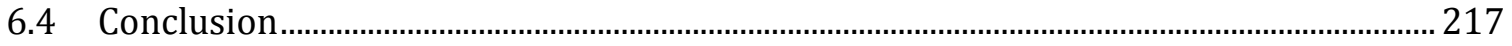

Chapter 7. Additional comparisons and a typology of social scares........................ 219

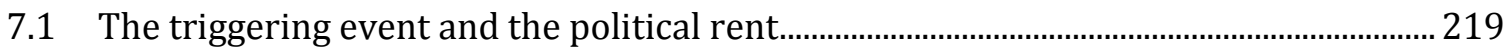

7.2 Strategies and actions of the actors regarding the two objectives ................................... 224

7.3 The framing of uncertainty and risk, and the role of experts ............................................. 229

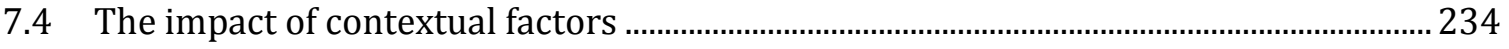

7.5 Policy outcomes and paths to change: a typology of social scares ...................................... 237

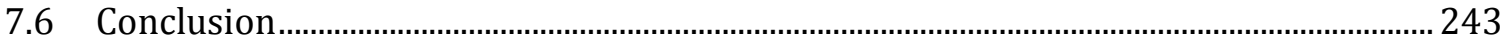

Chapter 8. A refined model to study energy scares ............................................ 244

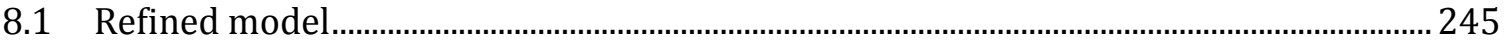


8.2 The 2010 Deepwater Horizon oil spill in the United States ............................................... 250

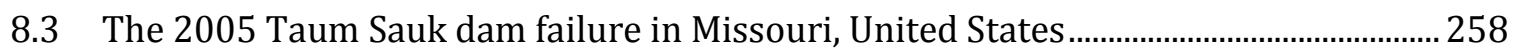

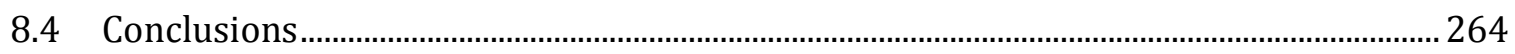

Chapter 9. Conclusions and policy implications ............................................. 265

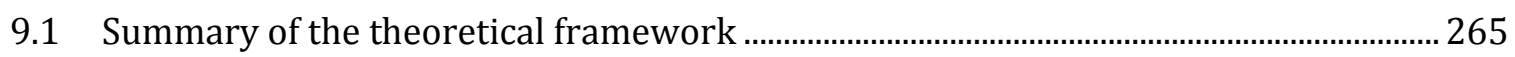

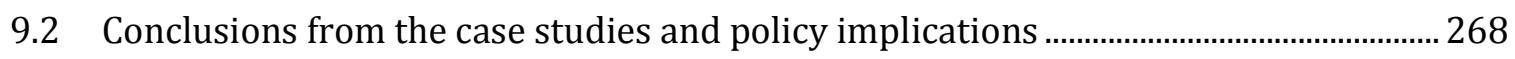

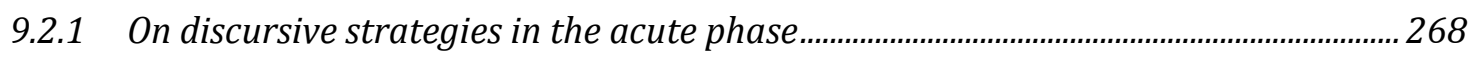

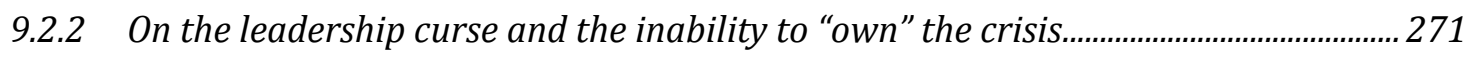

9.2.3 On the measurement of the "magnitude" of social scares..............................................22

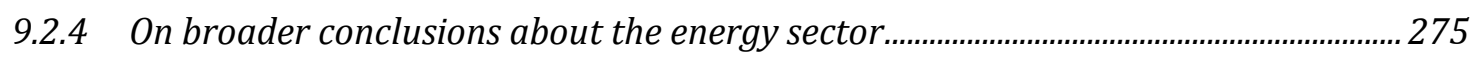

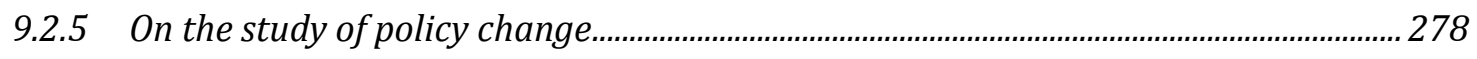

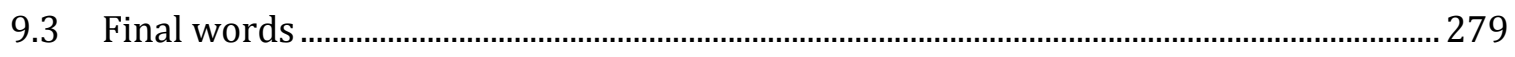

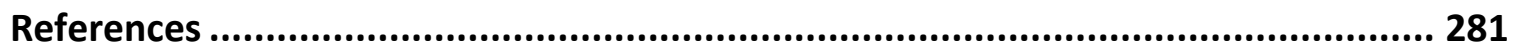

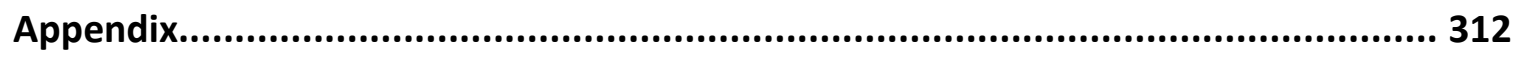




\section{List of Tables}

Table 1. U.S. Presidents attendance to disaster aftermaths.................................10

Table 2. Summary of distinctions between the two dimensions........................67

Table 3. Frames for state intervention in energy .......................................... 116

Table 4. Refined model to investigate energy scares and their impact on policy 


\section{List of Figures}

Figure 1. From social scare to policy change: basic causal chain..........................42

Figure 2. Potential symbolic capital prize (objective \#1) from the social scare.

Figure 3. World primary energy supply (1971).................................................. 107

Figure 4. World primary energy supply (2011)................................................... 107

Figure 5. OECD primary energy supply (1971).................................................. 107

Figure 6. OECD primary energy supply (2011) ................................................... 107

Figure 7. Non-OECD primary energy supply (1971)............................................ 107

Figure 8. Non-OECD primary energy supply (2011)............................................ 107

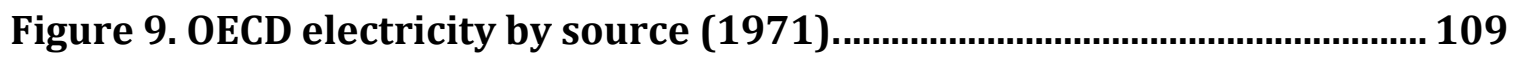

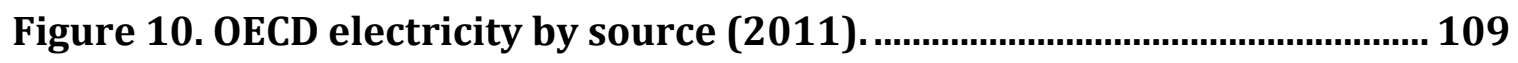

Figure 11. Typology flow chart: various paths to policy change or stability . 240 


\section{Chapter 1}

\section{Introduction: uncertainty, insecurity, and social scares}

This dissertation is about social scares, the policy process, and the energy sector. Social scares are periods that follow disruptive events, where the normal dynamics of the policy process are temporarily altered. In the first part of this dissertation, covered in Chapters 1 through 4, I develop a framework to analyze the impact of social scares on policy, with one overarching question in mind: why is it that some of these instances lead to major policy change, while others do not?

In the second part of the dissertation, I present four case studies from the energy sector. The case studies serve both to illustrate the application of the framework, and to analyze and refine its strengths and weaknesses. Once this is done, two further cases are discussed, and demonstrate the value of the framework for analytical purposes. Using this framework helps better understand energy policy-making in the aftermath of dramatic events, unveiling the mechanisms through which social scares cause different types of policy change. In the conclusion, I reflect on how this framework can be replicated in areas other than energy.

Imagine the following scene. You live in New York City and you are watching the morning news on television. The channels are all showing images of the devastation following the collapse, an hour earlier, of a major bridge in California, while hundreds of people were driving on it. You then have to drive to work, and while doing so, you go over a bridge similar to the one you saw on the news. As far as California is from where 
you are, at that moment, you cannot help but wonder, what if it had been you? And, could it be you the next time around?

Across the country, millions of people are having reflections similar to yours. To varying degrees, several questions will be asked in the public sphere, some very loudly by politicians and advocacy groups, in the days, weeks, and months following the event. On the news, on pundit shows, in conversations at lunchtime at work, around an afterwork drink or a dinner table. What needs to be done for the people trapped in the disaster? And later on, are authorities adequately equipped and competent in trying to save the people who have not died yet? Is there someone responsible for this man-made catastrophe? What was its cause? Does this cause imply that other similar pieces of infrastructure are in danger of collapsing elsewhere in the country? Is this revealing of a broader and larger problem in construction regulation? Or even in the way we manage transport around the country?

It is not particularly difficult to imagine that this single event may have repercussions on issues related to bridge collapses, but also ones well outside of that particular problem. Three years later, for instance, modifications to construction regulations may have been put into place; elections may have been lost due to public outrage for incompetency in managing rescue efforts; major changes in city transit planning may have been enacted and implemented; or maybe none of this happened, and the only changes are that debris have been removed and victims have been buried and mourned. Regardless of which outcome it is, however, one thing is certain: after these three years, when you drive to work in the morning, it is highly unlikely that you will be 
thinking about any of the questions mentioned above. The crisis, the shock, the scare, will be long gone, irrespective of - and sometimes despite - what was "done" in the aftermath of the collapse.

In the example used above, some items should be familiar: the spike of attention following a spectacular event, the hectic immediate aftermath, and the idea that these instances have the potential of becoming turning points in certain policy areas. Nothing in these processes, however, has to do with bridges. Terrorist attacks, hurricanes and tornadoes, health crises and virus outbreaks, industrial accidents, and many more possibilities all produce a certain departure from what is perceived to be the normal state of affairs. The sudden destruction that these events bring and the lives that they claim, caused by one form or another of nature's wrath or human negligence, often trigger this departure. So what is it, exactly, that makes a situation a crisis? Why are some events considered shocks? Why is major policy change more likely - but only more likely - in the aftermath of a disaster or any traumatizing event?

These are all central questions in the study of policy change. The different literatures linking natural disasters, traumatizing events, and crises and shocks of all kinds to policy change all share a general line of thought: whenever one or more events are raised to this exceptional status, societal and political debates occur in a special setting, and "normal" dynamics between public officials, interest groups, and the general public are altered. In these instances, which I label more generally social scares 
throughout this project, a broadly shared perception of insecurity comes to surround a particular area of activity, causing increased public and political attention. ${ }^{1}$

Regardless of their exact features, these instances also share another characteristic: an unusually high presence of uncertainty, whether it be with regard to the causes that led to the onset of the scare, the immediate impacts on the direct victims, the risks concerning the future in that sector of activity, the policy solutions that need to be put in place to prevent future occurrences of similar events, and so on. Uncertainty - the lack of one's ability to satisfyingly anticipate an outcome - is an inescapable part of life. It generally has negative connotations, however, as for most people it is associated with feelings of insecurity, of powerlessness. Even more, at least in Western democracies, many people see the basic function of government as being to manage and reduce uncertainties, and consequently expect authorities to act to abate, temper, compensate, and if possible prevent the brutal fluctuations produced by an unpredictable social and physical world. For these actions equate to providing a certain sense of safety for its population.

Somewhere within this changed political context, several factors make major policy change - otherwise very rare - more likely. Some scares do indeed modify policy regimes in a fundamental way. The September $11^{\text {th }}, 2001$ attacks in the United States, for instance, are one such case, where the administration in place was able to obtain the swift passage of sweeping legislation (e.g., the USA PATRIOT Act of 2001) and important modifications to the structure of the government (e.g., the restructuring of intelligence

\footnotetext{
${ }^{1}$ Although the term "social scare" has been used by others in the past - for instance see Ungar (1992, 2000), I use the term differently in this project, as defined and explained throughout the first two chapters.
} 
agencies and the creation of the Department of Homeland Security; see Birkland, 2004). Similarly, the oil embargo imposed by Arab states in 1973-74 on the United States and the Netherlands, which was later expanded and affected several other OECD members, was followed by the creation of a department of energy in several countries, the creation of the International Energy Agency, as well as the setup of a strategic petroleum reserve system (Yergin, 2008).

On the other hand, some major scares provoke only minimal change, for instance the North American ice storm in 1998 (see Chapter 5 in this document). And even when they do provoke policy changes, they often remain within the boundaries of the policy regime already in place, and could hardly be described as atypical - see, for instance, the changes in public school security after the Columbine High School Massacre (Birkland \& Lawrence, 2009), or the modifications to immigration policy after the 2005 riots in France (Pala, 2006). While we often assume that atypical policy change comes out of these periods, our understanding of the mechanisms linking social scares to different types and degrees of change remains limited.

This is a project about social scares, and the different ways through which they impact policy in Western democracies. The thesis I introduce in this chapter traces the effect of social scares on policy to the spike in insecurity that they bring, to the many uncertainties that they highlight, and to the combined impact that these features have on political battles that occur while societies progressively return to a more normal state of affairs. As a result, this thesis improves our understanding of the mechanisms that lead 
some - but only some - unusual or extraordinary events to changes that can be described as atypical.

\subsection{Three phenomena surrounding social scares}

I begin the discussion by highlighting three phenomena that are typically observed in the social scares that have occurred in the past few decades, illustrating the impact they have on the relationship between the government and the public. These phenomena are: (1) the abrupt heightening of expectations towards public officials following disruptive events; (2) the political importance for leaders to personally attend to the aftermath of a disaster; and (3) the reach of resulting policies outside of a narrow interpretation of the issue underlying the event triggering the scare. I then discuss how these phenomena provide hints into why these periods of social scare can be followed by changes in policy.

\subsubsection{Phenomenon \#1: Great expectations}

The first phenomenon can be observed in debates and interventions during the scare's duration. Whenever a scare is triggered, a large part of the State's population comes to be more demanding of their government(s) and leaders. If a natural disaster

produces refugees, if a military or terrorist attack results in dead and injured people, or if an international crisis forces people to wait in mile-long lines to buy gasoline at 10 times the usual price, the public's standard is that someone needs to lead and take care of the situation. 
There are two different aspects to this heightening of expectations. On one level, the victims of the events themselves, the ones directly affected, come to be completely dependent on the authorities. This is a gross generalization, of course, but these are instances where victims criticize authorities in a way that would be unimaginable in "regular" times - i.e., when they are not victims of this type of event, whether it's a catastrophe, a natural disaster, a large-scale financial fraud, or the like. In other words, the fact that they are victims of an unexpected and dire event temporarily intensifies their expectations toward the government's role, as they now see its responsibility as being to act as a safety net for whatever hardship they are being put through.

On another level, and perhaps more importantly for this discussion, this process can also be observed in the general public. Outrage is often felt when listening to victims' or pundits' criticisms of the authorities' incompetence, or merely the insufficiency of their effectiveness in helping the people stricken. What this suggests is that even for people not immediately affected by the current or even potential impacts of the events, i.e. people who are not even close to being victims, the expectations toward the authorities' actions are also dramatically enhanced.

Two observations follow from this. First, the disruption caused by the event, regardless of whether it is threatening to anyone's life, is not accepted as normal either by the victims or the general public. The expectations, in other words the broadly shared perception of the standard minimum for state involvement, are temporarily altered and raised. Ideally the authorities need to both provide an additional set of services to the direct victims and eventually find a credible way to prevent avoidable repetitions of the 
situation. Moreover, the effectiveness of the State's agents in doing so, especially for the phase immediately following the event - rescue efforts, for instance - must be flawless.

Second, whether the scare is a "natural" disaster or not changes little in this: sheltered hurricane victims in a stadium, injured people after a terrorist attack, or groups without electrical power for several days after a winter blackout can all be situations that manifest characteristics of this phenomenon. The nature and cause of the scare, as it is perceived, is then only relevant to the extent that there are different degrees to which the processes described above take place: certain scares produce a more intense spike in expectations than others, but smaller scares still raise the stakes.

\subsubsection{Phenomenon \#2: "Where were you, Mr. President?"}

The second phenomenon is that heads of government who do not attend physically the aftermaths of the event triggering a scare do so at their own political peril. To illustrate this, recall hurricane Katrina, which struck the United States in August of 2005 and became its costliest natural disaster in recorded history (National Oceanic and Atmospheric Administration, 2013). The hurricane is mostly remembered for the flooding of the city of New Orleans, which, coupled with images of a considerable number of refugees and difficult conditions in temporary shelters, rapidly became the main topic in the U.S. media ("Rewind 2005," 2006). As the national public watched relief efforts in the days and weeks following the disaster, some criticism emerged with regard to the federal government's actions. The Federal Emergency Management Agency (FEMA) and its director Michael Brown were particularly targeted with claims of 
incompetency, as its response quickly appeared to be slow and insufficient ("'Can I Quit Now'," 2005). President Bush was also personally criticized for two main reasons: first, he did not interrupt his vacation on his Texas ranch until more than a day after the disaster ("A look back to 2005," 2010); second, although he flew over the region on his way back to Washington, D.C., he visited neither the New Orleans area nor the temporary shelters before several weeks after the disaster ("Bush arrives on New Orleans tour," 2005).

Heads of government's presence on the site of a catastrophe like Katrina has hardly any direct impact on the effectiveness of the authorities' relief efforts. Nevertheless, it has become a necessity for them to physically attend to crises such as these. This is not a new phenomenon, but it is a trend that has been confirmed and solidified in recent decades, and seems to have become a rule of governance that can either play in the favor of heads of government, governors, mayors and other political figures, or be held against them when they ignore it. Criticisms of President Bush in the months following Katrina come in sharp contrast to his praise in September of 2001, for instance, when he visited Ground Zero in the days following the terrorist attacks (Hart, Tindall, \& Brown, 2009). Furthermore, these two events (Katrina and the September $11^{\text {th }}$ attacks) would seem, at first glance, to be of a different nature, which suggest that this rule of governance covers a variety of occurrences.

If this were indeed a strong trend, then we would expect that heads of government have been consistent in physically attending the aftermaths of traumatizing events. Table 1 presents a list of notorious events in the past four decades in the United States, and 
indicates whether or not the President physically visited the site. Different types of events are included (natural disasters, nuclear incidents, military threats, shootings, and others), and the list focuses on the ones with the highest one-time death tolls or monetary damage. ${ }^{2}$

Table 1. U.S. Presidents attendance to disaster aftermaths

\begin{tabular}{lllccc}
\hline Year & \multicolumn{1}{c}{ Incident } & President & $\begin{array}{c}\text { Fatalities } \\
\text { (injured) }\end{array}$ & $\begin{array}{c}\text { Estimated } \\
\text { damage } \\
\text { (millions of \$) }\end{array}$ & $\begin{array}{c}\text { Attended } \\
\text { physically } \\
\text { (within 5 days) }\end{array}$ \\
\hline 1977 & Beverly Hills Supper Club fire & J. Carter & $165(200)$ & N/A & No \\
1979 & Three mile island & J. Carter & 0 & 1,000 & Yes \\
1981 & Hyatt Regency walkway collapse & R. Reagan & $114(216)$ & 153 & No \\
1989 & San Francisco earthquake & G.H.W. Bush & $63(3757)$ & 6,000 & Yes \\
1989 & Exxon Valdez oil spill & G.H.W. Bush & 0 & $3,000-15,000$ & No \\
1993 & End of Waco Siege & B. Clinton & 76 & 0 & No \\
1993 & World Trade Center bombing & B. Clinton & $6(1000+)$ & N/A & No \\
1995 & Oklahoma City bombing & B. Clinton & $168(680)$ & 652 & Yes \\
1999 & Columbine High School massacre & B. Clinton & $15(24)$ & 0 & Yes \\
2001 & September 11 th attacks & G.W. Bush & $2,996(6,000+)$ & N/A & Yes \\
2005 & Hurricane Katrina & G.W. Bush & $1,500+(\mathrm{N} / \mathrm{A})$ & 108,000 & No \\
2004 & Hurricane Ivan & G.W. Bush & $57(\mathrm{~N} / \mathrm{A})$ & 14,200 & Yes \\
2007 & Minnesota bridge collapse & G.W. Bush & $13(145)$ & 400 & Yes \\
2007 & Virginia Tech massacre & G.W. Bush & $33(17)$ & 0 & Yes \\
2007 & California wild fires & G.W. Bush & $9(85)$ & $?$ & Yes \\
2008 & Hurricane Ike & G.W. Bush & $135(\mathrm{~N} / \mathrm{A})$ & 24,900 & Yes \\
2009 & Fort Hood shooting & B. Obama & $13(32)$ & 0 & Yes \\
2010 & BP oil spill & B. Obama & $11(0)$ & 42,200 & Yes \\
2011 & Tucson shooting & B. Obama & $6(13)$ & 0 & Yes \\
2011 & Tornado outbreak & B. Obama & $316(2,400+)$ & 4,200 & Yes \\
2012 & Sandy Hook Elem. school shooting & B. Obama & $28(2)$ & 0 & Yes \\
2012 & Hurricane Sandy & B. Obama & $147(\mathrm{~N} / \mathrm{A})$ & $50,000+$ & Yes \\
2013 & Boston marathon bombings & B. Obama & $3(200+)$ & N/A & Yes \\
\hline Note: & SOurces for estimates can be found & & & \\
\hline
\end{tabular}

Note: sources for estimates can be found in the Appendix.

a. "Attended" is defined here as instances where the President visited either the exact site of the incident, or a symbolic venue if this was not possible.

b. Attended a month later.

c. Attended 12 days later.

\footnotetext{
2 "One-time" is defined here as an event that lasted for a short period (a few minutes to 48 hours), which excludes some types of event such as heat waves. Furthermore, I focus here on events with an (at least symbolically) identifiable site, where the President can be seen as "physically attending." This excludes most plane crashes, for instance, but not events such as tornados or wild fires, since the President can attend any site that appears to have been damaged by the event - whereas speaking from an airport after a plane crash could hardly be seen in the same light.
} 
Looking at Table 1, we can see that U.S. Presidents regularly attend, and that this is not limited to specific types of events. A glance at several other (industrialized) countries suggests that this is not an American peculiarity. In Canada, for instance, the Prime Minister visited the regions affected by the Great Ice Storm of 1998 (Cobb, 1998), the Prairies floods of 2011 ("Manitoba delays plans," 2011) and the Alberta floods of 2013 (Clarke \& Edmiston, 2013), and attended funerals for victims of the Polytechnique Massacre in 1989 (Maser, 1989). Similar behavior has been observed elsewhere, and thus generally heads of government are eager to appear to take control of such events: they want to (and have to) show that they are in charge and that they are good at it, and making sure they are seen as physically attending is a tool in constructing and conveying these images. Leaders also want to show that they are there when the population needs them most, as we have become accustomed to hearing that leaders "have interrupted their vacation", or "have shortened their visit abroad". This is perhaps part of broader trends, most notably the advent of television as the prime media in the 1950s and 1960s, and continued today with the importance of the Internet, content sharing tools like Youtube, and social networking media such as Facebook and Twitter, although this is beyond the scope of this study.

\subsubsection{Phenomenon \#3: Creative solutions}

The third phenomenon refers to the observation that when this type of drastic event occurs, there is a window of opportunity that opens up for policy change that reaches beyond the situation's immediate scope. Put another way, natural disasters, 
traumatizing events, and crises and shocks of all kind, because they raise expectations and implicate political leaders, can produce major policy change outside the realm of a narrow interpretation of the triggering event, even if the direct issue was more limited in breadth. There is often a conflation between immediate impacts and merely potential ones, as debates emerge about the underlying causes, about the best policy remedies to the current situation, but also about the possible evolution of the situation surrounding the scare, the longer-term impacts of policies enacted and actions undertaken, and so on. In other words, although the social scare may be related to a specific set of circumstances surrounding a particular activity, there is a potential for a substantial expansion of the scope of the discussions.

This phenomenon emerges out of the numerous areas of uncertainty that accompany these situations. By definition, a scare embodies a disruption in the normal state of affairs. Its specific impacts on the concerned sector of activity, however, can be quite varied, depending on a myriad of factors, including past occurrences of a similar event, the sociopolitical context, cultural features of the society facing the scare, the availability of substitutes to a specific technology, and so on. Consequently, there is room for speculation regarding how the ensuing events will play out, what should and should not be done, and risk assessments of different courses of action. As with most public policy matters, there can be more than one seemingly "right" course of action: analyses and forecasts may differ, depending on how the uncertainties are interpreted and quantified. Since any public policy tends to benefit some groups more than others, there is a potential for competition between different analyses and forecasts, between different 
narratives of the scare and its aftermath, and thus between clashing policy recommendations. ${ }^{3}$

There are always several questions that come along with any path of resolution for a given scare, regardless of its exact features. For instance, the oft-cited Cuban missile crisis may have lasted only thirteen days, but it is reasonable to think that any path to resolution, including the one that actually occurred, came with very complex and uncertain implications about future developments in the Cold War. ${ }^{4}$ Importantly, this is not limited to military crises: if a major bridge collapses because of faulty design, building another (safer) one back up certainly resolves a narrow version of the problem at hand, but it also brings several other questions: are other bridges at risk? Is there a fundamental problem with the way they are built, or with maintenance over long-term periods? What about other major construction works, are some of them at risk of falling down too? Hence regardless of the sector, any "solution" to the scare has very uncertain implications for the future, and this is reflected in the political battles that ensue.

A well-studied social scare that illustrates this third phenomenon further is the one triggered by the September $11^{\text {th }}, 2001$ attacks in the United States. The event was major, but could be circumscribed within a relatively specific set of hard facts. Nevertheless, several potential visions about a "resolution" of this scare were possible in the days that followed the events. We know of one that included an invasion of Afghanistan, and by a controversial extension Iraq, in an effort to wage a "War on Terror". An alternative resolution path could have stopped at finding and trying the suspects of the attacks, which

\footnotetext{
${ }^{3}$ This discussion is covered at length in the risk society literature - see, notably, Beck (1992) and Giddens $(1990,1991)$. Space lacks here to provide a longer overview, but I return to these debates in Chapter 3.

${ }^{4}$ See Allison's (1971) discussion, for instance.
} 
might have also included an invasion of Afghanistan. And a narrowed-down version could have involved a pragmatic approach where substantial but geographically restricted measures would have been taken to prevent the possibility of such acts in the future. Even in countries outside the United States, the 9/11 attacks led in some cases to the passage of substantial modifications to domestic security legislation: this was the case, notably, in the United Kingdom, and although these legislative changes were compounded by the London Underground incidents in July of 2005, most were initiated well before the attacks (e.g., Hassan, 2010). Even more interesting are cases where a social scare leads to major policy changes in areas largely unrelated to the initial triggering event(s). Cigler (2004), for instance, has shown how the Enron scandal was pivotal for the U.S. Congress to pass long-awaited campaign finance reform (the Bipartisan Campaign Reform Act of 2002). Hence there is something about the uncertainty brought out in the context of social scares, which allows for very different interpretations and courses of action. Not all policy options are equal, however, and potential winners and losers from these options participate actively in the battles that determine the choices to be made.

These three phenomena are all hints of a more general process, one in which we see a temporary alteration of the relationship between the State and a large segment of its population. In these instances of social scares, a broadly shared perception of insecurity comes to surround a particular area of activity, causing increased public and political attention, as well as a different level of expectation toward governments. In the next section, I describe what this means for the politics of policy-making, and how this can help in building an analytical framework to analyze a wide variety of social scares. 


\subsection{Social scares, uncertainty, and policy change}

Liberal-democratic governments in the Western world have come a long way since they began replacing absolutist states in the late $18^{\text {th }}$ century. Despite substantial ideological differences within and between countries, by any measure the "size" of the state has increased spectacularly, and particularly at the national level (Peltzman, 1980). Some of this increase has of course followed population growth, but in great part it can also be associated with an expansion in the role(s) of the State. Although the function of the State was initially seen as ensuring physical security to its population (for instance, Tilly 1990), today the economy, education, health services, transportation infrastructure, energy, agriculture, the environment, and several others areas are now all widely recognized to be the State's purview, be it just to set basic standards for activities associated to the sector. ${ }^{5}$

As this set of roles grew to be substantial, so have the governments' resources to ensure socially acceptable conditions for activity in these sectors. Because of this, the expectations toward the "normal" state of affairs are extensive - in comparison to the past, or to countries where the extent of the government's capacity and reach is much less. Consequently, disruptions in the stable operation of these activities - be they using the transport infrastructure to get to work, having access to basic water and sanitation services in one's home, or safely investing in one's pension fund - are rare, temporary, and highly unusual. We have become accustomed to having a stable and reliable

\footnotetext{
${ }^{5}$ For a discussion of these developments, see for instance Esping-Andersen (1990).
} 
environment for all of these everyday activities - in other words, a certain sense of security, ultimately guaranteed by the State, should things go exceptionally wrong.

For the purposes of this project, I define security in plain terms: the freedom from danger, anxiety and fear (Merriam-Webster's, 2003). In this sense, security is commonly associated with the concept of safety, which can be viewed as a perception in the population that the conditions in which we conduct an activity present an acceptable level of uncertainty. This "acceptable level of uncertainty" corresponds, therefore, to an overall impression that the value provided to society by these conditions outranks whatever downside it entails. In particular, an activity is deemed "safe enough" when we are satisfied with an evaluation of the potential that the actions involved will lead to an outcome other than that for which they are intended. The absence of threat, although ideal, is not necessary: what we need to feel safe is a satisfactory, credible, and reliable knowledge of the threats involved - i.e., a known risk - so that we can choose whether or not to engage in the activity (or the conditions under which we let others do so), given the benefits that it brings. ${ }^{6}$ Sometimes this is a choice we make individually: for instance, we accept to drive cars not because we know it is impossible to get injured in doing so, but rather because we believe it unlikely enough so that the benefits of personal transportation outweighs this risk. At other times, it is akin to a collective choice made through policy: for instance, governments - and by extension, their populations - allow airlines to carry passengers not because there has never been a plane crash, but because regulations and practices make them very rare.

\footnotetext{
${ }^{6}$ There is a high level of subjectivity in these assessments, including an important distinction between objective and perceived risk. I return to these issues in Chapter 3.
} 
I get into more depth on these issues in Chapter 3, but generally, this is the starting point for the analytical framework presented in Chapter 2: the significant expansion of the State's role in the past century has produced a situation where periods of temporarily and unusually threatening conditions in a sector of activity produce social scares, when a broadly shared perception of insecurity emerges suddenly in the population. The concept of social scare encompasses periods that can be triggered by various types of events, including natural disasters, traumatizing events, catastrophes, and crises and shocks of all kinds. Moreover, various sectors of activity can experience this: in public health, for instance, we sometimes have to deal with outbreaks of bacterium infections in hospitals, or fears of a flu pandemic; in the transport sector, a major infrastructure can collapse; in the energy sector, there is a potential for abrupt gasoline shortages, as during the oil embargo of $1973-74$, or industrial accidents like the Fukushima nuclear disaster; and last but not least, the national security area, where immediate military threats or terrorist attacks produce such a feeling of increased insecurity. In all those very different situations, the one constant is that governments are at times asked to intervene decisively, and with a seemingly smaller or less effective opposition than usual, to "solve" the scare. Whatever the source and type of the event triggering the scare, the public expects political actors to quickly, convincingly, and successfully resolve the situation, albeit to different degrees. Furthermore, no area of activity is impervious to such a situation, as this is not confined to ones where there already is government intervention. In fact, in many cases it is because of the advent of such a situation that government intervention begins in the first place. 
In all of these instances, political actors are not only expected to deal with the issue underlying the scare, they may also be allowed to take measures that go beyond their usual reach. This political battle over what should be done, then, can lead to major policy change, depending on how various actors manage to participate and maximize the benefits they get out of the chosen course of action.

This brings us to one of the main features of the framework developed in Chapter 2 , which comes out of the combination of phenomena \#1 and \#2 described above (events that are disruptive are followed by an abrupt rise in expectations toward governments, and there seems to be a political importance for leaders to personally attend the aftermath of an event triggering a scare). From this combination, we get the idea that there is a political prize to be won if these raised expectations are met successfully - and a price to be paid when they are not. At least part of this prize is actually akin to a political rent, since it represents gains that go beyond those associated with certain policies, and access is largely restricted to a limited circle of political leaders.

While all policies - and changes therein - are associated with different costs and benefits for different actors, this political rent is a bulk of political capital that is available for certain actors to capture by being perceived as reducing the perception of insecurity. This rent is largest in the immediate aftermath of a scare's triggering event, for instance, but decreases in size rapidly with time. I develop these ideas further in Chapter 2.

Although this suggests that government leaders face a great opportunity to make political capital gains in the advent of social scares, this is counteracted by the fact that scares also present a leadership "curse". On the one hand, actors in the executive branch 
are in a great position to capture a maximal portion of the political rent available. On the other hand, this is not always easy, or even doable, depending on the context and nature of the scare; regardless, given their position, and given the raised expectations towards them, they need to "do something". In other words, they cannot let the rent float, because this may produce a vacuum that could be exploited by other actors - opposition leaders, for instance. Leading a nation out of a scare is not always an easy task, especially if the scare highlighted a policy failure for which fixes would mean policy changes unattractive to leaders in power.

Lastly, this neither implies that the decision to capture the rent is merely in the hands of government officials, nor that they are presented with a choice for which all the parameters are fixed. As suggested by phenomenon \#3 above, the temporarily different political context during a social scare is associated with a degree of uncertainty much higher than usual. Questions arise about the underlying causes of the triggering event, about the best policy remedies to the current situation, but also about the possible evolution of the situation surrounding the scare, the longer-term impacts of policies enacted and actions undertaken, and so on. This uncertainty creates a potential for a discursive flexibility in debates surrounding the events, even a substantial expansion of the scope of the discussions.

Uncertainty usually makes decisions much harder and more uncomfortable, because it hides the true value of a choice. Uncertainty can, however, be transformed and dispelled through the elaboration of a narrative to increase the choice's credibility, anchoring the debate on an activity's uncertainty by giving it a set of concrete, 
measurable, and comparable characteristics (risk assessments, predictions, or analogies with other past events, for instance). In circumstances where the dominance of one such vision is not obvious, there is a potential for a framing contest between proponents of different visions. This is likely to occur in the midst of a social scare, as different actors will attempt to provide a particular policy course that will credibly reduce the insecurity brought by the scare, and the uncertainty that accompanies the scare can be used to one's advantage by allowing for the elaboration of narratives successful in this endeavor.

This last aspect is far from trivial. Social scares provide an opportunity for governments officials, but also other actors, to capitalize on their "resolution" of the situation - the actions they take to both reduce the perception of insecurity and convince the population that the reduction was of their doing. Exactly how they are able to do so, and what this allows them to achieve, is a crucial aspect of the study of policy change, one on which this dissertation puts the emphasis.

There are thus two meanings to the "masters of uncertainty" title. First, during a social scare, a high level of uncertainty allows some flexibility for actors to try and convince a broad section of the population of the superiority of a certain assessment of the risks involved, and the actions needed, through the building of a narrative. If successful, these actors, by dominating the competition over the definition of the scare, are able to orient public and political debates in a certain direction. This direction is associated with a certain frame for problems and solutions, with the possibility to discredit and delegitimize some forms and sources of knowledge, and with a justification for some form of government policy intervention. In other words, by "mastering" 
uncertainty, actors impose a vision of a public issue that is conducive to certain specific policy solutions, sometimes succeeding in changing the policy regime in place.

The second meaning for the title is straightforward, and comes from the political rent created by the scare. This rent is an additional prize that political actors can gain from the process, by being seen as reducing - once again, mastering - uncertainty. These two meanings correspond to the twin dimensions of the political battle occurring during a social scare, on which I elaborate in Chapter 2. In the next section, I lay out the scope and limits of this research project.

\subsection{Scope and goals}

This study asks the straightforward yet difficult question of why some social scares end up having a major impact on policy, while others do not. The general thesis presented here is that during a social scare, a perception of insecurity emerges suddenly and leads to a unusual demand for political leadership, which forces actors to act in some way or another to resolve this insecurity. While this is a great opportunity to push for policy change, not all policy options are attractive to these actors, and their actions to seize the political rent created by the insecurity - or avoid for others to do so - constrains their policy options.

Moreover, while leaders of the executive branch of government have an important set of tools in the resources and means of the state and in their degree of influence sometimes complete - on the legislative process, actors outside of the normal allies of this group will also try to use the scare as an opportunity. The policy outcome, then, is a 
result of the combination of the obligation for actors in power to "do something" (the leadership curse mentioned above), of the constraints that this obligation imposes on them, and of the clashing sets of interest that the different groups have regarding the policy options.

I expand on these processes in Chapter 2, where they are used to build an analytical framework to study instance of social scares from a broad variety of sectors. Although this framework is developed for scares in any sector, this study's scope and goals are narrowed down as specified below.

\subsubsection{Scope of the study}

Since this is a dissertation project with limited resources, I reduced the scope in a variety of ways to make it more manageable. First, I develop a model out of the framework described in Chapter 2, and apply it to conduct case studies of scares within and around the energy sector. Energy has always been an area prone to scares, and presents a wide variety thereof. From very real immediate catastrophic events (e.g., the Chernobyl nuclear disaster) to more hypothetical ones (e.g., peak oil), and from highly scientific and technical problems (e.g., global warming) to more traditional foreign policy and economic issues (e.g., gas disputes between Russia and its neighbors), energy is also a sector that has become impossible to dissociate from modern economies.

Moreover, energy is a sector intricately linked with various others - transport, mining, and the environment, notably - making it susceptible to scares that didn't originate within its direct purview. The oil embargo imposed by the Organization of Arab 
Petroleum Exporting Countries (OAPEC) in 1973-74, for instance, triggered some of the most broad-reaching changes to energy policy in importing countries, despite its foreign policy origins. ${ }^{7}$ Simultaneously, triggering events within the energy sector often spill over to other sectors. For example, the resurgence of fears over peak oil in the mid-2000s, alongside greenhouse gas emission concerns related to global warming, led to substantial investments in "green" industrial policies (Renewable Energy Policy Network for the 21st Century, 2010). Finally, although several past scares have applied similarly to different countries, responses by governments have differed substantially. For these reasons and others described in Chapter 4, energy seems like a good place to start, and "energy scare" is defined loosely as a social scare triggering debates related to energy policy. In other words, the population of cases from which I made the selection incorporates ones where energy policy was a strong component of public and policy debates.

Second, the focus is limited to countries with a free press and a well-established capacity for governments to intervene in the economy, which roughly corresponds to industrialized countries. I neither contend that low- and middle-income countries are not conducive to the processes described above, nor that energy is less of a critical service there. However, I assume that the mechanisms I hypothesize within the analytical framework are most salient where officials are elected and accountable to the population, and where the means available to governments and political actors in general are substantial. The free press, moreover, ensures a way to measure dissent and pressure

\footnotetext{
${ }^{7}$ More details on this in Chapter 4.
} 
coming from the population toward elected leaders. It makes sense, therefore, to choose to apply this model first to high-income countries.

Third, the four main case studies described in Chapters 5 through 7, as well as the two further cases discussed more briefly in Chapter 8, look at instances of scares that occurred in the past four decades. Other than the methodological hazards of comparing over a longer period of time, both energy markets and energy policies have been radically transformed in the 1960s and 1970s. Energy markets have seen changes in state participation on the production side in the gas and oil sector (including notably the creation of OPEC), while both nuclear power and renewable sources have contributed to a reduction in oil and coal's share in electricity generation. Energy policies have been structured following the creation (or substantial reorganization) of energy ministries and departments in most industrialized countries, as well as the creation of the International Energy Agency. Finally, environmental concerns and their political representation have largely been born during that same period, and have become an inescapable part of the energy realm. ${ }^{8}$

The variation in the cases, as well as additional instances of energy scares analyzed in Chapter 8, allowed for the conduct of a project of manageable scope, while still retaining several goals.

\footnotetext{
${ }^{8}$ All these issues are explained in detail in the first part of Chapter 4.
} 


\subsubsection{Goals}

At a broad level, three main goals emerge out of this project. The first one is to improve our understanding of major policy change, and the role that social scares play therein. The development of a middle-range theory, focused on unveiling the mechanisms through which social scares cause different types of policy change, is the primary goal. This is done by elaborating an analytical framework to study these instances, and by postulating exploratory hypotheses in a research model that allows investigations of scares, one that can be replicated in areas other than energy. Chapters 2, 3, and 4 describe these steps, and Chapter 8 shows a refined version of the model after taking into consideration the results from the case studies.

The second goal relates more specifically to policy-making in the energy area. Various changes in energy policy have occurred in industrialized countries in the past 40 years, and many of these were in reaction to events that were unusual, and (in many cases) that transcended borders. The measures undertaken, and the choice to pursue them at all, have however differed. The results of this project help explain the process of making energy policy in these political environments.

Finally, a third goal is to provide some insights for policy-making during any type of social scare, even ones not linked to energy policy. The framework developed in this project, although it is only applied to energy scares due to limited resources, still helps understand general rules about the political context that surrounds social scares and their aftermath. The concluding chapter thus discusses such broader policy implications. 


\subsection{Organization of this document}

In the next chapter, the ideas briefly discussed in this introduction are assembled into an analytical framework. I begin by reviewing several aspects of social scares from literatures on the policy process, and then move on to describe how these insights can help elaborate the framework. I then describe how the context of a social scare is at the core of this framework, and can be analyzed as a two-dimensional political competition, which helps explain the policy impact of the processes triggered by social scares.

Chapter 3 situates this project and its theory of policy change within broader theoretical debates. It thus serves two purposes, the first being an extended literature review, to provide an in-depth investigation of the theoretical foundations surrounding and underpinning the model completed in Chapter 4. Three areas are covered. I begin with a review of the literature discussing the place of risk and uncertainty in modern societies, how we interpret them as individuals, as well as how they impact social and political relations. This discussion then leads to theories of framing and perception, and how these explain how uncertainty can be transformed into something tangible, as well as how this is used by policy entrepreneurs and advocacy coalitions to make certain policy options more appealing. Finally, I explore the role of scientific information and technical experts, given the highly technical aspects of many modern scares, particularly in the energy area.

The second purpose of Chapter 3 relates to the methodological tools used to conduct this project, which are based on the method of structured, focused comparison proposed by George and Bennett (2005), designed to conduct case studies of instances of 
a class or subclass of events. The method is structured because the researcher asks general, standardized questions pertaining to the research objective, and this is done of each case in order to structure data collection, allowing for systematic comparisons; it is also focused, since it uses a theoretical basis to put the emphasis on specific aspects of the cases that are considered most relevant and appropriate for the research objective. While the methodological design based on this method is described in Chapter 4, Chapter 3's second purpose is to set up the building blocks that serve to apply this method, thereby providing theoretical grounding for the investigative questions I later use to conduct the case studies.

Chapter 4 presents an overview of the political economy of the energy sector. It outlines a more specific model in order to understand the mechanisms leading to the adoption of particular "solutions" to scares around the energy sector. Because they imply a potential rethinking of the state's role in energy, and because they are by definition associated with a high degree of uncertainty (with regard to both the problem and the solutions), scares in and around this sector present momentous opportunities to improve our understanding of the link between social scares and the policy process. The chapter ends with the methodological design section, which presents the justification for the selection of cases and the list of investigative questions that were used in the case studies, in which I examine five exploratory hypotheses to structure the analysis.

Chapters 5 and 6 present the results from the application of the method on the four main cases. The cases are grouped in pairs, given a few characteristics they share. Chapter 5 contains the study of the passage of the National Energy Program (NEP) by the 
federal government of Canada following the second oil shock of 1979-1980, and of the North American Ice Storm of 1998 and its management by the provincial government of Quebec (Canada), where the storm's effects were most pronounced. The two cases occurred in a context containing several similar structural features, most notably the type of political regime (parliamentary), the country (Canada), and the tensions following from the federal structure. This ensured a degree of uniformity in the context.

Given the federal structure, the cases are also interesting because they were dominated by members of the executive branch, but at different levels: the national government in the NEP case, and the provincial level in the ice storm case. Furthermore, in both cases members of the corresponding executive branch of government had clear objectives for the policy outcome and succeeded in obtaining it, but these objectives were completely opposite. In the NEP case, the government wanted to pass a landmark legislation that would reorganize the distribution of oil revenues and federal-provincial powers; in the ice storm case, the government wanted no change at all to electricity or energy policy. These differences and others, given the similarities in the context, strategies of actors, and successes of these strategies, make the cases interesting because of the possibility of isolating some of the mechanisms described in Chapter 2.

Chapter 6 contains the next two cases: the scare in West Germany following the Chernobyl nuclear disaster, and the Exxon Valdez oil spill in the United States. Again there are similarities between the cases. They are both cases where the executive branch was not entirely successful in using the scare to its advantage. Both triggering events were somewhat played down by leaders of the national government, and the attempts to 
maximize the disruption and reach came mostly from groups opposed to these positions (environmental groups in the Exxon Valdez case and anti-nuclear groups in the Chernobyl case). In both cases, the executive branch seemed successful at first, as outside and opposition groups were not able to gain enough power to force the government to change its stance. Change did come in both cases, however, and the main difference is that in the Exxon Valdez spill case, the change was completely circumscribed within the boundaries of the policy sub-system. In the Chernobyl case, however, the changes enacted by those in power, also notable, were not enough to calm the building of a coalition for further modifications to energy policy, and the scare underlay debates for years after the event, eventually leading to further changes.

This pair of cases also presents particularities that make them different from the NEP and ice storm ones, as the policy outcome was not dictated by the executive branch, and emerged out of pressure from outside groups and enlarged coalitions opposed to the status quo. However, outside groups in the Exxon Valdez case did not manage to push policy debates outside of its traditional sphere (oil transport regulation this case), while in West Germany they managed to make the Chernobyl scare last and grow strong enough to eventually force more atypical changes. Consequently, the level of disruption brought by the triggering event, in these cases, seems to have had a strong influence on the outcome.

In Chapter 7, the cases are compared further - including the removal of the pairings of Chapters 5 and 6 - and this serves to build a typology described at the end the chapter. Given these conclusions on the four main case studies, Chapter 8 then presents a 
refined version of the model, and applies it to two additional cases: the Deepwater Horizon oil spill in the Gulf of Mexico, and the failure of the Taum Sauk hydroelectric storage plant reservoir in the U.S. state of Missouri. These are shorter cases studies, meant to demonstrate how the refined model can help to understand the policy process type that describes best the outcome of those scares.

Finally, Chapter 9 contains conclusions from the project as well as a discussion of the policy implications that come out of the application of the model. Assessing the progress made toward the goals mentioned above allows for a better understanding of how "masters of uncertainty", but also less successful actors and coalitions, operate during those difficult times following a disruptive event. 


\section{Chapter 2}

\section{Social scares and the policy process}

In the introductory chapter, I outlined initial ideas about the political context created by the eruption of a social scare. In the aftermath of a triggering event or series of events, expectations rise and expand for political leaders, and the actions they take to reduce the insecurity perceived by the population can enable them to push for a policy change that would otherwise be out of reach - or to resist pressure for change. In other words, those able to use this context to their advantage build a strong momentum for the aftermath, when battles ensue for changes in policy (regardless of whether these actors will be pushing for change or resisting it).

In this chapter, I elaborate on these ideas, and build an analytical framework to study instances of social scares. Since I posit that social scares have explanatory potential with regard to major changes in policy, I begin with an overview of this notion within theories of the policy process, and situate social scares therein by highlighting what these literatures have to say about the role that crises and drastic events can play. I then describe the framework, based on a two-dimensional political struggle, where actors and groups compete over two sometimes conflicting objectives: win symbolic capital, and secure their desired policy outcome.

\subsection{Social scares and theories of the policy process}

The different literatures linking natural disasters, traumatizing events, and crises and shocks of all kinds to policy change share a general line of thought: whenever one or 
more events are raised to this exceptional status, societal and political debates occur in a special setting, and "normal" dynamics between public officials, interest groups, and the general public are altered. The correspondence with differences in policy changes is based on the idea that the norm in the policy process seems to be incremental change, with infrequent atypical disruptions in policy direction, a process that has been said to resemble Niles Eldredge and Stephen Jay Gould's “punctuated equilibrium” schema of evolution (True, Jones, \& Baumgartner, 2007). While in policy theory the term is more specifically associated with Baumgartner and Jones' framework of policy change, other theoretical frameworks also subscribe to this general notion that not all policy changes are equal, and that in some instances the change is "atypical" or "major" (Kingdon, 1995; Sabatier \& Weible, 2007).

Two aspects come out of this general idea. On the one hand, there are reasons explaining the stability of the status quo over relatively long periods of time. Institutional path dependency reinforces a situation where certain groups of actors come to establish a policy monopoly, which prevents any substantial divergence from the policy regime corresponding to the status quo (True et al., 2007). On the other hand, the domination of a particular policy regime lowers its flexibility, and anomalies build up therein, eventually leading to short and sudden periods of atypical change (Howlett, Ramesh, \& Perl, 2009, pp. 198-210).

Various factors can lead to these atypical changes, coming from either exogenous or endogenous sources. Exogenous processes refer to external shocks (Sabatier \& Weible, 2007) as well as subsystem spillovers - changes following from activities outside 
the policy subsystem (Howlett et al., 2009, pp. 203-206). Endogenous processes refer to venue change strategies by actors shut out of the policy-making process (True et al., 2007), and policy learning (Heclo, 1974). The general idea underlying these different cases is that policy change, especially major change, can rarely be attributed to any one cause (Birkland, 2006). Moreover, with regard to social scares, external shocks and subsystem spillovers are of particular interest.

Social scares have a further impact on agenda-setting, as they generate media and public attention well beyond Downsian issue-attention cycles observed in other contexts (Downs, 1972). Peters and Hogwood (1985), for instance, have shown how attention triggered by disruptive or spectacular events does not "fade away" as Downs' cycle would predict (Howlett et al., 2009, p. 101), but persists instead. Moreover, dramatic events are particularly susceptible of having an effect on public and media attention, as well as increasing the impact of this attention on policymakers (Soroka, 2002).

In different theories of the policy process then, periods along the lines of social scares, alternatively named crises, shocks, dramatic events, disasters, or focusing events, often seem to play an important role in major policy change. Sabatier and Weible (2007) argue that crises and dramatic events are important because they set the stage for major change. Kingdon (1995), moreover, assumes that "focusing events" often arise when some event or crisis generates unusual public attention to some problem, such as disasters, crises, catastrophes, or scandals. Birkland (2006) goes further and emphasizes that these events are merely potentially focusing ones, and asserts that they usually highlight policy failure. In other words, the increased attention is generally negative and 
creates pressure on the dominant policy community or policy monopoly to open up to change (Baumgartner \& Jones, 1993). Some of these events, most notably catastrophes or disasters, gain great attention suddenly and rapidly, as the immediately and obvious harms they cause puts them rapidly over other problems such as endemic crime or disease brought out by longer-term statistical evidence (Birkland, 1998a, p. 54). As a result, political leaders are expected to "do something" (Grossman, 2012).

The nature of focusing events means they open a window of opportunity, a limited time period during which major policy change is more likely, given that key players in the political process can place issues on the agenda. The period triggered often dramatically highlights policy failures, or can also change the nature of the issue from a low-salience one to a very real and visible problem (Birkland, 2004, pp. 181, 187). The window opening results from a change in our understanding of the problem through a focusing event, leading "interest groups, government leaders, policy entrepreneurs, the news media, or members of the public to identify new problems, or to pay greater attention to existing but dormant problems, potentially leading to a search for solutions" (Birkland, 1998a, p. 55). Slovic, Kunreuther, and White (2000) use these observations as proof that focusing events and crises of all kinds have an unlocking impact on the stability or stalemate of a policy regime, highlighting that very often major changes do not emerge out of a conscious and rational attempt at strategic long-term policy planning, but rather come out of a crisis generated by catastrophic natural hazards or other similar events. 
Both Sabatier and Kingdon argue that such events are also unexpected and not understandable in terms of prevalent policy discourses, which allows policy entrepreneurs to use the changed circumstances to introduce new or marginal ideas. During the period that follows such an event, "new actors are often seen as engaged in a struggle with established ones, who usually resist the introduction of new ideas and defend the status quo or, at least, attempt to limit changes to those compatible with existing arrangements" (Howlett et al., 2009, p. 205). Dominant actors are more often put at a disadvantage, having to defend themselves against their policy agenda in the face of failure.

However, despite some work on the mechanisms linking these types of situation to instances of major policy change (notably, Birkland, 1997, 2006; Cobb \& Primo, 2003), it remains unclear how these instances lead to change, as well as why some do not. While leaving a place for crises of all kinds in their framework by stating that they are often related to major policy change, these theories provide little information regarding the mechanisms through which they impact policy. Moreover, there is little information on how to differentiate among these instances.

Among the authors that do investigate the mechanisms leading from crisis to major policy change, Birkland (2006, p. 1) finds that "there is an interaction between the event, the nature of the event (human versus natural, for example), and the composition of the community of actors who address the policy issues or problems revealed by the disaster". Birkland argues that specific types of focusing events (disasters, in his case) change the dominant issue on the agenda and can lead to interest group mobilization, as 
these groups often actively seek to expand or contain issues after an event (Birkland, 1998a, p. 53). This suggests conditions in which some events lead to change, while other do not:

The existence of groups that could make a sound claim to be representing the public interest is determinant .... A focusing event itself, without the intervention of interest groups, causes the same actors that dominated policymaking before the event to consider ideas more intensively than they did before. (Birkland, 2006, pp. 164-165)

Furthermore, "the presence, absence, or relative cohesiveness of certain types of advocacy coalitions can influence the policy community's reaction to events" (Birkland, 1998a, p. 57). The absence of a coherent advocacy coalition means few voices are available to intervene in the relevant venues, and no one is able to use the event as a rhetorical tool to push for change (Birkland, 1998a, p. 72). So the organization of the policy community influences post-event policy making, and Birkland concludes that focusing events occurring where there is a relatively well organized policy community, able to use the event to dramatize the need for improved policy, are much more likely to be important. "Where communities are less well organized, the ability to use events to improve policy is reduced, even if policy making appears to be event-driven" (Birkland, 1998a, p. 67).

Finally, impacts can be broad-reaching, as focusing events not only produce change in the concerned sector of activity, but often spill over into other sectors, as a byproduct of major change (Dery, 1999). The sector directly touched by the focusing event 
can be unrelated to the policy change and still facilitate it, as Cigler (2004) demonstrated in the case of the Enron scandal and campaign reform legislation. Birkland also discusses the extent to which the event triggers arguments specific to the event, or more generally on that topic. As he notes, this leaves researchers with the very difficult question of how much policy change is caused by the focusing event, and how much the event facilitates (Birkland, 2004).

The literature on foreign policy and international economic crises also provides helpful insights. The materialist strand explains crises' policy impacts by the fact that they provide "an environment of uncertainty that permits a market-clearing process in which struggles between coalitions with different material strengths determine some new policy course," which end up "altering the institutional equilibrium" (Seabrooke, 2007a, p. 798). Constructivist works, moreover, emphasize the role of "the exchange of ideas [which] can fundamentally alter interests before fighting breaks out during a period of crisis and uncertainty" (Seabrooke, 2007a, 799). The important distinction is that crises' meaning are not given but are instead constructed by agents, in a process where norm entrepreneurs attempt to frame ideas during a period of uncertainty (Seabrooke, 2007a, p. 799; see also Blyth, 2002; Widmaier, 2004).

The role of uncertainty is again seen as critical (Seabrooke, 2007b), especially when "agents have no idea what institutions to construct to reduce uncertainty" and must "resort to repertoires of action that resonate with their core identities" (Blyth, 2002, pp. 36, 267; see also Seabrooke 2007a, p. 799). For constructivists, in particular, the punctuated-equilibrium is endogenous, in that 
the general relationship assumes a consensus around a given set of political and economic ideas that are institutionally maintained until crisis and uncertainty arrive and send norm entrepreneurs into battle with one another. The winner from this battle is then able to proclaim the legitimacy of the ideas, or guiding norms, that inform institutional change to the mass public. (Seabrooke, 2007a, p. 799) ${ }^{9}$

Overall then, crises of all kinds signal to various agents through intersubjective understandings that something needs to be changed, and so the definition and structure of their material interests also depends on these understandings (Widmaier, Blyth, \& Seabrooke, 2007). The meaning of a social scare is thus at least partly framed, given that some actors will have an interest to attempt to achieve strategic social construction in defining it as the embodiment of a specific interpretation of the underlying problem. If the scares' origins and impacts are not clearly definable and consensual, then it is possible to construct different credible interpretations, and potentially several of these interpretations will compete to become the most widely accepted one.

Furthermore, the securitization literature suggests that there is more facility in achieving one's framing goals when the issue is defined along security lines (Balzacq, 2011; Buzan, Waever, \& Wilde, 1998). Very often, this is exactly what social scares - of any kind - allow for, since by definition they embody some kind of threat, be it immediate or potential on the longer term. If there is indeed a framing contest at work, then this would suggest that security or "threat" aspects play a role in the process.

\footnotetext{
${ }^{9}$ See also Widmaier (2007); Widmaier et al. (2007).
} 
Despite these insights, most of these works focus on short(er) term impacts of crises and wars, although there have been recent efforts to remedy this (see Widmaier et al., 2007). While leaving a place for crises of all kinds in their framework by stating that they are often related to major policy change, these theories provide only incomplete information regarding the mechanisms through which crises impact policy, and on how to differentiate among instances. Without these mechanisms, the link between shocks and major policy change thus runs the risk of becoming tautological, as major policy change is said to come out of crises because crisis events generate major policy change.

These literatures provide us with three general ideas. The first is that some events do lead to major policy change by opening of a window of opportunity, but the study of the event's characteristics is insufficient; rather, the period that they trigger is even more interesting, as actors engage in a battle for what changes will (or should) be pressed forward - if any.

The second idea is that the essential and overarching feature of this period is the uncertainty created or brought to the forefront by the triggering event, which not only leads to the questioning of myriad aspects of the status quo, but can additionally create an ideational vacuum where both the policy structure and the dominating ideas are reassessed in a new light. Relatedly, the third idea highlighted by these literatures is that this uncertainty seems fertile ground for a social (re)construction of material and ideational interests, and so part of the ensuing struggle is one of framing (of the meaning, the real and potential impacts, and the acceptable solutions to the triggering event and the social scare that follows it) where group mobilization is intensified. 
Put together, these three ideas suggests that the event does not merely trigger the opening of a window of opportunity where change is possible: after all, this is hardly helpful for a distinction between different such windows and the impacts that they have. What needs more investigation is that the heightened expectations, along with the possibility to inflate the stakes, create a particular kind of political battle, one which includes the possibility to construct narratives that maximize the political reward of successfully reducing the perception of insecurity created by the scare. In the next section, I present the analytical framework developed for this project, where all of these aspects are incorporated in order to understand the different types of policy change that follow from social scares.

\subsection{From social scare to major policy change - or not}

In this section, I lay down an analytical framework to study social scares. The ideas discussed in Chapter 1, and the ones highlighted by the policy process and foreign policy and international economic crises literatures reviewed above, are brought together to develop a two-dimensional framework that illustrates the importance of uncertainty, insecurity, and framing possibilities that characterize political struggles during social scares. I begin by describing the general causal chain, and then move on to refine it along two different dimensions, as well as relationships between them. 


\subsubsection{Causal chain: from social scare to policy change}

To reiterate, social scares are periods triggered by an event (or series of events) that produces a spike in insecurity in a large portion of the population. During that period, expectations towards the government are raised, and as a result some actors can benefit greatly from their perceived role in the resolution of the scare. Furthermore, since these periods encompass a high level of uncertainty with regard to the interpretation of the events (their meaning, their real and potential impacts, the relevant and acceptable solutions, and so on), advocacy coalitions ${ }^{10}$ within and outside the policy subsystem closest to the main concerned sector can use this uncertainty to frame the issue in order to ensure a particular course of action.

So how can we conceptualize this combination of insecurity, uncertainty, and policy change? I start with the assumption, coming from the literature review above, that a battle for policy change potentially ensues in the context of a social scare. If that is the case, then different actors and coalitions have a preferred policy outcome: some want no or little change in policy, others want more substantial change. There is thus a prize to be won at the outset of the scare, as with any other battle over policy making.

I argue that the particularity of social scares is a symbolic aspect to the actions taken and the positions defended by different actors and groups. The scare does not just create a battle where groups can obtain a prize associated with their preferred policy outcome: it also creates another, potentially large prize to be won by actors associated

\footnotetext{
${ }^{10}$ Throughout this document, I use the term advocacy coalition as defined in the Advocacy Coalition Framework developed by Paul Sabatier: "policy participants . . . seek allies with people who hold similar policy core beliefs among legislators, agency officials, interest groups leaders, judges, researchers, and intellectuals from multiple levels of government. If they also engage in a nontrivial degree of coordination, they form an advocacy coalition" (Sabatier \& Weible, 2007, p. 196).
} 
with action seen as reducing (both immediately and for longer term) the perception of insecurity brought about by the triggering event of the scare.

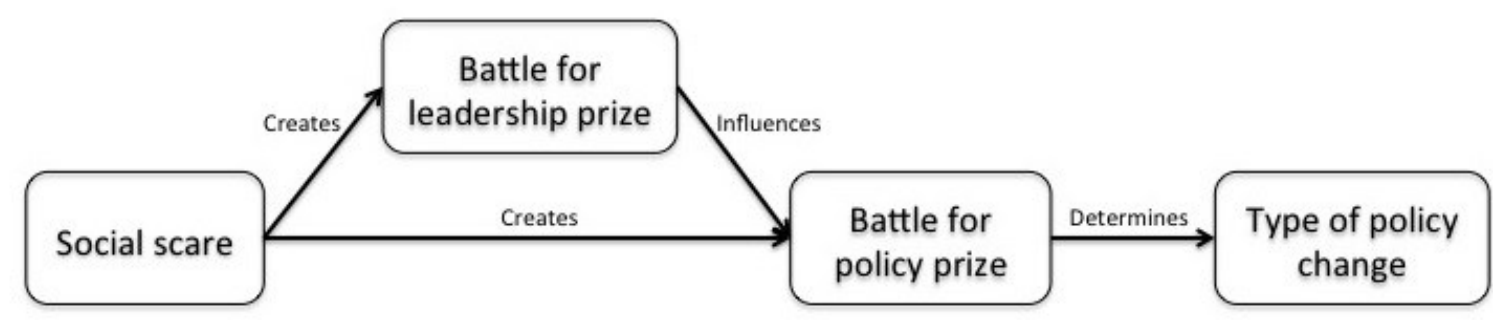

Figure 1. From social scare to policy change: basic causal chain.

Figure 1 shows the basic form of this process. During a social scare, the perception of insecurity leads to a demand, which can also be seen as a permission, for strong political action. This demand provides an opportunity for government or opposition officials to capitalize on their "resolution" of the situation, which is to say the actions they take to both reduce the perception of insecurity and convince the population that the reduction was of their doing. Although government and opposition officials hold the keys to initiating this kind of action, a broader coalition of actors can benefit from the changes enacted (or from the maintaining of the current policies), as this leadership prize becomes a resource in a battle for policy changes that ensues. Consequently, coalitions pushing for or resisting change need to take this into account in their actions, and those who are able to design and sell their proposed policy path in a way that allows some elected officials to seize a large leadership prize are more likely to succeed.

The policy outcome of a social scare thus results from a two-dimensional game related to the twin objectives that all actors and groups, including government and 
opposition officials as well as advocacy coalitions, have at the onset of a social scare. These objectives can be understood as a political necessity to make the most out of the scare, and are as follows:

- Objective \#1: can we obtain symbolic capital from the scare?

- Objective \#2: can we obtain our preferred policy outcome? ${ }^{11}$

During a social scare, a first prize goes to actors winning a symbolic aspect (for instance, from leadership during the acute phase of the scare, from good management of the negative impacts of the triggering event, or from convincingly improving the present and future vulnerability by their policy actions and propositions); a second prize comes with obtaining a preferred policy outcome in the aftermath of the scare (for instance, economic or social capital from the enactment of a particular policy, or ideological preferences).

Importantly, the first prize is a key resource in the battle for the second. If we conceive of political capital as a set of resources enabling an individual or a group to obtain a preferred policy or political outcome, we can consider four types of such resources: economic capital, such as campaign funds, financial and material resources, or personal wealth; social capital, such as acquaintances and networks, including party affiliation, relationships within and outside the political arena, or name recognition; cultural capital, such as cultural goods and services including educational credentials, or identification with regional or constituency interests; and symbolic capital, such as legitimation, including the politician's professional title, his status of war hero, and

\footnotetext{
${ }^{11}$ Although there are some parallels that could be drawn with Putnam's two-level game framework for international negotiations (Putnam, 1988), this comparison is limited, as the two dimensions discussed below actually represent the same "level" of domestic politics.
} 
reputation or reputation momentum built from his recognition as a leader or competent official (Bourdieu, 1986; Casey, 2008). Seen this way, the first prize described above consists of symbolic capital, and can be seen as a boost in the capacity of certain actors and coalitions to obtain a policy outcome they value.

As briefly discussed at the beginning of this chapter, several obstacles prevent substantial change in policy direction. The status quo prevails, more often than not, because of the political and economic transactions costs associated with alternatives, and because of sunk costs that produce a strong path-dependency effect. The resulting political economy of the current arrangement makes the assembling of a coalition for change, one that would be able to overcome these barriers, an arduous task. During a social scare, however, there is a new resource available, in the form of this leadership prize created by the broadly shared perception of insecurity in the population - and its associated sense of urgency for strong political action. If the prize is large enough, winners and their associated coalition have an opportunity to succeed in altering the status quo, by associating the scare to a fundamental flaw in the current arrangement.

In other words, change is more likely when there is an alignment between some narrative interpreting the scare and the possibility for government officials to seize the leadership prize created by the scare, by credibly committing to the enactment of solutions suggested by that interpretation. Since the uncertainty surrounding the scare provides some flexibility in the building of this narrative, it is thus the combination of the heightened expectations and the high uncertainty that increases the likelihood for policy change. As discussed at the end of the previous section, it is not merely that the triggering 
event opens a window of opportunity for change. Rather, the possibility to inflate the stakes by partly constructing the event's meaning can allow some actors to maximize the potential for the symbolic capital reward of winning the struggle. The bottom line is that understanding the dynamics in the battle for this first prize is key for predicting how the ensuing policy debates and struggles will play out.

Several questions arise about this leadership prize. What determines its size? Who can win it? What are the rules surrounding its possible capture? What strategies can actors use to win it, or to prevent others from doing so? I begin by outlining the contextual factors in which the battle for its capture takes place, and then expand on each of the two battles described above.

\subsubsection{Contextual factors}

Several contextual factors describe the social, cultural, political, and economic environment in which the social scare is triggered. The competition between different actors to "solve" the perception of insecurity is, as for most political processes, shaped by these contextual characteristics. Five such factors are considered. The first one is the electoral context, as the timing of elections implicating certain leaders or their political parties can have an impact on the acute phase of the scare. For instance, if the triggering event occurs a few weeks before a major election, chances are this could have an impact on the different actors' strategies (I return to this point in section 2.2.3 below). Moreover, in this context of a looming election, the potential for opposition leaders to capture a 
large prize in relation to objective $\# 1$ is greater, as they face the possibility of replacing the government.

A second contextual factor is the economic environment, where a recession, for instance, can modify not only the options available to government leaders, but also the frames that can be used to interpret the social scare. A third factor is the relationship of the scare to others, either occurring simultaneously or having happened in the recent past. For example, public and policy debates surrounding the occurrence of the 1979 ThreeMile Island nuclear incident in the United States were interrelated with concerns linked to the second oil-shock in 1979 (Joppke, 1993, pp. 138-139). Another example is how the 2007-2008 oil price spike scare receded due to the 2008-2009 economic crisis. While they both raised the perception of insecurity during their onset, the latter scare actually decreased the former's insecurity, as the recession brought oil prices down.

In a similar line of thought, dominant ideas of the time constitute a fourth factor. Is policy change in the air at the time of the scare? For instance, industrial policy to create "green" jobs in the aftermath of the 2008-2009 economic crisis was in the spirit of the time, as several countries had been discussing or implementing renewable electricity generation support schemes in the few years prior (Karp \& Stevenson, 2012). Finally, a fifth category is societal values, which restrict what kinds of proposed solution will gain traction in the population concerned, what options will be more popular, and so on.

Although these are broad categories, they provide a comprehensive picture of the context in which the political struggles for dominance occur during the social scare. Despite their disruption of the normal state of affairs, social scares do not produce 
political battles that are independent and isolated from the society they affect, and considering the context in which they occur is necessary to provide flexibility to the analysis.

While the two dimensions of the struggle are closely related, they each come with their own dynamics, participation requirements, and strategies. In other words, the battles that follow a scare's triggering event can be conceptualized as two distinct but interrelated games, and each comes with its own rules and reward. The next sections describe these aspects in more details, and how they interact and constrain one another.

\subsubsection{A political rent: the leadership curse and the resolution of the social scare}

The first dimension relates to prize \#1: the symbolic capital that can be won by appearing as a leader in the resolution of the scare. The scare creates a need for leadership, and actors - especially those in power and in the opposition - have to think about how the scare could help them gain symbolic capital - and/or avoid losing any. The prize associated with this dimension can be of different sizes, as it will be shaped both by variables directly related to the onset of the scare - i.e., the triggering event - and by the contextual factors surrounding its occurrence. Figure 2 presents the evolution of the prize's size over time. 


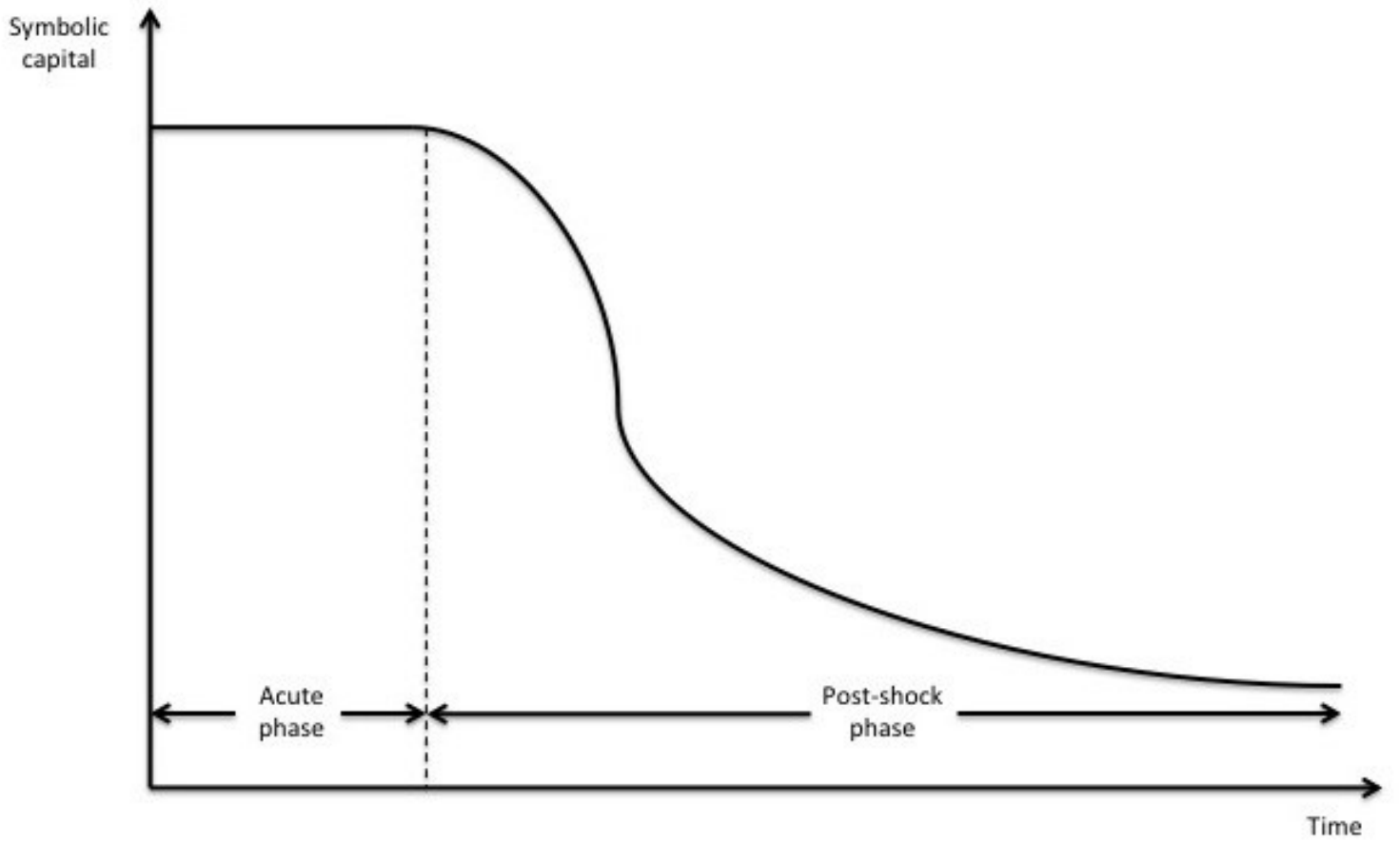

Figure 2. Potential symbolic capital prize (objective \#1) from the social scare.

As can be seen on the chart, there is a strong time constraint to this aspect of the scare. No social scare lasts forever, which suggests that given enough time, any perception of insecurity has the potential to diminish by itself. As a result, the actions taken by actors to win this prize \#1 result in a larger gain the earlier they are taken. A short period at the onset of the scare corresponds to the acute phase, where the peak in insecurity is highest and attention to the issue is most pronounced. If some actors are able to quickly appear as leaders, good managers, and resolute in their reaction to the triggering event, their gain in symbolic capital will be higher than if their only actions are taken later on. 


\subsubsection{What are the structural features of the battle surrounding this first prize?}

To describe this prize \#1, consider the rent concept in economics, used to describe any payment beyond the means necessary to the production process and the sustainment of supply. Members of a labor guild, for instance, can reap an economic rent if the guild creates a scarcity for members of their occupation. In that sense then, the economic rent comes out of (economic) market imperfections, that can be created and possibly magnified either by the actions of the rentiers (by imposing a quota on members of the guild, for instance), or by exogenous factors creating a scarcity, or both. Put differently, the capture of such a rent comes from an advantageous position as the owner of production means/resources, given the "biased" environment.

The parallel I draw here with the political process is that there is a "normal" reward for performing well as a politician, for instance by enacting policies that bring benefits to society, by managing public affairs well, or by arbitrating conflicts between different interests across the population. In times of social scare, however, prize \#1 represents a surpassing of the normal gains and losses from enacting "good" policy. This prize is thus a political rent, because the political capital won (in symbolic capital form) in successfully doing so comes merely from the context of insecurity created by the scare. For instance, the risks from using nuclear energy the day before an event like the Chernobyl disaster and the day after are technically the same. In the public and political spheres, however, the reward from making decisions, finding culprits if applicable and bringing them to justice, and enacting policies that will reduce the high perception of insecurity created by the use of nuclear energy is much higher immediately after the 
disaster. As explained above, this first dimension of the prize represents a bulk of symbolic capital available to actors able to reassure the public.

The acute phase is a period when leadership is expected, and so a key political leader (very often an important figure of the executive branch, but also potentially an opposition leader) can stand out. Note that symbolic capital can also be lost during this phase: failing to successfully demonstrate leadership and capture this prize is potentially harmful for political leaders, especially if they are in a position where the situation is viewed as their responsibility. Put differently, although the rent diminishes by itself over time, the competition over its capture is often a relative game, as the capture of a portion by an actor implies a loss by another, and vice-versa. As a result, actors in power are somewhat "forced" to try to win it, because not doing so could result in a loss of symbolic capital (more on this below). This brings us to the question of who exactly can capture the rent.

\subsubsection{Who can capture the rent?}

Not everyone can lead a nation out of an acute crisis, and actors who wish to go after this rent need specific resources: they need to be in a political position where their function is related to the prize, for instance an executive position; and they need a certain level of legitimacy, because although a discredited political leader can sometimes save his reputation by capturing a rent in these circumstances, it is likely to make it more difficult for him to do so. This is partly why the reward is a political rent: being able to capture the bulk of it depends largely on one's position when the social scare is triggered. 
While various groups can gain some symbolic capital from their leadership during a scare, only certain key people have access to its full extent, and this subset of political leaders is limited to actors in power, as well as actors in the opposition when an election is close (see the NEP case in Chapter 5).

This distinction is important: if this prize \#1 is considered to be a political rent, that is, something specifically created by the objective features of the scare and its triggering event, it is also distinct from "normal" gains in symbolic capital that can occur. In any given situation - social scare or not - different groups can win or lose symbolic capital through their actions. For instance, in the Exxon Valdez case described in Chapter 6, environmental groups gained symbolic capital through visibility in the media during the cleanup phase of the oil spill, and certainly this put them in a better position to ask for policy changes in the aftermath. However, the framework used in this dissertation puts the emphasis on a more limited set of symbolic capital: the prize \#1 is really circumscribed to what elected officials and opposition leaders can capture. Put differently, the symbolic capital that can be won by groups outside of elected officials during the acute phase can play a role in the policy battle that ensues, but it is not what makes social scares a special context. I return to these issues in section 2.2 .5 below.

Considering only elected officials then, actors in executive branches of government have resources especially useful for this battle, ones that are not available to other actors. In particular, they are the ones in charge, which means that they have the powers of the executive branch at their disposition. Every social scare has both immediate aspects and a longer-term dimension. The immediate aspects, in some cases, 
allow - and actually require - authorities to provide rapidly an expanded set of services to the direct victims. This acute phase of the scare was briefly discussed in Chapter 1 (see phenomenon \#1): in a hurricane, for instance, this phase consists of those days until the disaster has passed and dissolved, as well as a few extra days where the conditions for direct victims of the hurricane remain precarious.

During this acute phase, actors outside of a close circle in executive branches are likely to be relegated to the sidelines, and the door is open for the capture of a large rent. ${ }^{12}$ After the acute phase is over, however, not only is the rent smaller (as shown in Figure 2), it is also harder to capture because discussions of actions are about the future (i.e., potential impacts, possible repetitions of the triggering event, etc.).

Importantly, this highlights a conflicting and potentially difficult position for leaders in the executive branch. On the one hand, leaders of this group are often in the best position to capture the rent. I have just described one set of tools they have and that other actors lack, i.e. the capacity to use the government's resources in the acute phase, their prime position as recognized and legitimate leaders by the population and the media, or other executive powers that they may find use for. Another tool is their influence over the legislative process, especially in a majority government within a parliamentary democracy, which can ensure them a great deal of control over how the competition for policy change will evolve. Because of these tools, whatever leaders from the government

\footnotetext{
${ }^{12}$ I used the plural for executive branch because in some cases, it is possible for the scare to trigger a battle between actors of different levels of government (federal, provincial/state, municipal), especially if these are from different political parties. I leave this aspect for later in order to simplify the discussion here; the ice storm case, described in Chapter 5, elaborates on this issue.
} 
choose to do should be easier to achieve than for other actors, making it tempting for them to devise a strategy to capture a large rent.

On the other hand, however, in some circumstances this privileged position can become akin to a "leadership curse". During the acute phase, no matter what type of event triggered the scare, the spotlights are turned to these government leaders. So while this can be beneficial as just argued, some contexts can complicate these actors' capacity to compete for the rent. Being the most legitimate actor to take care of a dire situation also means that one needs to perform well on this matter, as I discussed in Chapter 1. Dangers of being accused of incompetency, or lack of empathy and care for the victims, for instance, are highest for these leaders.

\subsubsection{What are the constraints specific to the scare that these actors face?}

In addition to contextual factors described in 2.2.2, any given scare comes with specific constraints linked to the characteristics of its triggering event, and two variables stand out. The first variable is the level of disruption brought about by the event. Social scares follow an event that triggers the perception of insecurity, but triggering events can vary considerably, and one important characteristic with which to describe them is the disruption they bring to what is considered to be the normal state of affairs. A triggering event causing a high level of disruption would involve something spectacular, for example a rare and powerful natural disaster or a large-scale terrorist attack in a country that has little recent experience with these occurrences. If the trigger is more akin to an alarming report on an issue, for instance the very poor state of bridges and other 
infrastructure across a region, then the level of disruption is low. Some metrics can be used as proxies for this dimension, for instance the number of victims or the financial damage incurred. However, this needs to be done with care, as particular contexts (notably socio-cultural and historical aspects) may prevent the establishment of absolute thresholds. Note also that it needs to be taken into account whether this trigger was really one event (the 9/11 attacks, a major bridge that collapses, etc.), or a more progressive series of occurrences ( 5 minor terrorist attacks in the same decade, a worrying report on the poor state of bridges after several incidents, etc.).

A higher level of disruption means that impressive symbols and images become resources for actors trying to increase the size of the rent (the higher the perceived threat, the larger the rent, everything else being equal). Moreover (and relatedly), when the event is more traumatizing, the level of uncertainty that accompanies it is also higher, which becomes an additional resource for actors trying to highlight the failures of the current policy regime, a resource that also relates to the second dimension discussed below. More uncertainty allows for more flexibility in the framing of the causes and implications short term and long term - during the scare that ensues (I discuss this issue at length more in the next chapter). Finally, a higher level of disruption also increases the total time length of the scare.

The second variable related to the triggering event is the reach - i.e., the breadth of the potentially affected population. This is distinct from victims of the triggering event, and refers to the people directly concerned by the potential impacts coming out of the social scare. The reach variable is the answer to the question, who feels threatened 
with the onset of the scare? A low level here corresponds to an event that is perceived as local and circumscribed, such as a flood or a small hurricane. A high level would be something affecting the everyday activities of a large portion of the population, for instance an immediate but imprecise military threat. In between would be when the scare's potential impacts are not circumscribed to a specific region, but either affect the general population sparsely or have impacts that can only be theoretically extended to this population.

What changes with this second variable is the level to which a large portion of the population feels directly threatened by the issue underlying the scare. Since not only real but also potential impacts are included in this variable, this is a dimension that can vary substantially depending on the success of framing attempts. In other words, it can be a very dynamic dimension, as actors can manipulate the perception of insecurity with rhetoric. The higher the level of this variable, the greater the rent will be.

The rent's size is thus not only determined by the objective features of the triggering event, for instance the numbers of deaths or injured. The uncertainty regarding the potential future impacts, along with impressive symbols and images that accompany the disruption, can be used to frame the scare in a way that inflates the rent's size. This is where framing becomes important: the scare is vulnerable to discursive manipulation, which can result in a larger rent available to the actors described above (more on this below and in Chapter 3). 


\subsubsection{What strategies can they use to win it?}

During the social scare, and especially in the acute phase, political leaders can attempt to improve their chances of capturing the rent by maximizing exposure (of themselves, of key actors and representatives, of positions and policy solutions); by framing the social scare, its causes, its sensible solutions; and by entering into a damage control mode if necessary, for instance if it is too difficult or impossible for them to avoid losing some political capital by intervening. This last item is a particularly important feature, because in some situations the rent is very difficult to win - at least without renouncing to positions, policies, or principles to which the leaders may be attached.

Furthermore, while only certain officials have access to this rent (see 2.2.3.2 above), other actors and coalitions can try to shape the conditions that will have to be met by the leaders in order to effectively win it, by participating in the framing battles that occur, for instance. Since failing to capture the rent likely entails losing an important amount of symbolic capital, then this is an important power that groups have if they can devise an appropriate strategy (I expand on this point in section 2.2.4 below).

Overall then, the prize for this first dimension is created within a given context, and with a certain level of disruption and reach, linked to the scare's triggering event. Actors and coalitions can, especially in the early stages, attempt to manipulate some of these characteristics in order to inflate or deflate the prize - through a framing of the scare's causes and solutions. Additionally, while executive branch leaders are presented with a great opportunity to win symbolic capital during a social scare, they also stand to 
lose a lot. Moreover, they need to consider the second dimension to these battles, to which I now turn.

\subsubsection{Prize \#2: the battle of interests}

While this competition for supremacy in leadership in times of social scare is a critical component of any analysis of such events, there is another parallel battle that occurs during a social scare and that often outlives the acute phase: the battle for policy change. As the literatures reviewed above indicate, the scare is not just a moment for leaders to shine, it is also a window of opportunity for policy change. Social scares sometimes lead to major change, in particular, but also to various other types and degrees of policy changes - including no change at all in some cases.

At the onset of the scare, and regardless of the more immediate problems of the acute phase, a policy failure or gap is often highlighted. As a result, actors and groups must think about a second objective: can they get the policy outcome they prefer at the end of the social scare? Often even when the immediacy of the insecurity is perceived to have been reduced or eliminated at the end of the acute phase, the public problem brought about by the scare's triggering event may still be unresolved. In some cases, this can mean that insecurity remains as to the possibility of future similar events. Because of this, a social scare also includes a political struggle where the gains and losses are different from the leadership prize described above, and are related to the benefits and costs associated with different policy paths. 
The scare invades the policy process, as coalitions and actors have an opportunity to press for changes that were not on the agenda before the advent of the scare. In other words, even after the urgency of the acute phase is gone, the scare has not vanished and can still have an impact on the policy process. This situation creates a "battle of interests", as different coalitions of actors will have clashing preferences for the policy outcome - including, importantly, an outcome where policy change was minimal or nonexistent.

This prize \#2, the benefits of a policy course of action for a given group of actors, has a set of characteristics that are largely different from the rent described above. First of all, this policy outcome prize is of a different nature, and does not merely consist of symbolic capital like prize \#1. The policy process includes gains (and losses) that can be in various forms, which need not concern us here: what is important is that different coalitions have a preferred outcome in mind, one they value most. This is akin to what could be called the "normal" policy process (i.e., coalitions, including politicians, win some benefits from enacting or blocking a particular policy or reform), with the important exception that the scare's topic underlies the debates.

Competition for this prize involves a broader set of actors than for the political rent described above, and they need various resources. On the one hand, officials directly involved in the policy process need to have a position that allows them to have a say in policy introduction, design, deliberations, and votes and decisions - social capital, to continue using the terminology outlined in 2.2.1 above. All members of the executive and legislative branches have at least a small amount of this resource just by their position as 
an elected or appointed member, but some have more, for instance members of relevant legislative committees, members of party leadership, or holders of ministerial positions. Another source of this capital is the type of political regime, which may give more legislative power to actors in the executive branch - for instance, in a parliamentary system compared to a presidential, as legislative power is much more concentrated in the former. To a certain extent this is similar to what occurs for the leadership dimension, with the caveat that the key positions may be different. Social capital in this context is also useful in the form of interpersonal networks of relationships with other members of legislative assemblies, yielding influence over the process.

In this second dimension of political struggles during social scares, advocacy coalitions, including members outside of political assemblies, can participate more fully than for the political rent, as they have several resources they can use to ensure that their preferred outcome occurs. They can use their economic capital, for instance by contributing to electoral campaigns and my making funding promises to key legislative officials, which can additionally yield some degree of influence over what happens in committees and within legislative assemblies. Symbolic capital can also be used here, as actors other than legislators are generally called to intervene in the debates, be it at committee hearings or in the media. The legitimacy of scientists and various kinds of experts, for instance, certainly allows some of them to have a degree of influence over proceedings (I expand on this in Chapter 3).

A lack of social capital can be particularly problematic for these coalitions, as access to the policy process is always important: conflict with dominant policy actors, in 
any area of activity, can lead the latter to close debate space to outsiders, especially if they are pushing for change in policies that is unattractive to them. Whether or not competing coalitions have access to appropriate venues impacts the likelihood of policy change, as suggested by Baumgartner and Jones (Baumgartner \& Jones, 1993; True et al., 2007), and this is not different in the context of a scare. If a coalition is already associated with allies within the current policy regime, then they will have a strong advantage over other coalitions. If not, it will be arduous for the coalition to intervene in debates and challenge the policy regime in place, other than by making "a sound claim to represent the public interest" (Birkland, 2006, p. 164). In other words, if change does come during the post-shock phase of a social scare, it is likely to be the one favored by a coalition associated with members of the policy regime in place (all else being equal).

The possible strategies for coalitions include some similar to the leadership dimension, but also different ones, as they have more flexibility over what they can do. Framing causes and solutions of the scare's origins remain crucial, although here these need to incorporate a stronger emphasis on visions of the future, using the uncertainty available to build causal stories that logically and convincingly lead to certain policy options. The standard strategies of venue shifting and lobbying for policy change (or the blocking thereof) are also available to coalitions locked outside of the process. Finally, and more importantly for this discussion, this second battle is highly influenced by the struggle related to the rent described above. This brings us to the relationships between both prizes. 


\subsubsection{Interplay between objective \#1 and objective \#2}

So far I have described two dimensions, each associated with an objective, that characterize the political context during a social scare. The first objective is to win the prize that goes to actors able to gain symbolic capital from their actions (through competent rescue efforts in the acute phase, or credible propositions of policy or regulatory changes, for instance), while the second objective is associated with the prize that goes to those who obtain their preferred policy outcome.

Given that these two battles emerge out of the same social scare, there are important linkages between them. How much influence do considerations on each objective have on one another? Are there different possibilities for different actors? Is it always possible to win and/or maximize both? The last component of this analytical framework, which I develop in this subsection, describes how these considerations impact the policy outcome itself.

Although the two competitions present distinct characteristics and dynamics, they are intricately linked, and there are several aspects to this interdependence. A first aspect is that actions directed at the first objective (winning the political rent) constrain what can be done in the policy battle. A strategy aimed at maximizing the size and ability to capture the rent, for instance, could lead to a negative policy outcome. Put differently, actors' and coalitions' strategies for the two competitions must be compatible with one another.

While it is possible to ensure a framing of the social scare as a particular problem, the solutions that emerge as appropriate within that frame are linked to specific policy 
options. As a result, actors can use this as a way to maximize the potential size of the rent, if they think they can win it. Inflating the insecurity has the benefit of enlarging the rent, as well as extending the period during which it is available. The Bush administration's handling of the post-9/11 months and years, for instance, exemplify this strategy, with a frame that insisted the menace of further terrorist attacks on American soil continued to be very important. ${ }^{13}$ However, this implies the need for the capacity to act accordingly, that is, with decisions and policy changes that are continually perceived as decreasing the insecurity ("solving", albeit progressively, the scare). Some policies can be sold in compatibility with this frame, while others cannot.

Consequently, when leaders think about solving the scare and appearing as such (to capture the rent), they must also consider impacts that this will have on the longer policy battle that could ensue. Trying to maximize and win a very large political rent could leave them stuck with a definition of the problem that implies changes in policy that they do not want, for instance if the policy outcome is very costly given their interests.

These considerations are not just related to trying to inflate the leadership prize. If actors know that the scare is difficult to frame in a way that would lead to policy outcomes beneficial to them, they could also try to minimize the scare, in an attempt to eliminate a large part of the rent. This strategy is indeed what is often done when no policy changes are appealing to leaders (i.e., the policy outcome would be negative if any changes are enacted). In that case, these actors will often try to downplay the scare, or at

\footnotetext{
${ }^{13}$ Note that whether or not this was true has little to do with this choice of frame: the point here is merely that this describes the actions of the high-ranking officials in the Bush administration at the time.
} 
least the future impacts or probability of repetitions. Framing strategies that insist on the "natural" side of a disaster, for instance, imply that it was unavoidable regardless of the policies in place - and thus that no changes are required.

Even more importantly, performance with regard to one dimension influences the strength of the position of actors in the other. Specifically, if one makes early gains on the rent (i.e., while it is largest), for instance, this should bring one momentum for the battle of interests. Conversely, making early losses on the leadership dimension weakens these actors' position in policy debates, as I described this briefly in section 2.1 above. This is how the "battle of interest" described above actually differs from the policy process during any other period: actors who captured a large part of the rent during the acute phase possess a formidable resource in the battle over policy, in the form of the boost in symbolic capital associated with this rent. Hence this bulk of additional symbolic capital can tilt the balance to their favor, even if other coalitions and actors have substantial resources in other forms.

A second aspect of the interdependence follows from the leadership curse described above. Leaders of the executive branch of government are in a prime position to win the political rent, but in some circumstances this privileged position can complicate these actors' capacity to compete for the rent and get a beneficial policy outcome. Trying to minimize the scare, in particular, can be problematic in this context, as opposition actors will have more facility in criticizing the authorities' actions - or lack thereof. But even if government leaders do choose to act decisively to capture some part of the rent, they remain constrained by the features of the first aspect just described: that 
is, the need for their actions regarding the rent to be compatible with policy options that would remain beneficial to them.

An important factor influencing this aspect relates to the electoral context, which was mentioned at the beginning of section 2.2.2. There is a difference between a scare being triggered in the first year of a head of government's four-year mandate, and one triggered a month before an election. In the latter case, the pressure on the leaders to act, while potentially leading to a large rent, can lead them to get literally kicked out of the process and be replaced by a new government. If that is the case, this new administration will find itself in the former situation - the beginning of a mandate - and will even have won momentum with regard to both the rent capture and the battle of interests.

A third aspect illustrating the links between the two competitions relates to actors who, on the contrary, have little potential to win the rent. As I briefly mentioned above, although advocacy coalitions outside of policy circles can win some symbolic capital through their actions and interventions during the acute phase, this remains very small in comparison with government leaders seen as taking charge in resolving the insecurity triggered at the onset of the scare - that is, winning the rent. As a result, it would be tempting to consider these coalitions as mostly motivated by what happens in the policy battles: they may see the scare as an opportunity to promote change, perhaps, or on the contrary they see it as a menace to the current policy regime in place that they see as beneficial.

However, while it is certainly the case that these coalitions will be concerned mainly with the policy outcome, they cannot neglect the battle for the rent that occurs in 
the acute phase of the scare. Any advocacy coalition has allies and foes in power, and consequently it is to their advantage to ensure that the leadership prize is won by people in the former group, since it increases the potential for their preferred policy outcome. If they can, then, they should help allies capture the rent, even if that symbolic capital will not benefit them directly, because this will improve their position in debates over the policy changes they cherish - or fear. In the particular case of an adversarial administration in the beginning of a majority mandate, these groups should attempt to counteract any strategy by the administration to capture the rent, in order to prevent an even tougher battle of interests, perhaps capitalizing on the leadership curse described above. To do so, they can attempt to discredit the opponents' actions, criticize or debunk the explanations and suggested solutions to the underlying issue of the scare that are presented by these opponents, and so on. The hope is that at least those leaders will not be able to enjoy the boost in symbolic capital that would make them stronger adversaries in later policy discussions.

There is one additional particularity for groups in this position: the mere participation in the debates during the acute phase can be simply too risky. In some instances, the triggering event's impact on their position suggests that they are better off letting the acute phase play out without their intervention, as any participation would worsen their position in the upcoming legislative battle, regardless of whether the rent is captured by a foe. One recent example of this was the strategy of the National Rifle Association (NRA) in the acute phase of the social scare triggered by the Sandy Hook Elementary School shooting on December 14, 2012, in Newtown, Connecticut. While the 
United States is unfortunately home to several mass shootings every year, this particular case struck a nerve given the fact that 20 out of the 26 victims were young children, and reignited the recurring debate on gun control. For the NRA, a leading voice in the debates on gun control legislation in the United States, this was a difficult situation, since any intervention they would normally make in the aftermath of a shooting was riskier than doing nothing, given the high level of disruption brought by the age of the majority of the victims. Surprisingly for some, the NRA stayed completely silent for several days after the shooting, only stepping into the debates on gun legislation when the overwhelming attention to the events had somewhat receded from the media. In the circumstances, it may have been the best strategy, as they could hardly score any points in the acute phase except by amending some of their core positions - i.e., by compromising their commitment to their membership.

To recapitulate, the relationship between the political struggles surrounding the two objectives aforementioned have three main implications. First, actors and coalitions' actions for each battle must be compatible with one another; second, government leaders are in the best position to capture the rent (especially actors within the executive branch), but the leadership curse can place them in the uncomfortable position of having to take action requiring subsequent policy changes unattractive to them; and third, coalitions focusing on the second objective who have little to win with regard to the rent must still consider this first struggle, to ensure that whoever wins the rent is not going to push for a policy outcome they dislike. The two dimensions of political struggles occurring during a social scare are thus closely intertwined. Actors and groups focusing on only one 
objective when devising their strategy and course of action do so at their own peril. Table

2 presents a summarized version of all the items discussed above.

\section{Table 2.}

Summary of distinctions between the two dimensions

\begin{tabular}{|c|c|c|}
\hline Aspect & First dimension & Second dimension \\
\hline $\begin{array}{l}\text { Objective with } \\
\text { regard to the } \\
\text { scare }\end{array}$ & $\begin{array}{l}\text { - Obtain symbolic capital from the } \\
\text { scare }\end{array}$ & - Obtain preferred policy outcome \\
\hline $\begin{array}{c}\text { Features of the } \\
\text { prize }\end{array}$ & $\begin{array}{l}\text { - Symbolic capital } \\
\text { - Time-sensitive (the size decreases } \\
\text { rapidly with time) } \\
\text { - Potentially very large (inflatable } \\
\text { depending on disruption and reach) } \\
\text { - Restricted to key government and } \\
\text { opposition officials: depends } \\
\text { largely on the position of actors } \\
\text { (e.g., a little-known official cannot } \\
\text { "lead a nation" out of a social } \\
\text { scare) } \\
\text { - Important risk in trying to win it: } \\
\text { key actors may be forced to } \\
\text { compete for it (leadership curse) } \\
\text { - Important risk in forfeiting it: "not } \\
\text { winning" entails a potential loss }\end{array}$ & $\begin{array}{l}\text { - Mix of different forms of capital, } \\
\text { corresponding to a group or an actor's } \\
\text { preferred outcome } \\
\text { - Less subject to time constraints, } \\
\text { especially if actors do well in the first } \\
\text { dimension } \\
\text { - Open to actors outside of elected } \\
\text { officials and opposition leaders } \\
\text { (broader advocacy coalitions) }\end{array}$ \\
\hline $\begin{array}{c}\text { Possible } \\
\text { strategies by } \\
\text { elected officials } \\
\text { and broader } \\
\text { advocacy } \\
\text { coalitions }\end{array}$ & $\begin{array}{l}\text { - Maximize exposure (of key actors } \\
\text { or positions in the media/public) } \\
\text { - Framing of the scare's causes, } \\
\text { scope, and possible solutions } \\
\text { - Emphasize/discredit leadership of } \\
\text { specific actors (to prevent a win) } \\
\text { - Damage control (avoiding to } \\
\text { participate and downplay the scare) }\end{array}$ & $\begin{array}{l}\text { - Use of momentum from early wins in } \\
\text { first dimension } \\
\text { - Framing of the scare's causes, scope, } \\
\text { and possible and solution } \\
\text { - Conventional methods (lobbying, } \\
\text { campaign contributions, venue } \\
\text { shifting, etc.) }\end{array}$ \\
\hline
\end{tabular}

\subsection{Conclusion}

These possibilities provide two overarching conclusions on this framework. The first is that in order to explain what type of policy change follows a social scare, careful attention needs to be given to the first dimension in the framework. The symbolic capital 
prize of being seen as the "solvers" during a social scare, if it is large enough, becomes a critical resource in the policy battle that occurs in parallel by whoever was able to capture it.

These actors' intentions and preferences, then, become critical. Ideally, winners on the leadership dimension want to use this boost in political capital, whether for issues related to the scare or not. In other words, for leaders capturing a large rent early on through their actions during the acute phase, their preferences for the policy outcome will be determinant. It allows them to gain the commanding heights of the policy debates that will follow, and the prize they won becomes a resource for them to use in the legislative phase.

If they want to push for change related to the recognized policy area underlying the scare, change will be highly likely, which also implies that major change is also possible. The momentum they gain for policy battles also means that other government actors will want to join them in their policy change efforts, in order to capture the remnants of the rent by being associated with the reforms, increasing again the likelihood of their policy preferences being met. If they do not want change, however, the question becomes whether they will be able to prevent it, for instance by nipping any discussion in the bud or by simply overcoming any challenges to the status quo position. This reflects a situation when the leaders are attached to the policies currently in place, or when they simply want to use the capital won for something else - another battle, unrelated to the scare, for instance. 
The second conclusion is that actors and coalitions using strategies that work well for the two dimensions as a whole are more likely to see the policy outcome they favor. That is, successful strategies are ones that take into consideration possibilities for the two dimensions together. In these strategies, advocacy coalitions can determine what their preferred outcome at the end of the scare would be, given the possibilities at the onset, and then decide what they want to do for the rent during the acute phase (suggest an interpretation of the scare that will lead to specific policy "solutions" later on, adopt a low-key approach and try to weather the storm, or try to prevent key actors from winning a major prize, for instance), with a vision for the policy debates in mind (what the main issues debated will be, what policy options should dominate discussions, and so on).

To summarize then, while social scares of various types trigger a similar process in the political arena, the variety of policy outcomes that follow can be understood and analyzed largely in terms of the bi-dimensionality of the battle that ensues. While every actor and coalition would like to maximize their benefits in both dimensions, they rarely can, given the sometime difficult combination of the leadership curse and the battle of interests. Strategies used need to balance both objectives with a specific set of interests in mind, and the events that occur during a social scare can be interpreted in this light.

Before adapting this framework to the study of scares in a particular area, namely energy scares, Chapter 3 presents an extended literature review, intended to further theoretical discussions necessary to understand the possibilities for several additional factors to influence the onset and evolution of social scares. Given the features of the two battles outlined above, the role of risk and uncertainty, of framing and perception, and of 
scientific knowledge and expertise are issues that deserve special attention in order to develop further a research design that contributes to the literature on major policy change and on energy policy. 


\section{Chapter 3}

\section{Uncertainty, framing, and experts: additional theoretical considerations in}

\section{the analysis of social scares}

In the previous two chapters, I presented a framework describing the mechanisms explaining why and how social scares produce different types of policy change. The general process is that an event triggers a period where attention to an issue is unusually high, and where there is a spike in the perceived insecurity - in the general population and in political circles - with regard to that issue. The type of policy change that can follow is then linked to competitions over two distinct but related prizes, corresponding to leadership and policy objectives, emerging out of this insecurity.

As discussed briefly in the Chapter 2, one important dimension of any social scare is the uncertainty that surrounds it. This uncertainty needs to be dispelled by narratives put forward by advocacy coalitions to explain the causes and solutions to the scare, but it also provides some room for different such narratives. In this chapter, I push this notion further, discussing how notions of risk and uncertainty can help us understand the political struggle surrounding the perception of insecurity underlying social scares. I begin with a general introduction to the topics of risk and uncertainty in modern societies, and then go on to discuss aspects more specific to social scares: the individual perception and social construction of risk and uncertainty; the framing of social scares; and the competition for legitimacy and credibility in these framing attempts. The objectives of the chapter are two-fold: first, provide an extended literature review on these aspects, to refine the framework developed in Chapter 2; second, set up building blocks that serve to 
apply the method of structured, focused comparison described in Chapter 4, by providing theoretical grounding for the investigative questions I later use to conduct this study.

\subsection{The social scare context: additional elements in the competition for the prizes}

In Chapter 1, I stated that the past century has seen a spectacular expansion in liberal-democratic governments' roles and resources. This evolution has occurred alongside the fast-paced development and widespread diffusion of modern technologies: from the construction of nationwide and international networks of infrastructure (in transportation, in electricity generation and distribution, in communications, in production, and so on), this process has continued to evolve with the partial privatization and globalization of these infrastructures since the late 1970s.

The works of Anthony Giddens $(1990,1991)$ and Ulrich Beck (1992) are well known to have described the societal shift that this increased pace of technological change has bestowed on modern societies, making the evaluation and management of highly complex risks associated with certain social and economic practices the central feature of these societies. In Beck's view, this risk society causes a fundamental problem in the way we - individually, but also through our state and social institutions - deal with the risks and uncertainties embodied in the world that surrounds us:

Risks were first considered side effects of industrial processes, but now they are guiding the logic of the distribution of wealth (which used to determine social-theoretical thinking). These risks are now more universal (society-wide) than before, where their nature led them to be targeting 
specific groups of people. Now they are supra-national and non-classspecific global hazards with a new type of social and political dynamism. These social hazards and their cultural and political potential are one side of the risk society. (1992, p. 13)

According to Beck, the result of this is that history and society have seen unknown and unintended consequences of human activity become a dominant force, and more recently the collapse of risk calculations that science and legal institutions had established (Beck, 1992, p. 22). Consequently,

risks such as those produced in the late modernity . . . induce systematic and often irreversible harm, generally remain invisible, are based on causal interpretation, and thus initially only exist in terms of the (scientific or anti-scientific) knowledge about them. They can thus be changed, magnified, dramatized or minimized within knowledge, and to that extent they are particularly open to social definition and construction. Hence the mass media and the scientific and legal professions in charge of defining risks become key social and political positions. (Beck, 1992, pp. 22-23)

For Beck, the risk society does not necessarily replace older types, but "new problems relating to the 'production, definition and distribution of techno-scientifically produced risks' (Beck, 1992, p. 19) begin to 'accompany' and 'overlap' with the earlier problems revolving around scarcity" (Elbe, 2008, p. 185). The primacy of technology in modern societies thus produces a paradox through which this creates a world where laymen are forced to rely on experts, but simultaneously see science and industry as producing the 
risks, and thus science loses part of its privileged claim to rationality (Denney, 2005, pp. 28-34).

Giddens $(1990,1991)$ provides a different perspective, but also emphasizes that risk is an inherent part of modernity, and cannot be limited to technical aspects but is instead embedded in socio-cultural relations. In doing so he distinguishes between risks created by tradition or nature, which are not fundamentally different from prior periods in history, and manufactured risks, which come out of the impacts of technology, science and a developing knowledge of the world. In the second half of the $20^{\text {th }}$ century, the latter have become more globalized, and consequently in this period of late modernity, risks are more likely to be manufactured (Denney, 2005, p. 34). Additionally, Kasperson and colleagues, in developing their Social Amplification of Risk Framework in the 1990s, emphasized that risk is "in part an objective threat of harm to people and in part a product of culture and social experience" (R. E. Kasperson, 1992, p. 158; see also Van Loon, 2002, p. 171).

Any evaluation of risk, therefore, represents merely a broadly accepted interpretation of the uncertainty characterizing a given problem, as risk is socially and culturally embedded. Attempts to distinguish risk from uncertainty, in earlier scholars' definitions - an oft-cited is Knight's: risk as "measurable uncertainty" (1964) - have engendered instrumentality goals, seeing risk as "out there", ready to be objectively measured. In these arguments, the better we get at measuring risk, i.e. the probability and magnitude of an alternative outcome, the less uncertainty remains, and the more easily it can be circumscribed to error terms. Authors like Beck, Giddens and others, however, 
challenge these assumptions, pointing out the social and political character of risk evaluations, given that most are created, assessed, managed, and controlled through the activities of organizations and institutions. The complexity of these risk evaluations in modern societies make them out of reach from the people affected, which brings out the importance of power and social relations between certain groups in the population: those who provide evaluations and definitions of risks and who control, check or manage them, and those who are their audiences.

Overall, what these authors highlight is the overarching part that the management of risk and uncertainty by public institutions plays in post-industrial societies, and the consequences for politics in general. Since there is, in those discussions and debates, a distinction between what is real and what is possible, and since there is a social component to definitions of risk and uncertainty, political actors and advocacy coalitions have an incentive to master and control the process that leads to the broad acceptance of one particular definition or risk assessment. Statements on these are never reducible to mere statements of fact: as part of their constitution, they contain both a theoretical and a normative component (Beck, 1992, pp. 23, 27). In the end, whoever controls the definition of risk controls the rational solution to the problem at hand. If you define risk one way, then one option will rise to the top as the most cost effective, or the safest or the best. If you define it another way, perhaps incorporating qualitative characteristics and other contextual factors, you will likely get a different ordering of your action 
solutions. Defining risk is thus an exercise in power. (Slovic, 2000, p. xxxvi)

Hence there are always losers and winners in risk definitions. In most social scares, the triggering event embodies a disruption, even if temporary, in the stability of a specific belief system about the risks and benefits involved in an area of activity the way it is currently conducted. The perception of insecurity that it triggers partly comes from a drop in the credibility or legitimacy with regard to the safety of the conditions surrounding an area of activity. During that period, different actors can try to capture the high grounds over the specific way to obtain the social benefits out of that activity, given a certain narrative over the risks involved, with consequences for their (and others') political and economic interests.

In order to provide a background to study and understand how these issues impact the political struggles occurring in the midst of a social scare, I expand here on three aspects. First, cognitive, psychological and social factors: how we understand and react to risk as individuals, as well as how it is (and can be) socially constructed; second, the possibilities for - and constraints to - the framing of social scares, and how this can impact actors' position and power in the political struggle during the scare's twodimensional battle; and third, the experts who can play a major role in this struggle, and how knowledge, science, and politics intersect. 


\subsubsection{Individual perception and social construction of risk and uncertainty}

The first aspect I discuss is how we, as individuals, comprehend and react to the notions of risk and uncertainty, as well as how our social interactions impact the definition of these within a specific context - i.e., with regard to a specific problem. Before looking at their social construction and the power dynamics therein, I begin with a theoretical background highlighting the cognitive and psychological factors that intervene in our individual interpretation of risk and uncertainty. I focus here on the substantial body of work accomplished by research teams led by Daniel Kahneman, Amos Tversky, and Paul Slovic, sometimes in collaboration.

Kahneman and Tversky, through a series of experiments, attempted to explain discrepancies between decision-making under uncertainty and what the expected utility theory, often associated with rational choice, would predict. This research produced three sets of insights that are of particular interest here. The first is that people "rely on a limited number of heuristic principles which reduce the complex tasks of assessing probabilities and predicting values to simpler judgmental operations. In general, these heuristics are quite useful, but sometimes they lead to severe and systematic errors" (Tversky \& Kahneman, 1974, p. 1124). For instance, people often make predictions intuitively, by choosing the outcome most representative of the evidence. These predictions are consequently insensitive to the evidence's reliability or to the prior probability of the outcome, which violates the logic of statistical prediction (Kahneman \& Tversky, 1973, p. 237). As a result, "the degree of confidence one has in a prediction 
reflects the degree to which the selected outcome is more representative of the input than are other outcomes" (Kahneman \& Tversky, 1973, p. 249).

A related phenomenon is attribute substitution, whereby "an individual assesses a specified target attribute of a judgment object by substituting a related heuristic attribute that comes more readily to mind" (Kahneman, 2003, p. 707). Put simply, people who are confronted with a difficult question sometimes offer a reasonable answer to an easier one instead, one they have not been asked. Another way of interpreting this observation is that the judgment that respondents produce reflects their actual understanding of the question that was posed (Kahneman, 2003, p. 709). An important consequence of this is that uncertainty, in particular, is poorly represented in intuition as well as in perception (Kahneman, 2003, p. 701).

The second set of insights relates specifically to decision under risk. Prospect Theory, as a major part of Kahneman and Tversky's work is now known as, presents a model of choice that differs from utility theory, and stands on a few precepts. First, people normally perceive outcomes not as final states of wealth or welfare, but as gains and losses (Kahneman \& Tversky, 1979, p. 274). Additionally, outcomes that are merely probable are underweighted in comparison with outcomes obtained with certainty (Kahneman \& Tversky, 1979, p. 263). This leads to risk aversion in the domain of gains (a preference for a sure gain over a larger one that is merely probable) but to risk seeking in the domain of losses (a preference for a loss that is merely probable over a smaller loss that is certain). In other words, certainty raises both the averseness to losses and the desirability of gains (Kahneman \& Tversky, 1979, p. 269). 
Additionally, there is an isolation effect: people often simplify the choice between alternatives by disregarding components shared by the alternatives, focusing instead on the components that distinguish them. This approach may result in inconsistent preferences, given that the decomposition of a pair of prospects into common and distinctive components can be done in more than one way, with different decompositions leading to different preferences (Kahneman \& Tversky, 1979, p. 271). The choice process can thus be separated into two phases: an early phase of editing, where the outcomes and probabilities associated with the offered prospects are transformed through several operations, in order to organize and the reformulate options to simplify evaluation and choice; and a subsequent phase of evaluation, where the highest value is chosen between the edited prospects (Kahneman \& Tversky, 1979, p. 274).

Taken together, these insights suggest that the way people perceive and understand a problem will depend on its formulation and the level of uncertainty it appears to embody. Hence the third general result of Kahneman and Tversky's work follows from the first two: framing has a critical impact in individuals' perceptions of problems. Some thoughts come to mind more easily than others (there is a difference in accessibility), and there is an important distinction between deliberate and intuitive thought processes (Kahneman, 2003, p. 697). This helps to understand the basic principle of framing, i.e. the passive acceptance of the formulation given. I return to these issues in the next section to show how this influences public debates during a social scare.

In a different but overlapping body of research, Paul Slovic and colleagues have put the emphasis on how people perceive risk, in other words how we, as individuals, 
define risk itself. In their research, they have come to assume that risk is inherently subjective, and is defined by individuals influenced by a wide array of psychological, social, institutional and cultural factors:

In this view, risk does not exist "out there", independent of our minds and cultures, waiting to be measured. Instead, human beings have invented the concept of risk to help them to understand and cope with the dangers and uncertainties of life. Although these dangers are real, there is no such thing a real risk or objective risk. Even the simplest, most straightforward risk assessments are based on theoretical models, whose structure is subjective and assumption-laden and whose inputs are dependent upon judgment. (Slovic, 2000, p. xxxvi)

Therefore, it is impossible to distinguish risk from risk perception (Rosa, 2003, p. 67).

As with Kahneman and Tversky, this research also shows the difficulty that people seem to have in dealing with uncertainty. Several mechanisms are used to try and dispel it: in reaction to a natural disaster, for instance, a common one is to view the events as cyclical phenomena, replacing the randomness characterizing the occurrence of the hazard by a repeat of history at regular intervals. Other such mechanisms include the "law of averages" approach, where the occurrence of the hazard in one year is seen as making it unlikely to recur the following year; the attribution of the hazard to a combination of circumstances highly unlikely to recur; or plain denial, seeing the current situation as $100 \%$ safe. Through all these mechanisms, people reject the task of dealing directly with uncertainty (Slovic et al., 2000, p. 7). 
Other experiences have also shown people to behave erratically when facing complexity and uncertainty: they generally make an opinion (and decision) without prior analysis of the situation; and they focus on short term aspects, failing to anticipate longterm repercussions and assuming that the absence of immediately visible negative effects meant that correct measures had been taken (Dörner, 1996, p. 18). Additionally, they tend to be more hesitant when more information is available, as the uncertainty that comes along with it inhibits their decision-making (Dörner, 1996, p. 104).

These behaviours have an important consequence even for "experts", who tend to be inadequately "sensitive to those avenues to disaster that they have failed to consider because of ignorance, forgetfulness, or lack of imagination. People who are unaware of their own omissions are likely to seriously underestimate the true failure rate" (Slovic, Fischhoff, \& Lichtenstein, 2000, p. 42).

If risk is, at the individual level, subjectively defined, and if the framing of a problem influences the thought process through which we perceive, interpret and understand it, then this opens the possibility for a social construction of the risk and uncertainty embedded in many problems. Most risks are potential and so invisible, and are based upon supposed causal relationships and interpretation. They exist only in terms of the knowledge that individuals have about them, and therefore can be exaggerated, dramatized or minimized, and are open to social construction and political manipulation (Denney, 2005, p. 191). In other words, "actual or hypothesized accidents and incidents (or even new reports on existing risks) will be largely irrelevant or localized in their 
impact unless human beings observe and communicate them to others (Luhmann, 1979)" (J.X. Kasperson, Kasperson, Pidgeon, \& Slovic, 2003, p. 15).

The general idea is thus that risk and uncertainty emerge from, and are shaped by, the interaction between social agents and the physical world. One way of conceptualizing this is through the Social Amplification of Risk Framework (SARF). Developed by J.X. Kasperson, Kasperson, Renn, Slovic, and colleagues, ${ }^{14}$ the SARF holds that as a key part of that communication process, risk, risk events, and the characteristics of both become portrayed through various risk signals (images, signs, and symbols) interact with a wide range of psychological, social, institutional, and cultural processes in ways that intensify or attenuate perceptions of risk and its manageability. The experience of risk therefore is not only an experience of physical harm but the result of processes by which groups and individuals learn to acquire or create interpretations of risk. (J. X. Kasperson, Kasperson, Pidgeon, \& Slovic, 2003, p. 15)

These authors developed and applied the metaphor of amplification, borrowing the concept from classical communications theory, to analyze how different social agents generate, receive, interpret, and pass on risk signals. These signals are transformed predictably through amplification stations, increasing or decreasing the volume of information about an event, heightening the salience of a message's certain aspects, or reinterpreting and elaborating the symbols and images, which induces other participants

\footnotetext{
${ }^{14}$ Pidgeon, Kasperson, and Slovic (2003); see also the theoretical foundations in R. E. Kasperson et al. (1988); Renn (1991); R. E. Kasperson (1992); Burns et al. (1993); R.E. Kasperson \& Kasperson (1996).
} 
in the social system to react with particular interpretations and responses. These stations can be, for instance, scientists or scientific institutions, politicians and government agencies, reporters and the mass media, or any other individuals, social groups, or institutions. Amplification stations are influenced by institutional structure, functions, and culture when they perceive the risks, those who manage the risks, and the risk "problem" (J. X. Kasperson et al., 2003, p. 15).

There is then a second stage of the framework, where some events will produce "ripples" sometimes spreading well outside the event's initial impact, even reaching unrelated technologies or institutions. Examples of such impacts include "market impacts (perhaps through consumer avoidance of a product or related products), demands for regulatory constraints, litigation, community opposition, loss of credibility and trust, stigmatization of a product, facility, or community, and investor flight" (J. X. Kasperson et al., 2003, p. 16). This rippling effect suggests that each order of the risk amplification process, in addition to its social and political effects, can also "trigger (in risk amplification) or hinder (in risk attenuation) managerial interventions for risk reduction" (J. X. Kasperson et al., 2003, p. 16).

The conclusions of the various applications of the SARF suggest that generally, "the nature of discourse about risk that characterizes the social processing of the risk is important, including the political competition that occurs to control language, symbols, imagery, and definition or framing of the risk problem" (J. X. Kasperson et al., 2003, p. 40). Put differently, 
certain states of the world which are possible and not predetermined can, objectively, be defined as risk. The fact that these states are not predetermined means they are probabilistic and, therefore, embedded with some degree of uncertainty. . . . our ability to identify, measure, and understand risks ranges from the putatively certain to the totally uncertain. To the extent that we are limited in these abilities, risk will appear less and less like an objective state of the world, and more and more like a social construction .... Furthermore, what individuals or societies perceive as risk and decide to choose to concern themselves as risk are not shaped only by the objective state of risk, but are also shaped by social, cultural, and political factors .... Risk is a situation or an event where something of human value (including humans themselves) is at stake and where the outcome is uncertain. (Rosa, 2003, pp. 55-56)

Overall this suggests that the nature of risk and uncertainty, as well as their role in and impact on society, makes them particularly susceptible to framing, and relates to the notion that "all uncertainties in political and economic life are managed by intersubjective constructs of how the world works" (Seabrooke, 2007b, p. 371). Very often, then, the "actors facing uncertainty do not have the conceptual tools to even begin processing and calculating their odds", which forces them to "build constructs for the management of information that seem not only reasonable to ourselves but to others" (Seabrooke, 2007b, p. 373; see also Blyth, 2006). So because events leading to social scares are dependent both on hard-wired (social-cognitive) factors and on social 
construction processes, the answers to the questions "what has gone wrong" and "what needs to be done" are highly likely to be contested, which makes social scares particularly conducive to framing attempts.

\subsubsection{The framing of social scares}

Having looked at the cognitive and psychological factors as well as the social construction process of risk and its perception, I now turn to the framing of social scares. Framing occurs when "actors attempt to 'frame' normative ideas in a way that resonates with existing norms and with the interests of the target audience" (Cass, 2007, 24). Frames are defined as "specific metaphors, symbolic representations, and cognitive cues used to render or cast behaviour and events in an evaluative mode and to suggest alternative modes of action" (Zald 1996, 262; see also Turner, 1988, pp. 108-113). The frame provides a context for the issue, and one frame eventually dominates the others because it resonates with the audience (the general public, for instance), it has support from elites, or it is compatible with media practices. This domination sets limits on the vocabulary and metaphors used in debates and discussions over an issue. The availability of "cogent templates from the popular culture," for instance, can render complex problems understandable (Ungar, 2000, p. 305).

In times of social scare, the political rent described in Chapter 2 is based on the idea that there is a surplus benefit in being seen as the "solvers" of the insecurity. The political struggle that occurs around this rent and over potential policy changes is largely shaped by actors trying to define the problem and its importance, and impose this 
definition in public and policy debates. In other words, the result of this struggle depends on the framing of the social scare itself, which will become the embodiment of a specific problem. Sometimes this framing is straightforward, other times it is a more difficult task, depending on the exogenous factors surrounding and underlying the scare and its triggering event. These will determine, to a large extent, the uncertainties and thus the malleability of the scare's possible interpretations. The scare is constructed, but nevertheless is partly characterized and restricted by certain factors: not all policy actions are always available, especially since some social scares may have a particular time horizon. If the time frame of the scare is short, such as a virus outbreak or an immediate military threat, the rent will be very large and will need to be captured quickly, which has consequences for the choice of solutions. This might not be the case, however, if the time frame is more flexible, and where longer-term solutions could be satisfactory in bringing down the level of insecurity. Similar constraints relate to the different contextual and structural factors described in sections 2.2.2 and 2.2.3.

In addition, actors need to define commitments to solve the scare that will be credible in the eyes of the public. Despite the objective features of the scare and its triggering event, the high level of uncertainty surrounding it can allow a certain discursive manipulation of the scare's parameters: successful advocates build a convincing narrative by progressively reducing the uncertainty associated to their solution, adapting their strategies as some extrapolations, claims, and predictions become accepted as credible - i.e., "true". Narratives that define the problem as the embodiment of a specific interpretation of the underlying problem can be imposed, and these 
narratives can be conducive to a specific solution to the scare, one that precludes discussions of as many alternative solutions as possible. Hence we can expect coalitions to compete for this domination during the scare's political struggle.

In this context, the uncertainty embedded in the scare's underlying issue (and in the triggering event) makes framing possible and highly likely. "The range of what agents can do is not exhausted by adaptation to structural constraints or material incentives," as they can also "engage in efforts at "strategic social construction"” (Ungar, 2000, p. 305) to shape shared meanings and interpretations of events. Framing has social and political consequences, as the dominating frame will restrict debate to policies (solutions) with a particular distribution of winners and losers. Consequently, the question becomes what are the factors that constrain this framing process, and what are the ones that facilitate it.

Persuasion attempts are made through the deployment of causal stories that "provide agents with an interpretive framework within which they can define, diagnose, and explain a crisis as an event which necessitates a particular set of actions" (Finnemore \& Sikkink, 1998; see also Widmaier et al., 2007, p. 888). As result, the process of constructing the scare is often about making sense of the apparent or perceived failure of previous policy "by narrating its causes and establishing a model for resolution" (Widmaier et al., 2007, p. 33). The benefits associated with each dimension of the political battle will thus be easier to capture when the problem is framed into one that can be solved (by some specific solution), and when it is easier to prove that the increase in security that eventually resulted was indeed caused by these actions. 
There are several ways to operationalize the different types of narratives related to a scare or its triggering event. Deborah Stone (2012), for instance, has developed a typology describing four types of causal stories that can help us understand some of the strategies used by different actors. These causal stories are ways of identifying a cause for the problem depicted, including its definition, as well as potential solutions that would "solve" it. The first type is accidental causes, where the phenomenon is depicted as devoid of purpose and intention, for instance natural disasters and matters of fate. The second is intentional causes, willful actions that produced the purposeful consequences; this story can be used either by groups wanting to show their quality (when the consequences are perceived as good), or by groups attacking others (when the consequences are perceived as bad). The third type is inadvertent causes, or unintended causes of willful human action, for instance a story of the harmful effects (maybe predictable but still unforeseen) of well-intentioned policy. The fourth type is mechanical causes, when the story describes the effect of an action as intended, but unguided, for instance in cases where human technology behaves as planned but the end result does not follow from a specific purpose. I return to some of these types, especially accidental and inadvertent, in the description of framing strategies in Chapters 5 and 6.

Furthermore, I have argued that social scares represent a period of heightened public and political attention to the issue; this attention is unusual, in opposition to a "normal" state of affairs; and there is a sense of urgency, which indicates a threat element. As I developed in Chapter 2, this suggests an important role for the broadly shared perception of insecurity in the competition between groups for policy change. The 
insecurity exists because of the threat inherent to the situation, but what I want to highlight here is that the uncertainty characterizing the situation allows various alternative scenarios regarding its impacts - both immediate and potential - and some of these scenarios imply (sometimes highly) negative consequences. Hence while the perception of threat is broadly shared, there is no consensus on these potential consequences. This situation also provides discursive space for different interpretations, and thus framings, during this period of increased attention that follows the triggering event.

The threat element suggests that the security studies literature has some insights into the framing process occurring during social scares. In general, authors from constructivist security schools argue that (in)security is given meaning within socioeconomic contexts. Security is most commonly associated with "the alleviation of threats to cherished values" (Williams, 2008, p. 1). Within security studies, authors from the Copenhagen School argue that the central concept is securitization, which is more or less a discursive construction of threat. Securitization in that sense is defined as a process in which an actor declares a particular issue, dynamic or actor to be an "existential threat" to a particular referent object. If accepted as such by a relevant audience, this enables the suspension of normal politics and the use of emergency measures in responding to that perceived crisis. Security, in this sense, is a site of negotiation between speakers and audiences, albeit one conditioned significantly by the extent to which the speaker enjoys a position of authority within a particular group (Buzan et al., 1998; see also Berling, 2011). 
Other authors argue that the Copenhagen School's focus on securitization moves as merely speech acts neglects that such moves are socially, culturally and institutionally embedded. Balzacq (2011), in particular, incorporates a time constraint, and securitization more generally becomes

an articulated assemblage of practices whereby heuristic artefacts (metaphors, policy tools, image repertoires, analogies, stereotypes, emotions, etc.) [which] are contextually mobilized by a securitizing actor, who works to prompt an audience to build a coherent network of implications (feelings, sensations, thoughts, and intuitions), about the critical vulnerability of a referent object, that concurs with the securitizing actor's reasons for choices and actions, by investing the reference subject with such an aura of unprecedented threatening complexion that a customized policy must be undertaken immediately to block its development. (p. 3)

\section{Consequently,}

the very way threats are tackled depend upon how they are perceived which is not always commanded by the objective features of what is called a "menace". Instead, the social design of a security problem conditions and legitimates the kind of means used to stop it. Thus, defining a menace is a normative political act (p. xiii). 
This suggests that different advocacy coalitions may try to define the social scare as the embodiment of a particular threat, implying some policy solutions and eliminating others, as there is more facility in achieving one's framing goals when the issue is defined along security lines. How representatives of particular groups and organizations construct threat agendas is a critical element when studying this process (Hassan, 2010, p. 452).

Furthermore, still within security studies, the Paris School suggests that the framing of a triggering event does not operate independently from the institutions managing "unease", as these also determine what is - and what is not - a threat or a risk. For these authors, this is done not with dramatic securitization moves, but by the institutionalization and normalization of a dominant discourse that effectively homogenizes the way of looking at a problem (Bigo, 2000). The discourse is not focused on removing threats with emergency measures, but on managing (assessing and controlling) the risks involved. In the case of a social scare, this would suggest that actors associated with the policy regime in place have an advantage given that their particular frame already is dominant if not accepted, and will use a control or management discourse rather than an emergency one. Coalitions pushing for change, on the other hand, will attempt to use the scare to highlight coherence issues within the current understanding of the problem. Securitization is thus seen "as a not very spectacular everyday practice that often involves 'experts"' (Berling, 2011, p. 389).

For these authors and others inspired by thinkers like Foucault and Bourdieu, risk is thus "a particular rationality of government that works to legitimate certain technologies of power" (Corry, 2012, p. 242). Rather than focusing solely on threats, 
then, attention must be given to this distinct process of riskification, which activates what can be called a "second-order security politics" (Corry, 2012). Changes in policy that install and institutionalize potential responses to certain risks, which are often seen in the aftermath of a social scare, embody this process.

Finally, whether or not they are using a threat as their main tool, the legitimacy and authority of the actors and groups impact the likelihood of success in their attempts at framing. Who is able to speak with authority and evoke trust and legitimacy depends on actors' strategies and resources as well as whether or not their claims and consequent institutional reforms come to be seen as legitimate by the mass public (Seabrooke, 2007a). On the other hand, the struggle is also influenced by whether or not they can count on their position as professionals, and by the extent of the control they may have over the creation and use of knowledge relating to the issue (Bigo, 2000, 2002).

This last topic of experts - in other words, the participants' authority and legitimacy - is central to the possibilities of framing. Scientific facts, in particular, can be mobilized by securitizing actors "in attempts to seek back-up in the objective, disinterested aura of the scientific vocation" (Berling, 2011, p. 386). But simultaneously, "science communities/explanations can come to objectify an issue to the extent where securitization - and even politicization - becomes next to impossible" (Berling, 2011, p. 385). This dual role of science has important implications for social scares in areas such as energy or environmental issues. 


\subsubsection{Science, knowledge, and politics: the competition for legitimacy and credibility}

So far I have discussed two aspects of the social scare context, risk perceptions and framing possibilities, including the importance of a threat element in the latter. Additionally, the triggering of a social scare often ignites a crisis of legitimacy and credibility regarding the knowledge - and source thereof - that risk calculations regarding the concerned sector, in a broad sense, rely upon. Many social scares in the recent past have had at least some amount of technical and scientific aspects, given the widespread use of advanced technologies in production and consumption, as well as complex large-scale distribution systems. This suggests an important role for scientists and experts of all kinds, in a battle for legitimacy and credibility over the knowledge backing up positions in political debates.

This section looks at how knowledge can be generated in this situation, with a special emphasis on energy and environmental issues, since many of the debates observed in the case studies of energy scares also contain elements of environmental issues. In the context of a social scare, the nature of energy and environmental issues makes the framing competition, and the battle for credible solutions, conducive to the use of knowledge deemed scientific. The complexity of activities in these two areas demands that calculations of the risks involved be done by professionals, given the prominent presence of high technology in the tools involved in the production, distribution, and consumption activities, as well as the complexity of these systems and their interaction with societal and ecological ones. For instance, in addition to the high degree of specialization required to assess the risk of failure of a single nuclear reactor, a 
calculation already out of reach for the overwhelming majority of the population, the societal implications of using this reactor or not also come with other risks to calculate what other source will be used to generate power, for example, should we decide not to use this reactor.

Historically, this is not new, of course. A century ago, Max Weber described such a world of intellectual rationalization:

Unless he is a physicist, one who rides on the streetcar has no idea how the car happened to get into motion. And he does not need to know. He is satisfied that he may "count" on the behaviour of the streetcar, and he orients his conducts according to this expectation; but he knows nothing about what it takes to produce such a car so that it can move. The savage knows incomparably more about his tools. (2009, p. 139)

This does not merely apply to the use of a specific technological artefact, but also relates to risk and uncertainty involved in engaging in any activity. Although science did offer an alternative to "Gods and magical means" by moving us closer to the mastery of things by calculation, to continue using Weber's words, this does not mean that any individual is able to engage in such calculations. Rather, "the expectation is that someone will be performing the necessary calculations, and that the relevant person will be doing the counting in a way that can be "counted on"' (Freudenburg, 2003, p. 104). This leaves the place opened for a professionalization of risk management, a phenomenon described above in the discussion on the Paris School of security studies. 
The public issue of "how safe is safe enough", for any given area of activity, depends on both a cost-benefit analysis done by legitimate authorities with the information that is available (Starr, 1969), but also on the social acceptance of the method to determine the answer to the question (Rayner and Cantor, 1987). In modern societies, there is a deep-rooted notion that in situations of high uncertainty, and even more so in highly technical and/or complex issues, science - or rather, the scientific method - is the objective standard on which to rely. Risk calculations, so the argument goes, should be done by professionals using scientific methods, a process that is often believed in political circles to lead to a one-and-ultimate knowledge, embodying the best possible objective solution to a problem (Pielke, 2007). This leads to a latent belief in the general population that someone, somewhere, has ensured that it is those calculations that have been used to allow for the activity to take place the way it currently does. As a result, the impression is that science can resolve issues because it helps understand the conditions under which decisions are made, and the potential future consequences of those decisions.

This, however, is compensated by the fact that "the proliferation of available facts ... can be used to build competing pictures of current and future conditions" (Sarewitz, 2004, pp. 392-393). Scientific facts are mobilized strategically in political and ideological struggles. In these struggles, "the belief [is] that science is the appropriate battleground, under the assumption that if a perception can be created that science is on your side, you win," which leads advocates to "'spin', cherrypick, or even misuse information" to embellish their preferred action (Pielke, 2007, pp. 62-63). 
Consequently, the reality is more complex than an idealized quest for objectivity, as several aspects complicate the political contest over who will claim to have this "ultimate" knowledge. A first such aspect concerns the wide diversity of participants in knowledge generation in the energy and environmental areas. Knowledge is generated in an institutional infrastructure that is fragmented. For instance, in green building practices, "engineers, hydrologists, architects, planners, building material and equipment suppliers, horticulturalists, builders, wildlife biologists, home buyers, and others [all] create or analyze [relevant knowledge]" (Ascher, Steelman, \& Healy, 2010, p. 37). Similarly, in discussion over energy security, "lawyers, bankers, brokers, economists, geographers, geologists, engineers and journalists speak ... with the same confidence as generals, development workers, defence analysts or environmental activists" (Ciută, 2010, pp. 123-124).

In their study of the generation, transmission and use of knowledge pertaining to environmental policy-making, Ascher et al. (2010) argue that this diversification creates uncertainty regarding the dependability and validity of knowledge, and consequently for its consideration in decision-making processes (pp. 29-35). The knowledge generated is thus subject to power dynamics, as who decides on what knowledge will be used is critical, given the filters of acceptability it has to go through in order to be channeled into policy considerations (p. 11). The arena where this battle is played is also influenced by and in turn influences knowledge itself, as the relative balance of power and standing of participants hinges on what is deemed relevant to the decision making process, in other 
words the standards for "acceptable" knowledge in policy and decision making (pp. 2123).

A second aspect complicating the use of science in policy is that the pursuit of objectivity as the gold standard gives a privileged position to scientific expertise, and consequently the knowledge that is transmitted is not comprehensive. "Other types of knowledge, including some forms of science, are filtered out during the transmission process" (Ascher et al., 2010, p. 68). Although this is partly because of clearer rules and protocols guiding the creation of formal science, this far from eliminates the uncertainty and complexity of knowledge generated by the scientific process, certainly in the environmental and energy areas. Ascher et al. go on to argue that one might assume that experts - disciplined by the scrutiny of other experts, the need to maintain reputation and credibility, and the internalized norm of conducting and reporting research as objectively as possible - should be able to provide a check in the system for determining when knowledge is sufficiently comprehensive. However, these factors do not play as great a role as one might expect because the complexity of environmental systems means that complete analysis is impossible. Given the impossibility of comprehensiveness, selectivity is unavoidable, giving space for different predispositions to color the analysis in ways that cannot be fully identified or criticized. (2010, p. 35).

This also creates "unreasonable expectations about the role that scientific information can play in the development of environmental . . policies," leading to "the implementation 
of misguided and self-defeating policy initiatives designed to ensure the objectivity or 'soundness' of scientific inputs to the policy process" (Herrick, 2004, p. 419).

The third characteristic of the intersection between science and policy is that despite the centrality of controversy, falsification and dissent in the workings of science, from the outside the process is viewed as creating objective, autonomous and disinterested knowledge and thus remains cast in terms of "pure" or "tainted" once transported into the political field (Berling, 2011). Often battles take place over whether the science is "sound" (i.e. deserving support) or "junk", instead of debating the value, usefulness, or practicality of specific policy options. Additionally, in media accounts of complex scientific problems such as climate change or peak oil, uncertainty descriptions do not occur often (...) because the media do not usually offer estimates of uncertainty in their rhetoric. Part of the selection in presentation involving uncertainty comes from the lack of presentation of uncertainties, leaving the audience to supplant their own percentage likelihoods on top of predictions and information. (Rothman, 2012, p. 14)

This leads to a fourth aspect: part of this selectivity in the media's treatment of uncertainties is due to institutional factors. The privileging of certain types of knowledge, in particular, hides governing biases that influence the policy process itself, leading into several traps when this privileging occurs. One of the these traps is the certainty prejudice, which produces a preference for knowledge that can be proven with certitude or directly observed over knowledge that is subjected to even small amounts of uncertainty, even in cases where it might be prudent to take action before complete 
certainty is known. In some cases, these social and cultural standards are superimposed on those of science, and may become critical constraints to effective decision making (Bradshaw \& Borchers, 2000; Gunderson, Holling, \& Light, 1995). Another such trap is the importance of status hierarchies, which describes a "tendency to defer to knowledge provided by individuals who appear to be better credentialed and more senior, hail from a perceived 'better' institution, or meet a preconceived notion of what an expert on the topic should look like" (Ascher et al., 2010, p. 10).

Finally, a fifth aspect of the complex intersection between science and policy is that "the prevalence of some analytical routines has made these techniques more central to decision making, while also shifting the locus of decision making from legislative to administrative arenas" (Ascher et al., 2010, p. 101). When tackling highly technical problems, there often is a tendency in political circles to favor technical (technocratic) solutions, and quantification of the uncertainties is strategic because it provides the "cloak" of objectivity (Salter, 2008, p. 254). The related tendency to favor cost-benefit analysis and expert valuation, which can present decision makers with a particularly narrow sense of the public interest and preferences, reinforces the tendency to use quantitative approaches over more qualitative and rights-based appeals (Ascher et al., 2010, p. 49; see also Ascher and Steelman, 2006). These however often miss the broader points, as "certain" or "objective" knowledge oversimplifies issues. This widens the gap between scientific and social reflections over the "hazardous potential of civilization ... as social movements raise questions that are not answered by the risk technicians at all, 
and the technicians answer questions which miss the point of what was really asked and what feeds public anxiety" (Beck, 1992, p. 30).

In this context, science is, unsurprisingly, politicized by both politicians and the institutional structure surrounding its production and use, and efforts to characterize data in an objective/non-objective dichotomy become futile (Herrick, 2004). The politicization of science is also done by scientists themselves, again for both structural and strategic reasons, in a process that Pielke and others have called scientifization (e.g., Pielke, 2007). The scientific setting in a given field gives scientists "a place from where to speak" (Berling, 2011), and "many scientists encourage the mapping of established interests from across the political spectrum onto science and then use science as a proxy for political battle over these interests," strategically seeking "out scientific references in support of their political views" (Pielke, 2004, p. 412).

Overall several conclusions can be drawn from these observations. The first is that in the context of a social scare, the system for making political and policy choices relies very heavily on experts, and often this turns into a dubious competition to determine who has the "most scientific" arguments. This reliance stems from the widespread belief that uncertainty is itself the adversary to be tamed, with important consequences for the policy contest over how best to resolve a social scare. This frame suggests that the more we know about a reality, the more we can take action to resolve it, since the reduction of scientific uncertainty makes the "best" course of action become clearer (Ascher et al, 2010, pp. 39-43; Oreskes, 2004; Sarewitz, 2004). At the same time, there is a credibility-seeking reluctance to transmit potentially challengeable knowledge 
(Ascher et al., 2010, p. 72). This tension is compounded by the news media's characterization of uncertainty in exclusively negative terms (Wilkinson, Allan, Anderson, \& Petersen, 2007).

Another conclusion is that there is a tendency for experts themselves to underestimate uncertainty, as one naturally tends to base assessments on what one knows. "Probability estimates cannot fully address the uncertainty regarding whether the understanding that generated the probability estimates is itself in error" (Ascher et al., 2010, p. 43), an aspect otherwise labeled as "unknown unknowns" (Daase \& Kessler, 2007). Again this stems from the general belief just mentioned: more information should necessarily help unravel the "true" nature of things - and hence allow more accurate risk calculations. The reality is again more complex, however, as "greater comprehensiveness in knowledge generation may exacerbate problems in environmental decision making when additional knowledge reveals complexity in natural and social systems" (Ascher et al., 2010, p. 43).

This is often what happens when a social scare is triggered. No amount of information eliminates all uncertainty: in the aftermath of a social scare's triggering event, more scientific information serves mainly to question the previous scientific information about the sector around a specific issue. This additional information exacerbates problems in decision making by highlighting "differences between competing bodies of knowledge and expands the realm of what is known and unknown. . .. Additional scientific information ... may consequently reinforce value disputes and competing interests rather than harmonize them" (Ascher et al., 2010, p. 46; see also 
Sarewitz, 2004). This situation, where no source of knowledge can claim a dominant legitimacy, makes it easier for other groups to come and push forward their own assessment (Freudenburg, 2003).

In this context, uncertainty is "a resource for various interests in the process of bargaining, negotiation, and compromise in pursuit of desired ends" (Pielke, 2007, p. 37). "Political decision making requires a complex agenda-setting process, and before an issue becomes subject to political regulation, it must be framed as a problem that can be solved by political decision making" (Weingart, Engels, \& Pansegrau, 2000, p. 263). So when the problem is complex and filled with uncertainties, this normally would not encourage immediate decision-making. Moreover, as certainty is usually invoked as the basis for action, uncertainty can be used as a reason for delay, and then all the effort (by advocates for action) is spent on disproving allegations of uncertainty (Pielke, 2007, p. 72).

Criticizing one's opponents for the uncertainty in their knowledge is an obvious tactic. Less obvious is the impact that this tactic has on the focus of attention: it gives greater prominence to debates over the knowledge base than to debates over values at stake or to the compromise and negotiation needed to clarify and secure the common interest. (Ascher et al., 2010, p. 86)

In policy making and public debates, including during social scares, all knowledge is not created equal. The dominance of certain solutions is largely dependent upon the ability of their proponents to demonstrate the value of the knowledge they use to underlie their causal stories, their visions of the future, or the effectiveness of their proposed policy 
solutions. Social scares revolving around highly technical or scientific issues thus increase the possibilities for framing because they are associated with a higher level of uncertainty, as more actors and coalitions can use this level of "technicality" as a resource in building a suiting narrative. The necessity of expertise to defend these positions leads to a battle to establish legitimacy and credibility for the knowledge and technical information used, and this constitutes the last aspect of the framing competition that characterize the context of social scares.

\subsection{Conclusion}

Issues of risk and uncertainty are intricately linked to the (in)security that underlies public debates during social scares. Moreover, given the fast pace of technological development in the $20^{\text {th }}$ and $21^{\text {st }}$ century, most social scares in the recent past have had at least some amount of technical and scientific aspects. This does not merely lead to the presence, in public debates, of experts of the concerned field, but also to the necessity of expert interventions for public debates to take place. This suggests that a special emphasis must be put on the role of expertise in public and political debates in the context of a social scare.

The literature review of these aspects theoretically informs some of the questions that are used to approach the main case studies of this project. One overarching conclusion that can be drawn from putting the previous subsections together is that "uncertainty", in the context of social scares, actually comes in different forms and from different sources. Even more importantly, uncertainty can be manipulated and used as a 
resource by some actors trying to build support and acceptance for their position, especially if it challenges the status quo: some sources of uncertainty, for instance, can be played up to attack knowledge underlying a given position or policy option, while other sources can be toned down to compensate for weaknesses in causal stories.

In the next chapter, I present a background of energy issues, and then use the insights developed in the first three chapters to establish the methodological design used on the main case studies of this project. 


\section{Chapter 4}

\section{Harnessing power: investigating energy scares}

Over the past forty years, energy has repeatedly come to the forefront of public and political debates. Discontent from shortages or an abrupt surge in oil prices, geopolitical instability stemming from intense competition over access to energy resources, industrial accidents, as well as sustainability and environmental concern over the extensive use of fossil fuels, have periodically increased attention to the topic. Given the magnitude and extent to which energy penetrates societies, it is an area of human activity particularly prone to contentious debates in general, and to the occurrence of social scares in particular.

This chapter adapts and elaborates the framework described in Chapter 2, incorporating the insights from the extended literature review done in Chapter 3, in order to develop a research model to study and understand the mechanisms leading to the adoption of particular "solutions" to energy scares. This model starts with the assumption that energy scares of all kinds are particularly conducive to competition over the political prizes that they create. Actors within and outside of the designated authorities have the potential to participate in the definition of the nature and implications of, as well as policy solutions to, specific scares. Because these periods of increased attention imply a potential reshaping of the State's role in energy, and because energy scares are by definition associated with a high degree of uncertainty (with regard to both the problem and the solutions), analyzing and understanding these instances can substantially improve our understanding of policy change. 
In the next section, I first provide a brief description of the political economy of energy, in order to provide a background for the discussion that comes next over the analysis of social scares more specifically related to this sector. I then detail the methodological approach used in the next chapters, based on the method of structured, focused comparison, and provide a justification for the choice of the main cases presented in later chapters.

\subsection{A political economy of energy}

Given the importance and size of energy consumption among both industrializing and industrialized countries, energy is one of the largest economic sector in the world, amounting to around $\$ 5$ trillion in worldwide expenditure (8\% of global GDP) annually (Institute for Energy Research, 2010). Figures 3 through 8 present the evolution in the total primary energy supply over the past 40 years, comparing its composition by source between 1971 and 2011. The charts also present the breakdown according to OECD and non-OECD countries, since the former largely overlaps with the population of cases for this study (see Chapter 1). We can see that oil, natural gas, and coal still remain the principal energy sources. Also, between 1971 and 2011, the share of oil has substantially diminished, and natural gas' part went up. In OECD countries, nuclear energy also presents the most important increase. 


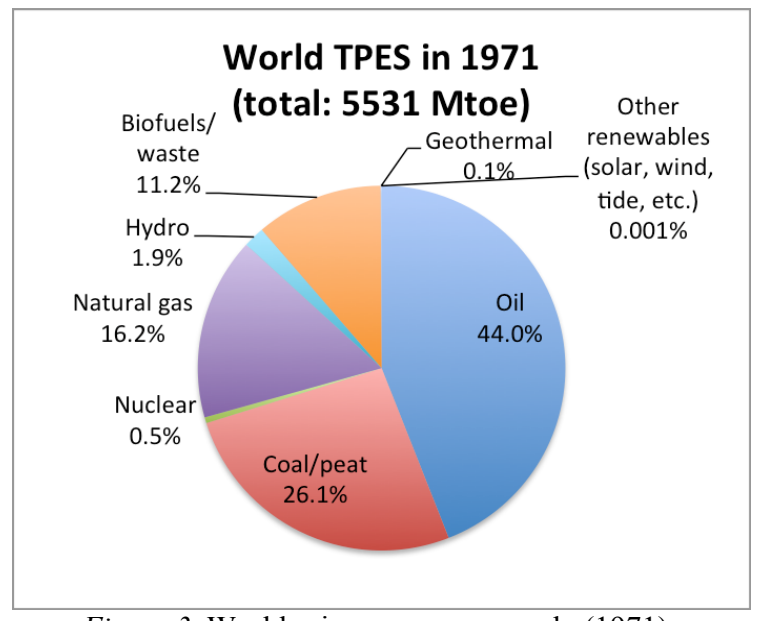

Figure 3. World primary energy supply (1971).

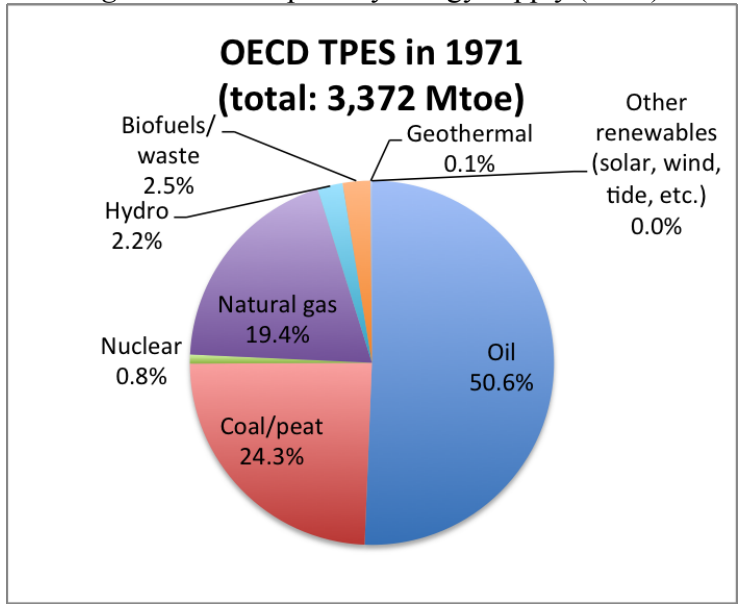

Figure 5. OECD primary energy supply (1971).

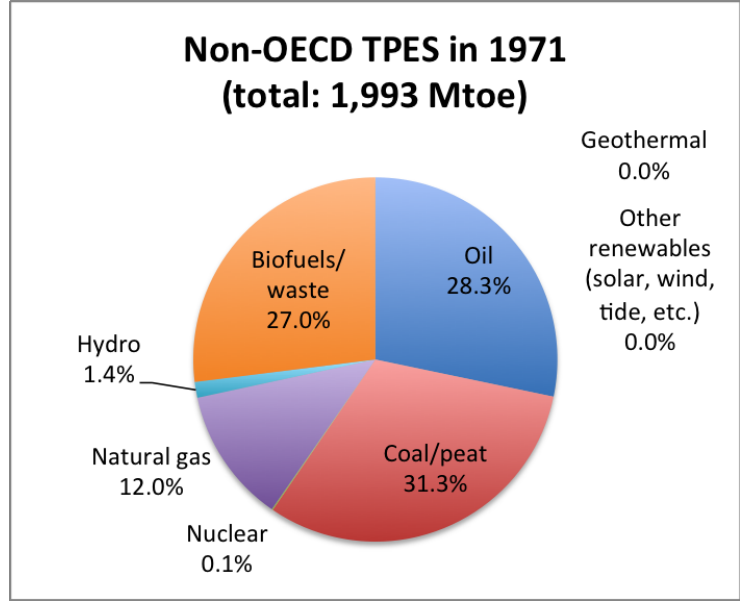

Figure 7. Non-OECD primary energy supply (1971).

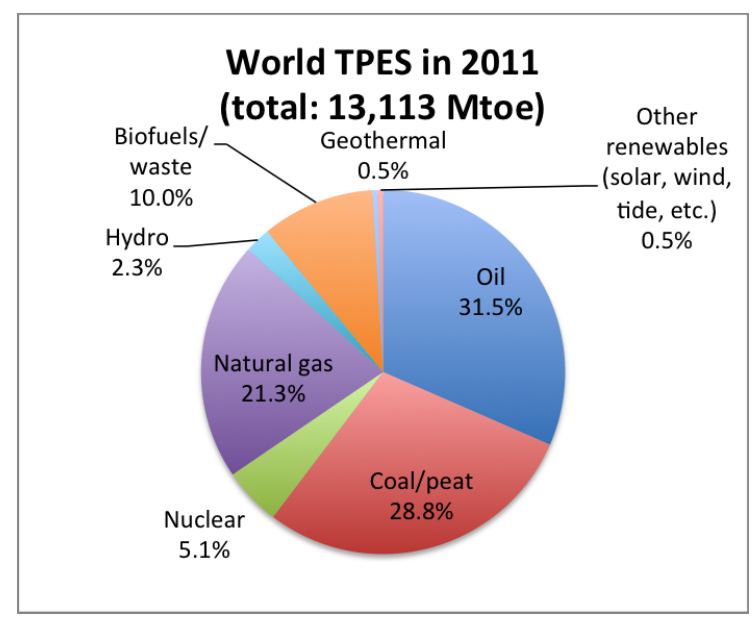

Figure 4. World primary energy supply (2011).

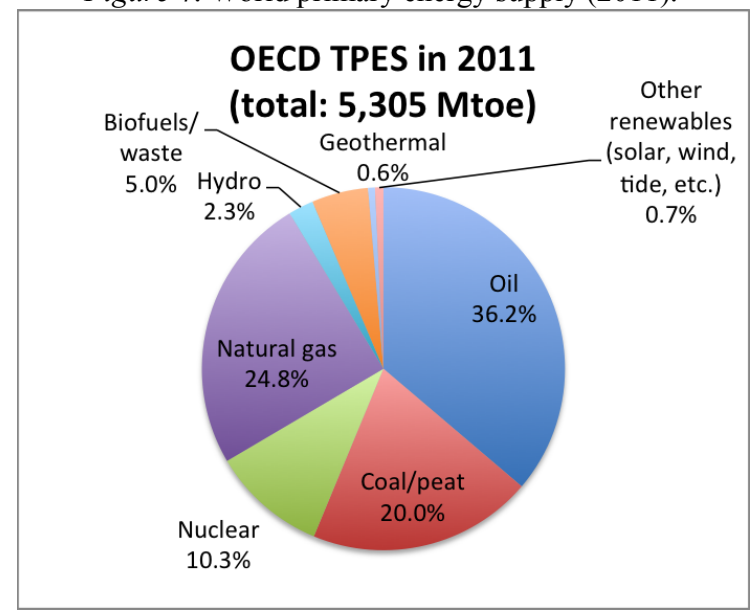

Figure 6. OECD primary energy supply (2011).

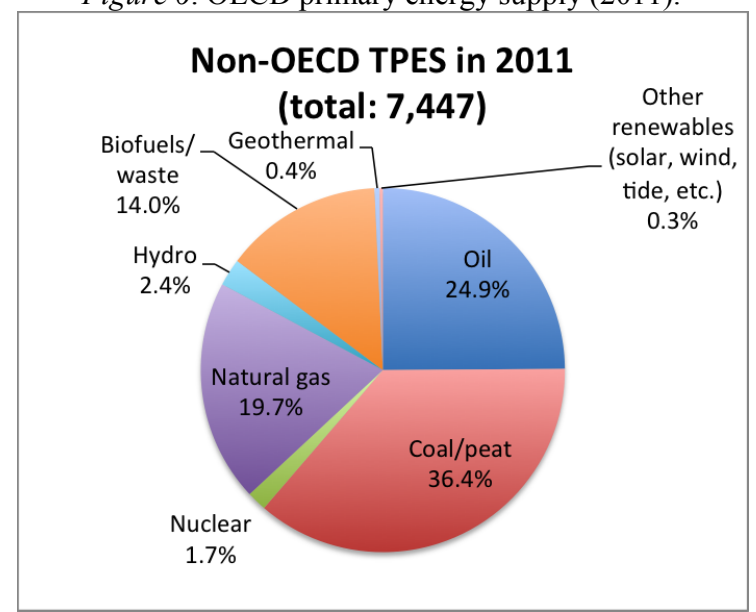

Figure 8. Non-OECD primary energy supply (2011).

Note: Mtoe $=$ millions of tons of oil equivalent. Numbers may not add up to $100 \%$ as a result of rounding. Numbers are from the International Energy Agency (2013a). 
Moving to specific subsectors, Figures 9 and 10 break down OECD energy consumption for electricity by source. In electricity generation, oil has all but disappeared, and natural gas, coal and nuclear constitute the main sources, although renewables occupy a substantial position (counting hydroelectricity). The transport sector is characterized by a very high degree of dependence on oil, which remains at $94 \%$ of total consumption today (IEA, 2013b) despite substantial investments in alternative fuels (biofuels, in particular). The production, distribution and consumption infrastructure for the socio-technical systems associated with these subsectors is considerable, and is attached to a significant set of interests (see for instance Tertzakian, 2006; Yergin, 2008). This incurs a strong path-dependency effect, and energy options compatible with existing pipelines, vehicles, centralized power generation facilities, and other infrastructure have a natural advantage when compared with sources that would require substantial modifications in infrastructure (Ladislaw, Zyle, \& Childs, 2008, p. 5; see also Geels, 2005; Torvanger $\&$ Meadowcroft, 2011). In other words, transaction as well as sunk costs are formidable, preventing rapid and large modifications to the current configuration. 


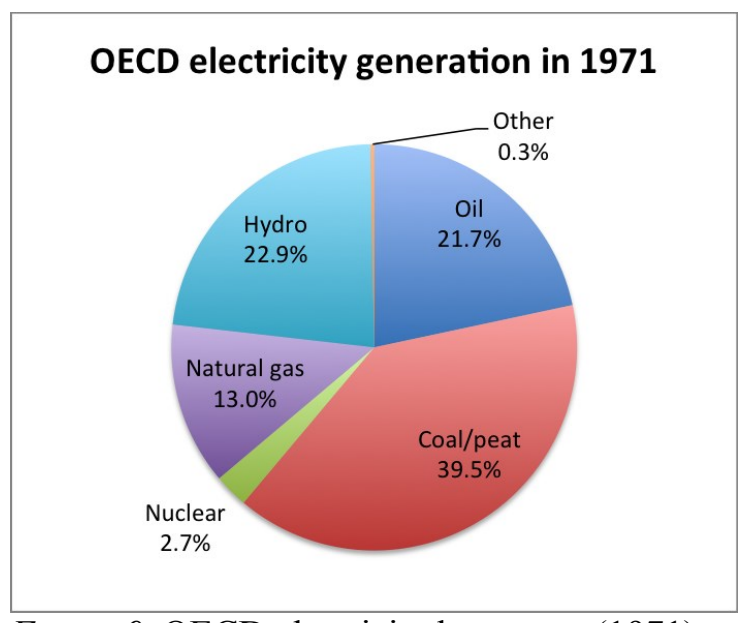

Figure 9. OECD electricity by source (1971).

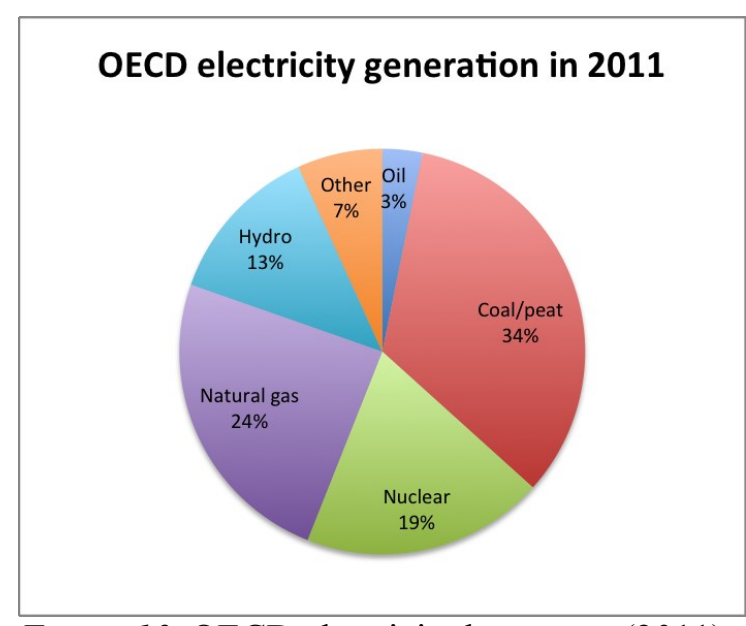

Figure 10. OECD electricity by source (2011).

Note: numbers are from the International Energy Agency (2013b).

In this context, the factors and rationales leading to state intervention are likely to be numerous and complex. In order to provide some information to adapt the analytical framework presented in the previous chapters for scares related to the energy sector, the next section provides an overview of the forms of state intervention in energy markets, which leads to a categorization of the frames used to discuss the various forms of energy policies.

\subsubsection{State intervention in energy markets}

While private corporations have a significant role in the energy sector, governments intervene massively in energy markets through myriad means. Energy is certainly not the only sector where markets are influenced by the State, but energy markets are shaped by an exceptionally high degree of intervention. To a large extent, this has always been the case since the beginning of the First Industrial Revolution, as major turning points concerning the energy sector have been linked to state intervention 
in one form or another. For instance, the fast-pace rise of oil as a key energy source in the $20^{\text {th }}$ century is often traced back to the British Navy's decision to convert their fleet from coal to oil prior to World War I (Sampson, 1975). Another example is nuclear energy, which also developed only through substantial state investments and control since the 1950s (Sovacool \& Valentine, 2012). Nevertheless, since the scope of this study is limited to energy scares of the past 40 years, I focus here on state intervention during that period to provide a brief description of the linkages between government policy and energy markets.

State intervention in energy markets takes several forms. First, states participate massively in the ownership of oil and gas resources. The 1970s were the rapid culmination of a nationalization trend in oil and gas producing countries that can be traced back to the end of World War II (Yergin, 2008). This period saw an important restructuring of ownership rights in oil production, starting with sharing agreements between producing countries and international oil companies, and evolving into nationalization, especially following the creation of the Organization of the Petroleum Exporting Countries (OPEC) in 1960. Before the end of the 1970s, full concession nationalization had occurred in Mexico, Iran, Iraq, Libya, Kuwait, Venezuela, and Saudi Arabia, furthering the decline of international oil companies' previous commanding role, to the benefit of producing states' governments (Marcel, 2006).

Therefore, since the 1970s, state participation in oil and gas ownership and exploitation has been substantial. In the 25 companies that own the largest reserves of oil and gas in the world, 18 are fully or partially state-owned (Radler \& Koottungal, 2008). 
In OECD countries, private ownership is more common, but a very large share of the primary energy supply is imported. Since oil and gas together constitute $61 \%$ of the total primary energy supply of these countries, and since a significant portion of this comes from imports from non-OECD countries (BP, 2013; IEA, 2013a), the prevalence of state ownership in non-OECD countries has obvious geopolitical implications even for OECD states.

These geopolitical implications are nothing new, as the role of energy (and oil and particular) as a strategic commodity has been illustrated on several occasions during the $20^{\text {th }}$ century: the aforementioned conversion of the British Navy fleet from coal to oil, the role played by the shortage of oil in Japan at the onset of World War II (Yergin, 2008, pp. 289-310), the growing involvement of the United States in the Middle East from the 1940s and the eruption of the oil crises of the 1970s (Yergin, 2008), and more recently the gas disputes between Eastern European countries and Russia (Crane et al., 2009), are but a few examples of the international security implications of these supplies. Today, the United States is still involved militarily to protect the main oil routes throughout the world, an expenditure of more than $\$ 100$ billion a year by some estimates (Klare, 2007, p. 150), and the natural gas disputes between Russia and Europe continue to illustrate the predominance of oil and gas in geopolitics. The security of supply for oil and gas is taken very seriously by OECD states: no other traded commodity is so specifically and substantially protected by the military, and this is on top of various expenditures for infrastructure protection programs within and across countries. ${ }^{15}$

\footnotetext{
${ }^{15}$ See, for instance, the U.S. Homeland Security Presidential Directive HSPD-7 (2003), or the European Programme for Critical Infrastructure Protection (Commission of the European Communities, 2006).
} 
A second form of state intervention in energy markets comes through support for research and development, as well as production. A prime example of this is nuclear energy, where public investments are in the order of several billions of dollars for every power plant built, along with extensive regulatory intervention (Sovacool \& Valentine, 2012). Hydroelectricity is another example, where again a public participation in costly construction and operation of large projects is frequent. Biofuels for transport, which can hardly be argued to be suffering from barring fixed costs for distribution and consumption infrastructure, are supported by over $\$ 20$ billion a year worldwide, ${ }^{16}$ while representing only around $1 \%$ of world energy demand (Gerasimchuk, Bridle, Beaton, \& Charles, 2012). Finally, even the well established fossil fuel industries are supported with $\$ 55$ to $\$ 90$ billions in the United States alone (OECD, 2012). These numbers demonstrate quite clearly that without certain state policies providing substantial help to specific energy industries and technologies, some of these sources of energy would be developed quite differently, if at all.

A third form of state intervention comes though industrial policy. Several examples of this have been witnessed in the period since the 2008-2009 economic crisis: which has seen an expansion in state-led creation of "green" jobs, usually in an effort to stimulate the ailing manufacturing sector in high-income countries (Renewable Energy Policy Network for the 21st Century, 2010; Carley et al., 2011). These industries would not be there without the state's choice to provide this support.

\footnotetext{
162010 estimate.
} 
Fourthly, states also intervene on the consumption side, and contribute to determining which resources end up being viable economically. This is certainly currently the case for renewable energies: in all countries using these technologies, and in addition to substantial public investment on the production side, electricity generated with solar panels, wind turbines and other means has been supported through policies such as feed-in tariffs or renewable portfolio standards, while biofuels are forced into the energy mix by mandatory blending ratios or tax credits at the pump (International Energy Agency Renewable Energy Technology Deployment, de Vos, \& Sawin, 2012; Renewable Energy Policy Network for the 21st Century, 2010). In all cases, the increase in market shares in electricity generation and transport described above comes out of this state support.

Bringing these aspects together leads to one observation: at least for OECD countries, the State's hand in energy markets is heavy and ubiquitous; energy markets are far from free and competitive, and exist in a specific form because of an elaborate configuration between dominant private and public players. This confirms that energy, or more specifically the different functions it occupies and the commodities on which they depend, are given a special importance in political circles. Given the extensive variation in the different policy tools pertaining to this sector, debates over these policies can be based on a variety of assumptions and priorities, which can be regrouped into several frames. 


\subsubsection{Four frames for energy policy}

Energy policy is a complex terrain with multiple goals, and is therefore an interesting field for the analysis of policy debates during a social scare. Given that it covers a broad range of sub-sectors (oil, natural gas, nuclear energy, renewable electricity technologies, and so on) and societal functions (electricity, heating, transport, industrial use), energy policy is therefore a category of state intervention regrouping a complex set of intertwined and overlapping policies. As explained above, all OECD governments intervene at length in at least some of these sub-sectors and functions. In this section I outline a way to analyze and interpret state intervention in the energy sector.

Each individual policy pertaining to the energy sector can be interpreted as part of a frame that links energy to a broad public problem for which state intervention may be the answer. When considering this energy aspect of the given public problem, several priorities can follow, and each of these priorities can be associated with certain policy tools. As a result, any policy can be seen as part of some narrative using a certain version of one or more of these frames.

I identify four frames for energy policy, and outlines these and their associated priorities and policies. Importantly, some of the frames can be combined, while others are contradictory by definition. For example, if one sees justification for state intervention in the foreign policy aspects of the problem (because of a country's high dependence on oil imports, for instance), then priorities could include a call for an expansion in the tapping of local natural resources and in the development of alternative sources in order to reduce imports. These priorities could be compatible with some environmental priorities, if this 
means the development of renewable energy technologies; these priorities could also fit with the desired expansion of the domestic energy industry; but even so, they would most likely prove incompatible with the objective of minimizing prices, since this will likely raise the costs of energy consumption, hurting economic growth.

Hence there are several important characteristics in this classification. First, certain elements within the four frames are interrelated. Second, some of them being contradictory, it is impossible to build a narrative that suggests the simultaneously pursuit of priorities from all four frames: a narrative that is based on one or several of the frames, then, implies a rejection of priorities associated with others frames. Third, narratives can be built around different variations of each of the four frames, based on which exact priorities are emphasized within each frame, as well as which specific policy tools to use in order to make progress towards these priorities.

For analytical purposes with regard to a specific energy scare - including the case studies presented in later chapters - this interpretation can help understand three things: first, it tells us what narrative(s) can be used during the scare; second, it tells us what policy options are associated to these frames, and - perhaps even more importantly - how changes and alternative policies will be discussed; and third, it tells us what broad objective(s) underlie(s) a specific proposition for a policy change. Put differently, this interpretation gives us the set of possibilities for narratives that can be used to sell certain policies, given the conditions and characteristics of the scare (and its triggering event). 
Table 3.

Frames for state intervention in energy

\begin{tabular}{|c|c|c|c|}
\hline Frame & Public issue(s) & Examples of priorities & Typical policies \\
\hline Economic growth & $\begin{array}{l}\text { Energy is essential for economic growth, } \\
\text { so price (both level and volatility), } \\
\text { availability, and intensity of use have an } \\
\text { important impact. Energy can be an } \\
\text { industry in itself. The totality of energy } \\
\text { in societies affects unequally different } \\
\text { groups }\end{array}$ & $\begin{array}{l}\text { - } \text { Favor cheapest sources } \\
\text { - } \quad \text { Minimize price level and volatility } \\
\text { - } \text { Increase efficiency in energy use } \\
\text { - } \text { Attract energy-intensive industries } \\
\text { - Develop domestic industry } \\
\text { - Use energy revenues to enhance social } \\
\text { welfare }\end{array}$ & $\begin{array}{ll}\text { - } & \text { Taxes on energy consumption } \\
\text { - } & \text { Competition incentives for suppliers } \\
\text { - } & \text { Consumption standards (e.g. CAFE) } \\
\text { - } & \text { Upgrade programs for inefficient } \\
& \text { buildings } \\
\text { - } & \text { Support for smart grid development } \\
\text { - } & \text { R\&D support for energy industries }\end{array}$ \\
\hline Environment & $\begin{array}{l}\text { Using energy causes various forms of } \\
\text { damage to the environment, whether } \\
\text { through air and water contamination, the } \\
\text { emission of greenhouse gases, or any by- } \\
\text { product of energy consumption and } \\
\text { production (e.g. nuclear waste). }\end{array}$ & $\begin{array}{ll}\text { - } & \text { Minimize pollution } \\
\text { - } & \text { Minimize greenhouse gas emissions } \\
\text { - } & \text { Minimize air quality } \\
& \end{array}$ & $\begin{array}{l}\text { - } \text { Carbon tax/cap-and-trade exchange } \\
\text { - } \quad \text { Air quality regulation } \\
\text { - } \quad \text { Emission regulation/taxes }\end{array}$ \\
\hline $\begin{array}{l}\text { Foreign policy and } \\
\text { national power }\end{array}$ & $\begin{array}{l}\text { Energy's role as a strategic commodity } \\
\text { has several implications with regard to } \\
\text { foreign policy, including political clout } \\
\text { given to exporters internationally, } \\
\text { foreign policy restrictions associated } \\
\text { with import dependency, and economic } \\
\text { (trade) and financial consequences of } \\
\text { being either an importer or an exporter. }\end{array}$ & $\begin{array}{l}\text { - } \quad \text { Favor imports from "friendly" countries } \\
\text { - } \quad \text { Diversify import sources } \\
\text { - Minimize imports } \\
\text { - Maximize clout from energy exports } \\
\text { - Expand domestic production }\end{array}$ & $\begin{array}{l}\text { - } \quad \text { Tariffs on energy imports } \\
\text { - } \quad \text { Bilateral agreements on energy trade } \\
\text { - Tax credits to domestic producers } \\
\text { - Lax permit allocation for exploration }\end{array}$ \\
\hline Security & $\begin{array}{l}\text { Energy is a targetable strategic } \\
\text { commodity that needs managed } \\
\text { protection from the potential for physical } \\
\text { damage (military protection of } \\
\text { infrastructure and trade routes) and } \\
\text { shortage (economic security from supply } \\
\text { shocks). }\end{array}$ & $\begin{array}{l}\text { - Ensure military security of global supply } \\
\text { chains } \\
\text { - Ensure protection for domestic } \\
\text { infrastructure } \\
\text { - Maximize resilience of energy technical } \\
\text { system }\end{array}$ & $\begin{array}{l}\text { - Military deployment in strategic } \\
\text { energy trade routes } \\
\text { - Infrastructure protection programs } \\
\text { - Strategic reserves programs }\end{array}$ \\
\hline
\end{tabular}




\subsection{Energy (in)security and social scares}

The section above provides the elements necessary to analyze debates over energy policy and interpret the arguments put forward for different options, including in the context of social scares. In this section, I ask the following questions: how do the notions of insecurity and uncertainty, discussed in the previous chapters, apply to energy issues? And how can this help build a model more tailored to analyze social scares in this sector?

Let us begin with the concept of energy security, a term for which definitional and conceptual problems regarding what it means and entails persist (Ciută, 2010). The question of defining and ensuring energy security is not limited to the securing of energy per se, but instead corresponds to the more complex task of determining what energy allows various actors in society to achieve. So to make sense of discussions on energy security, one needs to answer questions such as: what is energy insecurity a threat to? And what exactly constitutes a threat?

Discussions over energy security in the 1970s, having burgeoned amidst the transformation of energy markets surrounding and following the oil shocks, were at first based on narrow geopolitical and economic views related to the security of a reliable and affordable supply (Council on Foreign Relations, 2006; Correljé \& van der Linde, 2006; Fettweis, 2009; Klare, 2009; Nye, 1982; Youngs, 2009). Since then, they have evolved to encompass a broader range of considerations (Griffin, 2009; Lovaas, 2009; Noël, 2008; Sweet, 2009), illustrating the complexity of energy security, and reflecting the "totality" of energy in modern societies - the fact that energy penetrates virtually all aspects of our lives. This explains the four frames and the broad variety of possible priorities in energy 
policy described in the previous section. Energy is rarely discussed as a single public problem: to name one important distinction, discussions over insecurity in transportation issues, for instance gasoline prices or availability of oil supplies, are usually done in isolation from similar issues regarding electricity - i.e., prices and security of supply.

During an energy scare, as with any type of scare, issues arise over both immediate insecurities (e.g., turning the lights and heating back on during a blackout, stopping the leakage during an oil spill, or securing the facilities and surroundings after an industrial/nuclear accident), and uncertainty regarding their longer term implications (what are the odds of this event reoccurring in the near or medium term future, and what should be done to prevent this possibility). An energy scare, as I use the term in this study, is therefore a scare where the perception of insecurity that arises in the population is related to the production, distribution and use of energy. This can occur in several forms, for instance there can be a drastic shortage in oil, which in turn drives oil prices and by extension, gasoline prices - to an exceptionally high level; there can be a nuclear accident, which is certain to remind the public of the potentially catastrophic impact of such incidents; there can be new scientific evidence about critical environmental or health harm caused by some energy sources; or there can be an important cut-off in a major supply chain caused by political unrest. For a scare to fall in the energy scare category, it must simply be one that triggers debates related to energy policy.

Energy scares are often of a largely political nature, in the sense that providing more energy at that moment would likely not fully resolve the perception of insecurity at least not the longer term implications and the possibility for reoccurrences. As 
demonstrated in the previous section, policy and markets are inextricably linked in the energy sector. Hence what becomes needed during a scare is policy action that would appear to reduce the uncertainty associated with energy use - in the particular installment brought about by the scare - in the near future, or in other words that would convincingly decrease, and ideally eliminate, the insecurity felt by the population.

Looking at the variables described in Chapter 2, the level of disruption brought by the triggering event of an energy scare can be quite high, sometimes because of spectacular incidents like nuclear and other industrial accidents, and other times without this aspect, such as during energy-related political crises (the oil price spike of 20072008 , or the Russian-Ukraine gas disputes of the 2000 s, for instance). The disruption can also be reinforced by impressive symbols and images that accompany these events, for instance a high number of deaths, images of an explosion, animals stuck in bitumen, and so on. Accidents and political crises, in particular, present debates with a important level of uncertainty regarding long term choices about specific sources, which becomes an additional resource for actors trying to highlight the failures of the current energy policy regime. As explained in prior chapters, and keeping the four frames described above in mind, more uncertainty allows for more flexibility in the framing of the causes and implications - short term and long term - during the scare that ensues.

The reach of an energy scare's triggering event, that is, the level to which a large portion of the population feels threatened, can also be quite varied. Some events, for instance an explosion at a refinery or an oil spill, can have a low to medium reach, given their restricted geographic spread. Others, for instance some nuclear accidents or large 
electricity blackouts, can be high. Not only real but also potential impacts are included in this variable, and thus this dimension can vary substantially depending on the success of framing attempts. Consequently, energy scares may present substantial variation with regard to these two aspects of disruption and reach.

As for the contextual factors of social scares, also described in Chapter 2, most energy scares present the same aspects as for scares linked to other sectors, including the electoral cycle, the economic context, the relationship of the scare with other ones, the dominant ideas of the time, and social values. The competition between different actors to "solve" the perception of insecurity is, as most political processes are, shaped by these contextual characteristics.

Overall, then, the energy sector is associated with many insecurities, making it prone to a variety of scares, from very real immediate catastrophic events (e.g., Chernobyl) to more hypothetical ones (e.g., peak oil), and from highly scientific and technical problems (e.g., global warming) to more traditional foreign policy and economic issues (e.g., Russia-Ukraine gas disputes). The close and inextricable links between the energy sector and policy circles ensures that most energy scares will trigger some debate over energy policy, where the possibilities for arguments about solutions can be analyzed through a distinction among the four frames described in 4.1.2. This makes the energy sector an excellent departure point for applying the framework built in Chapter 2, as it provides multiple examples of social scares, and presents most of the dynamics highlighted in the three previous chapters. I now turn to a more detailed 
methodology to transform all of these considerations into a model, which is then applied to several cases in later chapters.

\subsection{A model to study energy scares: methodological approach}

The notions presented in Chapters 1,2 , and 3 provide a lens through which we can analyze the impact of social scares on policy. The main goal in applying this analytical framework is to determine the mechanisms by which some scares affect policy through the two-dimensional competition for political prizes. While the two previous sections of this chapter provided more depth to an application of the framework to scares related to energy, I lay out here the methodological approach used in this study.

The main method I use is the one of structured, focused comparisons as proposed by Alexander George and Andrew Bennett (2005), designed to conduct case studies of instances of a class or subclass of events. The method is structured because the researcher asks general, standardized questions pertaining to the research objective, and this is done of each case in order to structure data collection, allowing for systematic comparisons. It is also focused since it uses a theoretical basis to put the emphasis on specific aspects of the cases that are considered most relevant and appropriate for the research objective.

Here, the class of events is social scares, defined loosely as periods characterized by a broadly shared perception of insecurity in the general population. More specifically, the model focuses on a subclass of such events, those triggering debates related to energy policy. The main research objective is to understand the processes and mechanisms 
leading from the onset of the scare - the triggering event(s) - to a particular policy outcome, and this, in addition to the theoretical focus of the study, needs to guide the careful development of the investigative questions (George \& Bennett 2005, pp. 67-72).

As with many research projects, this study is neither fully inductive nor fully deductive. It is mainly inductive because one of the objectives is to contribute in building a theory by identifying and deriving new variables, hypotheses, causal mechanisms, and causal paths from the observations of the cases. Since there is no theory that provides a comprehensive and satisfactory explanation of the different outcomes, a fully deductive approach would be inappropriate here. Nevertheless, it is deductive to the extent that an emphasis will be put on certain theoretically derived, specific aspects that serve to guide the investigation, building on the framework present in Chapter 2 and the additional theoretical aspects discussed in Chapter 3.

Following George and Bennett, causal mechanisms are defined as ultimately unobservable physical, social, or psychological processes through which agents with causal capacities operate, but only in specific contexts or conditions, to transfer energy, information, or matter to other entities. In so doing, the causal agent changes the affected entity's characteristics, capacities, or propensities in ways that persist until subsequent causal mechanisms act upon it. If we are able to measure changes in the entity being acted upon after the intervention of the causal mechanism and in temporal or spatial isolation from other mechanisms, then the causal mechanism may be said to have generated the observed 
change in this entity. The inferential challenge, of course, is to isolate one causal mechanism from another, and more generally, to identify the conditions under which a particular mechanism becomes activated (2005, p. 137).

There are several reasons why case studies are most appropriate and useful here. First, they serve to derive new hypotheses and contribute to theory development. Second, they allow the unpacking and exploring of causal mechanisms and the conditions that trigger them. And third, case studies can "accommodate complex causal relations such as equifinality, complex interactions effects, and path dependency" (George \& Bennett 2005, p. 22; see also Ragin, 1987). Since the theory presented here is in its infancy and has never been tested yet, the evidence gathered through the analysis of the cases will serve to both test some aspects of the theory and considerably improve and refine it. Given that the number of cases studied is limited, assessing and improving internal validity is a main concern, while the potential for external validity is discussed in Chapter 9.

\subsubsection{Selection of cases}

The next three chapters present the results from four case studies of key instances of social scares linked to the energy sector. Given the large set of potential cases available (from all industrialized countries over the last 40 years), the selection went through several steps. First, I looked at a smaller set of countries: France, the United Kingdom, Canada, the United States, and Germany. These were countries that respected 
both the high-income and free press characteristics, but also ensured some minimum amount of available data given the resources that I had, including access to some primary sources (notably, newspaper in French or English).

I then looked at the 40-year period for each of these countries, starting with the 1973-74 oil shock. I excluded cases that were less than five years old in order to ensure a minimum of depth in the published analyses that were available. This preliminary list included more than 50 cases of scares of the following types:

- Oil-related accidents, such as the Piper Alpha disaster (1988), the Exxon Valdez spill (1989), and the Shell refinery explosion (1988).

- Nuclear accidents, including the Three-Mile Island incident (1979) and the Chernobyl disaster (1986).

- Hydroelectric dam and reservoir failures, for instance the Val di Stava dam collapse (1985) and the Hope Mills dam collapse (2003).

- Large-scale electricity blackouts, for instance the California electricity crisis (2000-01) and the North American Ice Storm (1998).

- Other types of political and foreign policy crises that caused supply shocks were also considered, notably the 1984-85 coal miners' strike in the United Kingdom, and the 1973-74 and 1979-80 oil shocks.

At this stage, the purpose was to be as exhaustive as possible, with no judgment on the specific characteristics of the scare, including its policy outcome. Furthermore, some of the cases on this list could be studied from the perspective of several countries: for instance, the oil shock of 1973-74 had an impact on energy policy all around the OECD. 
Single cases, in this situation, were considered to be national: this particular oil shock, as it evolved in the United States, was treated as one case, distinct from how the scare played out in France, for instance.

I set out to reduce this list based on a different set of criteria. One important consideration was the type of triggering event, where variation was ensured in order to see whether we could identify similar mechanisms in different types of scares. I chose four types of triggering events: one supply shock caused by a political crisis, one oil spill, one nuclear accident, and one large-scale electricity blackout.

The availability of data was a second consideration, as I wanted to use cases that had been thoroughly studied, in order to build on the knowledge provided by other authors' research on different aspects of the cases (media coverage, group mobilization, and policy debates, in particular). This left out several scares, particularly ones with smaller levels of disruption and reach, but it had the benefit of ensuring a rich amount of information for each case.

At the end of this filtering, the four cases selected presented what I believed to be the most interesting combination of variation and similarity. The cases are presented in pairs, in order to highlight similarities and differences between them as well as provide additional structure to the analysis, and the four cases are then compared all together. Chapter 5 presents the first two cases, the passage of the National Energy Program (NEP) by the federal government of Canada following the oil shock of 1979-1980, and the North American Ice Storm of 1998 and its management by the provincial government of Quebec (Canada). The two cases occurred in a context containing several similar 
structural features, most notably the type of political regime (parliamentary), the country (Canada), and the tensions following from the federal structure. This ensured a certain degree of uniformity in the context of the scares.

As cases of social scares, the events were also similar in several other points. First, they are both cases where leaders of the executive branch had a clear objective for the policy outcome. Second, these actors both used the scare's triggering event to its maximum potential, in order to gain a position where they could ensure their preferred policy outcome. And third, they did manage to get this policy outcome. To a large extent then, these are two instances of social scares occurring in a similar context, and evolving in a comparable manner.

There are important differences between the two cases, however. The first is that the policy outcomes, and the executive branch's preferences regarding change, were completely opposite. In the NEP case, the government wanted to pass landmark legislation that would reorganize the distribution of oil revenues and federal-provincial powers; in the ice storm case, the government wanted no change at all to electricity or energy policy. Second, the NEP case erupted out of an economic and political crisis, while the ice storm case was triggered by a natural disaster. And third, the NEP case had a much blurrier acute phase compared to the ice storm: the period during which the blackouts and extensive repairs occurred ended at a clear moment (with the end of the repairs). These differences, given the similarities in the context, strategies of actors, and successes of these strategies, make the cases interesting because of the possibility of isolating some of the mechanisms described in Chapter 2. 
The second pair of cases, presented in Chapter 6, covers the impact of the Chernobyl nuclear disaster on West German energy policy, and the Exxon Valdez oil spill in the United States. Important differences characterize the two cases: in particular, the former is an accident that occurred outside of the national territory, while the latter involved an American boat in American waters. There are still, however, several similarities between the cases.

First, these are both cases where the executive branch did not try to use the scare to its advantage. Both triggering events were played down by leaders of the government, and the attempts to maximize the disruption and reach came mostly from groups opposed to these positions (anti-nuclear groups in the Chernobyl case, and environmental groups in the Exxon Valdez case). Second, in both cases the executive branch of government preferred limited change, and thus tried to downplay the scare with minimal policy actions. In both cases, the executive branch seemed successful at first, as outside and opposition groups were not able to gain enough power to force the government to change its stance.

Change did come in both cases, but the main difference is that in the Exxon Valdez spill case, the change was completely circumscribed within the boundaries of the policy sub-system. In other words, while the policy outcome still embodied important changes, these were designed, introduced, and passed by actors close to the government position. The event mostly had an unlocking effect on a policy stalemate. In the Chernobyl case, however, the changes enacted by those in power, also notable, were not enough to calm the building of a coalition for further changes, and the scare underlay 
debates around energy policy for years after the event, eventually contributing to further changes.

This pair presents particularities that make the cases different from their NEP and ice storm counterparts. Here, the policy outcome is not entirely dictated by the executive branch, and emerges from somewhere else: pressure from outside groups, and enlarged coalitions opposed to the government's position, in particular. In part this could be attributed to the political regimes, which are substantially different. But interestingly, this regime type actually suggests an outcome other than what happened. In the Exxon Valdez spill, the federal regime is presidential, where it can be easier for outside groups to penetrate the political arena compared to a majority government in a parliamentary regime - as in the Chernobyl case. However, the former led to an outcome where outside groups ended up having very limited influence on the policy outcome, while in the latter they managed make the scare last and grew strong enough to eventually force substantial changes.

In Chapter 7, the cases are compared further - after removing the pairings of Chapters 5 and 6 - and this serves to build a typology described at the end the chapter. In Chapter 8 , the results of the case studies are used to refine the model, which is then applied on preliminary evidence from two further cases. These additional cases are selected using purposive sampling, since they are intended to be shorter cases studies, and comply with the scope criteria of this project (last 40 years in industrialized countries, touching on the energy sector). The first case in Chapter 8 is the Deepwater Horizon oil spill that occurred in the Gulf of Mexico, where comparisons are drawn with 
the Exxon Valdez case; and the second case is the Taum Sauk hydroelectric reservoir failure in the U.S. state of Missouri, a smaller and more local scare. Additional explanation on this selection is found in Chapter 8 .

\subsubsection{Data collection}

The data collected consisted of both secondary and primary sources. Secondary sources included scholarly publications on the events, mainly in the areas of political science, international relations, political economy, environmental studies, and sociology. These publications included a variety of data sources (interviews of key actors shortly after the scare, and the analysis of official reports on the events, for instance), and this made data triangulation possible across different case studies of the same scare. I also looked at official reports from public institutions published in the years that followed the triggering event.

I complemented these with primary sources, and looked at newspaper articles covering the scare during the months that followed the triggering event. Within these sources, I conducted a content analysis to identify terms that were frequently used to describe the events and the policy solutions that were proposed. This allowed a mapping of the arguments used in public debates, as well as the main actors defending them.

All the content analyses were done manually (i.e., without specialized software), as it was important to read the entire context surrounding the term(s) or the argument being made. One important consideration when doing exploratory content analysis is that flexibility be maximized in order to take the entire content of the article into 
consideration when noting specific terms. This lengthier analysis allowed an assessment of the tone, or of complex combinations of specific utterances, for instance, in certain interventions by actors.

The sources included mass-circulation daily newspapers, as well as international news sources (notably AFP), accessed through online database. The Globe and Mail archive database was used for the NEP case (the only Canadian newspaper I had access to for this period), and Eureka.cc was used for French language newspapers for the Ice Storm case. For the other cases, I conducted searches through the LexisNexis Academic database. The inclusion of primary sources also served to verify some of the broader claims made about media coverage in secondary sources, as well as complement these studies with my own assessment of the debates that occurred.

\subsubsection{List of investigative questions}

In order to use the method of structured, focused comparison, I developed a list of general questions used to investigate these cases. The purpose of this list is to allow for a rich understanding of the processes that follow the scare's onset, and that lead to a particular policy outcome. More specifically, however, the objective is to unravel the presence and influence of the aspects discussed in previous chapters, and see if the analytical framework can help understand the variation across the cases. In order to focus the analysis and discussion, I have formulated in each section an exploratory hypothesis linked to the explanatory framework. 


\subsubsection{What were the characteristics of the triggering event and the political rent?}

Social scares add a second dimension to the political struggles occurring in the aftermath of the triggering event, where there is a political rent available to actors who can be perceived as resolving the insecurity created by the context of the scare. This rent, its size, and its expandability, are all aspects that need to be investigated. The triggering event, in particular, influences these aspects by the level of disruption it brings and its reach to broader sections of the population. This first section of the case studies describes these aspects, as well as the contextual factors that surrounded the scare at its onset and for its entire duration. As a general hypothesis $\left(\mathrm{H}_{1}\right.$ : rent as resource) related to this matter, executive branch leaders who manage to win a large portion of the political rent early on should have more facility in securing their preferred policy outcome. For $\mathrm{H}_{1}$ to

be falsifiable, however, a case must be able to demonstrate clearly this capture, for instance by winning an election or through opinion polls, and hence this is discussed within the case studies.

\subsubsection{What were the strategies and actions of the actors regarding the two objectives?}

One of the main features of the framework is the interdependence between strategies regarding the leadership objective and the policy outcome preferences. Actors need to be wary of strategies that are developed with neglect for any of those two objectives, especially in cases where the optimal course on one of them risks leading to a loss on the second. This second section of the case studies focuses on these strategies, to see how they played out for different actors and coalitions, and what constraints they 
were facing. The second hypothesis $\left(\mathrm{H}_{2}\right.$ : compatible strategies $)$ is that actors and groups are more likely to use a strategy regarding the political rent that is compatible with their preferred policy option(s), even if this means forfeiting a large part of the rent. Consequently, the cases should show that the arguments and narratives used to capture the rent follow from the group's preferred policy outcome (e.g., the party in power's position on the issue).

\subsubsection{How did uncertainty and risk get framed, and what was the role of experts?}

This section focuses on unraveling the role that uncertainty and risk played in the development of strategies, as well as how experts intervened in the policy struggles. These are aspects for which the impact is difficult to predict, but nevertheless they represent an important aspect of social scares. The insights from Chapter 3, in particular, are used here to try and see how the different actors and groups manage the difficult context of the high uncertainty accompanying social scares. Uncertainty should be played up or down depending on the causal stories used by actors and coalitions to sell both their leadership and their preferred policy option. Given the leadership curse, executive branch actors are likely to want to control the information and minimize uncertainty, thereby simplifying the problem brought about by the scare, in order to be clearly perceived as acting toward a resolution (a reduction of insecurity). For opposition actors, the opposite is likely to be true, as they can use uncertainty in narratives to challenge the government's position. As an exploratory hypothesis $\left(\mathrm{H}_{3}\right.$ : uncertainty played up/down), all else being 
equal, actors in the executive branch will play down the uncertainty surrounding the cause(s) and solution(s) to the scare, while actors in the opposition will do the opposite.

\subsubsection{What was the impact of contextual factors?}

While the main contextual factors surrounding the triggering event are described under the first of these questions, this section addresses specifically the impacts on the overall outcome that can be attributed to these factors. For the most part these should be qualifiers that highlight constraints specific to certain scares. More interestingly, however, they should also provide information on how these factors influence the mechanisms described in the framework, and as a result they will serve to enrich the model at the end of the case studies. Put differently, this is largely a discussion of control variables for comparisons between cases. Two exploratory hypotheses are used. The first $\left(\mathrm{H}_{4 \mathrm{a}}\right.$ : looming election) is that a looming election (or possibility to replace a minority government) diminishes the advantage held by actors from the executive branch. The second $\left(\mathrm{H}_{4 \mathrm{~b}}\right.$ : regime type $)$ is that the type of political regime also influences the position strength of these actors. More specifically, $\mathrm{H}_{4 b}$ states that actors from the executive branch will hold a stronger position with regard to policy options when also controlling the legislative process (i.e., in a majority government with a parliamentary regime)

compared to regimes where legislative control is more diffuse (i.e., in a minority government or in a presidential system). 


\subsubsection{What was the resulting policy outcome?}

Finally, the fifth section analyses the policy outcome itself, including information on legislative battles. This represents an overall assessment of the policy side of the scare, and leads to conclusions about the application of the model on a particular case. These conclusions tell us how the framework helps in our general understanding of the mechanisms leading from the triggering event of a scare to different types or degrees of policy change. In other words, does it provide elements of answers to the main research question of this project? These elements provide the information required to build a typology of outcomes for social scares (presented in Chapter 7), and illustrate the external validity of this study.

\subsection{Conclusion}

This concludes the theoretical and methodological design part of the dissertation. The next chapters present the application of the model described above to the four cases, followed by a typology that comes out of the analysis of the data. Chapter 8 then presents the refined version of this model, and its application to the two additional cases. 


\section{Chapter 5}

\section{Using the scare for different purposes: the Canadian National Energy}

\section{Program and the North American Ice Storm}

In Chapter 4, I provided a background to study scares surrounding the energy sector, and specified the research design and methodological approach I use to apply the analytical framework described in Chapters 1 through 3 . This chapter presents the results obtained from the first two cases, the passage of the National Energy Program (NEP) by the federal government of Canada following the oil shock of 1979-1980, and the North American Ice Storm of 1998 and its management by the provincial government of Quebec. This first pair of cases shares certain characteristics, as they occurred in a context containing several similar structural features, most notably the type of political regime (parliamentary), the country (Canada), and the tensions surrounding the federal structure. This ensured a certain degree of uniformity in the scares' context.

Furthermore, in both cases members of the executive branch of government had clear objectives for the policy outcome and achieved them, but these objectives were completely opposite. Additionally, the dominance of the federal government in the former case and of a provincial one in the second raises some questions about the competition between levels of government in the context of a social scare. These differences and others, given the similarities in the context, strategies of actors, and successes of these strategies, make the cases interesting because of the possibility of isolating some of the mechanisms described in Chapter 2. To structure the case studies, I use the list of five investigative questions described at the end of Chapter 4 to approach 
and detail the cases, and then do a summary comparison on each aspect, including the exploratory hypotheses.

\subsection{Case \#1: the 1979-1980 oil shock and the passage of the National Energy Program in Canada}

The oil shock at the end of the 1970s, often termed the "second" oil shock in contrast to the "first" shock around the Arab oil embargo in 1973-74, caused dramatic increases in oil prices that severely affected net-importing countries. The shock began following the Iranian revolution in early 1979, and was compounded by panic resulting from the United States' decision to stop imports from Iran, by the Soviet invasion of Afghanistan later that year, and by the breakout of the Iran-Iraq war in the months that followed. The complexity of the links between these events and others, including the Iranian hostage crisis and the heightened Cold War tension illustrated by the establishment of the Carter Doctrine after the invasion of Afghanistan, produced a context where uncertainty about the future price of oil became paramount.

In Canada, the initial months of the oil shock were followed by the reelection of the federal Liberal Party led by Pierre Elliott Trudeau, who passed the country's most sweeping energy legislation since the end of the second World War. Entitled the National Energy Program (NEP), the legislation was controversial, and led to bitter fights between the federal and some provincial governments. In this first case study, I detail the context of the social scare, the presence of the political rent described in Chapter 2, as well as the evolution of the political struggles that followed its onset. 


\subsubsection{The triggering event and the political rent}

The first step in the analysis is to look at the level of disruption of the triggering event, as well as its reach - i.e., the extent to which a segment of the population broader than the direct victims were concerned by the potential impacts of the scare. As was the case in many oil-importing countries, the level of disruption following the initial steep increases in oil prices was very high, and only got worse with time. Under a provincialfederal agreement passed in the wake of the 1973-74 crisis, Canadian prices, which were regulated by the federal government at the time, had progressively increased, and approached world prices in 1978. International prices suddenly more than doubled, however, from $\$ 16.50$ a barrel in October 1978 , to $\$ 25.70$ in late 1979 , to almost $\$ 40$ by mid-1980 (Pratt, 1982). Panic buying and shortages again became a concern as they had been in the previous oil shock. While price controls tempered the initial effect of the increases, the widening gap between domestic and international prices indicated that sooner or later a drastic adjustment would have to take place, a situation complicated by Canada's position as both an exporter (from Western provinces) and an importer (into Eastern provinces).

The reach was also very broad, given that oil was virtually the sole source of energy used for personal and commercial transport. This is not merely to say that the entire population felt an increase in gasoline prices, since the disruption was obviously higher for lower-income groups than for richer Canadians; but the magnitude of the increases, and especially potential later ones to come, meant that even middle-income groups faced increases large enough to make them wonder about the sustainability of 
these price levels and the future of oil prices. Moreover, shortages caused by price controls had resulted in lines at gas stations during the 1973-74 crisis. With the price increases throughout 1979, fears of similar problems were echoed in the media, especially given their occurrence in the United States, adding doubts about the capacity for the current price system to remain stable ("Prices rise as supplies shrink," 1979). In other words, the high disruption was felt by a large majority of the population and businesses.

Several contextual factors also shaped the environment in which the scare took place. The 1970s saw inflation and unemployment levels go much higher than the norm for Canada, and these were recurring topics of concern throughout the decade, even starting before the $1973-74$ oil shock. ${ }^{17}$ Consequently, questions of price level (for any commodity or service) were already frequently debated in the public and policy spheres. This meant that the new increase in oil prices saw a continuation of some debates over general price levels, but also on broader economic problems, among which chiefly the persistently high unemployment rates - especially in Ontario and Quebec, the main base of support for the federal Liberal Party.

Another contextual factor was the timing of the crisis, which occurred only a few years after the trauma of the 1973-74 oil embargo. The experience of the previous shock, and perhaps more importantly the persistence of post-embargo price levels throughout the rest of the decade, gave some grounding to discussions about oil prices, the future of energy use in Canada, and the different tools of energy policy, mostly along the economic

\footnotetext{
${ }^{17}$ See, for instance, "The budget objective is to counter unemployment and inflation" (1973); "Unemployment, inflation blamed by Bourassa for Liberals defeat" (1977).
} 
growth and foreign policy frames described in Chapter 4. In other words, the Canadian political class had, at the time, a few years of experience in the new international political economy of oil, which meant that some energy policy tools had already been imagined (and some publicly debated and put into place) just a few years before.

Furthermore, the federal-provincial relations need to be mentioned, since energy has the particularity of being a jealously guarded provincial sphere of jurisdiction in Canada (Harrison, 1981). Although the federal government participated in energy policy increasingly since the early 1970s (through the creation of a national oil company, PetroCanada, for instance), such intervention remained contentious (Foster, 1982). Moreover, with regard to oil, a regional split existed (and still does) between the oil-rich Western provinces, led by Alberta, and the importing and more populated provinces of Quebec and Ontario. While the former was the main electoral base for the Conservative Party, the latter were strongholds for the Liberals, which would end up stirring controversy over the exact content of the National Energy Program that would be passed (see 5.1.4 and 5.1.5).

Finally, the electoral context is particularly interesting in this case. The spring of 1979 saw the replacement of the Liberals, who had been in power for over a decade, by a Conservative minority government led by Joe Clark. Given the step-wise nature of the prices increases, the Clark government witnessed a wave of increases from June to November of 1979. The difficult first few months of the new government made it consistently prone to being threatened in parliament, and the continuation and worsening of the oil crisis, coupled with the Clark government's lack of decisive action regarding the matter, became a major factor in its defeat over the late 1979 budget, where a 
proposed tax hike on gasoline provoked a vote of non-confidence. The oil crisis remained the major issue of division in the ensuing election, and the Liberal Party led by PierreElliott Trudeau was able to portray the tax hike as an inappropriate solution to the crisis (Anderson, 1980). This is thus a case where an electoral context gave a window of opportunity for an opposition party to capture the political rent created by the crisis, reducing the advantage held by a group in power. Such an electoral context should exacerbate the dynamics described by the leadership curse, whereby the executive absolutely has to perform well not just to win the rent, but to remain in power (more on this in 5.1 .4 below).

While it would be unwise to ascribe the results of the 1980 election solely to the energy crisis, the propositions on how to deal with the increase in oil prices did constitute a major factor in both the ousting of the Clark government and its defeat by the Trudeau's Liberals (Uslaner, 1989). Importantly, the policy options were the main dividing factor between the parties during the campaign (Rusk, 1980), and Trudeau presented the Liberal's plan in a mid-campaign speech in Halifax - although leaving many of the details up for speculation - dominating the debates for the rest of the campaign (Trueman, 1980a). As a result, Trudeau and his party captured the rent in the most fundamental manner: by replacing the government, winning a majority in the election, which guaranteed them a full mandate and a very high degree of control over the policy debates that would follow. 


\subsubsection{Strategies and actions of the actors regarding the two objectives}

By mid-1979, it became clear that the price increase was not going to recede and would only present a new permanent floor level for oil prices. Since this was potentially a mere first step towards substantially higher increases, the Conservative government was put in the leadership curse position: they had to do something to solve the insecurity brought about by the steep price increases and the gasoline shortages that they caused. This implied that any temporary measures would not be sufficient to reduce the insecurity, and so a more broad-reaching policy solution was necessary. The Conservatives decided to introduce such a measure as part of their 1979 budget.

The proposition of the Conservatives both within the December budget and during the January election campaign was a new pricing agreement with the provinces, that would raise the price of a barrel of oil by $\$ 4.50$ per year, until 1984 where it would have reached 85 percent of the lower of the world price or the U.S. Price in Chicago (Anderson, 1980). Additionally, they would impose an 18-cent per gallon excise tax on gasoline to curb consumption and collect the windfalls from the rising prices.

The Liberals, on the other hand, argued that the price increases were neither temporary nor complete, and criticized the government's tax proposition as inappropriate and short term at best, claiming that it would do nothing to temper the impact on the population. What was needed was a new arrangement with "made in Canada" prices (Trueman, 1980b). Hence both approaches were mainly concerned with issues under the economic growth frame, but the Liberals' also included considerations from the foreign policy and national power frame. 
One particularity of the Liberals' strategy was that while it might have worked to capture a large-sized rent (by overturning the government and getting elected, virtually ensuring the passage of whatever legislation they would propose), they also needed a policy solution that would fit with their claims. In other words, one that would convincingly reduce the insecurity by tempering the impact of price increases and that would work to put Canadians in a better position over the medium- to long-term future of oil prices. While the laying out of the strategy was not necessary for them to defeat the government in the vote over the budget, in order to win the election, they needed to gain the high grounds in the debates, especially if they were to obtain a majority.

On January 25th, at a speech in Halifax, Trudeau announced the Liberals' solution to the crisis if elected, a large change in the federal energy policy and pricing system (e.g., Pratt, 1982). Although the details were scarce and questions remained, especially on what price level the Liberals were expecting (more on this in 5.1 .3 below), the main components and objectives they intended to focus on were laid down. This also provided them with some flexibility toward the elaboration of the whole policy, all the while ensuring that it would appear as expected from the campaign promise. In other words, in this context, the more difficult part of the battle was with regard to the first dimension, since if elected with a majority, the parliamentary system ensured a large degree of control over the legislative process - with the important caveat of the federal-provincial relations issue. In the end the Liberals' strategy worked, and the campaign was marked by a labeling of the Conservative's proposition as tax-based and regressive, leading to the election of Trudeau with a majority. 


\subsubsection{The framing of uncertainty and risk, and the role of experts}

The energy crisis of 1979-80 was accompanied by various uncertainties, several of which were the culmination of a decade of instability and transformation in the international distribution of power with regard to oil and gas, and of a shift in economic and monetary policy in Western countries. In the Canadian context, two questions particularly underlay debates around this scare. First, international prices of oil and gas had remained high since the first oil shock, and now were increasing further and rapidly, which begged the question of how high they would go after the shorter-term turbulence was over. Second, what would be the impact of different policy tools on the political economy surrounding oil and gas if changes were made? Or to put the latter differently, what could - and what should - the government do in this case, and how could it be effective?

Both issues were linked, of course: any fears of large increases, and of their duration, pointed to the need for a policy response; at the same time, however, the size of the eventual increases needed to be evaluated in order for policy tools to be designed appropriately. So while it was the high level of uncertainty regarding the possibilities for prices in the short and long term future that produced the demand for policy, it also complicated energy market predictions that were essential to any claims related to a given policy option.

The Conservative government initially faced difficulties in trying to devise a response to the crisis. The split between the industrial central region of Ontario and Quebec, which imported most of their oil, and the producer provinces of the West only 
worsened the negative impacts of any government control over prices. If the government attempted to keep the prices low, for instance by improving transfers between producing and consuming provinces, it would benefit importing provinces which could now buy a large portion of their demand at prices lower than international markets. Simultaneously, however, producers would incur an important opportunity cost, since they made much less revenue when selling to central and Eastern provinces compared to what they would have made if selling on the international market, given the price controls. On the other hand, trying to eliminate these conundrums by progressively removing price controls, which in effect meant increasing prices levels dramatically at one point or another, would have a large impact on consuming provinces (and on the population at large, given the virtual monopoly of gasoline as an energy source for personal transportation).

Hence before convincing anyone of which approach should be pursued to solve this dilemma, one critical question needed to be answered: what would the price of oil look like a few months in the future? And what about in a few years? The uncertainty surrounding the future of oil prices came to play a critical part in the election in early 1980, illustrating a dominance of the economic growth frame in the debates. As mentioned in the previous section, the Conservative government argued that domestic prices could be brought up to $85 \%$ of world prices within four years with a yearly raise of 4.50\$ per barrel. Consequently, their policy proposition to deal with the increase in oil prices was focused around a new federal-provincial pricing agreement, in addition to an 18-cent per gallon tax on gasoline. The Liberals, on the other hand, spent the first part of the campaign arguing that such a tax would actually worsen the impact on the population. 
They went further and attacked the Conservatives' position by claiming that their figure of $\$ 4.50$ was highly problematic.

While the Liberals criticized the policy option defended by the Conservatives partly on the basis of doubts over their predictions for future prices, in his speech on January 25th, Trudeau gave little details on the Liberals' own predictions: all the Liberals did was argue that a long-term strategy of price controls was needed, one which would spread both the benefits and costs linked to the changing international prices of oil. After the election, this evolved into the National Energy Program, through which the revenues would be transferred from the West to the East (more details on the NEP in 5.1.5 below).

Consequently, while both parties certainly attempted to make some predictions for how high the prices would go in the near future, the Liberals chose to play up the uncertainty while the Conservative tried to give a strict prediction. This had the effect of orienting the debates, at first around the budget vote and then during the election campaign, on the validity of the Conservative's predictions, and the Liberals managed to convince a large portion of the population that these predictions were wrong. Put differently, while the Conservative's bet was that the insecurity caused by the shock would be tempered by measures and claims intended to eliminate the uncertainty surrounding the evolution of the prices, their adversaries used this uncertainty to their advantage, without ever committing to specific numbers. 


\subsubsection{The impact of contextual factors}

When analyzing the impact of contextual factors, the minority status of the government is difficult to avoid, as the electoral context, combined with the long duration of the scare, played a large part in both the strategies of the two main political parties as well as their successes and failures. If the early 1979 election had produced a majority Conservative government, it goes without saying that the Liberals likely would never have been able to pass their program, or to use the scare's rent for electoral purposes. The minority government situation meant that leaders from the executive branch of government did not have as strong an advantage as usual: not only did they lack control over the legislative process - and thus on the passage of different policy solutions to the scare - they were also in a position where they could be challenged and replaced. Furthermore, this was worsened (for the Conservative government) by the nature of the triggering event, which presented them with little control over the source causes of the scare since the events were mostly complex political crises abroad - a topic to which I return in Chapter 7.

This is thus an example of the leadership curse, where the government is forced to act but there are limited options as to what it can do, in particular because of its minority position in the parliamentary system. The lack of improvement of the economy, in addition, contributed to the fall of the government.

Another important and related contextual factor relates to the distribution of hardship during the scare across the Canadian provinces. The Conservative Party's main base was in the Western provinces, mostly oil producers, who on one hand were eager to 
reap the benefits of higher international prices, and on the other preferred the federal government to intervene as little as possible in energy markets. The Liberal Party's base, however, was in Central Canada (Ontario and Quebec) and consisted of largely oilimporting provinces, who were already struggling with persistently high unemployment. This not only provided the Liberals with an opportunity to capture the symbolic capital of the scare and get reelected by giving the bulk of their attention to central Canada's woes: it also helped shape the policy response. Ever since the oil embargo of 1973-74, the Liberals had been debating ideas for a new and expanded role in energy policy for the federal government, and the shock of 1979 confirmed to many in the Liberal ranks that something drastic was needed, a policy that would rearrange power relations and give primacy to the federal government in energy policy (Doern and Toner, 1985; Foster, 1982; James \& Michelin, 1989, pp. 69-71).

\subsubsection{Resulting policy changes and conclusions}

The main policy change that emerged from the social scare was the National Energy Program, passed by the Liberal government in the fall of 1980. The program had three main objectives. First, ensure a safe supply of energy by moving Canada away from the necessity of imports, a popular item given the perceived foreign source behind the

price increases. Second, increase opportunities for Canadian participation in the oil industry, again following from autonomy and independence concerns. And third, establish fairness in energy costs and benefits for all Canadians, by ensuring that pricing 
was adequate and that arrangements in revenue sharing were made (James \& Michelin, 1989, p. 60; see also Jenkins, 1986).

Taken as a whole, the policy completely reversed the trend toward a greater degree of correspondence between domestic and international prices, with the intent to provide an economic environment characterized by "made in Canada" prices. The most controversial of these points was linked to the third objective, since the Liberals introduced a revenue transfer mechanism that forced an export tax on Canadian oil barrels corresponding to the difference between the regulated price for purchases within Canada (i.e., the level incurred by Canadian consumers). In practice then, this tax was equivalent to taking revenues away from the producing provinces and giving to the consuming provinces. As already discussed, the former were largely Conservative, while consuming provinces, hit hardest by the oil shock, represented regions where Liberals had a high degree of support.

Overall then, this illustrates a case where one group of actors, the Liberal Party of Canada leadership, attempted and succeeded in using the scare to gain the ultimate potential benefits of the political rent: overrun the government and replace it. To do the first part, however, they needed to play up the scare, and use the uncertainty on future oil prices to discredit attempts by the Conservative government to defend their solution. Furthermore, they had a policy option that happened to fit with this strategy for the rent, one which had the advantage of ensuring their reelection as well as change the federalprovincial dynamics in energy matters, a topic that the Liberals had been debating for some time (Doern and Toner, 1985; James \& Michelin, 1989; Pratt, 1982). When this 
was done, the parliamentary system gave them a strong advantage in passing the legislation.

\subsection{Case \#2: The 1998 Great Ice Storm in Quebec, Canada}

In early January of 1998, a combination of warm weather and precipitation led to an unusually lengthy period of continuous freezing rain, which accumulated in such quantities as to cause great damage to infrastructure in Eastern Canada and New England. The storm affected a narrow but very long area of land across four Canadian provinces, from Eastern Ontario to Nova Scotia, as well as bordering regions in the U.S. states of New York and Maine, causing an estimated $\$ 6.4$ billion in damage.

I focus here on the scare as it played out in the province of Quebec, where the most severe damage occurred and where the acute phase of the social scare that ensued was longest, as tens of thousands of homes were left without electricity for several weeks. The Greater Montreal region, in particular, saw the most severe effects. This represents a case where the political rent was won by two leaders in power, and where subsequent attempts at policy change were thwarted by these winners.

\subsubsection{The triggering event and the political rent}

The level of disruption for this case was very high, as events such as these, in a region where natural disasters are relatively rare, tend to capture public attention. To be sure, difficult winter weather - including freezing rain - occurs several times a year in that region, and so this type of precipitation is not unusual. However, the events of 
January 1998 were of an intensity rarely seen, and the damage they caused was well outside the norm. To quantify this disruption, several facts can be considered. First, the damages to the electricity transmission and distribution infrastructure, combined with the high percentage of the population using electricity as their sole heating source, ended up causing at least 30 deaths because of lack of heating/electricity in cold weather, or poisoning following from improper use of diesel generators (Quebec 1999, pp. 41-42). Second, the storm caused the largest deployment of Canadian Forces personnel since the Korean War, and a shutdown of activities in both Ottawa and Montreal for several days. Third, and more specifically regarding the electricity infrastructure, at least 1,000 electrical pylons and 30,000 wooden utility poles were crushed or collapsed under the weight of accumulated ice (or by trees that fell for similar reasons) (Statistics Canada, 1998). This damage not only caused well over a million households (and nearly half the population of the province) to be cut from the electrical network for days, but also hundreds of thousands of people to be without electricity or heating for several weeks, around 100,000 having to resort to emergency shelters (Statistics Canada, 1998).

The reach of the triggering event was also extensive. With nearly half the population of the province experiencing blackouts for an unusually long period of time, the crisis easily reached most of the population, even when the electricity came back in most regions. The weeks of news concerning inhabitants of the "black triangle", an especially problematic region on the South shore of Montreal, were followed on the news by the rest of the population. The daily press conferences from the government continued until the end of January, ensuring a continued visibility to the issue in news coverage, 
even in regions with power. A unusually high number of deaths, in particular, added to the insecurity perceived by the large portion of the population that were affected by blackouts even just for a day or two.

The high level of disruption and the broad reach of the triggering event created a large rent. In a survey conducted at the end of the year, for instance, journalists from across the country ranked it as the biggest news story for the year (White, 1999). After conducting a study on the storm at the end of the year, a Statistics Canada report further concluded that it was "the most disruptive and destructive storm in Canadian history" ("Ice storm most disruptive in our history," 1998).

Several contextual factors characterized the political environment at the time of the event. The first was the state of the federal-provincial relations. Quebec Premier Bouchard was the head of the independence-promoting Parti Quebecois, since the aftermath of a very close referendum for the independence of the province in 1995 . Bouchard's status and charisma within the Quebec population at the time facilitated his leadership during the weeks of the blackouts. At the same time, Canadian Prime Minister Chrétien faced incentives to appear helpful to victims in the eyes of the public, having faced criticism a few months before for triggering an election while floods were occurring in Manitoba (Alberts \& Lindgren, 1997). As I discuss below, this context had some consequences for the capacity and strategy options for actors trying to gain from the scare.

Regarding some of the dominant ideas of the time, it should be mentioned that despite the absence of substantial privatization efforts for the publicly-owned provincial 
monopoly (Hydro-Quebec, or HQ), the trend towards privatization of the electricity sector among industrialized countries at the time still had some resonance within Quebec. The company was being restructured in the late 1990s, splitting into three business entities for the generation, transmission, and distribution of electricity, a process accompanied by an emphasis on export opportunities, to the Northeastern United States and to New Brunswick in particular (see for instance Campbell, 1998).

Hence the political rent was large and restricted to leaders who could act to convincingly reduce the insecurity in the population, and demonstrate leadership in dire times. The socio-political context of the storm in Quebec influenced who would be able to have a shot at the rent, and the strategies of the winning actors had a role to play.

\subsubsection{Strategies and actions of the actors regarding the two objectives}

The actors who stood out on the government side were Quebec Premier Lucien Bouchard and Hydro-Quebec President André Caillé. After the storm started during the first week of January, the pair appeared on television for daily press conferences during the entire month, detailing to the population what was being done, suggestions about measures people should take, and the state of repairs. This strategy largely left federal politicians on the sidelines, since attempting to grab attention ran the risk of being seen as politicizing a disaster. Other prominent figures within the Quebec government who were - in practice - responsible for rescue operation and planning, most notably the Minister of Public Safety, were also relegated to behind-the-scenes functions. The wisdom of the decision to use this means of communication during the scare was confirmed by results 
from focus groups in the first few days of the scare, with the strategy being to restrict communications to only two main spokespeople at the highest level, lending credibility but also minimizing the risks of rumor spreading and panics (Lévesque, 2008; Murphy, 2009, p. 175). Despite the irony that most people affected by the events were without electricity - and thus could not be reached directly through televised conferences - the top provincial leadership decided that it was still the best way to reach as many people as possible, hoping that the information would then be transferred through telephone and word-of-mouth (Murphy, 2009, pp. 175-176).

By using this strategy, Bouchard and Caillé were able to impose a very specific angle to the events: that the problems were all caused by an extraordinary natural disaster, which made preparation impossible. The office of the Quebec Premier and Hydro-Quebec were highly coordinated in their communications to the media. From the population's perspective, terms such as "once-in-a-century" and "mother nature", as well as symbols like "heroic" Hydro-Quebec line crews doing overtime to repair lines, added to the impressive images of large quantities of ice accumulated on transmission lines as well as pylons bent and crushed by the weight of the ice (Radio-Canada, 1998). This gave credibility to the causal story of the extraordinary nature of the events, which largely shielded Hydro-Quebec from blame regarding the blackouts themselves - and to a certain extent on the speed of repairs. This strategy achieved four objectives: (1) it prevented blame on Hydro-Quebec for the gravity of the events, even given the length of the blackouts, by imposing a natural and accidental cause for the blackouts (in other words, the blackouts and the ice storm were not dissociable); (2) it presented Hydro-Quebec 
managers and government officials as leaders doing their best to help resolve the consequences of this natural disaster; (3) the strategy also provided a definition of the problem at hand during the blackouts, which were mainly to de-ice the lines and repair the damaged infrastructure; and (4) it eliminated or severely restricted discussions of longer-term solutions to these types of events, given the definition of the problem and its identified causes (more on this below).

Moreover, the uncertainty about the more specific causes of the problems across the network was almost entirely controlled by Hydro-Quebec, as they were the sole source of information (and thus the government's) on the physical state of the lines. It was difficult for other actors to come up with alternative information or even confirmations, given that virtually all the available experts were either Hydro-Quebec employees, or were relying on the information given by the public entity. Finally, the strategy of holding daily press conferences by only two actors, at the highest level, tended to eliminate uncertainty about the evolution of the repairs, and also about what could be done to prevent these types of major blackouts (or what could have been done, for instance with regard to the speed of repairs).

Other prominent politicians found it very difficult to get their spot in the sun. Canadian Prime Minister Chrétien did attempt to capture attention and demonstrate leadership, for instance by offering military aid on television even before informing the military, or by ensuring repeatedly that the Canadian government would provide all the resources needed (Murphy, 2009, pp. 175-176). Nevertheless, the domination of the public attention by Bouchard and Caillé remained, even within the provincial 
government's ranks. As already mentioned, the Minister of Public Safety, in charge of operations on the ground, was largely overshadowed by the Premier. As for provincial opposition leader Daniel Johnson, he was largely invisible during the first days of the scare, and was eventually limited to either supporting the government's actions or timidly criticizing them, in both cases having to resort to responding and never having the upper hand (David, 1998; Gagnon, 1998).

Montreal Mayor Pierre Bourque, whose city was paralyzed by the ice for several days, interrupted his trip to Asia, and visited several shelters (as did Members of the Canadian Parliament from Montreal ridings). However, he was largely seen as out of the loop from the management of the repairs, shelters and emergency measures, often appearing to learn information at the same time as the news media (Gagnon, 1998).

Some groups did try to use the scare to launch a discussion about priorities at Hydro-Quebec. Since nationalization in the 1960s, the public monopoly's strategy had revolved almost solely around hydroelectricity, given the abundance of these resources in the northern Quebec region, a direction that came to be questioned during the ice storm scare (see for instance Maltais, 1998). Moreover, in the 1990s the development strategy of Hydro-Quebec included progressively increasing sales to neighboring provinces and American states. Opponents to both these policies attempted to point out that the severity of the disaster following the ice storm in 1998 was not entirely inevitable, as a shift in priorities at Hydro-Quebec could have foreseen weaknesses in the transmission system that were highlighted by the damage (notably in the region where electricity was out for almost six weeks). Resilience in the domestic network, instead of profits from export 
expansion, should have been the main priority, according to groups like the Syndicat des Professionnels de l'IREQ, the union from Hydro-Quebec's research center (Francoeur, 1998).

As a result, critics of Hydro-Quebec presented the gravity of the events as an avoidable lack of resilience of the network, inadvertently - but directly - caused by the culture and strategy of a state entity that behaved as a private company. These critics claimed that the monopoly was ill-prepared to face such a crisis, and that a network built with different objectives and purposes would have prevented the worst of the impacts.

As discussed in the previous chapters, however, the acute phase of a scare is a more difficult terrain for actors outside of key executive positions, and the fact that the two leaders (Bouchard and Caillé) were both perceived as credible and compassionate eased the acceptance of depictions of the crisis as a set of effects following automatically from a purely natural disaster. But perhaps more importantly, they gave great attention to controlling the information, including the uncertainty regarding the evolution of the situation.

\subsubsection{The framing of uncertainty and risk, and the role of experts}

Several sources of uncertainty and risk were at play at different moments during this social scare, and I focus here on four: the uncertainty on the eventual gravity of the damages, as well as the exact causes of the blackouts, in the early stages of the scare; the uncertainty on the time that repairs would take to be completed; the risks inherent to Hydro-Quebec's development strategy prior to the storm; and the risks linked to similar 
future events, along with the risks linked to specific changes to the network - or absence thereof - after the scare would be over. As discussed in previous chapters, in order to help win the battle or impose a preferred storyline, uncertainty and risk assessments need either to be used to strengthen the story, or tempered when it is impossible to do so. In some - but not all - of the categories in this case, the role of experts is an important aspect to consider.

Regarding the uncertainty during the early development of the acute phase (i.e., during and immediately after the storm), not much could be done by any actors as long as the storm went on. Indeed, as the freezing precipitation continued, Hydro-Quebec declared that it was impossible to produce estimates of the damage before the freezing rain had stopped (Murphy, 2009). The uncertainty as to how bad the situation became was actually hidden from the public at the height of the storm, where the island of Montreal ended up having only one line bringing it power. This, in conjunction with blackouts at filtration stations that came within a few hours of causing water supply disruptions, even made municipal and provincial leadership briefly consider an evacuation of the city (Murphy, 2009, pp. 196-199). In the worst days of the scare, these decisions were made to avoid panics (especially since the road conditions had greatly deteriorated), and eventually the information was spread once the storm itself was over.

The uncertainty about the more specific causes of the problems that emerged across the electricity transmission and distribution network was almost entirely controlled by Hydro-Quebec, as they were the sole source of information (and thus the government's) on the physical state of the lines. It seemed difficult for other actors to 
come up with alternative information, given that virtually all the accepted experts were either Hydro-Quebec employees, or relying on the information given by the public entity.

The uncertainty with regard to the length that repairs would take was tempered by the strategy of daily press conferences by only two actors at the highest level. Premier Bouchard would make suggestions to the population as to how to cope with the blackouts in different regions (Wilton \& Semenak, 1998). Moreover, although they couldn't eliminate uncertainty regarding when the power would fully return, they gave detailed information on the evolution of the repairs, and also about what would be done next. This reinforced the perception in the public that they were well in charge, and that they were competently managing the crisis the best way that they could. With little alternative information available, the leaders took complete charge over the information on this critical aspect of the evolution of the scare.

In many ways there were two distinct crises, one natural - the storm itself, from January $5^{\text {th }}$ to $9^{\text {th }}$ - and one human and technical ${ }^{18}$ - the blackouts and the management of their impacts. However, in practice they were difficult to differentiate, and the government and Hydro-Quebec's storyline of a natural and unavoidable event, did resonate in the media and the general public. At the crisis' worst, a survey conducted on satisfaction rates for Hydro-Quebec and Premier Bouchard gave them an outstanding $92 \%$ and $84 \%$ respectively, even while over a million households were without electricity ("Bouchard, army winners in poll," 1998).

\footnotetext{
${ }^{18}$ For a discussion of this aspect, see Murphy (2009).
} 
The third source of uncertainty was related to the role that Hydro-Quebec's development choices had in the gravity of the blackouts. After the storm had stopped and electricity supply had resumed in a majority of regions, Hydro-Quebec started to be questioned about different aspects of the blackouts, including its lack of contingency plan to work with the municipalities, the absence of a permanent crisis unit, and its management of the staff during the repairs (Murphy, 2009, pp. 124-126). In particular, some groups tried to push the view that Hydro-Quebec's strategic plan of development since the 1990s made things worse than they would otherwise have been. According to these arguments, the mission of Hydro-Quebec, as a state enterprise, should be to favor Quebec citizens, not maximize profits (Riga, 1998). This, in combination with the emphasis on hydroelectricity since the 1960s that led the monopoly to neglect the development of other sources of energy, resulted in the lack of resilience of the network in the face of the dire events of early 1998. In other words, according to these arguments, a potentially large part of the gravity of the blackouts in January of 1998 was the result of the culture and strategy of HQ.

Nevertheless, the position of the leaders (Bouchard and Caillé) and the acceptance of their accidental causal story ${ }^{19}$ (this was a dramatic, but natural, disaster that no one could fully prepare for) dominated public opinion and no serious debates were initiated on the longer term strategy on Hydro-Quebec in the short- to medium-term aftermath. Despite the attempts of opponents to Hydro-Quebec's long-term strategy to depict events

\footnotetext{
19 This terminology follows from Stone (2012), as described in Chapter 3.
} 
with an inadvertent causal chain, this was successfully downplayed by Hydro-Quebec's refusal to discuss the matter.

The fourth category regroups risks linked to similar future events, along with the risks pertaining to potential changes to the network - or absence thereof - after the scare would be over. This is typical of the questioning that follow any scare triggered by a natural disaster: what are the risks that we encounter a similar situation in the near future? And could we prepare enough so that the negative impacts are minimized, in other words, can we learn from this instance? These questions inevitably came up once the storm itself had ended. For the most part the leaders asserted that it was the kind of storm that would not repeat itself before a very long time, and that it would be overkill to spend too much in order to plan for something against which it is impossible to completely be prepared. However, they also admitted the possibly of more frequent large ice storms in the future (Yakabuski, 1998). This also had the effect of narrowing the debates on technical aspects in the security frame of energy policy, enhancing the importance of expertise in the current network, leading again to Hydro-Quebec being perceived as the best experts on the topic.

The "management" of these sources of uncertainty and risk helped the provincial government, but Hydro-Quebec in particular, with their blame-shifting strategy. The ease with which the population could understand the communication of technical information, in this case, helped Hydro-Quebec present itself as the sole source of expertise. Instead of debating complex issues of electricity network distribution and various strategies to ensure resilience, Hydro-Quebec's role as the source of expertise allowed it to keep most 
debates and discussions focused on repairing infrastructure crushed by the weight of ice, an issue that could resonate easily with the public.

\subsubsection{The impact of contextual factors}

Although we should be prudent in giving any explanatory power to broad factors such as federal-provincial relations, a few tentative conclusions on their partial contributing effect can be made in this case. On the one hand, the difficulty for federal politicians to try and capture part of the rent (or to participate in any influential way to the management in the acute phase) could be interpreted as an instance where the distance between the victims - and to a lesser extent the general population - was paramount. The ice and the electrical blackouts were geographically circumscribed, after all, and the management of the electricity system by a monopoly that was provincial gave credence to the corresponding level of government. This would explain why provincial leaders were turned to, in contrast to their federal counterparts. With regard to MPs this is partly expected, as actors in an executive position should always have a marked advantage in competing for the political rent, although it is possible for legislative actors to "piggy-back", at the very least, which was only done with very limited success by federal MPs.

On the other hand, however, if we followed further this logic of giving a strong advantage to actors closer to the victims, then the case of the Montreal mayor becomes problematic. Although the region affected for the longest time was outside of the city's territory, Montreal was still gravely affected for several days at the beginning of the 
scare, and Mayor Bourque was virtually absent from the coordination of the efforts in the eyes of the public. Thus with regard to the rent, the success of Bouchard and Caille in appearing as the men in charge, and the failure of other actors like Bourque to do so, confirm the importance of the actors' strategies.

It is also important to return briefly to the peculiar situation of the Canada-Quebec relationship, especially in the years that followed the second referendum for independence in 15 years. The difficulty of federal leaders to participate more meaningfully in the management of the scare could also be partly due to this tense relationship, where a strong federal intervention into what was quickly seen as a provincial crisis ran the risk of being portrayed as an intrusion into provincial affairs, a particularly contentious issue in that period.

Finally, it should be noted that the domination of provincial leaders when compared to federal actors remained despite the use of spectacular measures by the federal government, most importantly the dispatching of thousands of members of the Canadian Forces and an unlimited tab for the relief efforts. Prime Minister Chrétien stated repeatedly that the relief forces should spend whatever they needed and that the Canadian government would foot the bill later on (Arcand 1998). This highlights the importance of the communication strategy, where visibility - in this case, through the daily press conferences - seemed to trump most other aspects during the acute phase. 


\subsubsection{Resulting policy changes and conclusions}

The ice storm of 1998 is a case where the potential struggles for changes in policy or in Hydro-Quebec's corporate strategy were thwarted by the actions of dominating actors during and immediately after the acute phase. The political rent, in this case, was captured by Premier Bouchard and André Caillé, as their leadership was widely recognized in the population during and after the acute phase (Pineau, 1998). Their positions and the acceptance of their accidental causal story (this was a dramatic, but natural, disaster for which no one could fully prepare) dominated public opinion and no serious debates were initiated on the longer term strategy of Hydro-Quebec outside of the security frame (at least not for a few years). The control of the technical information, and the credibility of the sources of this information, joined with the symbols and images associated with the storm, gave them the necessary stature and resources to push the (purely) accidental causal storyline.

When the blackouts were finally over in early February, no actor was able to jump in with enough political capital to challenge the two leaders' position that the scare was over. The rent's symbolic capital, on the contrary, was used to prevent any serious discussion of Hydro-Quebec's policies, and virtually no policy changes were enacted. Despite the attempts of opponents to Hydro-Quebec's long-term strategy to depict events with an inadvertent causal chain (i.e., that the worst impacts were a consequence of Hydro-Quebec's culture and strategy), the perception of the uncertainty with regard to the resilience of the network had been quickly reduced and transformed by Hydro-Quebec's 
commanding role in suggesting an interpretation of the events on the ground during the acute phase.

There is a caveat to this particular case. The government, as well as HydroQuebec, did try to use the crisis as an opportunity for some changes. The priority at Hydro-Quebec since the mid-1990s had been the construction of additional transmission lines for exports to the United States, which were controversial because of opposition from residents on the planned route for at least one particular line (between Hertel and Des Cantons, just South of Montreal). At the height of the scare the Premier signed decrees allowing Hydro-Quebec to bypass the normal environmental impact studies as well as the public consultation process, initiating the construction of the new line. A few weeks after the end of the last blackouts, opposition to the line caught up with these decrees, and courts eventually stopped the construction (Bisson, 1999). In many ways, the government (and Hydro-Quebec) wasted part of the political rent won by Bouchard and Caillé, as they lost part of the symbolic capital when the decrees became more controversial.

\subsection{Comparisons between the two cases}

Now that the first two case studies have been summarized in the last two sections, I continue the description further by comparing the two cases with each other. This serves as a first step in the comparative process. To keep the discussion structured, I use the list

of investigative questions as a framework here again, and further comparisons are done in Chapter 7 - between the four cases all together, and on some aspects I skip over here. 


\subsubsection{The triggering event and the political rent}

The triggering events differed in significant ways. In the ice storm case, it was clearly delineated in time (i.e., the ice storm itself in early January), and the cause of the event was natural. In the NEP case, although it could be argued that the first trigger to the energy crisis in 1979 was the Iranian revolution, the onset of the scare was more complicated and spread over time. Since the scare was mainly linked to sudden and successive spikes in oil and gas prices, this was a much more progressive process than in the case of the ice storm. Several additional events amplified and extended this scare, which ended up lasting for over two years. During the course of the Conservative term and then the Liberals' first few months in office, then, it was difficult to pin down the source of the scare to a particular event.

There is, however, an interesting similarity between the two cases on this point. In the ice storm case, the trigger was a natural disaster, which suggests, at first glance, that it was a very different type of onset than the international political crisis caused by the Iranian revolution and further events in the NEP case. Upon closer examination, however, this distinction needs to be toned down. Instead, and perhaps in part because the emphasis is put here on policy and political dynamics within the boundaries of a state or province, we can notice that in both cases there is a sort of distance between the event(s) and the society it ended up affecting. In both cases, the leaders used this distance as a way of taking control over the scare, arguing that the main cause of the scare was out of their control, so they would "do their best" to manage the events' impacts on their constituency. In the ice storm case, this was done explicitly, with the government and 
Hydro-Quebec leaders repeatedly referring to the "natural" character of the disaster, while in the NEP case this was implied given the foreign nature of the causes. Consequently, the debates could only occur on the impacts of the event, not on the cause of the triggering itself. This also supports a claim made in Chapters 1 and 2 that distinctions between these events by type (political crisis, natural disaster, industrial accident, etc.) is not determinant in both the political dynamics that follow and the way the events are understood by participants in policy debates.

The rent as resource hypothesis $\left(\mathrm{H}_{1}\right)$ can also be tested on these two cases. $\mathrm{H}_{1}$ states that executive branch leaders who manage to win a large portion of the political rent should have more facility in securing their preferred policy outcome. These are two cases where the bulk of the rent was won by some actors who were then in power in the aftermath of the scare. In the NEP case, the Liberal party and its leaders won the rent in perhaps one of the most prominent ways of all: by bringing down the government and replacing it. The defeat of the government in late 1979, and the election of early 1980, were both predicated on the energy crisis issue. In the ice storm case, the rent capture must be measured differently, since no election occurred in the immediate aftermath. Opinion polls, as mentioned above, clearly demonstrate an "ice storm effect" in the popularity and satisfaction toward both the Premier and the president of Hydro-Quebec.

Did this rent help, or rather, was this rent determinant in helping them obtain their preferred policy outcome? In the NEP case, the only way that the Liberals could revamp the national energy policy the way they did was to be in control of a majority government. The capture of the rent was thus instrumental: for the Conservatives, the 
inability to obtain their preferred outcome resulted from their loss in this leadership battle. It is not unreasonable to imagine that a different outcome in the election (or even merely on the budget vote) would have yielded a different policy outcome.

In the ice storm case, the picture is less clear and the conclusion on the rent and the rent as resource hypothesis needs to be more prudent. Although it was clear from the start that the government and Hydro-Quebec did not want to enact major changes in electricity policy or strategy, it would be unreasonable to ascribe their success in doing so merely to their winning of the rent, as Bouchard's team were in control over the legislative process given their position as majority government. Nevertheless, their successful strategy during the crisis allowed them to thwart discussions about HQ strategy in the aftermath of the crisis, despite some challenges. Similarly, in the next election a year later, it remained risky for other actors - the provincial Liberal Party, in particular - to criticize the government's or Hydro-Quebec's actions during the scare without appearing as putting Bouchard and Caillé's leadership into question. Thus these two cases give some support to the rent as resource hypothesis, with the important qualifier that the electoral context and the type of political regime were critical in its impact. I return to these factors in section 5.3 .4 below.

\subsubsection{Strategies and actions of the actors regarding the two objectives}

As mentioned in 5.2.2 above, the Bouchard-Caillé strategy was able to achieve several objectives. First and foremost, it simultaneously shifted any possible blame away from Hydro-Quebec and presented the government officials and the state company 
managers as leaders doing their best to help deal with the consequences of the natural disaster. Second, the strategy also imposed a frame of the problem that deterred discussions of substantial modifications in Hydro-Quebec policy and strategy. This meant a complete compatibility between objectives for the first and second dimensions: on the one hand, the daily press conferences were designed to maximize the impression in the population that the people in charge were great leaders and on top of the events on the ground; on the other hand, emphasis was put on the idea that the direness of the situation was due to something neither caused nor preventable by policy. This shows support for $\mathrm{H}_{2}$ (compatible strategies), since we would expect that arguments and narratives used to capture the rent follow from the group's preferred policy outcome. It should be noted, however, that in this case the management of the acute phase by the government could have been done similarly and led to changes in policy, since they were in complete control of the legislative.

The NEP case is complex on this matter. If we focus our attention first on the Conservative government before the election, a key difference with the ice storm case was the uncertainty concerning the end of the "abnormal" situation created by the scare here suddenly high oil prices. In the ice storm case, everyone in the population, at HydroQuebec, and in the government knew that the power would eventually be restored, the issue was merely when. This remained an important source of uncertainty, as electricity is essential in the winter, but the government and Hydro-Quebec leadership could count on a clear end to the conditions created by the scare. In the NEP case, however, no one knew when the prices would go down, or whether they would go further up. As a result, 
government leaders could not use a strategy where they would blame the scare on the foreign events and enact measures merely aimed at helping the population cope with the temporary situation.

The challenge, for the Conservatives, was thus to come up with policy actions that would reduce both the immediate situation (the suddenly high prices) and the fears of a repetition or worsening of this scare. This was no small feat, and the minority government situation exacerbated their position. For the Liberals, however, the task was somewhat easier, as they benefitted from their parliamentary opposition position. Their strategy to win the rent, consequently, could be aimed at blaming the government. For them, the important part of the strategy was the rent, because they needed first and foremost to get elected. This again shows support for the compatible strategies hypothesis, but with additional insights. This prioritizing of the rent also highlights another difference with the ice storm case: in the latter, the leaders could "demonstrate" the actions they were taking, since they could show images of repairs being made and interviews with Hydro-Quebec crew or residents. In the NEP case, this was more difficult to achieve, if possible at all.

\subsubsection{The framing of uncertainty and risk, and the role of experts}

Looking first at the ice storm case, it is interesting to see that the narrative put forward by the government-HQ leadership, through an accidental causal story, considerably diminished the difficulties linked to the various sources of uncertainty characterizing the scare's acute phase. In this particular case, the government and the 
electricity monopoly were difficult to challenge given their virtually complete control over the technical information necessary to making assessments. Not only was the information given out by Hydro-Quebec treated as "true" by the media and the population; even when it was shown that the company had relayed incorrect information, the storyline of the natural disaster combined with the leadership of Caillé and Bouchard made it seen as "normal". In other words, mistakes were expected, and not interpreted as incompetency given the dire conditions in January of 1998.

As a result, and while the leaders from the government and Hydro-Quebec tended to argue that uncertainty was reduced to a minimum by their actions (which supports the $\mathrm{H}_{3}$ : uncertainty played up/down hypothesis), a certain level was presented as inevitable. The caprices of the weather were a reality that everyone had to accept, and consequently, it was normal that once in a while a major event came and caused some damage. Hence uncertainty here was part of the strategy, as its acceptance as normal allowed blameshifting from Hydro-Quebec: for the laborious conditions experienced by many of the victims, explanations could always resort to the natural disaster storyline. Moreover, the use of experts was prominent in Hydro-Quebec's public relations strategy, where the leadership of President Caillé allowed him and his communications team to claim sole legitimacy over expertise during the scare - expertise on the problems, the ways to repair them, as well as solutions for the future. This leadership was successful in eliminating the perception of uncertainty in the population, as well as the insecurity it created. This line of defense, however, seems easier when information in general (and the uncertainty perceived in the population in particular) can be controlled by the defending groups. 
In the NEP case, the uncertainty regarding the future of oil prices was problematic for the Conservative government, but less so for the Liberals both before and after the election. Because of the leadership curse, the Conservatives had the lead in the policy formulation, and were attacked both on the impact of their proposed pricing arrangement and tax hike, as well as on their predictions for future prices (the $\$ 4.50 /$ barrel/year discussed above). The Liberals, however, ended up claiming that these predictions were wrong, while not putting any clear figures on their own.

Consequently, while both parties certainly attempted to make some predictions for how high the prices would go in the near future, the Liberals chose to play up the uncertainty while the Conservative tried to give a strict prediction, as the uncertainty played up/down hypothesis suggests. This had the effect of orienting the debates, first at the time of the budget vote and then during the election campaign, around the validity of the Conservative's prediction, and the sense of certainty provided by the Conservative strategy failed to bring them enough support. It should be noted, furthermore, that the debates over the price predictions, at least in the mainstream newspapers, were led by political figures with little reference to experts.

Thus, it seems that uncertainty is a malleable tool that can be used differently in various strategies, of both "status quo" actors and challengers, with the important caveat that they still face the constraints provided by the events. These constraints do not merely include the physical features of the social scare, but also the socio-cultural context where the scare occurs. Depending on their position and on the context, as expected, some groups highlight the uncertainty in their strategy, while others try to dispel it. 


\subsubsection{The impact of contextual factors}

With regard to contextual factors, the electoral context and the political regime stand out as determinant in these two cases, suggesting support for both $\mathrm{H}_{4 \mathrm{a}}$ (looming election) and $\mathrm{H}_{4 \mathrm{~b}}$ (regime type). The former states that an election planned during or very shortly after a scare diminishes the advantage held by actors from the executive branch (discussed in 2.3.1 of Chapter 2). The NEP case provides support for this, although not in the expected form. What made a difference was not the fact that an election was looming, but more specifically that there was a very real possibility to defeat the government to produce this election context. The context of minority government, in this case, was a conditional step in the process. Regardless, however, the end result is the same: if there is a possibility to challenge the executive branch in its very position, the strong advantage that they usually hold in their access to government resources and their legitimacy as leaders is diminished. Compare this to the level of control enjoyed by the Bouchard government in the ice storm case, where it seemed much harder for actors outside of the executive branch to come in and challenge the government's position, even once the acute phase was over.

The latter hypothesis states that the type of political regime also influences the strength of these actors' position. More specifically, the regime type hypothesis $\left(\mathrm{H}_{4 \mathrm{~b}}\right)$ states that actors from the executive branch will hold a stronger position with regard to policy options when also controlling the legislative process. Since governments in both cases were characterized by a parliamentary regime, comparison possibilities here are limited, and I return to this issue more at length in Chapter 7. What can be said, however, 
is that $\mathrm{H}_{4 b}$ cannot be rejected by these two case studies, as the parliamentary regime did indeed have a strong influence on the ability of actors from the executive branch to obtain their preferred policy option. Both the Liberal government (post-election) in the NEP case and the Bouchard government in the ice storm case had strong control over the policy process, not merely because they enjoyed a boost in symbolic capital from their capture of the rent, but quite simply because this is the way the regime is set up. A within-case comparison can also be made for the former: in a parliamentary regime, a majority government has more control of the policy outcome of the scare than a minority government, which again is simply the nature of the regime. What is more interesting for this study, however, is the fact that the leadership dimension of the scare can exacerbate the instability of a minority government, since opposition actors are likely to try to capture the rent and overturn the government.

The bottom line for this section is that the electoral context and the political regime appear to be, unsurprisingly, important conditional variables in the outcome of a social scare. The electoral context, summed up in the election looming hypothesis $\left(\mathrm{H}_{4 \mathrm{a}}\right)$, is critical for the first dimension of the struggles, in that an upcoming election causes the rent to become entirely available and more accessible to actors not in power, which is a key difference from a case where the executive is in the beginning of a mandate (as a majority in a parliamentary regime, or in a fixed-term presidential one). The type of regime, as described in $\mathrm{H}_{4 \mathrm{~b}}$, is key in the second dimension of the battle, where control over the legislative process is an important resource for the executive branch. Further comparisons on this item are done in Chapter 6. 
Finally, it is worth mentioning that the ice storm case highlights another aspect of the battles, as this was a situation where the executive branch dominating the battle was from the provincial level, despite the theoretical possibility for actors at the federal level to seize the rent. There are several factors that partly explain this, notably the fact that public safety and electricity policy is the purview of the province, the localized nature of the events, and the fact that electricity is provided and managed by a provincial state monopoly. None of the mechanisms described in the framework are strongly affected by this possibility, but more attention certainly needs to be given to this aspect. Furthermore, it should be noted that the federal structure was much more conducive to this possibility than would have been the case under a unitary state structure.

\subsubsection{Resulting policy changes and conclusions}

The major difference of outcome on the policy side is quite obviously the complete absence of new policy in the ice storm case, compared to both a change in government and the passage of the revamp of national energy policy in the NEP case. In the former, the potential challenges to Hydro-Quebec's corporate strategy were thwarted by winners of the political rent, i.e. Premier Bouchard and André Caillé, who continued to use the accidental story line with success and focused energy policy discussion on the security frame. In the latter, leaders of the Liberal Party of Canada used the scare to get elected, and then for passing the announced NEP.

In both cases however, the parliamentary system gave the executive branch a strong advantage in passing the legislation, with the interesting caveat of the initial 
minority government situation in the NEP case. When in power at the time of the legislative battle, executive branch actors in both cases had the opportunity to pursue the option they favored, given how they had presented and framed the scare during earlier stages.

\subsection{Conclusion}

These first two cases help confirm many of the basic features of the theoretical framework. Some degree of support is found for all hypotheses, although the type of political regime and the electoral context emerge as strong conditional contextual factors. The comparison with the next two case studies provides more depth to this link. The evidence is mixed, however, concerning the role of experts. In the ice storm case, HydroQuebec quickly emerged as the main source of expertise, but in the NEP case, the predictions supposed to provide some tempering of the uncertainties linked to rising oil prices seemed to have come merely from the political leaders, with limited references to experts to back up these claims.

Additional factors that were scarcely discussed in previous chapters also emerge as important. First, the possibility for the triggering event to be treated as exogenous, whether it's a natural disaster or a political crisis, appears to have some influence over the actors' strategies, providing both opportunities and constraints (see 5.3.1 above). Second, the degree to which there is a clear delineation of the acute phase also impacts the position of the different actors. In other words, the uncertainty about whether the scare's acute phase has ended - or when it can reasonably be expected to do so - appears to 
exacerbate the leadership curse. As a result, attention will be given to these in Chapter 7 when comparing with the other two cases, in addition to the basic list of investigative questions used so far. 


\section{Chapter 6}

\section{Forfeiting the rent: the impact of the Chernobyl nuclear disaster in West}

\section{Germany and the Exxon Valdez oil spill in the United States}

In this chapter, I present the results from two more case studies, the impact of the Chernobyl nuclear accident in West Germany, and the Exxon Valdez oil spill in the United States. These cases represent instances where the executive branch did not try to inflate the scare to its advantage: both triggering events were played down by leaders of the national government, and the attempts to maximize the disruption and reach came mostly from groups opposed to these positions. In addition, in both cases the executive branch of government preferred limited change, and thus tried to downplay the scare with minimal policy actions.

In these two cases, politicians and other actors eventually found themselves not in an emergency politics setting, but rather in an in-between state where the sentiment of urgency is gone, while the social scare is still present, alongside its symbols and the insecurity it brought. As a result, a different kind of battle occurs for actors trying to push for policy changes by using what is left of the scare. Using the same structured framework as in Chapter 5, the cases are described with additional attention to the postshock period following the triggering event.

\subsection{Case \#3: The 1986 Chernobyl accident and its impact in West Germany}

The incident at the Chernobyl nuclear reactor in Ukraine occurred on April $26^{\text {th }}$, 1986, when a power surge during a systems test caused an explosion and fire, sending 
highly radioactive fallout into the atmosphere and over a considerable geographic area across the Western U.S.S.R. and Europe. The incident became a symbol of the dangers of the technology, and associated nuclear energy with insecurity around the world, creating or confirming a stigma that remains to this day.

This case study is centered on West Germany's response during that period. The relative proximity of West Germany to the incident created a social scare that lasted for several months, and substantial changes to its energy policy and surrounding institutional structure were enacted in the years that followed. The rent was not successfully used by the government in place to impose its preferred policy outcome, so this is a case where the struggles during the post-shock phase were critical in determining the outcome.

\subsubsection{The triggering event and the political rent}

The Chernobyl incident was a highly disruptive and spectacular event, as it was at the time the first of this scale and gravity, reaching level 7 on the International Nuclear Event Scale (the Fukushima, Japan incident of 2011 is the only other incident ever to have reached this level). Although the Three Mile Island incident in the United States in 1979 had brought attention to the potentially catastrophic dangers of using nuclear power for electricity generation, the damages and casualties had been limited; the Chernobyl incident, by contrast, killed at least 31 people in the immediate aftermath, and exposed hundreds of thousands more to high doses of radiation, bringing the total casualties (due to radiation-induced cancers, in particular) to at least several thousands (World Health 
Organization, 2006; Yablokov, Nesterenko, \& Nesterenko, 2009), depending on the source of the estimates.

This case study focuses on the impact it had on West Germany. The level of disruption can be evaluated in terms of the measures that were taken by West German authorities in reaction to the event. In other words, these were signs of disruption witnessed by members of the West German population that directly identified with the event. Major airports and passenger trains saw border officials test passengers from places like Kiev or Warsaw for radiation levels (Tagliabue, 1986). Fresh food imports from several Eastern European countries were banned by the European Economic Community, and farmers were instructed to destroy contaminated crops, eventually leading to substantial financial compensation by the West German government (Brown, 1986; Jensen, 1987). Additionally, despite repeated statements from the West German federal government that radiation levels were safe, different state and local governments issued further measures, for instance warning against letting children play in sandboxes, or about consuming milk and vegetables (even domestic), adding to the public anxiety over what the true risks actually were (e.g., "West Germany issues warning on milk," 1986).

Turning to the reach that the event had in the West German population, some of the measures just mentioned are also good indicators, in particular the various bans or warnings on food consumption. However, when assessing the reach we need to consider not just the direct impact of these measures, but also the symbolic value that they had. For the West German population, it became clear that everyone was concerned by the 
impact of a nuclear incident in a direct way (for example through what people ate, or where their children played), even one that had occurred well outside their immediate locality. This was reinforced by worries, during the weeks that followed the event, about the direction of the fallout, and about how much of the radioactive cloud would reach West German regions - worries that were similarly echoed in other European countries, even as far as the United Kingdom (Fairhall, White, \& Tran, 1986).

This case thus presents high levels of disruption and reach, which creates a very large political rent. Regarding the conditions surrounding the capacity of political officials to capture it, two characteristics are especially interesting about this case. First, the event itself had a specific locality (the nuclear power plant in Ukraine) that was well outside of the West German territory. Consequently, leaders trying to take care of the Chernobyl aftermath could hardly do anything about the exact site and source of the scare, short of a substantial international effort to ban nuclear energy altogether. ${ }^{20}$ Second, and despite this, most of the debates that followed within the country concerned the West German nuclear industry (and in some instances the West's industry more generally), which could hardly be argued to be at fault in these events.

Several other contextual factors need to be mentioned. West Germany had considerable nuclear ambitions at the time, being poor in other energy resources except coal, which reserves were known to be insufficient to make it the cornerstone of any long-term energy supply strategy. The oil shocks of the 1970s had created security concerns regarding a long-term plan relying on imports, and given the high cost and high

\footnotetext{
${ }^{20}$ On this matter, it is interesting to note that the event occurred in the midst of intense negotiations between the U.S.S.R. and the United States regarding a diminution of nuclear weapons stockpiles, negotiations in which European countries, including West Germany, were eager to participate.
} 
uncertainty associated with alternative sources of electricity generation at the time, it seemed essential to have nuclear energy as an important piece of the national policy. As a result, nuclear energy, for proponents, was identified with the restoration of economic growth (Joppke, 1993, p. 92). For instance, the Third Energy Program of 1981 was based on the idea that it was unthinkable to have a West German future without nuclear energy (Joppke, 1993, p. 163).

Concerning the electoral context around the specific time period of the Chernobyl accident, one state-level election was held a little over a month following the disaster, and a national election took place in January of 1987. Additionally, it is difficult to discuss issues linked to nuclear energy in West Germany without mentioning the existing antinuclear movement. Since at least the 1970s, there was resistance to nuclear energy and several protests occurred in the decade prior to the Chernobyl incident, starting with the Wyhl protest in 1975. Even between the beginning of 1986 and the Chernobyl incident in late April, several protests occurred, in link with the construction of a waste reprocessing plant in Wackersdorf ("Easter march in federal Germany draws to end," 1986). Furthermore, opposition to nuclear energy was linked to fears regarding the modernization of missiles on West German soil (Cowell, 2011).

This set the stage for the battles over political dominance that ensued. In this case, however, "solving" the social scare caused by the Chernobyl disaster would prove difficult for the actors in power. The post-shock period, in particular, saw lingering effects of the scare combine with the absence of a clear capture of the rent in the initial phase. 


\subsubsection{Strategies and actions of the actors regarding the two objectives}

Different groups of actors are considered here, with attention given to their actions during the months and years following the triggering event. The first set of actors revolves around the Kohl coalition government. As described in the previous section, the prize was large, but the conditions to allow for its capture were restrictive. A large part of the prize came from the rent created by the important disruption and reach of the triggering event. The Kohl government, however, was staunchly pro-nuclear, and along with the nuclear industry and other proponents had managed since the 1970s to frame nuclear power as an economic necessity. Even if the political rent was large then, the Kohl government did not want to discuss a moratorium - even less a phase-out - despite pressures from opposition parties and from an important part of the public. ${ }^{21}$

The Kohl government tried to reassure the public with claims that radiation levels were safe, that this type of accident could not happen with the safety standards of the West German industry, and that nuclear energy should still be the favored option for the future of the West German economy. However, during the acute phase, this strategy proved ill-fated, which highlights the difficulty of winning the political rent by maintaining that little needs to be done: in social scares with high levels of disruption and reach, there is a strong bias in the population in favor of taking strong action; as a result, the reaction of the government to the scare quickly came to be treated as either of two options: ban nuclear energy ("do something"), or don't ("do nothing"), a situation that the leadership curse would suggest. This dichotomy would play against the government at

\footnotetext{
${ }^{21}$ In December 1986, seven months after the accident, 75 percent of the public favored an instant or gradual nuclear moratorium (Peters et al., 1987, as cited in Joppke 1993, p. 179).
} 
least in the acute phase, and nuclear energy opponents successfully prevented the government from winning substantial recognition for easing the high level of insecurity. In this context, the federal government under Chancellor Helmut Kohl had to resort to drastic measures of conflict containment. On the one hand, Kohl praised the high safety standards of West German plants, and he drew the bleak, and somewhat farfetched, scenario of "total economic pauperization and mass unemployment" that would result from a nuclear phaseout. On the other hand, he symbolically appeased public concerns by creating, just one month after the accident, the Ministry for Environmental Protection and Reactor Safety (BMU). (Joppke 1993, p. 182)

This measure met with some success, but fell short of winning the rent created by the scare. In the years that followed the disaster, pressure continued to build for the largescale development of alternatives to nuclear power, from renewable energy in particular. The government initially kept resisting the idea of a broad-reaching renewable energy law by implementing different $R \& D$ and market creation measures, but eventually support for these sources built and forced it to consider a national support mechanism (see section 6.1.5 below).

Nuclear opponents are the next group I turn to. Although a movement against nuclear energy had started in the 1970s with an anti-statist stance, by the time of the Chernobyl event the opposition had become fairly institutionalized. First, the Green Party, created in 1980 largely from opposition to nuclear energy, was now represented in 
the federal and state governments. Second, sizeable sections of the SPD (the leading opposition party) represented anti-nuclear positions within the party system, and Chernobyl had the effect of completing its conversion to the anti-nuclear camp (Joppke, 1993, p. 181). In the month that followed the incident, the five SPD state premiers even agreed to abolish nuclear energy ("SPD agreed to end nuclear power in West Germany," 1986). Third, the Enquete Commission on Future Nuclear Energy Policy, created as an institutional body charged with analyzing different future energy scenarios, had began to provide evidence of the feasibility of a West German energy future without nuclear energy.

As mentioned above, during the acute phase, the anti-nuclear camp had the advantage of proposing action in the form of a moratorium or a phase-out. This helped nuclear opponents make their case in West Germany, and they could easily build narratives that took advantage of the reach of the social scare: the "what if" thought of another similar incident in the future came to be of great concern for a large portion of the population. This also helped anti-nuclear groups to continue their efforts in the postshock phase, as these narratives still had some effect even when the public anxiety that followed the event had passed. ${ }^{22}$ With the CDU-FDP coalition returned to power after the federal election of 1987, however, a short-term nuclear phase-out seemed unlikely.

\footnotetext{
${ }^{22}$ The Lower Saxony state election in June 1986, where the ruling coalition narrowly remained in power despite observers' predictions of a defeat linked their pro-nuclear stance, suggested that the nuclear fears had quickly receded. However the Greens performed well, and the national election of January 1987 saw them grasp $8.2 \%$ of the vote, an increase from $5.7 \%$ in 1983 . The CDU, the leading coalition partner and Chancellor Kohl's party, obtained its lowest result at the polls since 1949, but was able to remain in power given the good performance of the coalition's junior partner (FDP) (Jautz, 1987).
} 
Furthermore, one of the issues surrounding nuclear energy was whether conservation alone could compensate for the elimination of nuclear power. Although West Germany had launched aggressive conservation programs since the 1970s, it was clear to many that this would not be enough for a long-term energy policy. Coal reserves were declining, and although natural gas had played a rapidly increasing role in the energy mix, it suffered from the same security concerns that oil faced since the shocks of the 1970s. In this context, alternative energy sources looked increasingly interesting.

At least since the oil shock of 1973-74, an important advocacy coalition pushing for a shift to renewable energy in West Germany had existed and was strengthened by the overlap with nuclear energy opponents, especially in the aftermath of Chernobyl. The coalition was successful in obtaining modest funding for research and development programs in the early 1980s, and developed relatively cost-efficient technologies, notably in small hydroelectric projects and wind turbines (Jacobsson \& Lauber, 2006). When Chernobyl occurred, this coalition, bolstered by the recent technological breakthroughs in wind energy (and to a lesser extent solar energy), was ready to step into debates for a major shift toward renewables in West German energy policy. Once the debate over a nuclear moratorium or phase-out waned, they obtained support from the Greens, as well as rural MPs from both the CDU-FDP governing coalition and the SPD opposition (Laird \& Stefes, 2009; Lauber \& Mez, 2006). Consequently, this coalition was able to get access to political debates through backbenchers and rural MPs from parties across the ideological spectrum. Chernobyl was a symbol that groups pushing for alternatives to nuclear energy could use in their campaign. Given the limited options for the eventual 
replacement of nuclear power, the development of renewable energy sources (wind and hydro energy in particular) fitted into a narrative that portrayed it as the main viable option for the future of West German energy (even within the economic growth frame used by the pro-nuclear side). As is discussed in section 6.1 .5 below, this battle occurred in the period that followed the January 1987 election and eventually led to a shift to renewables in West German energy policy.

\subsubsection{The framing of uncertainty and risk, and the role of experts}

Three different categories of risk and uncertainty are discussed here. The first category pertains to the effects of the Chernobyl incident itself. The Soviet Union's reluctance to release information detailing the incident exacerbated the perceived insecurity surrounding the event (Patterson, 1989). Moreover, despite the West German government's reassuring stance that radiation levels outside of the Chernobyl zone remained low, the scare led to widespread anxiety in different regions. Joppke (1993), studying the anti-nuclear movement in West Germany, summarizes the situation in the days and weeks following the Chernobyl incident:

While the federal government still denied that any acute health risks existed for the population, several state and country governments issued emergency decrees, barred the sale of fresh food, and recommended that people stay indoors. Each state established different tolerance levels of radiation, thus heightening the general confusion. A true informational chaos reigned for several weeks - politicians and experts at odds in their 
evaluation of the situation and unable to calm the public hysteria. The political authorities failed to deliver what was needed most in view of the invisible threat: credible outside information. ... The federal government and its expert bodies, such as the Radiation Protection Commission, tried to minimize the impact of the accident to prevent what eventually could not be prevented: the questioning of domestic nuclear power. (p. 178)

Apart from the immediate safety impacts, high levels of uncertainty also led to widely varying information on the true, long-term health toll. Even a year later, estimates on the potential cancer rates that would be attributed to the event ranged from "in excess of 1 million cancer and leukemia cases" to a number of deaths in the twelve European Common Market countries that would be "too few to be detected" ("Experts differ on eventual Chernobyl toll," 1987). This uncertainty made it extremely difficult for the government to convince the West German public that nuclear power was safe and that no major shift in energy policy was needed. Furthermore, this also meant that arguments on energy policy options could use the nuclear issue very differently.

The second and related category of uncertainty included concerns about the risks of another incident occurring in the near to medium-term future. This was a situation where the potential risks of nuclear power were experienced directly by the population, where "the worst-case scenario, which the official risk assessments had relegated to the realm of improbability, became reality (Radkau, 1986)" (Joppke, 1993, p. 178).

For anti-nuclear activists, these two sources of uncertainty could be combined in arguments for different energy policy options. The wide variation in casualty estimates 
meant that for cost-benefit analyses built using worst case "what if" scenarios, the sky was virtually the limit. The uncertainty regarding these estimates meant that these groups could use wildly inflated numbers - or at least, the highest estimates - which during the years that followed the event resonated with the public and part of the political class, and could never be contradicted with authority. This points to the difficulty of debating these issues when no source of expertise is perceived to have enough legitimacy to trump other claims.

The third category of uncertainty pertained directly to the viability of having a West German economy without nuclear power. During the 1970s and early 1980s, the pro-nuclear side had argued with success that nuclear energy was an economic necessity. The importance of having nuclear power in the energy mix, and the likely economic impact of not having it, was enough to convince most of the political class and a large portion of the population that doing without it was just not possible. By the time of the Chernobyl incident, this had changed, however. The Enquete Commission aforementioned, created in 1979, had demonstrated that a future economy without nuclear power could be achieved without negative consequences for economic growth and living standards, and would even provide social advantages (Joppke, 1993, p. 128). ${ }^{23}$ Additionally, organizations such as the Freiburg Institute for Ecology provided academic expertise that made the critique of nuclear power legitimate and respectable (Joppke 1993, pp. 167-168).

\footnotetext{
${ }^{23}$ On this issue, the Federal Ministry of Research and Technology had commissioned a 5-year study that released its report coincidentally two weeks before the Chernobyl disaster. The report mentioned that not only was an alternative energy policy centered on renewables and conservation more compatible the basic values of a free society, it was also cheaper and as conducive to economic growth (Meyer-Abich \& Schefold, 1986, as cited in Jacobsson \& Lauber, 2006, p. 261).
} 
Contrary to the early years of anti-nuclear struggles then, voices that ran against the pro-nuclear expert opinion were heard in the policy process, and the public had come to give weight and credibility to information coming from these and other critical expert organizations (Peters et al. cited in Renn, 1990, p.160). But this was an important development for another reason. In the past, the debates had been between two camps "pitting unacceptable levels of risks against the indispensability of nuclear energy for economic growth and energy independence" (Joppke, 1993, p. 127). Because of the new legitimacy of the anti-nuclear expertise, advocates of alternative energy policy options, renewables in particular, could now fight fire with fire. In other words, their arguments and storylines could challenge nuclear power with cost claims, within the boundaries of the economic growth frame, adding only as a bonus the question of unacceptable risk. "Backed by the expert-proved feasibility of a nuclear moratorium, the voices calling for the phaseout of domestic nuclear power grew louder throughout the political parties, even within the ruling Christian Democrat" (Joppke, 1993, p. 181).

Two points stand out. First, the uncertainty associated with nuclear power in general, including the exact health impact of Chernobyl, the risks of having another of those incidents occur in the future, and the costs and benefits of abandoning nuclear power in West Germany, all combined to give ammunitions to proponents of alternative energy options. The uncertainty provided discursive space and flexibility in the storylines, making it easier to challenge the government's position. Even groups linked to the coal industry, such as the DGB (Confederation of German Trade Unions), a historical 
ally of the nuclear industry, came to ask for phase-outs (Schumann, 1986, as cited in Joppke, 1993, p. 182).

The second point is that "more" experts in this case certainly did not help settle the disagreements with regard to the risks and benefits of nuclear power. In fact, it seemed to have produced the opposite, where the multiplication of legitimate sources of expertise caused technical information to lose its primary importance. In other words, this information and the credibility of its sources were essential resources in the building of the different arguments, but did the opposite from rendering the debates technical. Instead, the debates remained in the public sphere as largely discursive battles: the expert information was both critical in the building of coherent narratives, and useless in attempts to settle disputes and determine the "right" course of action. I return to these points in the comparison section (6.3) at the end of this chapter.

\subsubsection{The impact of contextual factors}

The fact that the Chernobyl incident occurred outside of the West German territory provides an interesting aspect. During the acute phase, leadership in taking action to convincingly reduce insecurity is key. Consequently, one might be tempted to conclude that in a case like this, the constraint placed on leaders by the foreign nature of the triggering event should eliminate the possibilities for their taking action. In other words, it is very difficult to "own" the scare and take action to solve it. However, this would be a mistake: there is little difference between an incident happening beyond the (national) borders and having a direct impact in the concerned country, as Chernobyl in 
West Germany, and a natural disaster that was also out of the control of the government (as in the ice storm case) or a series of international political events that caused drastic changes in energy prices (as in the NEP case).

There is one exception, of course, in that natural disasters can be - at least in theory - prepared for. A convincing reorganization of state disaster management agencies could be seen as a valuable action by the public, but there is no satisfactory equivalent for an event like Chernobyl. This partly explains why the creation of a Ministry of the Environment and Nuclear Safety by the Kohl government seems to have had only a limited impact on the perceived insecurity. The West German government in this case was not able to reduce insecurity decisively.

Another contextual factor that shaped the debates and struggles over energy policy in the aftermath, particularly in the post-shock phase, was the energy situation in West Germany. The resource endowment made coal a declining source, and the still recent memory of the oil shocks of the 1970s kept energy supply security issues at the top of West German objectives. If oil was difficult to avoid for transportation, natural gas became a more difficult option to defend for electricity generation. To a large extent, this meant that slowly, the debate evolved over a choice between nuclear and renewable energy sources. In any other context the former would have seemed impossible to challenge by the latter, but the context of the social scare produced a long period over which these debates would remain, while the small research and development investments in renewable energy since the early 1980s made some technologies ready to 
take on conventional sources, provided that federal support would come for their deployment (see, for instance, Jacobsson \& Lauber, 2006).

Concerning the electoral landscape in the months that followed Chernobyl, the picture is less clear. The state election in Lower Saxony in June of 1986 provided mixed signals to all parties, as did the federal election in January of 1987. In the first case, Kohl allies managed to retain a thin majority despite predictions of a defeat linked to a Chernobyl effect, and in the second case, Kohl stayed in power despite his party obtaining its worst result since 1949, and the Greens obtained over $8 \%$ of votes. In addition to the fact that elections are often poor barometers for single issues, the sigh of relief pushed by Kohl after being reelected did not undo the anti-nuclear coalitions that Chernobyl had brought together. These coalitions would eventually grow strong enough to include even members of the ruling party, which brings us to a discussion about policy changes in the post-shock period.

\subsubsection{Resulting policy changes and conclusions}

The overall period of the social scare following from the Chernobyl disaster lasted for several years in West Germany, as lingering effects were observed well after the acute phase was over. Although panic and widespread public debates lasted for months following the incident, government leaders (Chancellor Kohl in particular) were unable to convincingly reduce the insecurity. Given the necessity to act in the acute phase due to the leadership curse, the government's largest concrete action was to create a new Ministry for the Environment, Nature Conservation and Nuclear Safety (BMU), a largely 
symbolic action that failed to win it a large rent. Capturing a larger rent meant taking actions unattractive to the Kohl government, given that its leadership preferred little change in policy on the nuclear energy front.

In this situation where no one was able to capture the political rent to its full potential (i.e., by reducing the insecurity in the acute phase with concrete actions), the topic of changes in energy policy (and in the West German energy mix more generally) remained high in public debates even well into the post-shock period. The negative symbols now associated with nuclear power could be used to push for an alternative energy policy, even if the sense of urgency felt in the immediate aftermath of Chernobyl was gone. As discussed above, the role of experts on the anti-nuclear side was critical in having the political class accept the viable possibility of a future without nuclear power in West Germany. This was further helped by the release of a report in late 1986 resulting from a five-year study by the Ministry of Research and Technology into the future of energy in West Germany, which concluded that nuclear energy was incompatible with the basic values of a free society (see note 23 ).

In this context, the post-shock battle was key. Advocacy coalitions, especially those associated with renewable energy, were able to provide a narrative that combined the security and environment frames (including policy options). This narrative became widely accepted and produced an opportunity for policy actors to push for change. However, it was the coalition building during both the acute and the post-shock phase that was critical in ensuring their success. 
For ideological reasons or by inadequate strategic calculations, the conservative CDU-FDP coalition government in place initially kept resisting the idea of broadreaching state support for renewable energy by implementing different research and development as well as market creation measures, most notably small hydro, wind and solar subsidy programs (Jacobsson \& Lauber, 2006). Also, after initial pressures by backbenchers of all parties in the Bundestag to introduce feed-in tariff legislation, the government attempted to get a voluntary commitment by the electricity sector to provide more favorable terms for renewable energy producers (Laird \& Stefes, 2009, p. 2622; Lauber \& Mez, 2004, p. 601). These small programs had the somewhat unintended effect of increasing support for these sources even in conservative (CDU) constituencies, with small hydro and wind projects obtaining high support with farmers and rural inhabitants, in largely conservative regions. With even its own rural MPs now lobbying for a new national energy policy, the government ended up reluctantly introducing what would become the Law on Feeding Electricity into the Grid (StrEG) at the end of 1990, the first major piece of legislation launching the large-scale deployment of renewable energy in West Germany (Lauber \& Mez, 2006).

Hence the debates following the Chernobyl incident evolved over the months and even years that followed April of 1986. At first the public anxiety produced a focus on nuclear energy itself, and government leaders failed to completely capture the prize that the social scare had created. In part this played in their favor, because the group's position was to try and change the national energy policy as little as possible, and in that way they certainly succeeded in doing so. However, this also illustrates the perils of 
managing a major social scare like Chernobyl without fully capturing the political rent: a new battle can emerge in the post-shock phase, where coalition-building can lead to major change. MPs from various parties were able to support the legislation and claim that they were doing so to both resolve the nuclear energy policy "problem" and help the future of the West German economy, especially in rural regions.

\subsection{Case \#4: The 1989 Exxon Valdez oil spill in the United States}

The Exxon Valdez oil tanker, on its way to Long Beach, California, struck Prince William Sound, Alaska's Bligh Reef on March $24^{\text {th }}$ of 1989. The tanker spilled around 11 million U.S. gallons of crude oil (Alaska Oil Spill Commission, 1990), and the magnitude and remote location of the spill complicated cleanup efforts. The spill is considered one of the worst environmental disasters in U.S. history.

This case study demonstrates that as for the previous Chernobyl case, the political rent was left largely un-captured at the end of the acute phase. However, the post-shock phase led to a different policy battle, one where groups that were dominant in the acute phase were able to force some level of policy change, but without any fundamental alterations to the national energy policy surrounding oil consumption and production. Instead, the changes enacted were confined within the parameters of the policy subsystem of oil transportation. 


\subsubsection{The triggering event and the political rent}

The Exxon Valdez incident produced the largest oil spill in U.S. waters until the Deepwater Horizon platform exploded in 2010. Because of its size and impact on the local economy and wildlife, the level of disruption of the event was moderately high, as images of the tedious and painfully slow cleaning attempts were broadcasted nationally in the days and weeks following the event.

The reach of the incident was limited, however, as the event occurred in a remote region. In order to sensibilize the U.S. population to the dangers of oil transportation and the alleged negligence of operating companies, attempts were made by environmental groups to display the event as inevitable in an economy based on oil, suggesting that another spill would eventually happen elsewhere, likely causing an impact far worse (more on this in the strategy section below). Nevertheless, this attempt was only partly successful, and the debates focused on environmental and oil transport regulation.

Several contextual factors also stand out in the political and social circumstances where the spill occurred. The first is the overwhelming role that oil plays in the United States economy. This is not to say that oil consumption is notably higher in the United States than in other OECD members or any large net-importing country, but the international responsibilities of the United States government and military, and its relationship with oil-producing states, made it without a doubt the key player of the consuming block in 1989. Following from this, it goes without saying that any move away from oil, in the American economy, would have been (and would still be) no small matter. 
Furthermore, at the time of the spill, the George H.W. Bush administration had just been elected for a four-year mandate, and the next Congressional election was more than a year and a half away. The electoral context was thus less of a factor in the debates that followed. It should be noted, however, that President Bush had courted environmentalists in his presidential campaign, and was thus elected under their wary eye, as they waited to see a real departure from the Reagan years.

More specifically to the sector directly concerned by the spill, oil transport regulation had faced a stalemate regarding reform that went back to the mid-1970s. Several attempts had been made to modify oil transport regulation, but had generally met with little success at the federal level (Kurtz, 2004).

Overall then, the Exxon Valdez spill comes as an example of a social scare triggered by an event in the oil sector. Media attention was acutely focused on the spill for the first few weeks, but continued to discuss it for several months. Hence debates erupted and continued over the potential environmental and social disasters that could occur in the future, and over what changes could be initiated to avoid these.

\subsubsection{Strategies and actions of the actors regarding the two objectives}

Although the political rent had the potential to be inflated, with the symbols of environmental and animal destruction shown repeatedly on television for weeks, no leader in the Bush administration attempted to capture it in the days following the spill. In particular, President Bush neither visited the site nor attempted to pledge major actions to reduce the insecurity, other than relatively plain and sparse statements on the incident. 
The spill and the social scare that ensued, in a context where the preferred course of action for the Bush administration was not linked to any major changes in energy policy, produced a situation where an inflation of the rent was too risky. This even entailed some level of loss for the administration, as efforts to step into the game - first by sending a team to assess clean-up efforts, then by ordering troops to help with it - were perceived as too little, too late (Shabecoff, 1989b).

This reluctance of the Bush administration to participate more actively during the first few days had the effect of leaving a vacuum for coalitions including the oil industry in general (and Exxon in particular) and environmentalists, who would then occupy a central position in debates that ensued. Given the political rent's relatively small size because of the moderate disruption and reach of the event, and of the absence of inflation attempts by elected officials - the environmental movement intended to use the symbols of the acute phase to convince legislators of the need to review a national energy policy centered on oil (Stevens, 1989). To a large extent, the task of defending the status quo was left to Exxon, and different strategies were tried. At first, Exxon pushed an accidental causal story, where the spill was depicted as an act of God, and was more specifically due to the calving of icebergs off glaciers that forced an unexpected route on the tanker. This storyline was difficult to defend, as the channel was still very wide and the icebergs could be avoided. In a second story, Exxon tried to put the blame on the tanker's captain, Joseph Hazelwood, who was intoxicated when the ship left port, and who was not on the bridge at the moment of the incident. This storyline was of an inadvertent cause, although to make this work, Exxon needed to distance itself from the 
captain. This was successfully rejected by environmentalists and their allies, "who asserted that Exxon knew of the captain's drinking problem, and that, in any case, Captain Hazelwood's drunkenness did not absolve Exxon of corporate responsibility (a conclusion reached by the courts as well)" (Birkland, 1997, pp. 96-99; see also Smith, 1992, pp. 89-91).

Environmental groups were bolstered by the spill as it quickly came to embody the hazards of oil, and they attempted to launch a discussion over energy futures and their associated environmental consequences, most notably on the opening of the Alaska National Wildlife Refuge for drilling (Boyd, 1989; Stevens, 1989; Wald, 1989). In order to make the U.S. population aware of the dangers of oil transportation and the negligence of operators, some groups attempted to portray the event as inevitable, suggesting that another spill would eventually happen elsewhere, likely causing an economic impact far worse (Boyd, 1989). In other words, in this narrative, this was an instance where recklessness by the transporter and the oil industry in general, in addition to the environmental dangers inherent to the use of oil, made the event an "expected" accident, something that was bound to happen and that would happen again. This causal story, buttressed by the symbols of environmental and animal destruction shown repeatedly on television for weeks (Smith, 1992, pp. 105-109), became part of the effort by several groups to convince legislators of the need to discuss action to reduce the economy's dependence on oil as a source of energy. As for anti-nuclear groups in the aftermath of Chernobyl in West Germany, environmentalists in this case used "what ifs" and pressed 
the argument that oil transporters were unable to confirm the absence of risk, which meant that these events were inevitable.

While this met with considerable success in the weeks following the beginning of the spill, in the post-shock phase environmental groups met with greater difficulties. First, the event had receded from media attention, which was now focused on other matters. Second, they found they could not take control of the legislative agenda as easily as they did the media attention. After all, having successfully made the case in the public about Exxon's negligence - and potentially other players in the oil business - they now faced the awkward position of having reinforced the idea that oil regulation was at fault. Even more, convincing a good portion of the public and even policy actors that negligence in oil transport could have disastrous consequences was one thing; but convincing a large portion of the political class that the United States should move away from the source of energy that was the backbone of their economy, especially given the virtually total dependence on it for transport, was an entirely different challenge.

\subsubsection{The framing of uncertainty and risk, and the role of experts}

Two main categories of uncertainty appeared in the debates that followed the Exxon Valdez oil spill. First, what were the chances of this kind of event reoccurring? What were the odds of this occurring in a more populated area? And how much of these risks could realistically be tempered by regulation on oil transport? Second, when considering alternatives to maritime oil transport, including using different energy 
sources, what were the economic, social, and political risks of moving away from oil and having energy policy attempt to spur this move?

In the debates that occurred in the first days and weeks following the spill, environmental groups put the emphasis on the inability of oil producers to assert the absence of risk when transporting oil. Since this could happen to one tanker, and given the immense and highly negative impacts of just one of those spills, the issue of the inevitability of other incidents in less remote regions was put forward with some success, as Exxon's inability to depict the event as an accident for which they were not responsible gave traction to these claims (Boyd, 1989; "Exxon reduced its staff of oil spill experts," 1989).

Rather than pointing out the problems of maritime transport, however, these types of "what ifs" were intended to spur debate over the country's reliance on oil as a major source of energy, and alternatives to oil were then presented on more solid grounds (despite other uncertainties that a future with less oil would entail) (Shabecoff, 1989a; Wicker, 1989). In the end, however, environmentalists and renewable energy proponents were not successful in going that far. Despite these arguments, Exxon and the oil industry were able to reduce the insecurity by both dispelling the uncertainty linked to oil transport - insisting successfully, at least in policy circles, that this was merely an issue of transport regulation - and emphasizing the risks (economic, in particular) linked to a shift from oil to other energy sources (Boyd, 1989). Although the policy changes that resulted ended a long-standing stalemate in oil transport regulation, the problem 
highlighted by the oil spill was restricted to the industry coalition's version, and could thus be solved by better regulation.

The question of the credibility of sources also had two angles. On the one hand, given the non-technical nature of the main event (a shipwreck causing the spill of its oil cargo), environmental groups managed to participate in the debates following the onset of the event. Moreover, they were a credible source of information - especially given the imagery relayed by the news media - as far as the environmental impacts were concerned. The oil industry in general, and Exxon in particular, had difficulty imposing their own take on the impacts when it quickly appeared that cleanup preparation and measures were grossly inadequate (Birkland, 1997; Smith, 1992, pp. 77-114).

On the other hand, however, this non-technical aspect of the triggering event gave more difficulty to groups trying to push for a revamping of energy policy. After all, it was "simply" a shipwreck, so stories and arguments about tougher regulation were easy to sell. This is an interesting point: in this case the story - that regulation was the solution was successfully sold by the actors with the least credibility in the aftermath of the event - i.e., Exxon and its allies. The causal theory of inadvertence, i.e. oil companies being negligent, did not imply that other actors needed to be turned to for credibility and advice about future policy. This is partly due to the fact that proponents of other sources of energy, in particular, were little known to the public at the time.

Given this limited scope in debates, the level of technicality of the underlying topic remained low, since very little discussion occurred on the possibility of fundamentally changing the energy consumption landscape in the country. Rather, the 
attention was turned to Exxon's responsibility in the disaster, to determine if it was guilty of negligence and what legal action could be undertaken, both on their conduct regarding what led to the wreck and their contingency measures in case of disaster. Consequently, the question became how much it should provide in the efforts to clean up and cover damages. In other words, in the end the main debates remained about the issue of pollution in oil transportation.

\subsubsection{The impact of contextual factors}

The Exxon Valdez oil spill occurred at the end of a decade that saw oil prices drop dramatically, making the cost of moving from oil to alternative sources higher. This compounded difficulties of groups trying to spur discussion on the possibility of fundamentally changing the energy consumption landscape in the country. Given the limited role that alternatives to oil had in the U.S. landscape at the time, no coalition was able to present a clear and convincing plan for a long-term energy plan that would diminish oil consumption drastically in the future, given the costs entailed by such an endeavor. In other words, as disruptive as the event was, the debates remained about the narrower issue of pollution in oil transportation.

As mentioned above, oil transport regulation had been facing a stalemate since the mid-1970s regarding a long-awaited reform. Several attempts were made over the 14 years preceding the spill to modify the regulation regime, with little success. This stalemate had an impact on the legislative battles to the extent that somewhat ironically, the fact that the regulation had not been reformed for a long time gave a legislative culprit 
on which to pin the event. Put differently, the legislative stalling could be portrayed as having had needlessly raised the risks of oil transport accidents, which had the effect of suggesting that the problem was indeed fixable with the ending of this stalling.

The type of political regime also needs to be discussed, especially since the government structure in the United States is very different from West Germany's. While the influence of the executive branch on the legislative process is considerable in the United States, there remains a separation between the two, and consequently the President has less power in introducing and passing legislation than in parliamentary regimes. However, this also means that the legislative process is particularly susceptible to influence by advocacy coalitions, given the multiple points of entry available to groups pushing for change (Howlett et al., 2009, p. 60; see also Besley \& Case, 2003). Consequently, given the legitimacy captured by environmental groups during the acute phase of the scare, it would suggest a possibility for them to introduce the larger issue of energy use in policy sub-systems other than transport regulation.

Finally, the election timing shielded the debates surrounding the event from substantial electoral pressures. No impending elections around the time of the spill meant that public opinion was less of a threat for the President and for members of Congress. As a result of this and of the refusal to maximize the rent by leaders from the Bush administration, the spill had mostly an agenda-setting effect on the battle of interests. 


\subsubsection{Resulting policy changes and conclusions}

Apart from the notable impact that the Exxon Valdez spill had by forestalling oil exploration of the Alaska National Wildlife Refuge (Birkland, 1998b), the most important policy change that emerged in the aftermath was the Oil Pollution Act of 1990 (OPA), introduced in both houses of Congress shortly after the spill, which expanded the federal government's ability and financial resources to respond to oil spills. Moreover, the OPA imposed new requirements on both the government and companies to prepare and plan for contingency, in order to avoid and if necessary minimize the environmental impacts from oil spills in the future (U.S. Environment Protection Agency, 2011).

As mentioned earlier, the passage of the legislation ended a 14-year stalemate on oil transport regulation reform, which made it an important policy change in that area. Prior to the incident, oil spill regulation consisted of fragmented and inconsistent laws and regulations, with legislation from two main federal statutes and several state and local laws regulating oil spill recovery, cleanup, and liability (Marquiss, 2007, p. 10). Simultaneously, however, the OPA is also a legislation very narrowly built around the problem of oil spills, and hence constrained to the specific question of oil transport regulation (Birkland, 1997, pp. 74-105). The spill did not lead to any expansion of the issue outside this interpretation of the underlying problem.

For government officials, the OPA 1990 provided an opportunity to capture what was left of the rent, by attempting to convince the public that the regulation solved the spill risks problem. President Bush, in particular, tried to take back the lead (Cushman, 1989). This remained a small part of the original rent, however, as the prize diminished 
rapidly in size once the spill had receded from media attention - that is, once the acute phase was over (see section 2.2.3). Attention was mostly turned to Exxon's responsibility in the disaster, to determine if it was guilty of negligence, both in their conduct regarding what led to the wreck and their contingency measures in case of disaster, and consequently how much Exxon should provide in the efforts to clean up and cover damages. Environmental groups were the main voice of discontent in the face of Exxon's responsibility in the spill, and the initial reaction and public relation strategy of Exxon to try and sell this with an accidental storyline ultimately failed.

Regardless, however, environmental groups were never able to convince that this was more than a regulation problem, albeit an important one. When discussions shifted to policy solutions, environmental groups and their renewable energy allies tried to extend the causal story of inadvertent effects. In that version, it was not just that the spill was inevitable given Exxon's negligence, but Exxon's negligence itself was inevitable given the structure of energy production and consumption - and thus of energy policy - in the United States. This was a much more arduous sell, and the oil industry shifted the focus on the uncertainty associated with any move away from oil, in particular economic concerns and performance and costs uncertainties related to alternative sources of energy. In the end, these groups were able to restrict the debates to the initial inadvertent causal story, which constrained discussions to changes in regulation for oil transport. As a result, and although Exxon was unsuccessful in its attempt to portray the incident as a series of misfortunes (or as a problem of personal responsibility, for instance that of the tanker's captain), discussions never moved passed the fundamental issue of oil transport safety. 
The primary conclusion that emerges out of this case is that although the rent was left on the table by the federal government in the immediate aftermath of the spill, this strategy was consistent with the policy debates and changes favored by leaders of the executive branch. Since an inflation of the scare would have entailed debates about alternatives to oil that were riskier from the government's position, leaders from the executive branch were satisfied with losing some control on the actions of coalitions during the acute phase. While this resulted in an increase of symbolic capital for environmental groups, this was not enough to have influence over the battle of interests that followed to obtain any major transformation of energy policy, except in the pressure for regulatory changes in oil transport. Although the environmental coalition was able to participate actively in policy debates (Kurtz, 2004), their interventions were mostly constrained to the pollution issue, and thus centered on finding the culprits, which reinforced the status of the incident as a tanker safety issue rather than a fundamental policy failure. The policy regime attached to oil was left untouched, and opposition voices were not able to get enough allies within the policy subsystem (or to use other strategies such as venue shifting) to broaden the scope of the discussions. In the next section, I expand on these issues and provide a comparison of these different insights with those from the Chernobyl case.

\subsection{Comparisons between the two cases}

As done in Chapter 5, I continue here the description by comparing the two cases with each other, with the objective of determining what the main differences and 
similarities are between two cases where a triggering event did not lead to a maximizing of the political rent by leaders from the executive branch.

\subsubsection{The triggering event and the political rent}

The triggering events of these two cases share several similarities: they both fall into the category of industrial accidents; they were both entirely perceived as "manmade", as they were caused by a combination of human negligence and the societal decision to use a particular technology and energy source; and the immediate vicinity of the accident went through a cleanup period that lasted for several months. At first glance then, the events themselves seem to be of the same type.

However, they differed significantly in certain aspects. First, in the West German case the event itself occurred beyond the national territory, while in the U.S. case the tanker spilled within domestic waters, although in a location distant from the mainland. Second, the level of disruption and the reach were both higher in the Chernobyl case. For various reasons described in 6.1.1 and 6.2.1 above, the Chernobyl incident created an intense acute phase in West Germany, both because of the panic and anxiety over what the health impacts would be, and because the measures taken by various levels of government to deal with the risks involved touched a large portion of the population. In the Exxon Valdez case, the reactions over the environmental impacts of the spill were mostly of outrage, but not of personal safety concerns.

Looking at the rent as resource hypothesis $\left(\mathrm{H}_{1}\right)$ to see whether the rent was helpful in securing a preferred policy outcome, there is some support found in these cases 
even though the situation is different from Chapter 5, where key actors of the executive branch managed to win a large rent. In the Chernobyl and Exxon cases, executive branch leaders only partly did so, and chose instead to forfeit a larger win that would have implied more substantial policy changes. The former saw Chancellor Kohl try to downplay the scare, thereby attempting to reduce the size of the rent, and the latter saw the President play a somewhat self-effacing role during the acute phase, delaying action.

According to $\mathrm{H}_{1}$, when executive branch leaders manage to win a large portion of the rent, they are more likely to get their preferred policy outcome, other things being equal. The two cases here show support for a corollary $\mathrm{H}_{1 \mathrm{~b}}$ : when executive branch leaders do not manage to win a large portion of the rent, other actors are more likely to influence the policy outcome, other things being equal. In the Chernobyl case, although state-level parties close to the Kohl coalition won the state election in June of 1986 and Kohl's coalition got reelected in the next general election, the drop in support shown in both elections suggest that the Chancellor was not able to capture the bulk of the rent. In the years that followed, and despite the majority coalition government's control over the legislative process, anti-nuclear groups and renewable energy proponents managed to build a coalition strong enough to influence the legislative process, using the Chernobyl disaster as a centerpiece of their strategy. In the Exxon Valdez case, environmental groups got widespread recognition at the national level for their role in the relaying of images, information and criticism during the acute phase of the spill, and did participate in hearings on policy held in the aftermath (Kurtz, 2004). They did manage to obtain substantial changes in the regulation of oil transport, but not more radical changes. 


\subsubsection{Strategies and actions of the actors regarding the two objectives}

The Chernobyl case shows support for the compatible strategies hypothesis $\left(\mathrm{H}_{2}\right)$, that is, that arguments and narratives used to capture the rent follow from the group's preferred policy outcome. In the case of the Kohl government, the favored policy outcome quickly emerged as an absence of change to energy policy, especially in relation to nuclear energy. The actions and narratives put forward by the executive branch and its allies reflected these preferences and beliefs, with most communications in the acute phase and thereafter reasserting the soundness of the West German nuclear technology (Done, 1986), the extremely small risks of nuclear energy (Hatter, 1986), and the economic necessity of the technology (Tomforde, 1986). The leadership curse, however, made it difficult for them to pursue this course of action without being perceived as not being active enough in the face of the scare, and as a result they resorted to the creation of the BMU. This choice meant foregoing a large part of the rent, however. Anti-nuclear groups faced a substantially more favorable context, since they could say that they were proposing measures to concretely reduce the insecurity linked to nuclear energy - i.e., a moratorium or phase-out.

The evidence of support for $\mathrm{H}_{2}$ in the Exxon case is more limited. First, actors from the (federal) executive branch scarcely participated in the debates during the acute phase (especially in the first few days), only claiming that this was an accident. Second, actors from the oil industry were facing a very difficult position, needing to defend the status quo. The most telling set of actors is the third one, environmental groups. Their strategy was centered around a narrative that put the blame on negligence in the oil 
industry, and they emerged as legitimate actors in their efforts surrounding the cleanup efforts. This allowed these groups to capture some symbolic capital out of the events, but it also illustrates the limits of a strategy for the acute phase that lacked allies in key elected officials who would be able to capture the rent. Without a corresponding level of support in the high leadership of the government or the opposition during the acute phase, and without the building of further support during the post-shock phase, it becomes very difficult for these groups to obtain any major changes. These difficulties come in contrast with West Germany's renewable energy proponents, where support in the legislative branch was cultivated and grew during the post-shock phase of the Chernobyl scare.

Hence both cases show a forfeiting of the opportunity to capture a large political rent by the national executive branch's main actors. The Chernobyl case also shows the difficulty of holding a position where no change is preferred when facing a scare with a large political rent. Despite the framing possibilities, scares come with some characteristics that constrain framing attempts, and in this case the levels of disruption and reach were too high to successfully let attention to the issue wane. For anti-nuclear activists, the context was substantially easier to begin with, given that their preferences allowed for propositions of "action". Both cases also show difficulties for subnational (state) actors to step in and capture the rent, an aspect I return to in Chapter 7.

\subsubsection{The framing of uncertainty and risk, and the role of experts}

The Chernobyl case presents a situation where the highly technical aspects of the triggering incident exacerbated the problems in interpreting and evaluating uncertainties 
linked to the underlying topic of the scare. In theory, this was a situation where a highly technical matter could be discussed with a paramount role for scientific information, given the expertise on both sides now that anti-nuclear groups had established their own credentials. This could be a series of debates on both the risks of nuclear energy and its economics, with highly knowledgeable participants on both sides.

In practice, however, a very different situation occurred. On the health impacts, the uncertainty related to estimations meant that no one was able stand out, and consequently expertise became somewhat inconsequential in the debates. At the same time, however, this also meant that basically anything could be claimed with regard to the numbers involved, from virtually no impact to wildly inflated estimates. As a result, antinuclear groups played up the uncertainty in their arguments, while actors from the government's executive branch tended to present the accident as an anomaly, which supports the uncertainty played up/down hypothesis $\left(\mathrm{H}_{3}\right)$. The uncertainty provided discursive space and flexibility in the storylines, making it easier to challenge the government's position. This is thus a case where expert information was both critical in the building of coherent narratives, and useless in attempts to settle contentions and determine the "right" course of action. Technical information, which should probably have been at the center of these debates, lost its primary importance.

In the Exxon case, fears of other similar accidents were played up by environmental groups to highlight the potential imminence of another spill. According to some of these groups, this suggested that major changes were necessary to prevent other catastrophes, starting with a tightening of oil transport regulation, but expanding to 
alternatives energy sources. For the oil industry, the certainty about a future similar to the present, with oil still playing a large role, was an argument for the status quo and for regulation adjustments (rather than any radical energy policy changes to move away from oil). This fits with $\mathrm{H}_{3}$.

The battle between experts of all sides during the Exxon spill case was also indeterminate, with no clear winner. In a way, the oil industry was the main beneficiary of this absence of winners, because this meant that by default, the status quo associated with the policy regime would remain, after adjustments to transport regulation. What this case brings out is that although the use of experts is central in getting the credibility of story lines and arguments accepted, it is not clear what the end result is when the debates occur at different levels. In other words, experts from environmental groups had more legitimacy when discussing the damage of the spill, but oil industry experts dominated the delineation of the battle related to energy policy.

With regard to the legitimate sources of information, the confused and diffuse leadership from Exxon executives contributed to their difficulties in the first phase of the debates. Paradoxically, this happened despite the low level of technicality of the triggering event, and still produced a result similar to the Chernobyl case, that is, a failure for government actors to convince the public of the superior legitimacy of their information. Nevertheless, the non-technical aspect of the triggering event (a shipwreck) countered the uncertainties in attempts to build narratives about the necessity reduce dependence on oil. The exact opposite happened in the Chernobyl case, as problems in 
defining clearly the impact and implications of the accident itself made alternative visions of the future, associated with different energy options, easier to defend.

\subsubsection{The impact of contextual factors}

With regard to contextual factors, several aspects of these two scares can be considered. First, the fact that the triggering incident occurs outside of the country's borders does not appear to have a determinant effect, having had a limited impact on the debates. Second, the perceived necessity of the concerned energy source (economic growth frame), in these cases nuclear energy and oil, appear important but malleable. It could be argued that in the Chernobyl case, alternatives were easier to find for nuclear electricity than for oil in transportation, the chief concern of the Exxon case. Looking more closely, however, West Germany's electricity options were seen by many - notably the Kohl government - as extremely limited, and nuclear energy had been enshrined in national energy policy for at least a decade prior to the incident. Hence while options akin to an oil moratorium or phase-out in the Exxon case were hardly realistic, this difference to the West German's nuclear situation should not be overstated.

Looking more specifically at the two hypotheses, $\mathrm{H}_{4 \mathrm{a}}$ (election looming) relates to the electoral context and states that an election planned during or very shortly after a scare diminishes the advantage held by actors from the executive branch. While the state election in June of 1986 did cause some concern for the Kohl government, both cases

present situations where the electoral context provided some room for manoeuver for the national government in place. The Kohl government did not have to think about re- 
election for another seven months, hence the leadership curse was not exacerbated by electoral considerations. In the Exxon case, the Bush administration had just been elected for four years, and members of Congress and of the Alaska gubernatorial administration were not facing re-election for another year and a half. This confirms the relatively short window created by the scare to capture a political rent.

The second hypothesis, regime type $\left(\mathrm{H}_{4 \mathrm{~b}}\right)$, states that actors from the executive branch will hold a stronger position with regard to policy options when also controlling the legislative process. In the Chernobyl case, Chancellor Kohl was heading a majority government in a parliamentary regime, although within a two-party coalition. This ensured virtually total control over the legislative process, and the Kohl government limited changes to ones it found acceptable, keeping nuclear energy policy, in particular, mostly intact. In the Exxon case, the level of control of the executive branch over the legislative process, while substantial, was considerably lower, given the United States' presidential regime. In combination with Bush administration leaders' reluctance to lead decisively in the acute phase, this provided an opportunity for a large influence for outside groups. These were indeed able to participate actively in policy debates through Congressional hearings, and although radical changes favored by some did not go through, the pressure they put on legislative actors for major changes in the regulation of oil transport did produce results.

Finally, the Chernobyl case also illustrates that control over the legislative process is not everything in the context of a social scare and its aftermath. While the Kohl government enjoyed a large degree of control over changes to energy policy in the years 
that followed the Chernobyl incident, the pressure built from a broad coalition that regrouped opponents to nuclear power and proponents of renewable energies. The main difference with the Exxon case is that these groups found progressively more allies in parliament, even eventually within the government's coalition itself, leading first to small programs for alternative energy sources, and then to more pressure to provide a largescale program to introduce these sources into the country's energy mix.

\subsubsection{Resulting policy changes and conclusions}

Overall these two cases illustrate limits to the usefulness of trying to classify types degrees of policy changes as atypical versus normal. Instead, policy changes in the Chernobyl and Exxon cases can be described as major, but the process leading to them differed substantially. In the post-shock phase of the latter, one policy solution quickly emerged as viable and appropriate: a revamp of oil transport regulation, including a new scheme for cleanup liability, had been discussed several times within the policy subsystem in the 10 to 15 years prior to the oil spill. Consequently, there was a readily available policy solution to the scare that could be put forward by the Bush administration and by legislative actors in response to pressures from environmental groups, one that would appear to reduce the insecurity regarding future similar events.

In the Chernobyl case, policy options put forward by the Kohl government were not able to eliminate the fears related to nuclear power. The creation of a ministerial department dedicated to nuclear safety and environmental concerns did not match the stigma associated with nuclear energy following from the incident (and containment 
measures taken during the acute phase), and as a result the issue remained within policy circles for years. In particular, the ability of renewable energy proponents to enlarge their advocacy coalition by incorporating legislative actors of all stripes enabled them to obtain major changes to energy policy, even if the coalition government was largely opposed to them. This comes in sharp contrast to groups calling for a push for oil alternatives during the policy debates following the Exxon Valdez incident.

\subsection{Conclusion}

These two cases provide additional information concerning the unfolding of social scares around the energy sector. In cases where the political rent is not successfully captured by leaders from the executive branch, other groups can compete aggressively for influence in the policy debates that follow, producing risks for groups in power, despite their level of control over the legislative process. Moreover, this is not limited to the immediate aftermath of the acute phase, as the Chernobyl case demonstrates that policy debates around the scare can linger for several years following an incident. This process is limited, however, by these groups' ability to get allies within the executive and legislative branches to relay their policy options.

Additionally, a few more factors are highlighted by the cases. First, as expected from the framework, it seems very difficult to win the rent when a group's preferred option is to enact little change, unless it is somehow possible to take strong action despite the absence of follow-up (as in the Quebec ice storm case). If the acute phase does not allow this group, actors from the executive branch in particular, to be perceived as 
sufficiently "doing something", the opportunity associated with the rent will be lost, with consequences for the policy debates that will ensue. Second, the influence of experts and their use of technical information, in cases where the underlying issue is highly complex, is tempered when both sides of the debates have some degree of legitimacy and credibility with this expertise. This technical debate, far from settling disputes over the different sources of uncertainty related to the scare and to possible solutions, instead broadens the possibilities for framing attempts. These factors, and the ones highlighted at the end of Chapter 5, are discussed for all four cases in the next chapter. 


\section{Chapter 7}

\section{Additional comparisons and a typology of social scares}

The case studies presented in Chapters 5 and 6 provide detailed information on the different aspects of the social scares they illustrate, as well as a first step of comparison between pairs of cases. In this chapter, I continue this comparative analysis by including all cases at once. Some of the items discussed were mentioned in the paired comparisons done in Chapters 5 and 6, but are considered here with different combinations of cases. Other items are new, and come out only when considering the four cases altogether.

To ensure consistency and facilitate the links with the analysis done in the previous two chapters, I use again the list of investigative questions to structure the discussion. Then, I develop a typology of social scares that comes out of all these comparisons.

\subsection{The triggering event and the political rent}

The four cases studied suggest that we should focus on a few aspects of the triggering event and the possibility to capture a political rent in the early stages of a scare. A first aspect is concerned with the dimensions of disruption and reach discussed in the previous chapters. To reiterate, the level of disruption is the perceived departure from what is considered to be the normal state of affairs. The reach represents the breadth of the potentially affected population, in other words the extent to which a larger group feels threatened by the scare. 
With regard to the level of disruption, the symbols associated with the scare and its triggering event seem important, in particular the issue of whether the triggering event echoes the recent past. These symbols matter because they influence how people logically draw inferences about the meanings, risks, and dangers linked to the triggering event. In the NEP case, for instance, a similar scare had occurred a few years before, and many of the forthcoming discussions had already happened or were still ongoing. The same can be said for the Chernobyl case, because of a decade of protests and debates over nuclear energy, and because of the Three-Mile Island incident seven years before. This is less so for the Ice Storm and Exxon Valdez cases, where debates over the soundness and resilience of the electricity distribution network and of the oil transport sector had been (mostly) out of the public domain for over a decade.

These symbols help determine whether the topic is going to be treated as "new" or not, which in turn impacts the ideas present in policy debates. In the NEP case, for instance, the 1973-74 oil crisis had triggered discussions over policy solutions to security and price concerns linked to oil, so some of these were now ready for a try. The same thing can be said of the Chernobyl case, where small coalitions had made progress with possible alternatives to nuclear energy. As in the NEP case, these potential solutions to the problem of relying on nuclear energy were in their infancy, but they existed and were building momentum. Contrast this with the Exxon case, where the idea of getting away from oil in transportation was largely perceived as an impossibility, despite some modest successes by early corn ethanol programs in the 1980s. 
Finally, the level of disruption is certainly affected by the visibility of some symbols. During the Ice Storm and Exxon cases, the images relayed by the news media illustrated the spectacular side of the triggering event, although in the later case this was tempered by the low reach of the incident (more on this below). In the Chernobyl case, some visible symbols were also available, as the news reported the cleaning of cars entering the West German territory for radioactive dust, and some images of the nuclear accident itself were broadcasted. In the NEP case, these symbols mostly came from news reports of shortages in the United States (including queues at gas stations). The level of disruption thus needs to be evaluated not just in terms of the number of dead or injured, or by the financial amount of damage, but also in terms of the visible aspect of the symbols that accompany the triggering event, as well as their cultural resonance (especially the link to similar past events).

The reach variable is important because of the worries to personal safety: if the reach is broad, a larger group of people feels directly and personally threatened by the scare, even if the triggering event is over and did not affect them. The Chernobyl and NEP cases represent a broad reach, whereas the Exxon case was perceived as isolated geographically, and as a result the threat to the rest of the United States population was hypothetical. The Ice Storm case is somewhat in between, where the group of direct victims was very large (nearly half the population was out of electricity for at least a few days), but where the threat to the rest of the population remained hypothetical.

A second aspect of this first section relates to the question of whether the notion of a "type" of cause - catastrophe versus natural disaster versus industrial accident, for 
instance - for the scare can really be useful for understanding the political and policy outcomes of such periods. In regard to the four cases studied here, this notion seems misleading, at least as it has been described and used by others before (see for instance Birkland, 2006). From the analysis done in this project, two characteristics really stand out. The first is whether the source cause of the triggering event is seen as external or not. Since the first dimension of scares is a political battle that is focused on the reputational aspect of leaders in power, many of the actors involved end up arguing about the responsibility of the current leaders over this triggering event. If the leaders win this struggle and the general public perception is that the scare was at least not caused by something they did, they should be in a better position to capture the political rent. If they are not, however, and adversarial coalitions convince the public that the scare was linked to actions (or inaction) taken by the leaders in power, then capturing the rent will be a substantially more contested battle.

The NEP and Chernobyl cases, for instance, despite displaying important differences in their triggering events, were both instances where the perceived source of the triggering event was foreign. In other words, the distance between the event and the society concerned by its impact (for our analytical purposes, at least) could be used by leaders in power as a way to take control of the scare. The point, however, is that this notion needs not be restricted to a territorial one: the 1998 ice storm was undeniably local, but it could still be treated as "external" given its natural cause. The key factor for the government during the Ice Storm case was to be able to prevent a public perception of the scare as somehow man-made, and the leaders successfully managed to push forward 
the entirely "natural" cause of the events - despite arguments made that Hydro-Quebec policies had made its impact much worse that it could have been.

In the end, there is little difference between these three cases as leaders in place could in theory take control of the scare, and this was done well in the Ice Storm case, less so in the Chernobyl one, and even worse so by the Conservative government in the NEP case (the opposite is true if considering the opposition Liberals). So the distinction of the type of triggering event, as was discussed in Chapters 1 and 2, may be a misleading way of looking at these: the importance relies in the capacity of the different actors to take control over the debates over the scare, and this is largely shaped by how external the cause of the triggering event is perceived, as it produces different possibilities for pointing the blame.

A third aspect of the triggering event is whether the acute phase could be clearly delimited in time. Every scare eventually wanes, but some acute phases are more clearcut than others. Whereas the Ice Storm and the Exxon spill cases had a defined period to their triggering event, a situation like the NEP case meant that the perception of insecurity and the heightened public attention can be re-confirmed or re-emphasized at different points in time.

Finally, the last aspect I discuss relates to the rent as resource hypothesis $\left(\mathrm{H}_{1}\right)$ and the capture of the rent. The hypothesis states that executive branch leaders who manage to successfully capture the political rent should have more facility in securing their preferred policy outcome. The NEP and Ice Storm cases support this, with the qualifier that electoral context and the type of political regime were important. Analytically, 
applying this framework needs to be done with care on this aspect: in considering the rent to be whatever political capital was won by actors who got what they wanted, this could lead to a tautological trap. The bottom line seems to be that efforts should be put on measuring the rent's size (regardless of the exact manner in which it can be captured, which can vary depending on the context) and on distinguishing clearly between the reputational aspect of the acute phase and the policy battles of the post-shock phase.

As explained in Chapter 6, the Chernobyl and Exxon cases show support for the corollary $\mathrm{H}_{1 \mathrm{~b}}$ : when executive branch leaders do not manage to win a large portion of the rent, other actors are more likely to influence the policy outcome, other things being equal.

\subsection{Strategies and actions of the actors regarding the two objectives}

The strategies and actions of actors and coalitions in both the acute phase and its aftermath are constrained in various ways. A first of these constraints is the uncertainty regarding the length of the acute phase. As discussed in the previous section, in some cases it is obvious to both the public and political actors that the acute phase will end at a specific moment in time. This constrains the strategies of coalitions, especially actors in power. In the NEP case, it was impossible to say when the scare would end (or at least when its most acute effects would), while in the Ice Storm case everyone knew that at some point, it would be completely over (when the repairs would be completed). In cases like the latter, the elected leaders must take action to get through the acute phase, with a 
specific end in sight, which makes it possible to take actions related just to this phase. In other words, there is a clear delineation between the acute and post-shock phase.

Then there is a communication aspect: for leaders in power, the issue quickly becomes a matter of being able to demonstrate their actions during the acute phase. In the Ice Storm case, the strategy of the daily press conferences presenting the two leaders as "hands-on" worked toward having this effect. In the NEP case, it was more difficult, although the electoral campaign provided the visibility needed to make concrete statements about the scare, with the liberals having the upper hand in controlling the message. But more to the point, leaders in power need to demonstrate the impact of their strategy: in the Ice Storm case, it was also possible for them to "show" the repairs being done, something unavailable to leaders during the NEP case.

A third constraint is the one faced by subnational actors. In major social scares, it is more difficult - although by no means impossible - for subnational actors to capture the rent. The visibility of national leaders, and their determination in seizing the opportunity to get the reputational prize in the acute phase, makes them difficult to compete with for actors at lower jurisdiction levels. It remains a possibility, however, as some local or provincial leaders are able to get a major part of the attention, as Premier Bouchard in the Ice Storm case. Nevertheless, some questions remain as to why the Alaskan governor during the Exxon case was not able to do the same. The fact that statelevel authorities were overwhelmed with the task of dealing with the spill (i.e., without federal help) is an inadequate explanation, since the Quebec government did need the help of the Canadian army sent by Prime Minister Chrétien. Outside of the four case 
studies, we have seen cases of mayors capturing a large share of the rent, for instance Rudolph Giuliani in New York City after the 9/11 attacks, or Naheed Nenshi in Calgary after the Alberta floods in 2013, so perhaps additional cases could yield some interesting insights on this matter.

The fourth factor having an influence on the possible strategies of actors is the degree of institutionalization of opposition coalitions. When the scare is triggered, the readiness of advocacy coalitions is critical if these groups want to come out of the scare as winners. One difference between the Chernobyl and Exxon cases, therefore, was that the (anti-nuclear) opposition coalition in the former was largely institutionalized, meaning they were both inside and outside of the political system. They had declared allies in the SPD (main opposition party), in the growing Green Party, and in the scientific community. This helped them considerably in making their case.

The Exxon oil spill case, by contrast, showed an environmental coalition that did gain some symbolic capital through their efforts during the acute phase. However, without an important ally capturing the political rent, and with limited support in the legislative arena, attempts at obtaining their preferred policy outcome met important obstacles once into the post-shock phase. In the end, coalitions need important allies within the executive and legislative branches, which was problematic for groups pushing for modifications to energy policy not limited to improved transportation regulation. The Exxon case also shows that the strategy of emphasizing the recklessness of the oil transport industry painted members of this coalition in a corner for the post-shock battle, 
because it became difficult to argue the need to move away from oil; in other words, framing has its limits.

A fifth constraint relates to the past position of the different political groups with regard to the issue associated with the triggering event. If the issue is already politicized i.e., if the issue is not new in public debates - then the leaders in power are very likely associated with a specific position thereon. This can put them in a difficult spot if this happens to be a position that favors the status quo. In the Chernobyl case, for instance, the issue had long been politicized, and the Kohl government was clearly on one side (nuclear energy). In the Ice Storm, this was less clear, as the last time a storm caused damage of this magnitude occurred several decades prior to 1998. This meant that the slate of public debates on the resilience of the electricity network to major ice storms was clean, which allowed more flexibility in the leaders' strategies.

Finally, a sixth and related aspect is the difficulty for leaders in power to deter debates on policy changes during a social scare. As the Chernobyl case illustrates, when the levels of disruption and reach of the triggering event are high, it is virtually impossible to play down the scare. This exemplifies the leadership curse, as the Kohl government tried to appease the public and opposition with largely symbolic measures and claims, with limited success. The Kohl government's strategy was to contrast the current risk of nuclear energy against another potential catastrophe, that is, the "total economic annihilation" that would result if West Germany abandoned this source of energy. In other words, it was not merely that he needed to "do something", he actually needed to act in a manner that would appear to be decisive enough to reduce the 
insecurity. Short of a nuclear phase-out (or at least a temporary moratorium on new plant construction), it seems that there was nothing convincing enough that the Kohl government could do to fully satisfy public anxiety on the issue. At the other end of the spectrum, the Ice Storm case shows that it is possible for leaders in power to have a strategy that enables them to completely curtail debates over major policy change. The case also suggests, however, that only a particular type of strategy, and only its total success, can achieve this: the communication strategy during the acute phase allowed the Bouchard-Caille team to control the evolution of the debates. Importantly, this was partly dependent on the uncertainty linked to the level of technicality of the topic at hand, as ice storms seemed easier to grasp for the public than nuclear accidents (more on this below).

All these factors lead us back to the compatible strategies hypothesis $\left(\mathrm{H}_{2}\right)$, which states that the arguments and narratives used around the capture the rent follow from the group's preferred policy outcome. Put differently, there should be a correspondence between coalitions' strategies in each of the acute and post-shock phases. Actors and groups are thus more likely to use a strategy regarding the political rent that is compatible with their preferred policy option(s), even if this means that elected officials forfeit a large part of the rent.

All four cases show evidence supporting this hypothesis. The Exxon case in turn shows the downside of a strategy where a coalition - here, environmental groups neglects entirely the capture of the rent by a government or opposition ally. In the very different NEP case, the Liberals needed a large policy change to capture the rent, and they remained short on details during the campaign - thus for the capture of the rent - 
which gave them some flexibility afterwards. The Ice Storm case also supports $\mathrm{H}_{2}$, as the communication strategy allowed for a stance on policy changes - or rather, the absence thereof - favored by the government and Hydro-Quebec.

\subsection{The framing of uncertainty and risk, and the role of experts}

The third dimension I focused on in the case studies was the interplay between uncertainty and risk, experts, scientific information, and framing attempts by different groups. Discussions related to the perception of insecurity triggered by the scare largely revolve around different sources of uncertainty that are brought to the forefront of public debates. In this section I build on the items mentioned in the corresponding sections of Chapters 5 and 6, in order to analyze how it is exactly that "uncertainty" - in the broadest possible sense - impacts the public and policy debates, including the strategies and performance of the coalitions involved.

A first aspect to discuss relates to the credibility and acceptance of the information provided not only by leaders in power, but also by outside groups. In a case like the Ice Storm, for instance, the information provided by Hydro-Quebec (and the government) was treated more often that not as true and mostly correct, but this was not so in the Exxon and Chernobyl cases. The question of who speaks with dominant authority, or even whether there is one source of information that dominates, is critical in determining the framing options available to the actors involved.

As a general rule coming out of all the cases, an increase in the quantity of information, as well as an increase in the number of experts participating in the public 
debates, increase the uncertainty over the issue(s) and confuses more that it clarifies the discussions over what should be done. Ironically but somewhat unsurprisingly, too little information produces a similar increase in uncertainty, as demonstrated by the first few days of the Chernobyl scare, where the withholding of information by the Soviet Union over what exactly had happened produced widely varying claims.

The intersection between the scientific arena (associated with the issue underlying the scare) and the policy world is a complex one (see Chapter 3), and the cases presented do shed some light over the importance and impact of experts in these debates, although the evidence on the use of experts is not conclusive. Looking at the Ice Storm case, the use of experts was prominent in Hydro-Quebec's public relations strategy, where the leadership of President Caillé allowed him and his closest spokespeople to claim sole legitimacy over expertise during the scare - expertise on the problems, the ways to repair them, and solutions needed for the future. This leadership was successful in eliminating the perception of uncertainty in the population, as well as the insecurity it created. Contrast this with the Exxon case, where we see a battle between experts of all sides that was more indeterminate, with no clear winner. In a way, the oil industry was the main beneficiary of this absence of winners, because this meant that by default, debates and changes would remain within the boundaries of transport regulation. What this comparison brings out is that although the use of experts is central in getting the credibility of story lines and arguments accepted, it is not clear what the end result is when the debates occur on different aspects. Experts from environmental groups had more legitimacy when discussing the damages of the spill, but oil industry experts 
dominated the battle related to energy policy. This would make it very difficult to predict the outcome when in the early stage of such a crisis, and at the very least it would be dependent on debates over the definition of the problem. Thus having "science on your side" is highly relative in situations where uncertainty about the source of a problem is important.

A second aspect surrounding uncertainty is the level of technicality of the topic(s) at hand. It seems easier to appear as credible when the aspects discussed are less complex. In the Ice Storm case, it was easier for Hydro-Quebec to convince the population when discussing less complex aspects like repairs (compared to opponents' discussions of complicated distribution issues), than for instance with the Kohl government's claims over the health risks following the Chernobyl incident. When the level of perceived technicality is lower, it is thus easier to control the impact of uncertainty. However, a high level of technicality is not necessarily beneficial to challengers of the status quo, because no one stands out in this situation during the acute phase, so the attention needs to be put on the policy battle. In other words, the level of complexity allows a more serious challenge to claims made by actors in power during the acute phase, but the downside is that it also increases uncertainty with regard to the social desirability of any particular policy course.

This contrast points to a third aspect: the time dimension. There is a distinction to be made between the uncertainty linked to the scare itself (mostly regarding the triggering event) and uncertainty regarding the future - for the design of policy tools, in particular. A first general pattern that can be observed relates to when uncertainty is used 
in framing strategies. In the NEP case, for instance, uncertainty was used differently at different stages: first the liberals played it up to topple the government, and then, when they were in power, they tempered it (which mattered less at that point because they held a majority government position).

Moreover, using an accidental causal story as a defense seems easier when information in general (and the uncertainty perceived in the population in particular) can be controlled by the defending groups. One difference between the ice storm and the oil spill was that in the former case, the government and the electricity monopoly were difficult to challenge given their virtually complete control over the technical information necessary to making assessments. Not only was the information given out by HydroQuebec treated as true and legitimate by the media and the population; even when it was shown that the company had relayed incorrect information, the storyline of the natural disaster combined with the leadership of Caillé and Bouchard made it seen as normal. In other words, mistakes were expected in the management of the acute phase, and not interpreted as incompetency given the dire conditions in January of 1998. This certainly differs from the Exxon case, where these mistakes - about the magnitude of the incident and the capacity of Exxon to clean it - appeared as negligence. The fact that HydroQuebec was a public company could have made a difference, but this is something that would need further investigation.

These different sources of uncertainty thus produce different options for storylines, but put coalitions in a difficult position, as they create a demand for policy, while simultaneously making the design of such policy much harder. A second pattern 
emerges regarding how uncertainty fits into the framing strategies used by different groups. Depending on their position and on the context, some groups highlight the uncertainty in their strategy, while others try to dispel it. In the oil spill case, fears of other similar accidents were played up by environmental groups to highlight the potential imminence of another spill. This position suggested that major and swift changes, including an effort to move away from oil, were necessary to prevent other catastrophes. For the oil industry, the certainty about a future similar to the present, with oil playing a large role, was an argument for the status quo and for policy changes restricted to transportation regulation.

In the Ice Storm case, on the other hand, and while the leaders from the government and Hydro-Quebec tended to argue that uncertainty was reduced to a minimum by their actions, a certain level of uncertainty was presented as inevitable. The caprices of the weather were a reality that everyone had to accept, and consequently, it was normal that once in a while a major event like this storm came and caused some damage. As a result, uncertainty here was part of the strategy, as its acceptance as "normal" allowed blame-shifting away from Hydro-Quebec: for the dire conditions experienced by many of the victims, explanations could always resort to the natural disaster storyline.

More generally, certain conditions make it easier to incorporate the uncertainty issues - or reduction thereof - into different storylines. The Chernobyl case shows how the wide variety of information available meant that different numbers and claims could be incorporated selectively into very different narratives, and thus uncertainty in that 
sense led to an increase in discursive flexibility. In the Exxon case, the fact that there was an identifiable policy problem - the stalemate that prevented new oil transport regulation - helped tone down the fears raised by the event. In the Ice Storm, the causal storyline exteriorized the uncertainty. This, in combination with the leaders taking charge, produced something akin to a war narrative - "us" against "this" - and the storyline then took care of all the issues mentioned above: the future, the present, and the responsibility of people in charge. This also suggests, however, that it is very difficult - given the leadership curse - to act when a storyline like this is unavailable, as was the case for the Conservative government in the NEP case.

Overall, the cases show support for the uncertainty played up/down hypothesis $\left(\mathrm{H}_{3}\right)$, as uncertainty is usually played down by actors and coalitions reluctant to introduce major changes in policy, while the opposite is true for challengers. Uncertainty is a malleable tool that can be used differently in various strategies, both by actors attached to the status quo and by challengers, with the important caveat that they still face the constraints provided by the events. These constraints do not merely include the physical features of the social scare, but also the contextual factors surrounding the scare.

\subsection{The impact of contextual factors}

The four case studies also provide some insights regarding the importance of contextual factors, with the emphasis being put on those apparently having the largest impact on the policy process and outcome during the scare. Generally, the energy situation of the country had an impact on the policy debates in all cases, especially with 
regard to the availability of alternatives to the source highlighted as problematic by the triggering event. In the NEP and Exxon cases, the lack of any serious alternatives to oil for transportation made it difficult for opponents to provide any sensible path away from this source. In West Germany, by contrast, opponents were ready to argue for alternatives to nuclear energy, and the debates during both the acute and post-shock phases quickly made most on the anti-nuclear side pro-renewables, while the government and the pronuclear side insisted these alternatives could never replace nuclear energy. This aspect was different in the Ice Storm case, where the debates were never about finding alternatives to hydroelectricity (the main source of generation for Hydro-Quebec), but rather focused on issues related to the management of demand and distribution.

In this section of the case studies, two hypotheses were examined. $\mathrm{H}_{4 \mathrm{a}}$ (election looming) was concerned with the timing of the electoral cycle, and proposed that an election planned during or very shortly after the triggering of a scare diminishes the advantage held by actors from the executive branch. This is equivalent to saying that the leadership curse is worsened in this situation, and is likely to be worst of all for a government in a minority position. The NEP case certainly confirms this proposition. The flexibility and options of the government in power with regard to their leadership performance in the face of the triggering event is reduced by this minority position.

Besides the minority government situation, other electoral considerations influence the battle during the acute phase. For instance, the distribution of hardship across the population can have an impact, especially if the policy solutions would also be distributed unevenly. One issue that arises is whether the regional trends in electoral 
intentions interplay with the distribution of hardship related to the scare. In the NEP case, the Liberals proposed a solution that would benefit some provinces in particular, insuring them a return to power, while the Conservatives had a harder time in designing a policy solution that would be welcomed both in producer provinces (which were their main base) and in consumer ones (which they needed to remain in power). The Liberals were looking for an opportunity to get back some of the votes they had lost from their large base in the consumer provinces of Ontario and Quebec, where the effects of the higher prices were more strongly felt. In the different context of the Chernobyl scare in West Germany, the irregular timing of elections in that country meant that these were always a potential source of concern for leaders in power. In a system with fixed election terms like the United States, a scare occurring shortly after an election does not create similar worries for national politicians.

Generally then, the presence of an election shortly after a triggering event is a strong conditional factor for the options available to different coalitions during the acute phase. In particular, it can help opposition leaders get access to the political rent, as in the NEP case. This, however, is also dependent on the type of political regime. $\mathrm{H}_{4 b}$ (regime type) proposes that actors from the executive branch will hold a stronger position with regard to policy options when they are also controlling the legislative process. I have already discussed the minority government situation, which is the domain of parliamentary regimes, but more generally it is the degree of control over the policy process that is important, and legislation is an important part. In the NEP case (after the election of the Liberals) and in the Ice Storm case, the strong control over the legislative 
process provided by the Parliamentary structure meant that the government had a lot of flexibility in the policy battle, since in the end they could technically pass any program they wanted, even very controversial ones (as the NEP proved to be). In other words, in these cases, the strength of these coalitions in the post-shock phase was not merely a question of them having captured the rent (although in the NEP case the Liberals would not have been in power without it), it is also largely because they happened to have a high degree of structural control over the legislative process. In the West Germany case, the Kohl coalition did succeed in postponing major changes to energy policy for several years. In a Presidential regime, it is likely to be harder for actors in power to pursue their preferred policy option (all else being equal), but the cases here provide only little information on this possibility.

Overall then, the timing of an election $\left(\mathrm{H}_{4 a}\right)$ seems to impact mostly the acute phase, since it gives access to the rent to actors normally excluded; furthermore, the regime type $\left(\mathrm{H}_{4 b}\right)$ mostly has a conditional impact on the post-shock phase.

\subsection{Policy outcomes and paths to change: a typology of social scares}

As evidenced by all four cases, the type of the triggering event or the nature of the scare, and the importance given to it by the media, never completely preclude a stage where some policy options will be put forward. In trying to understand the policy impacts of social scares, therefore, questions over the emergence of these debates, and over the positions of the different coalitions therein, are critical. The elements mentioned in the case study chapters, and the broader comparisons made above, provide answers to these. 
Understanding the distinctions between the acute and post-shock periods, and between the two prizes, allows for the creation of a typology to describe the different possibilities for the policy struggles that happen in the aftermath of social scares. Figure 11 summarizes the different possibilities that follow a triggering event. The first branching concerns the winning of the prize in the acute phase. Then, the results of the battles in the post-shock phase produce a total of four different types of policy processes. It is important to restate that this is not a typology for all instances of policy change, but rather a classification of possibilities for the policy process that follows social scares. Furthermore, rather than attempting to classify the possibilities according to which type of policy change follows, the types characterize the policy process that may or may not lead to policy change. In other words, the policies themselves that were enacted (or not) at the end of social scares are not considered in detail, apart from the attention given to how they came to be. There is no judgment as to whether these changes in policy are "major", "atypical", or "minor", but rather the emphasis is on the process through which they were pushed and enacted (or blocked).

The first branching in the typology relates to the outcome of the acute phase. Given the nature of social scares, there is always a prize to be captured in this phase - the political rent - although it is smaller or larger depending on the levels of disruption and reach, and can be enlarged or reduced by framing attempts. As I discussed earlier, however, this does not mean that this rent is always won by whoever is in a position to do so. In some cases, the best strategy of groups who may lose the most from changes will be to attempt to defuse the crisis either by portraying it in a certain way (framing), or by 
discrediting the actions of certain political leader(s). In other cases, the nature of the events triggering the scare can prevent a capture, for instance if the actors of the executive branch fear the position that this will put them into for later policy battles. The question we need to ask at the end of this acute phase is then the following: did one actor (or a set of very few actors) from the executive branch clearly win the prize?

The answer to this first question determines the environment for the post-shock period, as well as the second question that needs to be asked. The first possibility is that there was a concentrated win for leaders in power, with one or a very few actors standing out. If that is the case, then the second question is whether these winners favor policy change. If they do, then their position will be strongest in the post-shock phase. In other words, the political rent can be used to secure the desired policy changes (including the option of not changing anything), as it grows out of the causes of the insecurity identified by winners in the acute phase. When leaders in power win the rent and are then pushing for change, change is highly likely, resulting in a process where we see a bulldozing executive. The NEP case presented in Chapter 5 fits this category, where the acute phase was a moderately long period of instability that led to the defeat of the minority Conservative government. Once the Liberals were in power, they acted on the promise that got them elected, and enacted their broad-sweeping reform in energy policy. Note 


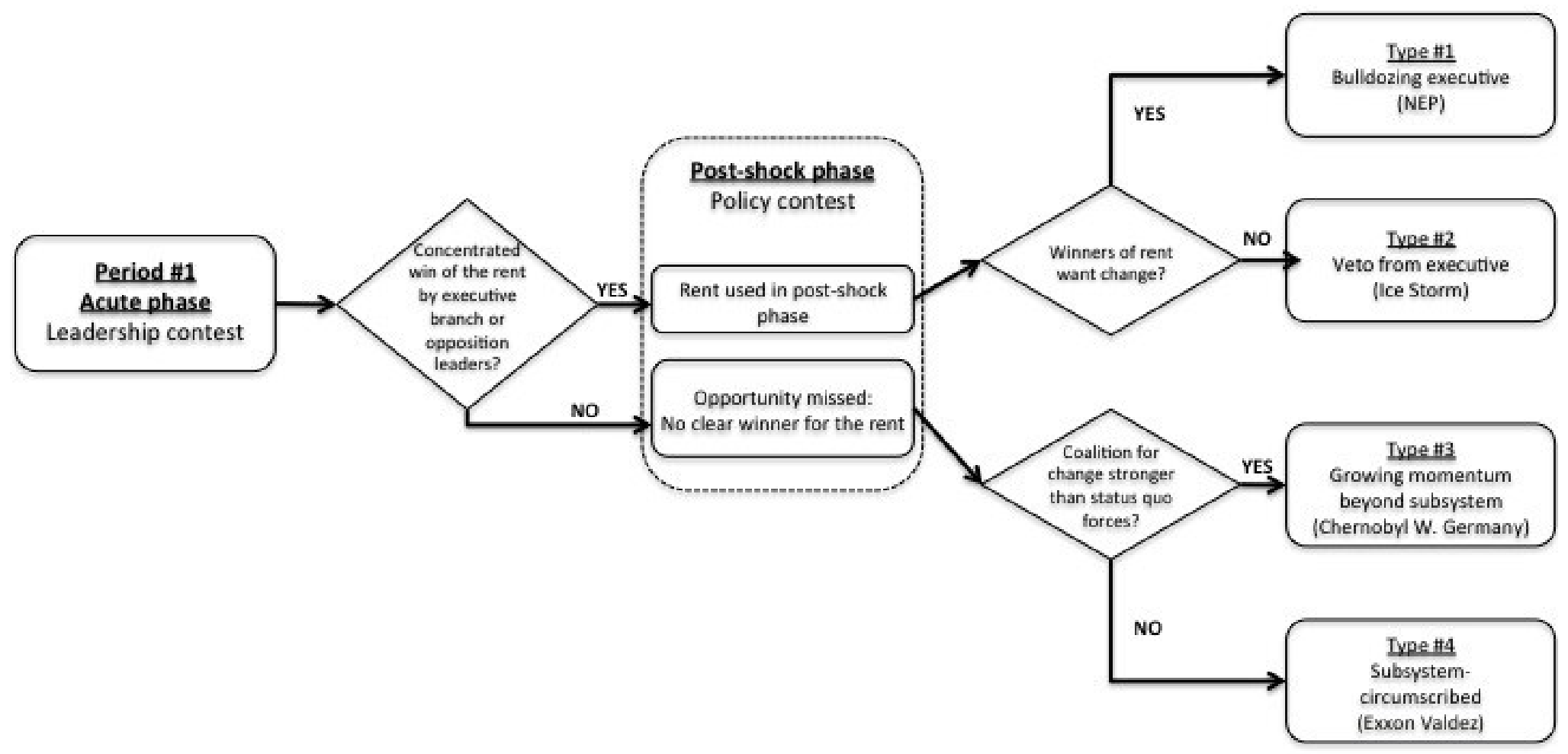

Figure 11. Typology flow chart: various paths to policy change or stability 
that it is also a case where the rent winners were originally in the opposition, so the capture of the rent is actually what made them executive branch leaders. ${ }^{24}$

The second possibility, if the rent was captured by one or a very few actors, is that they do not want change, and ideally would like to avoid a policy debate in the postshock phase altogether, favoring the status quo. Given the bulk of symbolic capital won, the rent is used to block the possibilities for change. The North American Ice Storm of 1998 in Eastern Canada, where the Quebec provincial Prime Minister was a clear winner of the rent, is a case that fits this category. At the time, the policies of the province's electricity monopoly were kept untouched.

The other two possibilities come from a different answer to the first question, that is, situations where the acute phase did not produce a clear winner among leaders in power. In many ways the struggles that occur in the second phase resemble more typical policy battles, with the important exception that the scare is still the background for the debates. The second question then becomes, did a coalition exist or emerge that was powerful enough to challenge status quo forces?

If the answer is yes, then change could still be substantial, but will take much longer to come about, multiplying the risks of veto from opponents. This type of process can occur when the scare was important enough to make a large rent grow out of the acute phase, but that was not captured entirely by the government coalition. In these instances, other coalitions can grow stronger with regard to their credibility for policy

\footnotetext{
${ }^{24}$ As briefly explained in the discussion over the leadership curse in Chapter 2, actors from the executive branch can also lose, and this is not necessarily because opposition actors "won". It would be conceivable that a head of government lost symbolic capital during the acute phase of a social scare, but where the absence of an election for a few years did not produce a clear winner in the opposition as a result.
} 
issues related to the scare. If the scare was important enough so that the missed opportunity of large rent capture by the leaders in power did not reduce substantially the perception of insecurity, then it is likely that these leaders will be challenged in the postshock phase. This results in a process where we see a growing momentum for a coalition that goes beyond the policy subsystem most closely linked to the issue, where legislative changes can still be important, despite the blocking attempts by the coalition in power. The Chernobyl case in West Germany, as described above, is an example of this situation.

Finally, if there was no concentrated win by executive branch actors for the political rent and coalitions wanting change were not able to decisively overcome the status quo, a fourth type of process can occur. In these cases, debates in the aftermath are dominated by actors well within the policy subsystem. Coalitions outside of the policy regime are in effect partially locked out of the policy debates, being reduced to ask for changes that remain within this constrained environment. The oil transportation regulation debates following from the Exxon Valdez oil spill fall into this category. As explained in Chapter 6, a key factor determining the difference between these two types is whether coalitions have strong allies within the political system. Pro-renewables groups in the Chernobyl case did find such allies, while environmental groups in the Exxon Valdez case were less successfully in doing so.

These categories are ideal-types and an in-depth analysis of both the acute and post-shock phases is necessary to classify cases along this typology, as several factors shape the political battles in both periods and have an influence on the two dimensions. 
The predicting power of the model, in particular, is concentrated at the intersection of both periods: by knowing the conditions and results of the acute phase, one should be able to narrow down the possibilities for the post-shock phase.

\subsection{Conclusion}

This chapter completes the set of comparisons made across the four cases studied in depth in the project. Putting all these results together now allows for an elaboration of the model described in Chapter 4 and used in Chapters 5 through 7 to analyze energy scares. Hence in the next chapter, I use these insights to refine the model and analyze two further cases of energy scares. 


\section{Chapter 8}

\section{A refined model to study energy scares}

The previous three chapters have shown how the analytical framework developed in the first three chapters could be used to analyze cases of social scares. Furthermore, I conducted the case studies with the model presented at the end of Chapter 4, which was adapted for energy scares. This model was exploratory, as the questions asked with the method of structured, focused comparison were broad. The results from the four case studies, including the typology developed in Chapter 7, can now help in refining this model, with more specific questions to ask of cases of energy scares.

In this chapter, I present this refined model and apply it to two further cases. The first is the oil spill that occurred following the explosion of the Deepwater Horizon oil platform in the Gulf of Mexico in 2010 - also often labeled the "BP oil spill". The second is the failure of the Taum Sauk hydroelectric reservoir in the U.S. state of Missouri.

The cases were chosen according to different criteria. First, they are both recent cases from the United States: since the Exxon Valdez spill case highlighted differences between Presidential regimes and their Parliamentary counterparts, and since three out of the main case studies occurred in countries with Parliamentary regimes, these two additional cases provide further insights into cases of energy scares in such political structures. Second, the Deepwater Horizon oil spill was a partly similar instance of a previous scare, as it was the only oil spill larger than the Exxon Valdez to occur in the United States. Direct comparisons with some aspects of the Exxon case should then be possible. And third, the Taum Sauk case presents a "local" energy scare, where state- 
level politicians dominated the scene. This produces further insights, including through comparison with the Ice Storm case, to see whether the dynamics described in the framework differ when occurring within a more restricted political scene.

\subsection{Refined model}

I begin with a description of the refined model. The purpose is to provide a more detailed list of investigative questions to be used in analyzing energy scares. The model is summarized in Table 4.

A first step is to look at the triggering event and the battle for the political rent during the acute phase. Details regarding the variables of disruption and reach, which help get an idea of the basic size of the rent as well as the potential for its inflation, need to be considered before determining whether or not actors from the executive branch were successful in capturing a large rent. In this case, following from the evidence found on the rent as resource hypothesis $\left(\mathrm{H}_{1}\right)$, these winners should have more facility in obtaining their favored policy outcome in the later post-shock phase.

Other aspects help determine these answers, in particular whether the source of the scare came to be pinned town to a particular event, whether there was a clear delineation of the acute phase, and whether the cause of the scare (or specifically of the triggering event) could be treated as "external". Finally, an analysis of the symbols and 
Table 4.

Refined model to investigate energy scares and their impact on policy

\begin{tabular}{|c|c|}
\hline Core aspect of the case & Specific questions to ask of the case \\
\hline $\begin{array}{l}\text { Triggering event and } \\
\text { political rent }\end{array}$ & $\begin{array}{l}\text { Assumption from } \mathrm{H}_{1} \text { (rent as resource): winning the rent allows more facility in securing policy outcome. } \\
\text { Aspects to consider: } \\
\text { - disruption and reach? } \\
\text { - } \quad \text { rent and rent winner(s)? } \\
\text { - } \quad \text { acurce of the scare pinned down to a particular event? } \\
\text { - } \quad \text { "external" cause to the scare? } \\
\text { - issue treated as new (symbols and images echoing something known)? }\end{array}$ \\
\hline $\begin{array}{l}\text { Strategies and actions } \\
\text { regarding the two } \\
\text { objectives }\end{array}$ & $\begin{array}{l}\text { Assumption from } \mathrm{H}_{2} \text { (compatible strategies): actors and groups use compatible strategies between rent capture and desired } \\
\text { policy outcome. } \\
\text { Aspects to consider: } \\
\text { - ability to demonstrate "action" during the acute phase with symbols and images? } \\
\text { - } \quad \text { outcome of early debates over definition of the problem? } \\
\text { - } \quad \text { causal story lines and energy policy frames used in the actors' strategies? } \\
\text { - } \quad \text { subnational actors trying to intervene? } \\
\text { - } \quad \text { policy option(s) ready to be used? } \\
\text { - degree of institutionalization of opposition coalitions (including support within executive or legislative arena)? }\end{array}$ \\
\hline $\begin{array}{c}\text { Framing of uncertainty } \\
\text { and risk } \\
\text { and role of expertise }\end{array}$ & $\begin{array}{l}\text { Assumption from } \mathrm{H}_{3} \text { (uncertainty played up/down): executive actors play down uncertainty while opposition plays it up. } \\
\text { Aspects to consider: } \\
\text { - when is uncertainty used? } \\
\text { - how is uncertainty used? } \\
\text { - authority and legitimacy of different actors/coalitions, and control of information? } \\
\text { - practical alternatives to current policy? }\end{array}$ \\
\hline
\end{tabular}




\section{Table 4 (continued)}

\section{Core aspect of the case}

\section{Specific questions to ask of the case}

Assumption from $\mathrm{H}_{4 \mathrm{a}}$ (election looming): nearing election makes challenges to actors in power more intense and effective. Assumption from $\mathrm{H}_{4 \mathrm{~b}}$ (regime type): policy regime influences strength of executive leaders through legislative control.

Aspects to consider:

Impact of contextual factors

- $\quad$ election timing impact on the acute phase (intense participation of opposition leaders)?

- regime type influence on the post-shock phase?

- impact of economic context on policy discussions?

- impact of social values on the public's reception of the triggering event?

- links between the scare and others?

- influence of dominant ideas of the time?

Type of process from the typology:

Resulting policy process

- $\quad$ bulldozing executive

- $\quad$ veto from executive

- growing momentum beyond subsystem

- $\quad$ subsystem-circumscribed 
images relayed through the media and political discourse also helps determine whether the issue could be treated as new, or if it echoed a known problem, for instance. Putting all these answers together provides a rich picture that allows an understanding of the evolution from the acute phase to the post-shock period.

The second set of questions relates to the strategies used by actors regarding the two objectives of capturing the rent and obtaining a satisfactory policy outcome. We know from $\mathrm{H}_{2}$ that actors and groups normally use compatible strategies between these two objectives, which helps explain some seemingly odd positions. Details on this aspect can be established by looking at whether actors from the executive branch had the possibility to demonstrate decisive actions during the acute phase; what definition of the problem came to be used during the acute phase; and the causal story (accidental or inadvertent, for instance) and energy policy frames (economic growth, environment, foreign policy, or security) that were used in the actors' discourse. Given the leadership curse and the possible past position of government leaders on the issues discussed, it should be easier to defend narratives that fit with "action", although the assumption of compatible strategies can be a contradictory constraint. Moreover, attention must be given to different levels of government.

In studying this aspect of strategies, attention must be given to all actors and coalitions participating in (or at least, attempting to participate in) public and policy debates during both phases, and not merely to elected officials competing for the rent. The degree of institutionalization of the different coalitions, in other words how much support they have in the executive branch (to help an ally capture the rent) or in the 
broader government apparatus (to help push for a given policy option), should be key in explaining the policies discussed. A final consideration that may shape these debates is whether a particular policy option already exists to fit with the definition of the problem, which may explain the dominance of certain narratives.

The third aspect to analyze is the use of uncertainty in framing strategies and the role of experts in these struggles. One trend we know from $\mathrm{H}_{3}$ is that actors from within the government (the executive branch, in particular) are more likely to play down uncertainty, while the opposition are more likely to play it up. This trend only provides a rough understanding of the use of uncertainty, however, and the more specific questions of when and how this is done need to be considered. In this process, the control over the information used in debates, the authority and legitimacy of the different actors and coalitions, and the experts that participate in shaping these positions, are key aspects to investigate. More than the availability of policy options identified in the first set of questions above, the details concerning the framing and legitimacy battles can help determine which alternative policies come to be seen as practical, in contrast to being considered more radical and risky changes.

The fourth aspect concerns broader contextual factors that shape both the acute phase and the post-shock phase, as they may influence several of the items discussed above. Chapter 2 identified five broad contextual factors that need to be considered: the electoral timing, the economic environment, the dominant ideas of the time, the link between the scare and others occurring during the same period, and social values that may be related to debates over the issues identified with the scare. From the case studies, 
we saw that the regime type was also important, as it influences the possibilities for government actors in the post-shock phase, especially in the case of legislative battles for certain policy options. The election looming hypothesis $\left(\mathrm{H}_{4 \mathrm{a}}\right)$, on the other hand, should give information on the acute phase, especially concerning the ability of opposition leaders to compete for the rent.

This analysis allows an in-depth understanding of the type of policy process that followed from a social scare, as described at the end of Chapter 7. I now test this more elaborate model on two additional cases, to see if it can provide us with a ready guide for assessing occurrences of energy scares, and what additional aspects it can identify.

\subsection{The 2010 Deepwater Horizon oil spill in the United States}

On April $20^{\text {th }}, 2010$, the Deepwater Horizon drilling rig exploded and caught fire in the Gulf of Mexico, killing 11 workers (Welch \& Joyner, 2010). The explosion of the platform triggered an oil spill that continued until it was capped on July $15^{\text {th }}$ of the same year, resulting in the discharge of an estimated 4.9 million barrels of oil, making it the worst environmental disaster in U.S. history (National Response Team, 2011; Robertson \& Krauss, 2010).

Using the grid presented in Table 4, I look first at the triggering event. In terms of oil spills, the case dwarfed the Exxon Valdez spill in almost every aspect: the quantity of oil discharged in the Gulf of Mexico was over 10 times that not recovered in the Exxon Valdez case; the distance from inhabited shores, although technically greater than in Alaska, could also be considered much less because of the highly populated areas all 
along the United States' South coastline; and, partly as a result, the damage on the economy of the region was substantial, especially in the fisheries and tourism sectors. Consequently, the disruption and reach of the event were greater than the Exxon Valdez spill, and the issue was not treated as new, with symbols and images in large part similar to the Alaska case.

In this case, the source of the scare could be pinned down to a particular event (the explosion of the platform), and the Obama administration was quick to point out the problems surrounding the regulation of oil platforms, as well as the negligence of the company ultimately responsible for this particular one (BP). The actions it undertook were mostly related to these issues:

- The Minerals Management Service (MMS), under the United States Department of the Interior, was responsible for oil platform regulation and was criticized in the immediate aftermath of the explosion for having failed to prevent the conditions that allowed the spill to occur. Secretary of the Interior Ken Salazar announced on May $19^{\text {th }}$ that he would divide the MMS into three separate divisions: the Bureau of Ocean Energy Management, the Bureau of Safety and Environmental Enforcement, and the Office of Natural Resources Revenue (although the split was only effective in October 2011) (Straub, 2010).

- On May $27^{\text {th }}$, President Obama announced a six-month moratorium on new deep water oil permits (Baker, 2010).

- On June $1^{\text {st }}$, the U.S. Department of Justice announced its intention to initiate criminal prosecutions, looking into the Clean Water Act, the Oil Pollution Act of 
1990, the Migratory Bird Treaty Act, and the Endangered Species Act (CNN Wire Staff, 2010). ${ }^{25}$

- In June, President Obama had BP agree to fund a $\$ 20$ billion escrow account to be administered by Kenneth Feinberg to handle spill-related claims (Bigg, 2010).

The cause of the scare was thus not seen as "external", but the aggressive stance that the Obama administration took with regard to BP helped build a narrative with "us" and "them". This was also fueled by public relations difficulties for BP, especially after a few clumsy remarks by BP chief executive officer Tony Hayward (Webb, 2010).

In the public debates that followed, the comparisons with the Exxon Valdez oil spill were frequent, and questions on the safety of oil exploration and transport in technologically challenging areas came up in public and policy debates. The Obama administration's stance in the face of the disaster was different from its Bush counterpart 21 years earlier, however. Administration officials, including the President, were on the forefront of all debates, promising to find culprits and prosecute (including with criminal charges), to improve legislation for oil drilling, even going as far as enforcing a sixmonth moratorium for all oil drilling on the outer continental shelf while the risks were reassessed. BP was also temporarily banned from government contracts, on top the imposition of various fines (Chazan \& Rigby, 2013).

Contrary to the aftermath of the Exxon Valdez spill, media attention was dominated by exchanges between the President and BP (Hoffman, \& Jennings, 2011). Despite these attempts, the Obama administration was never able to capture the rent, and

25 In November of 2012, BP pleaded guilty to 11 counts of manslaughter, two misdemeanors, and a felony count of lying to Congress, paying a record total of $\$ 4.525$ billion in fines and other payments (Krauss \& Schwartz, 2012). 
continued to be associated to the disaster in the American public, with several polls indicating that at least half the population did not find the administration and government's handling of the disaster satisfactory (Camia, 2010). The acute phase was also clearly delineated, ending when the leak was capped on July $15^{\text {th }}$. This led to a postshock phase where debates over modifications to energy policy were very limited, and where virtually no changes were enacted apart from the regulatory reorganization done in the weeks following the triggering event. The Obama administration, not having captured a large rent, was not in a position to push Congress to adopt anything substantial, especially given the political climate at the time (more on this below).

We know from the earlier case studies that the strategies and actions used during the acute phase should be compatible, for a given set of actors, with objectives for a postshock policy battle. Consequently, and especially given the Obama administration's election campaign pledge to enact changes to energy policy by supporting "greener" energy sources, a large rent capture could have allowed them to push further the energy policy reforms favored by the administration. Furthermore, one interesting aspect in this case is that the option of pushing harder for oil alternatives was not entirely appropriate to pursue during the acute phase given the high level of disruption: action was needed first to dissolve the acute phase, that is, the spill itself. Hence although President Obama's earlier energy policy pledges presented a potential "solution" to the risks of deep water oil drilling, his administration needed to get through the immediate problem first, and this took much longer than expected. 
Looking further into the executive branch leaders' strategy, President Obama visited the costal regions touched by the spill repeatedly, and his administration quickly took action against $\mathrm{BP}$ - although on the spill itself they were somewhat limited in demonstrating their actions with symbols and images. Early debates over the definition of the problem rapidly identified criminal negligence by BP as the main cause, with important regulatory failures worsening the situation. This narrative used by the Obama administration led to a strategy of aggressive attacks on BP, asserting repeatedly that they would have to pay the full price for the damage incurred. In a televised address to the nation on June 15th, Obama depicted the spill itself in war language, alongside BP:

Tonight, I've returned from a trip to the Gulf Coast to speak with you about the battle we're waging against an oil spill that is assaulting our shores and our citizens.... We will fight this spill with everything we've got for as long as it takes. We will make BP pay for the damage their company has cost. (The White House Office of the Press Secretary, 2010)

This narrative fitted with the actions undertaken during the acute phase, which included the reorganization of the MMS as well as the use of various judiciary means against BP. Despite all these actions, members of the Obama administration came to be criticized by a broad section of the public and the media. To a large extent, this stems in the length of the acute phase: when it became apparent that the spill would last for several weeks, the administration quickly became hostages of efforts to cap the well. As the spill continued, all they could do was be more aggressive toward BP, masking the fact that they were somewhat powerless. Leaders from the administration, including President 
Obama, were limited to finding out about the efforts as they were unfolding, a sharp contrast with a case like the Ice Storm, for instance, where it was much easier for the government to be proactive.

The administration's claims on key information - the rate of the spill, in particular - were also being challenged (Talev, 2010). They were not able to control information used in debates over the spill and convincingly demonstrate that they were solving the scare. Normally, $\mathrm{H}_{3}$ tells us that executive actors are likely to play down uncertainty, especially during the acute phase, since they need to show that they are in control. The Obama administration was never able to do that, as the legitimacy and credibility of their estimations were continually challenged, especially in the first few weeks of the acute phase (see, for instance, MacDonald, Amos, Crone, \& Wereley, 2010).

With regard to debates in the post-shock phase, the absence of practical alternatives to oil (and in particular, to oil drilling in the Gulf of Mexico) made it difficult for the President to convince lawmakers to make any substantial changes, as the uncertainties associated with any move away from oil in transportation continue to be seen as daunting.

That being said, again in this case the political and societal context in which the spill occurred was highly influential. The year 2010 presented an important shift in the political landscape in the United States, with the continuing emergence of the Tea Party movement and the related wave of Republican candidates taking control over the U.S. House of Representatives in the November, 2010 election. It is not the place here to discuss in detail the full extent and roots of this movement and the 2010 political context, 
but $\mathrm{H}_{4 a}$ (election looming) tells us that we would have expected challenges to the executive branch actors to be more intense in the months prior to the election, which correspond here to the beginning of the post-shock phase. This, in a political regime where legislative control is largely separate from the executive branch, and in an environment where the party closest to the President was to lose control of the House of Representatives, made it very unlikely that substantial changes to energy legislation would be enacted. In this context, and especially given the absence of rent capture by the President, it is hardly surprising that projects to push alternatives to oil drilling further in Congress were not initiated after the election.

The refined investigative model presented in Table 4 allows for a relatively quick analysis of the scare. Regarding the framework more generally, this particular case raises some issues about certain aspects of the scare and how we could better understand its impact. Overall, these issues include the following:

- The very aggressive position of the Obama administration during the acute phase did not translate into broad public support, preventing a rent capture that could have been used for further changes in policy. This suggests a complication to the leadership curse, as it seemed difficult for the government to distance itself from the disaster, despite their strategy of aggressively blaming BP. It also highlights the importance of resolving the immediate impact of the triggering event first, in order to be able to capture the rent.

- Almost four years after the initial explosion, the United States has not witnessed any major change in the national energy policy with regard to oil, including 
polices related to deep water drilling (apart from the reorganization of the MMS mentioned above). So as discussed in Chapter 7 regarding the Exxon Valdez case, oil seems to present a unique case in energy policy. The path-dependency in transportation is extremely resistant to abrupt changes. The question of whether this is due to the oil spill triggering event, which may have had limited disruptive impact, or to the sturdiness of the dependency on oil as a source of energy as well as the influence of the oil lobby, would need further investigation. One thing can be said, however: on the face of it, for an oil-related scare, this event could hardly have been more disruptive, as it contained several deaths, substantial economic damage to populated areas, and images of a spectacular explosion and fire. This hints that the reach dimension may be more important than disruption, as there seems to be an important difference between an event related to the safety of a technology (e.g., a spill) and a scare related to the availability of supplies (e.g., the 1973- 74 shock).

- More generally, the particularities of presidential systems, where the executive usually has a much weaker control over the legislative process (at least in highincome countries), raise questions about the post-shock phase and the potential policy outcomes in the aftermath of a scare. The (partial) inability of the leading actors from the executive branch to impose policy changes outside of actions directly related to the triggering event, and the inability of these actors to capture the political rent during the acute phase and use it to push for further policy or legislative changes, make it more difficult to draw a bottom line. Additional 
research on U.S. cases, in particular, is needed to learn more about this process. Interestingly, this case could also be studied from a state-level perspective, for instance in the coastal states directly affected by the spill and ensuing moratorium.

In sum, what is perplexing in this case was the inability of the Obama administration to distance itself from the cause of the scare, and to win a large rent despite its aggressive stance and consequent actions toward BP. In other words, despite the pressure to "do something", doing "more" does not necessarily lead to success. Given the apparent failure of the Obama administration to use an aggressive strategy to capture the rent during the acute phase, this case would appear to fall in the fourth type described in the typology, as the changes enacted occurred well within the policy subsystem directly concerned with deep water oil drilling.

\subsection{The 2005 Taum Sauk dam failure in Missouri, United States}

Early on the morning of December $14^{\text {th }}, 2005$, part of the upper reservoir of the Taum Sauk hydroelectric plant near Lesterville, Missouri collapsed, releasing over one billion gallons of water on the Johnson's Shut-Ins State Park. Soon after the event, the 150 residents of Lesterville were evacuated to higher ground, and Governor Matt Blunt signed two State of Emergency Disaster Executive Orders giving authority to state agencies and the Missouri National Guard to respond to local requests ("Gov. Blunt issues disaster declaration," 2005; Leonard, 2005a). The torrent of water also swept away the house of the park superintendent, Jerry Toops, who was rescued by a truck driver and 
a fire chief moments later after climbing in a tree. Rescuers then searched for an hour to find his wife and three young children. Although they were hospitalized in St. Louis, with two of the children in critical condition caused by hypothermia and breathing problems, they all eventually recovered (Leonard, 2005a).

The water receded by the end of the day, significantly damaging the wildlife in the park. Despite initial fears that the zone devastated by the water was a camping site and tourist area, no campers or hikers were found to have been using the site on that night, leaving the body count at zero.

The triggering event was represented in the news media with images of the zone ravaged by the water, and by the story of the Toops family. The lack of deaths, nevertheless, made for a relatively low level of disruption. The reach, however, was of more concern across the state in the days that followed, as it quickly emerged that hundreds of dams were not regulated by the state or the federal government, due to a distinction between "agricultural" dams and others (Hand \& Frankel, 2005). The Taum Sauk station was actually one which was regulated and regularly inspected by the Federal Energy Regulatory Commission (FERC), who had reported in August of 2005 that the reservoir was maintained properly (Leiser \& Naudi, 2005). This led some, including the region's U.S. Representative Jo Ann H. Emerson, to argue that the population was very lucky that this event had occurred on a well-maintained dam in a sparsely populated area, given the risks to more densely populated zones threatened by unregulated dams ("Rep. Emerson radio address," 2005). 
Media attention during the acute phase was monopolized by Governor Blunt, who was sharply critical of Ameren Corporation, the company owning and operating the station (for instance, Leonard, 2005b). Governor Blunt ordered a review of dam safety rules for the entire state, wanting to ensure that "Missouri citizens . . . feel confident that we are doing everything we can to protect them and their families from failure of these dams" (Leiser \& Naudi, 2005). He also pointed fingers at the FERC, who had authority for the regulation of the dam, even sending a letter to FERC Chairman Joseph T. Kelliher asking the agency to investigate whether the commission had "failed to provide the regulatory oversight required by federal law" ("FERC chair defends oversight of Missouri dam," 2006). During the acute phase then, the Blunt administration seemed to have successfully managed to take the initiative on the issue. The Blunt administration's strategy was also compatible with policy options down the road, as they were favorable to changes in the regulatory structure of dams at the state level.

In this case, the source of the scare could be pinned town to a particular event the breach in the reservoir - but for the weeks that followed, a lot of uncertainty remained as to what exactly was responsible for the failure. The acute phase could be clearly delineated and was very short, as the water receded in a matter of hours and no further damage occurred. The issue could also be treated as new, as this was the first incident of this kind in the region, although links were made with the devastation caused by water during the Katrina hurricane flooding of New Orleans a few months earlier ("Rep. Emerson radio address," 2005). 
Although the images were impressive, all in all the event could not have produced a large rent in and of itself, given the lack of deaths and the fact that the damage was mostly done to an unpopulated area. The only way to inflate and capture a larger rent was to link the event to other potential disasters (the reach dimension), which was quickly done by various actors as mentioned above. Measuring the rent in this case is, however, more difficult, because no state-wide polls allow us to measure changes in Governor Blunt's approval ratings, for instance (more on this below).

The strategy used by the Blunt administration can be summed up as follows: they took several actions very early in the days following the event, although symbols and images to demonstrate these were difficult to find; they pushed for a definition of the problem that put the fault on the utility operating the bridge and, to a lesser extent, on federal regulators, using a narrative of negligence and improper oversight (security frame for energy policy); and they quickly stated that they would take action against the company, including criminal charges.

With regard to expert information, little uncertainty existed regarding the impacts of the triggering event, apart from some disagreements over the financial damage due to a drop in tourism. However, uncertainty was played up by the Blunt administration with regard to what the event meant for other dams across the state. This strategy actually contradicts $\mathrm{H}_{3}$, as we would expect the executive branch leaders in power to refrain from doing this. One explanation could be that the Blunt administration was not reluctant to inflate the insecurity, as it meant capturing a larger rent with the changes in policy that they were confident they could pass to resolve it, especially since there was no coalition 
that could reasonably challenge them on this position. In other words, the legitimacy and control over the information allowed for more flexibility in how they could use uncertainty in their strategy.

A few items need to be pointed out with regard to contextual factors. Although no gubernatorial election was held shortly after the event, partisan tensions quickly arose in early 2006 between the Republican Governor and the Attorney General of the state, Jay Nixon - an elected Democrat. Nixon had known intentions to run against Blunt for Governor in the next election (to be held in November of 2008), and political jabs were launched from both offices in the months that followed the dam failure. In particular, both sides accused the other of not doing enough (Jonsson, 2006; Leiser, 2006a). Nixon also found himself in political hot water when it was discovered that his campaign had received indirect donations from Ameren while it was investigating the company, and had to defend himself and refund the donations. For our purposes, however, the significant time delay between the event and the election contributed to making Nixon's actions mostly defensive, and no one seriously attacked the Governor on the Taum Sauk issue (as the election looming hypothesis would suggest).

The Republican Party controlled both houses of the Missouri General Assembly (along with the governorship) at the time of the event, and there does not seem to have been any tensions between the state Republican caucus and the Blunt administration. As can be expected, then, the legislation concretizing Blunt's pledge to change regulation for all state dams was introduced and defended by state Senator Kevin Engler, whose district included Reynolds county and Lesterville ("Dams: Gov. Blunt proposes giving Mo. 
authority," 2006; Leiser, 2006b). Given the upcoming November, 2006 election for state representatives and senators, this was a way for Senator Engler to capture some part of the political rent, by associating himself with the Governor's actions and propositions.

This case falls into the bulldozing executive category, and is an illustration of what was discussed at the end of Chapter 7 , namely that there is no judgment in the typology about what constitutes a "major" or "atypical" change. The type simply describes the policy process following the acute phase, and in this case the entire acute and post-shock phase was dominated by the actions and preferred policy options of the Governor's team. This case, however, raises a critical issue: in the context of a local scare, it may be difficult to measure the capture of the rent, especially if the scare is not rapidly followed by an election. As discussed at the end of section 7.1, for falsification considerations, we cannot assume that the rent existed and was captured just because the actors in power successfully made policy changes after a scare. Measuring the rent capture is thus something that needs to be done with attention, and when polls or election results are not available, ingenuity on the part of the analyst or researcher is important. In the Taum Sauk case, it seems safe to assume that the Governor's actions were well received in the population, because: no other political actor challenged or criticized him in the media for the months following the event (apart from a very brief period where Nixon tried); legislation was introduced and passed easily that corresponded to what the Governor had proposed; and no Missouri politician tried to publicly distance himself from the Governor, which would suggest it was not seen as a good idea to do so. Polls or 
interviews conducted in the population at the time would nevertheless have been a better way of measuring this.

Keeping this caveat in mind, the case further illustrates that the model used in this project can serve to analyze smaller social scares, where federal actors are not involved, as the Ice Storm case had suggested. There does not seem to be anything different about how the dynamics described in the framework operate when the scope of the political battles is not national.

\subsection{Conclusions}

This chapter presented a more elaborate model to analyze social scares, built on the results from the main case studies of this project. The application of this refined model to the BP spill case show how the "do something" imperative for actors from the executive branch is not the same as "do anything". The aggressive stance of the Obama administration and its consequent legal action toward BP did not enable it to distance itself from the cause of the scare. In other words, despite the pressure to "do something", doing "more" does not necessarily lead to success. The application on the second case further illustrates the importance to give special attention to measurement issues regarding the rent. Taken together, these cases are illustrations of how the model works to provide a ready guide for analyzing a variety of social scares. 


\section{Chapter 9}

\section{Conclusions and policy implications}

This project set out to achieve three goals listed in the introduction. The first goal was to improve our understanding of major policy change, and more specifically the role that is played by social scares. The second goal was related to policy-making in the energy area, as the hope was that the project would shed some light on variation in reactions to social scares in this sector. And the third goal was to provide some insights for policy-making during any type of scare, even those not related to the energy area. In this chapter, I return to some key aspects that emerge from the results, assessing what can be said about each of these goals. I begin with a summary of the framework, and then revisit the main policy insights that the framework alerted us to in the four case studies completed in this project, as well as additional cases discussed in Chapter 8.

\subsection{Summary of the theoretical framework}

In this project, I presented a new way of looking at instances of social scares, with illustrations from the energy sector. In this framework, social scares are understood as producing a spike in insecurity and uncertainty regarding the way that activities in a particular sector are conducted, creating worries and increased attention in a large group of people, for instance the population a given region, province, or country. This context, the scare, creates a different but temporary political environment, as demands for leadership and expectations from public institutions and officials are heightened. 
As a result, the policy process during the total duration of the scare differs from politics as usual: not only are policy discussions influenced by the potential gains and costs to different coalitions (as is always the case), but a second dimension is added to the process. This second dimension is the symbolic capital that is available to leaders who will "look good" in their actions, recommendations, speeches, management of rescue efforts, and any endeavors in reaction to the triggering event and its implications. In other words, the scare creates a political prize associated with an atypical demand for political leadership and competence. This prize is akin to a political rent, because it represents a political reward surpassing the normal gains from "good" governance. Moreover, leaders in power - more specifically, members of the executive branch and their allies - have a strong advantage in their attempts to capture the rent, because of the tools they have at their disposition (for instance, control over the legislative process, or direction of rescue efforts and regulations) and because of their legitimacy (they are the ones on whom the public and the media turn the spotlight first and foremost).

This political rent is largest in the days following the triggering event, but diminishes rapidly as time goes by. Actors and coalitions, but especially members of the executive branch, thus need to decide quickly how they will react to the scare. Ideally they would like to capture the rent at its maximum size, and they can even inflate the scare to do this, by choosing specific narratives that expand the insecurity following from the scare - as long as they are confident that they can act to convincingly resolve this. But there is an important constraint: actions undertaken to do so (in particular, the use of a given strategic narrative, and the policy solutions that follow from it) need to be 
compatible with their interests for the policy outcome that will ensue. Hence executive branch leaders can choose to downplay the scare and deflate the rent, in order to capture a smaller version, but one which has more chance of leading to a policy outcome they favor (or they can choose not to capture it at all). However this, too, is risky: when the executive opts for this strategy, it is hard to predict how quickly the potential for rent inflation will dissipate: on the one hand, opposition leaders can try to inflate and capture it, if the electoral context allows them to; on the other, if no one captures the rent, the scare can linger and allow coalitions to challenge the executive's policy position later on - during the post-shock phase.

The policy battle that follows from a social scare, and its potential outcome, is thus dependent on the combination of the two dimensions: the battle of interests, in other words the more typical part of the policy process; and the "leadership curse", which forces actors in power to lead. This latter constraint refers to the fact that actors in power are in many ways forced to do something to capture the rent (otherwise risking a loss of symbolic capital to adversaries), but may find it difficult to reconcile the actions necessary for this capture with their own policy preferences.

For descriptive purposes, this analytical framework, along with the model to study energy scares refined in Chapter 8, allow us to produce a better overall assessment and understanding of the process that leads from a triggering event to a given policy outcome, including the impact of contextual factors, of the historical background, or of current events such as looming elections. This result relates to the first key goal of the project: 
improve our understanding of major policy change, and more specifically the role that is played by social scares (more on this in 9.2.5 below).

\subsection{Conclusions from the case studies and policy implications}

Chapters 5 through 7 analyzed four instances of social scares linked to the energy sector, applying the analytical framework developed in the earlier sections of this dissertation. With these results, I used a refined version of the model in Chapter 8 to present more briefly additional cases and test this refined version further. What I propose, in this section, is an overview of highlights that come out of these analyses, in order to see what overarching conclusions can be drawn, with possible policy implications in mind.

\subsubsection{On discursive strategies in the acute phase}

As demonstrated throughout the case studies, actors and coalitions in the early stages of the acute phase must usually respond to the triggering event through some form of communication strategy. This is especially true for the leaders in power, but other groups such as opposition members or even outside coalitions will likely enter public debates with conflicting arguments about the causes, actions needed, and policy solution(s) to the scare. Given their position, leaders in power usually have some discursive space - sometimes quite a lot - on these issues, and normally we would expect them to use this space in order to attempt to maximize their benefits in the two dimensions of the scare (i.e., regarding the political rent and the policy outcome). 
This potential for framing varies substantially between different instances of social scares, especially with regard to the triggering event's characteristics. The scare is, after all, triggered by a specific event which, even if it highlights issues broader than the event itself, often represents the main topic of concern surrounding the insecurity perceived in its aftermath. The consequence for framing strategies is that certain symbols, statistics and facts will need to be incorporated and explained in the storylines. The issue of how much flexibility the coalitions actually have, in the end, becomes crucial for the options they face and their potential success.

In theory, leaders in power could want to inflate the scare to make the political rent as large as possible, since they usually are in the best position to capture it. This is not to be overly cynical: leaders are, most of the time, trying to help their constituents in so doing. Nevertheless, the point is that their actions are never entirely detached from reputational and electoral considerations - that is, we should expect them to try to grasp any symbolic capital that they see as available. As was discussed in the case studies, this is importantly constrained by what a narrative inflating the scare means for the policies in place - and for potential changes. Playing up the scare is a strategy that implies increasing the stakes for resolving the insecurity, which in turn implies a policy solution up to the task. The Chernobyl case demonstrates how the leadership curse can put a government in an uncomfortable position on this aspect, while the NEP case shows how a coalition ready to implement substantial change is more at ease.

Interestingly (at least from an analytical perspective), the cases also suggest that downplaying the scare presents almost as many risks as playing it up. Downplaying is 
risky because it implies that less decisive action will be taken, and it seems difficult to resolve the heightened perception of insecurity by doing little - regardless of whether this is the best course of action or not. Leaders in power may attempt to "weather the storm" and get past it, for instance because they do not want to open up a can of worms on policy aspects. In doing so, they are placing their bets on the reality of political life: that attention to a specific issue eventually wanes, no matter how socially traumatizing the event. This, however, is akin to relinquishing control over public debates, and crucially, if these political calculations are wrong and the scare lasts for more time than was expected, this strategy means the actors in power leave the closure - the "resolution" of the perception of insecurity - to a more complex set of actors. These could include opposition parties, or adversarial lobbies and coalitions. A capture of the rent by these adversaries can be extremely damaging, as it could ultimately lead to a replacement of the government - as the NEP case shows - or to a buildup of pressure for change that eventually becomes strong enough to force the government's hand - as the Chernobyl case illustrates.

That being said, the Exxon Valdez case also shows that it is sometimes possible to downplay the scare with little negative impacts. The bottom line, then, is that deciding not to play up the scare because of adverse consequences for policy debates to come does not entail sitting back and hoping for the best. If the objective of the coalition is to retain the status quo in policy, then perhaps the best strategy is to play up the scare, while finding a way to frame it with a storyline that eliminates the need for policy change (as was done in the Ice Storm case). Generally then, even if it may appear so when glancing 
at a scare, the orientation of the policy debates that occur during the post-shock phase are not solely dependent on the decisions and framing strategies used by the executive branch actors: they too are importantly constrained in their options.

\subsubsection{On the leadership curse and the inability to "own" the crisis}

The public debates surrounding a scare and its triggering event are difficult to control for any coalition or actor, even leaders in power. A coherent and strong discursive strategy is one way of attempting to gain this control, but in most cases additional strategies may be both advised and necessary.

Looking at the four cases, one example of such a strategy is for leaders to try to add their own symbols to the ones already provided by the triggering event and the sociohistorical context in which it occurs. For instance, in the Ice Storm case, the government commented at length on the bravery of the repairmen that the population were seeing on the news everyday. In addition, some specific news reports demonstrated the difficulty of the task, such as complex and dangerous repair operations.

Adding these symbols is not merely about showing that the people in charge are good at it, nor is it just about appearances. It also tempers the problems linked to the high uncertainty regarding the information on the triggering event's impact. This comes in contrast to the difficult few weeks following the Exxon Valdez spill - where the U.S. federal government was perceived as late in the game, and where Exxon's information was contradicted by groups completing the cleanup effort. The same applies to a comparison with the Chernobyl case in West Germany, where the multitude of widely 
varying estimates and risks from the nuclear fallout prevented the Kohl government from convincingly establishing a firm set of facts and statistics about the event.

Moreover, the leadership curse also means something else: one important aspect, for leaders in power, is to "own" the crisis all the while blaming it on an external cause (regulation passed by a previous administration, a foreign country's political actions, or a faulty set of safety standards set up by a company, for instance). What is likely to follow is that the information will be more trusted, but also mistakes will be tolerated, as all four cases highlight. From a decision-maker's perspective, then, the implications are indeed similar to what was expected in the early chapters of this project: it is important to have means of ensuring that results are perceived to be of these actors' own making. They need to convincingly reduce the perception of insecurity, but simultaneously must show that this reduction was indeed the result of their decisions. Rejecting the blame for the scare can thus only be one part of the strategy, as it needs to be complemented by more proactive measures.

\subsubsection{On the measurement of the "magnitude" of social scares}

As was posited in the first four chapters, from a methodological standpoint, trying to assess the magnitude of the scare through some index grouping objective characteristics of the triggering event can be highly misleading. Even when using the two aspects of disruption and reach, as I did in the case studies, relying on standardized indicators is limited, and comparisons between different scares need to be made with caution. 
For instance, some indicators seem promising when attempting to provide an objective measure of the level of disruption. The number of deaths, the adverse financial impact, or the number of victims more broadly are certainly relevant measures when analyzing this dimension. However they cannot, in and of themselves, be relied upon, as their meaning - and significance - differs depending on the context.

In the Ice Storm case, the number of deaths was moderately low (around 30), but was perceived as high given the rarity of deaths following from natural disasters in Eastern Canada. In the Chernobyl case, the number of deaths was also low (especially within West Germany, where it was nil), and in the NEP case, the number of deaths was zero, but the financial impact was large. Hence efforts to explain policy change coming from scares by any standardized metric seems at best risky, and at worst futile. This is where the reach variable can be helpful, but it is one that is much more difficult to quantify.

A very recent example of the critical importance of the reach of an event can be seen in the scare that followed the Fukushima Daiichi nuclear disaster in 2011, one of only two incidents to reach level 7 on the International Nuclear Event Scale (the first being the Chernobyl accident). The incident occurred far from German territory, did not cause any damage or deaths in the German population, and yet it revived fears that followed the Chernobyl disaster twenty-five year earlier. The scare provoked the Merkel government to reverse its stance on nuclear power (including a new pro-nuclear policy it had announced the year before), as well as reinstate the phasing-out of nuclear energy in the country (Connolly, 2010; Cowell, 2011). 
This problem is not restricted to energy scares, of course, as the point here is that 1,000 deaths, for instance, do not represent the same symbol when caused by an earthquake, a terrorist attack, or a nuclear accident. The same would be true of $\$ 1$ billion worth of damages in the case of a bridge that collapses and causes 500 deaths, and the same $\$ 1$ billion worth of damages on the same bridge collapse occurring at night, with no one left dead.

Besides these issues, the uncertainty pertaining to these measures plays an important role as well. When the impact (deaths or financial damage) cannot be established with certitude and precision, the levels of both reach and disruption can be perceived as higher. In the Chernobyl case, part of the scare was related first to the true impact of the incident itself - how many deaths in Ukraine, how many cancers would now develop on the longer term, and how many of those in West Germany; second, to the risk of a similar event within West Germany - or at least, closer than Ukraine - in the future; and third, to the victims and financial hardships following from such an event should it occur. While the second and third items are important, it is the first that I want to highlight here. Not knowing the exact number of victims, or the real financial impact of a triggering event, produces debates where arguments can be inflated, as the Chernobyl and NEP cases demonstrate. As a result, from an analytical standpoint, looking merely at standardized indicators to assess the potential policy impact of the triggering event is likely to be misleading.

Looking at the Ice Storm case and contrasting it with the three others that were analyzed in the main case studies of this project, it appears that controlling the 
information on these matters, through eliminating the uncertainty over the impact of (at least) the triggering event, is the best strategy for actors in power. This is very difficult to do, however, especially in situations where the level of technicality is high, and contentious debates often occur even about merely one key specific indicator (the rate of spill in the BP case, or the number of deaths in the Chernobyl case, for instance).

A final issue that would need further investigation is the case of very long acute phases. The BP case showed how dependent the Obama administration was on efforts to cap the well, and the scare could have played very differently if it had been successfully completed within a few days or weeks. The ongoing Fukushima nuclear disaster, mentioned above, is even worse in this regard, as the technical difficulties with permanently containing the reactor have continued for at least two years (at the time of writing). These cases bring the question of whether it is possible at all to move beyond the event with policy while the acute phase is still ongoing, or at least while the triggering event has not been resolved.

\subsubsection{On broader conclusions about the energy sector}

The second goal outlined in the introduction pertained more specifically to understanding the process of making energy policy in social scare contexts. This goal points to a first degree of external validity, that is, to be able to make some generalizations from the cases studied to other energy scares, past and future. In this regard, the cases have a lot to say, although the complexity of social scares and the variability in political and policy contexts should make us wary of sweeping 
generalizations. Nevertheless, a few conclusions about policy directed toward the energy sector come out of this study.

The first, and perhaps the least surprising, is the extraordinary resilience of the oil socio-technical system in the area of transport, at least in countries falling under the scope of the project - that is, highly industrialized democracies with freedom of the press. The Exxon Valdez and Deepwater Horizon oil spill cases, described in Chapters 6 through 8 , demonstrate how difficult it is to modify broad orientations in energy policy when it comes to oil, even in the aftermath of very large catastrophes linked to the sector. So far the response to the more recent oil train derailment in Lac-Mégantic (Quebec), where an unattended 73-car freight train carrying crude oil exploded in July 2013, killing forty-seven people and destroying half of the downtown area (Banerjee, 2013), suggests that the Canadian situation is not different. So the answer to the question of whether an oil catastrophe can really be a first step in moving a country away from oil, according to these results, is closer to the negative, at least not in any drastic manner. It seems that the Exxon Valdez and Deepwater Horizon oil spills do show how attitudes change, but they also clearly demonstrate that this is a long historical process that is simultaneously dependent on the accompanying innovations in technology, and on the broader societal context (decades of debates over global climate change, for instance).

As was expected from the theoretical aspects developed in Chapter 3, this seems at least partially caused by the grasp that the public has on those incidents: an explosion and a shipwreck leading to a spill are things that are somewhat easy to understand, including the implications they may have. For more scientifically complex incidents, for 
instance in the nuclear sector, the stigma associated with any adverse event sticks for a long time, and the Three-Mile Island incident in 1979, and even more the Chernobyl case in 1986 have remained in collective memories for many countries. In other words, it seems the insecurity linked to this sector was never completely resolved, and any further incident is certain to bring up serious discussion about other options for electricity generation. The influence of this aspect should not be overstated, however, as one must keep in mind that alternatives to nuclear power for electricity generation are simply more readily available than for oil in transport, at least for the United States and Germany.

More generally, the negative impact of most energy scares on the environment and on public health also implies that renewable energy sources may have an advantage in comparison to other technologies: with the exception of the rare breach of a hydroelectric dam, most potential catastrophes linked to renewable sources like solar and wind energy have so far been financial and lacked the impressive symbols of danger associated with other types of incidents. This may change in the future, of course, but for now there is no stigma associated with most of these sources. This is not to say that there is no opposition, relating for example to the use of land in the food versus biofuel debate or to the siting of wind turbines. But these debates rarely occur in the special setting of highly disruptive social scares. The results of this project might prove interesting to proponents of renewable energy sources, who may see a possibility to capitalize on this advantage whenever a scare linked to another source occurs.

A final observation on energy policy regards developing and emerging economies, which were excluded from the scope of the project. Policy choices made 
today with regard to the development of a given energy mix will likely have impacts for the next century both within those countries, as well as across the world economy as a whole. Global issues, such a the competition for fossil fuel resources and the race for energy technologies less damaging for the environment and the earth's climate, add up to the already tall task for low-income countries to ensure their own energy security, required as a foundation for their development. These governments face constraints that are largely different from their counterparts in high-income countries, including whether to privilege cheaper sources for faster economic growth or more sustainable (but expensive) ones, how to develop their infrastructure efficiently to reach remote regions of large territories, and how to ensure supply security. Hence understanding the impact of energy scares on energy policy in those contexts is an avenue that is certainly worth exploring, and much work remains to be done to investigate the applicability of this project's insights for those very different political environments.

\subsubsection{On the study of policy change}

This project started with its first objective being to provide a more appropriate and informative framework to understand the policy process that follows from social scares, taking a "building-block" approach to theory building. Apart from the specific items mentioned above and others discussed in the previous four chapters, the case studies suggest a few more general insights. A first is that I find little use in focusing attention on distinguishing precisely between different "degrees" of policy change. The findings of the case studies led to a typology that is based on the type of process that 
ensues in policy battles, rather than an attempt to classify these policies as being minor vs. major, or typical vs. atypical. This comes at the expense of a less precise dependent variable, but in the end the main purpose of analyzing these instances is to understand the processes and mechanisms, and not necessarily to have a clear metric just for the sake of measurement precision. For this reason, it seems substantially more informative to do these analyses with a focus on what the policy process looks like instead.

Finally, the third objective of the project was to get some information on policymaking during social scares in any sector, a second degree of external validity where generalizations could be attempted to areas other than energy. There was some adaptation necessary to go from the analytical framework developed in the first part of the dissertation to a model to study energy scares more specifically. However, after conducting the main case studies, and after briefly testing a model refined from these results, the necessary adaptations remain minor. In other words, although one should be very cautious in generalizing the applicability of a model designed for a given sector to all policy areas, there is nothing in the results that suggest the model and its insights could not be used for social scares from other sectors. An expansion of this study to cases of social scares in other sectors would go a long way in confirming this potential generalization.

\subsection{Final words}

This dissertation was about energy policy, about social scares, and about how the policy process evolves in tense settings, where uncertainty is highest. The topic at hand, 
its socio-historical context, its political environment, and related fears and insecurities for both the present and the future, all combine to produce certain debates and political struggles that may have an important impact on a jurisdiction's policies, be it merely to provide new bases for future debates. The various coalitions that populate the political and societal spheres navigate these parallel forces, sometimes succeeding in "mastering uncertainty" - and thus the political outcome. 


\section{References}

Alaska Oil Spill Commission. (1990). Spill: The wreck of the Exxon Valdez. Implications for safe transportation (Final report). The State of Alaska.

Alberts, S., \& Lindgren, A. (1997). Leak, flood leave PM in hot water: Jean Chretien may have joked about the early disclosure of his policy book, but talk was serious about Manitoba floods. The Windsor Star [Windsor, Canada], p. A1.

Allison, G. T. (1971). Essence of decision: Explaining the Cuban missile crisis. Boston, MA: Little, Brown and Company.

A look back to 2005: President Bush and Katrina. (2010, August 29). CBSNews.com. Retrieved from http://www.cbsnews.com/news/a-look-back-to-2005-presidentbush-and-katrina/

Anderson, R. (1980, January 24). Election will determine response to oil crisis. The Globe and Mail, p. B2.

Arcand, D. (1998, January 14). On ramassera la facture après [We'll foot the bill later]. La Presse [Montreal, Canada], p. B1

Ascher, W. \& Steelman, T. (2006). Valuation in the environmental policy process. Policy Sciences, 39, 73-90.

Ascher, W., Steelman, T, \& Healy, R. (2010). Knowledge and environmental politcy: Reimagining the boundaries of science and politics. Cambridge, MA: The MIT Press. 
Baker, P. (2010, May 27). Obama extends moratorium; Agency chief resigns. The New York Times. $\quad$ Retrieved from: http://www.nytimes.com/2010/05/28/us/28drill.html?pagewanted=all\&_r=0

Balzacq, T. (2011). Securitization theory: How security problems emerge and dissolve. London, United Kingdom: Routledge.

Banerjee, Sidhartha. (2013, July 19). Death toll in Lac-Megantic disaster now set at 47. CTV News. Retrived from http://www.ctvnews.ca/canada/death-toll-in-lacmegantic-disaster-now-set-at-47-1.1374099

Baumgartner, F. R., \& Jones, B. D. (1993). Agendas and instability in American politics. Chicago, IL: University of Chicago Press.

Beck, U. (1992). Risk society: Towards a New Modernity (M. Ritter, Trans.). London, United Kingdom: SAGE Publications. (Original work published in 1986)

Berg, Robbie. (2010). Tropical cyclone report: Hurricane Ike. National Oceanic and Atmospheric Administration: National Hurricane Center. Retrieved from: http://www.nhc.noaa.gov/pdf/TCR-AL092008_Ike_3May10.pdf

Berling, T. V. (2011). Science and securitization: Objectivation, the authority of the speaker and mobilization of scientific facts. Security Dialogue, 42(4-5), 385-397.

Besley, T., \& Case, A. (2003). Political institutions and policy choices: Evidence from the United States. Journal of Economic Literature, 41, pp. 7-73.

Bigg, M. (2010, August 23). Compensation czar takes charge of \$20 billion BP fund. Reuters. Retrieved from http://www.reuters.com/article/2010/08/23/us-oil-spillfund-idUSTRE67J1F920100823 
Bigo, D. (2000). When two become one: internal and external securitisations in Europe. In M. Kelstrup \& M. C. Williams (Eds.), International relations theory and the politics of European integration: Power, security and community (pp. 171-204). London, United Kingdom: Routledge.

Bigo, D. (2002). Security and immigration: Toward a critique of the governmentality of unease. Alternatives, 27, 63-92.

Birkland, T. A. (1997). After disaster: Agenda setting, public policy, and focusing events. Washington, DC: Georgetown University Press.

Birkland, T. A. (1998a). Focusing events, mobilization, and agenda setting. Journal of Public Policy, 18(1), 53-74.

Birkland, T. A. (1998b). In the wake of the Exxon Valdez: How environmental disasters influence policy. Environment, 40(7), 4-32.

Birkland, T. A. (2004). "The world changed today": Agenda-setting and policy change in the wake of the September 11 terrorist attacks. Review of Policy Research, 21(2), 179-200.

Birkland, T. A. (2006). Lessons of disaster: Policy change after catastrophic events. Washington, DC: Georgetown University Press.

Birkland, T. A., \& Lawrence, R. G. (2009). Media framing and policy change after Columbine. American Behavioral Scientist, 52(10), 1405-1425.

Bisson, Bruno. (1999, February 24). Les décrets de Québec sont jugés illégaux [Quebec's decrees judged illegal]. La Presse [Montreal, Canada], p. A1. 
Blyth, M. (2002). Great transformations: Economic ideas and institutional change in the twentieth century. Cambridge, United Kingdom: Cambridge University Press.

Blyth, M. (2006). Great punctuations: Prediction, randomness, and the evolution of comparative political science. American Political Science Review, 100(4), 493498.

Bouchard, army winners in poll. (1998, January 25). The Gazette [Montreal, Canada], p. A3.

Bourdieu, P. (1986). The forms of capital. In J. Richardson (Ed.), Handbook of theory and research for the sociology of education (pp. 241-258). New York, NY: Greenwood.

Boyd, G. M. (1989, March 29). Bush sends team to assess cleanup. The New York Times, p. B5.

BP. (2013). Statistical review of world energy 2013. Retrieved from http://www.bp.com/en/global/corporate/about-bp/energy-economics/statisticalreview-of-world-energy-2013.html

BP Fighting A Two Front War As Macondo Continues To Bite And Production Drops. (2013, February 5). Forbes. Retrieved from http://www.forbes.com/sites/afontevecchia/2013/02/05/bp-fighting-a-two-frontwar-as-macondo-continues-to-bite-and-production-drops/

Bradshaw, G. A., \& Borchers, J. G. (2000). Uncertainty as information: Narrowing the science-policy gap. Conservation Ecology, 4(1). 
Brown, D. (1986, May 8). EEC extends ban on food imports/Fresh food from Yugoslavia halted following Soviet Chernobyl nuclear disaster. The Guardian.

Burns, W. J., Slovic, P., Kasperson, R. E., Kasperson, J. X., Renn, O., \& Emani, S. (1993). Incorporating structural models into research on the social amplification of risk: Implications for theory construction and decision making. Risk Analysis, $13(6), 611-623$.

Bush arrives on New Orleans tour. (2005, September 11). CNN.com. Retrieved from http://www.cnn.com/2005/US/09/11/katrina.impact/index.html?section=cnn_worl d

Buzan, B., Waever, O., Wilde, J. (1998). Security: A new framework for analysis. London, United Kingdom: Lynne Rienner.

Camia, C. (2010, May 26). Poll: majority give Obama, feds a failing grade on oil spill $\begin{array}{llll}\text { response. } & \text { Today. } & \text { Retrived }\end{array}$ http://content.usatoday.com/communities/theoval/post/2010/05/poll-majoritygive-obama-feds-failing-grade-on-oil-spill-response-/1\#.UvVkcUIXTvs

Campbell, C. (1998, February 27). Quebec okays Hydro strategy: Delays would only help competitors get to markets first, utility tells MNAs. The Gazette [Montreal, Canada], p. A5

'Can I quit now?' FEMA chief wrote as Katrina raged. (2005, November 4). CNN.com. Retrieved from http://www.cnn.com/2005/US/11/03/brown.fema.emails/ 
Carley, S., Lawrence, S., Brown, A., Nourafshan, A., Benami, E. (2011). Energy-based economic development. Renewable and Sustainable Energy Reviews, 15, 282295.

Carmichael, E. A., and Stewart, J. K. (1983). Lessons from the National Energy Program. Montreal, Canada: C.D. Howe Institute.

Cass, L. R. (2007). Measuring the domestic salience of international environmental norms: Climate change norms in American, German, and British climate policy debate. In M. E. Pettenger (Ed.), The social construction of climate change: Power, knowledge, norms, discourses (pp. 23-50). Burlington, VT: Ashgate Publishing Company.

Casey, K. L. (2008). Defining political capital: A reconsideration of Bourdieu's interconvertibility theory. Critique: A Worldwide Student Journal of Politics.

Chazan, G., \& Rigby, E. (2013). London brands US ban on BP 'excessive'. Financial Times, p. 1.

Cigler, A. J. (2004). Enron, a perceived crisis in public confidence, and the Bipartisan Campaign Reform Act of 2002. Review of Policy Research, 21(2), 233-252.

Ciută, F. (2010). Conceptual notes on energy security: Total or banal security? Security Dialogue, 41(2), 123-144.

Clarke, K., \& Edmiston, J. (2013, June 25). Dress shoes just don't cut it in mud; Disaster dress code. National Post [Toronto, Canada], p. A4. 
CNN Wire Staff. (2010, June 1). Feds have launched criminal oil spill investigation, AG $\begin{array}{llll}\text { says. CNN.com. } & \text { Retrieved }\end{array}$ http://www.cnn.com/2010/CRIME/06/01/holder.gulf.spill/

Cobb, C. (1998, January 11). 'It's very important that we work together': Prime minister flies into town ravaged by storm. The Ottawa Citizen, p. A3.

Cobb, R. W., \& Primo, D. M. (2003). The plane truth: Airline crashes, the media, and transportation policy. Washington, DC: Brookings Institution Press.

Commission of the European Communities. (2006). Communication from the Commission on a European Programme for Critical Infrastructure Protection (COM(2006) 786 final). Brussels, Belgium.

Connolly, Kate. (2010, August 31). Merkel risks voters' ire with fresh commitment to nuclear energy. The Guardian, p. 21.

Correljé, A., \& van der Linde, C. (2006). Energy supply and geopolitics: A European perspective. Energy Policy, 34, 532-543.

Corry, O. (2012). Securitisation and 'riskification': Second-order security and the politics of climate change. Millennium: Journal of International Studies, 40(2), 235-258.

Council on Foreign Relations. (2006). National security consequences of U.S. oil dependency. New York, NY: Author.

Cowell, Alan. (2011, June 2). Germans' deep suspicions of nuclear power reach a political tipping point. The New York Times, p. A11.

Crane, K., Goldthau, A., Toman, M., Light, T., Johnson, S. E., Nader, A., Rabasa, A., \& Dogo, H. (2009). Imported oil and U.S. national security. Santa Monica, CA: 
RAND Corporation Infrastructure, Safety, and Environment and National Security Research Division.

Cushman, J. H. (1989, May 12). Administration proposes creating oil spill fund. The New York Times, p. D2.

Daase, C., \& Kessler, O. (2007). Knowns and unknowns in the 'War on Terror': Uncertainty and the political construction of danger. Security Dialogue, 38(4), $411-434$.

Dams: Gov. Blunt proposes giving Mo. authority over federal structure. (2006, February 14). Greenwire.

David, M. (1998, January 29). Les malheurs de Daniel [Daniel's misfortunes]. Le Soleil [Quebec, Canada], p. B7.

Denney, D. (2005). Risk and society. London: SAGE Publications.

Dery, D. (1999). Policy by the way: When policy is incidental to making other policies. Journal of Public Policy, 18(2), 163-176.

Doern, G. B., and Toner, G. (1985). The politics of energy: The development and implementation of the NEP. Agincourt, Canada: Methuen Publications.

Done, K. (1986, April 30). The Soviet nuclear disaster: Sweden protests to Moscow over lack of warning. Financial Times, p. I3.

Dörner, D. (1996). The logic of failure: Recognizing and avoiding error in complex situations. New York, NY: Merloyd Lawrence.

Downs, A. (1972). Up and down with ecology - the 'Issue-attention cycle'. The Public Interest, 28, 38-50. 
Easter march in federal Germany draws to end. (1986, April 1). The Xinhua General Overseas News Service.

Elbe, S. (2008). Risking lives: AIDS, security and three concepts of risk. Security Dialogue, 39(2-3), 177-198.

Esping-Andersen, G. (1990). The three worlds of welfare capitalism. Princeton, NJ: Princeton University Press.

Experts differ on eventual Chernobyl toll. (1987, April 26). United Press International.

Exxon reduced its staff of oil spill experts. (1989, March 30). The New York Times, p. A20.

Exxon Valdez damage may hit $\$ 15$ billion. (1991, October 9). The New York Times, p. B7.

Fairhall, D., White, M., \& Tran, M. (1986, 3 May). Radiation cloud reaches Britain/Department of Health says no risk to public from Soviet Chernobyl nuclear accident. The Guardian .

Federal Bureau of Investigation. (2008, February 26). FBI 100 - 1993 Trade Center Bombing. Retrieved from: http://www.fbi.gov/news/stories/2008/february/tradebom_022608

FERC chair defends oversight of Missouri dam. (2006, January 26). Electric Power Daily, p. 2.

Ferrell, T. (1992, July 5). When gravity strikes back. The New York Times, p. 7-5. 
Fettweis, C. (2009). No blood for oil: Why resource wars are obsolete. In G. Luft \& A. Korin (Eds.), Energy security challenges for the $21^{\text {st }}$ century: A reference handbook (pp. 66-77). Santa Barbara, CA: ABC-CLIO.

Finnemore, M., \& Sikkink, K. (1998). International norm dynamics and political change. International Organization, 52(4), 887-917.

Fire deaths, damage come into focus as evacuees cope. (2007, October 29). CNN.com. Retrieved from http://www.cnn.com/2007/US/10/26/fire.wildfire.ca/index.html?eref=onion

Firestorm claims $9^{\text {th }}$ victim. (2007, November 8). NBCSanDiego.com. Retrieved from http://web.archive.org/web/20071202033303/http://www.nbcsandiego.com/news/ 14546772/detail.html?dl=headlineclick

Fischhoff, B., Slovic, P., Lichtenstein, S., Read, S., \& Combs, B. (1978). How safe is safe enough? A psychometric study of attitudes towards technological risks. Policy Sciences, 9(2): 127-152.

Foster, P. (1982). The sorcerer's apprentices: Canada's super-bureaucrats and the energy mess. Toronto, Canada: Collins.

Francoeur, L.-G. (1998, 10 January). Les conséquences de la tempête: Un avant-goût du réchauffement de la planète [The consequences of the storm: A primer of global warming]. Le Droit [Gatineau, Canada], p. A5.

Freudenburg, W. R. (2003). Institutional failure and the organizational amplification of risks: The need for a closer look. In N. Pidgeon, R. E. Kasperson, \& P. Slovic 
(Eds.), The social amplification of risk (pp. 104-120). Cambridge, United Kingdom: Cambridge University Press.

Frommer, F. (2008, November 13). NTSB: Design errors factor in 2007 bridge collapse. $\begin{array}{llll}\text { USA Today. } & \text { Retrieved }\end{array}$ http://usatoday30.usatoday.com/news/world/2008-11-13628592230_x.htm

Gagnon, L. (1998, January 13). Une ville déjà sous tutelle? [A city already under trusteeship?]. La Presse [Montreal, Canada], p. B3.

Geels, F. (2005). Technological transitions and system innovations: A co-evolutionary and socio-technical analysis: Cheltenham, United Kingdom: Edward Elgar.

George, A., \& Bennett, A. 2005. Case studies and theory development in the social sciences. Cambridge, MA: The MIT Press.

Gerasimchuk, I., Bridle, R., Beaton, C., \& Charles, C. (2012). State of play on biofuel subsidies: Are policies ready to shift? Winnipeg, Canada: International Institute for Sustainable Development.

Giddens, A. (1990). The consequences of Modernity. Cambridge, United Kingdom: Polity Press.

Giddens, A. (1991). Modernity and self-identity: Self and society in the late modern age. Stanford, CA: Stanford University Press.

Gov. Blunt issues disaster declaration in response to Taum Sauk dam flooding. (2005, December 14). US States News. 
Griffin, J. M. (2009). A smart energy policy: An economist's Rx for balancing cheap, clean, and secure energy. New Haven, CT: Yale University Press.

Grossman, P. Z. (2012). The logic of deflective action: US energy shocks and the US policy process. Journal of Public Policy, 32(1), 33-51.

Gunderson, L. G., Holling, C. S., \& Light, S. S. (Eds.). (1995). Barriers and bridges to the renewable of ecosystems and institutions. New York, NY: Columbia University Press.

Hand, E., \& Frankel, T. (2005, December 16). Most dams are unregulated: Reservoir collapse raises Missouri safety concerns. St. Louis Post-Dispatch, p. A1

Harrison, R. J. (1981). The constitutional context of Canada's National Energy Program. In E. H. Fry (Ed.), Energy development in Canada: The political, economic, and continental dimensions (pp. 65-76). Provo, UT: Center for International and Area Studies, Brigham Young University.

Hassan, O. (2010). Constructing crises, (In)securitising terror: The punctuated evoluation of EU counter-terror strategy. European Security, 19(3), 445-466.

Hart, P. t., Tindall, K., \& Brown, C. (2009). Crisis leadership of the Bush presidency: Advisory capacity and presidential performance in the acute stages of the 9/11 and Katrina crises. Presidential Studies Quarterly, 39(3), 473-493.

Hatter, D. (1986, November 1). Chernobyl disaster fuels German fear of nuclear dangers. The Financial Post [Toronto, Canada], p. 38.

Heclo, H. (1974). Modern social politics in Britain and Sweden: From relief to income maintenance. New Haven, CT: Yale University PRess. 
Herrick, C. N. (2004). Objectivity versus narrative coherence: Science, environmental policy, and the U.S. Data Quality Act. Environmental Science \& Policy, 7, 419433.

Hofman, A. J., \& Jennings, P. D. (2011). The BP oil spill as cultural anomaly? Institutional context, conflict, and change. Journal of Management Inquiry, 20(2), $100-112$.

Howlett, M., Ramesh, M., \& Perl, A. (2009). Studying public policy: Policy cycles \& policy subsystems. Don Mills, Canada: Oxford University Press.

Ice storm most disruptive in our history: StatsCan. (1998). The Record [Kitchener, Canada], p. A3.

International Energy Agency [IEA]. (2013a). Energy balances of non-OECD countries. Paris, France: Author.

International Energy Agency [IEA]. (2013b). Energy balances of OECD countries. Paris, France: Author.

International Energy Agency Renewable Energy Technology Deployment, de Vos, R., \& Sawin, J. (2012). READy: Renewable energy action on deployment presenting: policies for accelerated deployment of renewable energy. Oxford, United Kingdom: Elsevier.

Institute for Energy Research. (2010). A primer on energy and the economy: Energy's large share of the economy requires caution in determining policies that affect it. Washington, $\quad$ DC: Author. Retrieved from: http://www.instituteforenergyresearch.org/2010/02/16/a-primer-on-energy-and- 
the-economy-energys-large-share-of-the-economy-requires-caution-indetermining-policies-that-affect-it/

Jacobsson, S., \& Lauber, V. (2006). The politics and policy of energy system transformation - explaining the German diffusion of renewable energy technology. Energy Policy, 34, 256-276.

James, P. M., Michelin, R. (1989). The Canadian National Energy Program and its Aftermath: Perspectives on an Era of Confrontation. American Review of Canadian Studies, 19(1), 59-81.

James, S. D. (2009, April 13). Columbine shootings 10 years later: Students, teacher still haunted by post-traumatic stress. ABCNews. Retrieved from http://abcnews.go.com/Health/story?id=7300782\&page=1\#.Ua4zCuuXxTA

Jautz, K. (1987, January 26). Kohl Blames Infighting, Environmental Disasters Party's Losses. The Associated Press .

Jenkins, B. (1986). Reexamining the 'obsolescing bargain': a study of Canada's National Energy Program. International Organization, 40(1), 139-165.

Jensen, G. (1987, 24 April). Europe still paying price for Chernobyl. United Press International.

Jonsson, G. (2006, January 18). Blunt, Nixon battle over Taum Sauk probe. St. Louis Post-Dispatch, p. B12.

Joppke, C. (1993). Mobilizing against nuclear energy: A comparison of Germany and the United States. Berkeley: University of California Press. 
Kahneman, D. (2003). A perspective on judgment and choice: Mapping bounded rationality. American Psychologist, 58(9), 697-720.

Kahneman, D., \& Tversky, A. (1973). On the psychology of prediction. Psychological Review, 80(4), 237-251.

Kahneman, D., \& Tversky, A. (1979). Prospect theory: An analysis of decision under risk. Econometrica, 47(2), 263-291.

Karp, L., \& Stevenson, M. (2012). Green industrial policy. Trade and theory (Policy research working paper 6238). Washington, DC: The World Bank Development Research Group Environment and Energy Team \& Sustainable Development Network Office of the Chief Economist.

Kasperson, R. E. 1992. The social amplification of risk: Progress in developing an integrative framework. In S. Krimsky \& D. Golding (Eds.), Social theories of risk (pp. 153-178). Westport, CT: Praeger.

Kasperson, R. E., \& J. X. Kasperson. (1996). The social amplification and attenuation of risk. The ANNALS of the American Academy of Political and Social Science, 545, 95-105.

Kasperson, J. X., Kasperson, R. E., Pidgeon, N., \& Slovic, P. (2003). The social amplification of risk: Assessing fifteen years of research and theory. In N. Pidgeon, R. E. Kasperson, \& P. Slovic (Eds.), The social amplification of risk (pp. 13-46). Cambridge, United Kingdom: Cambridge University Press. 
Kasperson, R. E., Renn, O., Slovic, P., Brown, H. S., Emel, J., Goble, R., Kasperson, J. X., \& Ratick, S. (1988). The social amplification of risk: A conceptual framework. Risk Analysis, 8(2), 177-187.

Kingdon, J. W. (1995). Agendas, alternatives, and public policy. New York, NY: Harper Collins.

Klare, M. T. (2007). The futile pursuit of 'energy security' by military force. Brown Journal of World Affairs 13(2), 139-153.

Klare, M. T. (2009). There will be blood: Political violence, regional warfare, and the risk of great-power conflict over contested energy sources. In G. Luft \& A. Korin (Eds.), Energy security challenges for the $21^{\text {st }}$ century: A reference handbook (pp. 44-65). Santa Barbara, CA: ABC-CLIO.

Knabb, R. D., Rhome, J. R., \& Brown, D. P. (2005). Tropical cyclone report: Hurricane Katrina. National Oceanic and Atmospheric Administration: National Hurricane Center. Retrieved from http://www.nhc.noaa.gov/pdf/TCRAL122005_Katrina.pdf

Knight, F. H. (1964). Risk, uncertainty, and profit. New York, NY: Sentry Press.

Krauss, C., \& Schwartz, J. (2012, November 15). BP will plead guilty and pay over $\$ 4$ billion. The New York Times. Retrieved from: http://www.nytimes.com/2012/11/16/business/global/16ihtbp16.html?pagewanted $=$ all\&_r $=0$

Kurtz, R. S. (2004). Coastal oil pollution: Spills, crisis, and policy change. Review of Policy Research, 21(2), 201-219. 
Ladislaw, S., Zyle, K., \& Childs, B. (2008). Managing the transition to a secure, lowcarbon energy future (Issue brief: Energy security and climate change). Washington, DC: World Resources Institute/Center for Strategic \& International Studies.

Laird, F. N., \& Stefes, C. (2009). The diverging paths of German and United States policies for renewable energy: Sources of difference. Energy Policy, 37, 26192629.

Lauber, V., \& Mez, L. (2004). Three decades of renewable electricity policies in Germany. Energy \& Environment, 15(4), 599-623.

Lauber, V., \& Mez, L. (2006). Renewable electricity policy in Germany, 1974-2005. Bulletin of Science, Technology \& Society, 105-120.

Leiser, K. (2006a, January 29). Who is regulating the environment, Blunt or Nixon? Actions in the wake of the Taum Sauk plant reservoir, a battle over the sale of a bridge and more have some accusing the two of playing politics. St. Louis PostDispatch, p. B1.

Leiser, K. (2006b, March 2). Bill calls for increased state oversight of dams. St. Louis Post-Dispatch, p. B2.

Leiser, K., \& Naudi, J. (2005, December 17). Blunt orders review of dam safety rules. St. Louis Post-Dispatch, p. A10.

Leonard, Christopher. (2005a, December 15). Two injured children improve following reservoir breach. The Associated Press State \& Local Wire. 
Leonard, Christopher. (2005b, December 16). Gov. Blunt says Ameren should pay all costs from reservoir breach. The Associated Press State \& Local Wire.

Lévesque, K. (2008, January 5). Autopsie d'un cauchemar de glace [Autopsy of an ice nightmare]. Le Devoir [Montreal, Canada]. Retrieved from: http://www.ledevoir.com/politique/quebec/170810/autopsie-d-un-cauchemar-deglace

Lovaas, D. (2009). Balancing energy security and the environment. In G. Luft \& A. Korin (Eds.), Energy security challenges for the $21^{\text {st }}$ century: A reference handbook (pp. 318-334). Santa Barbara, CA: ABC-CLIO.

Luhmann, Niklas. (1979). Trust and power. New York, NY: John Wiley \& Sons.

MacDonald, I. R., Amos, J., Crone, T., \& Wereley, S. (2010, May 22). The measure of a disaster. The New York Times, p. A17

Maltais, M. (1998, January 14). Le colosse humilié [The colossus humiliated]. Le Droit [Gatineau, Canada], p. 14.

Manitoba delays plans to cut dike to contain flood; Harper, premier pay visit as planned break pushed back. (2011, May 12). Edmonton Journal, p. A8.

Marcel, V. (2006). Oil titans: National oil companies in the Middle East. Brookings Institution Press and Chatham House.

Marquiss, K. D. K. (2007). The Exxon Valdez oil spill: Industry response and the evolution of environmental policy (Doctoral dissertation). Philadelphia: University of Pennsylvania. Available from ProQuest (AAI3260952). 
Maser, P. (1989, December 12). Thousands share gried at funeral; 'I ask God to give you peace'. Edmonton Journal, p. A3.

McKee, C. (2014). Oklahoma city to Rocky council; Planning: new director appointed. The Morning Bulletin [Rockhampton, Australia], p. 7.

Merriam-Webster's collegiate dictionary (11th ed.). (2003). Springfield, MA: MerriamWebster.

Murphy, R. (2009). Leadership in disaster: learning for a future with global climate change. Montreal, Canada: McGill-Queen's University Press.

Nagourney, A. (2012, January 9). Subdued remembrance of a dark day in Tucson. The New York Times, p. A8.

National Commission on Terrorist Attacks upon the United States. (2004). The 9/11 $\begin{array}{lll}\text { Commission } & \text { Report. } & \text { from }\end{array}$ http://www.gpoaccess.gov/911/pdf/fullreport.pdf

National Oceanic and Atmospheric Administration. (2012). The historic tornadoes of $\begin{array}{lll}\text { April 2011. } & \text { Retrived } & \text { from }\end{array}$ http://www.nws.noaa.gov/os/assessments/pdfs/historic_tornadoes.pdf

National Oceanic and Atmospheric Administration, National Climatic Data Center. (2013). Billion-dollar weather/climate disasters. Retrieved from http://www.ncdc.noaa.gov/billions/events.

National Oceanic and Atmospheric Administration. (2013). Hurricane/post-tropical cyclone Sandy, October 22-29, 2012. Retrieved from http://www.nws.noaa.gov/os/assessments/pdfs/Sandy13.pdf 
National Response Team. (2011). On scene coordinator report Deepwater Horizon oil spill.

Neitzel, S. L. (2008, October 29). Panel to review arson claims in deadly 1977 Kentucky fire. The New York Times, p. A14.

Noël, P. (2008, January 11). Challenging the myths of energy security. Financial Times. Retrieved from http://www.ft.com/intl/cms/s/0/40c2f8aa-bf93-11dc-80520000779fd2ac.html\#axzz2w8L8ZVHE

Nye, J. S. (1982). Review: Energy and security in the 1980s. World Politics, 35(1), 121134.

Organization for Economic Cooperation and Development [OECD]. (2012). Inventory of estimated budgetary support and tax expenditures for fossil fuels 2013. Paris, France: Author.

Oreskes, N. (2004). Science and public policy: what's proof got to do with it? Environmental Science \& Policy, 7, 369-383.

Pala, V. S. (2006). Novembre 2005: sous les émeutes urbaines, la politique [November 2005: under the urban riots, politics]. French Politics, Culture \& Society, 24(3), $111-129$.

Palm, R., \& Hodgson, M. E. (1992). After a California earthquake: Attitude and behavior change. Chicago, IL: The University of Chicago Press.

Patterson, P. (1989). Reporting Chernobyl: Cutting the government fog to cover the nuclear cloud. In L. M. Walters, L. Wilkins, \& T. Walters (Eds.), Bad tidings: 
Communication and catastrophe (pp. 131-148). Hillsdale, NJ: Lawrence Erlbaum Associates.

Peltzman, S. (1980). The growth of government. Journal of Law and Economics, 23(2), 209-287.

Peters, B. G., \& Hogwood, B. W. (1985). In search of the issue-attention cycle. Journal of Politics, 47(1), 238-253.

Pielke, R. A., Jr. (2004). When scientists politicize science: Making sense of controversy over The Skeptical Environmentalist. Environmental Science \& Policy, 7, 405417.

Pielke, R. A., Jr. (2007). The honest broker: Making sense of science in policy and politics. Cambridge, United Kingdom: Cambridge University Press.

Pineau, Y. (1998, 26 January). L'armée et André Caillé profitent de la crise [The army and André Caillé benefit from the crisis]. La Presse [Montreal, Canada], p. A8.

Police: Second person injured in Connecticut school shooting survived. (2012, December 17). NBC News. $\quad$ Retrieved from http://usnews.nbcnews.com/_news/2012/12/17/15969867-police-second-personinjured-in-connecticut-school-shooting-survived?lite

Pratt, L. (1982). Energy: The Roots of National Policy. Studies in Political Economy, 7, $27-58$.

Prices rise as supplies shrink: Line-ups, fights for gasoline spread across U.S. (1979, May 8). The Globe and Mail. 
Putnam, R. (1988). Diplomacy and domestic politics: The logic of two-level games. International Organization, 42(3), 427-460.

Quebec. (1999). Facing the unforeseeable: Lessons from the Ice Storm of '98. Report of the Commission scientifique et technique chargée d'analyser les événements relatifs à la tempête de verglas survenue du 5 au 9 janvier 1998. Sainte-Foy, Canada: Les Publications du Québec.

Radio-Canada (Producer). (1998, January 15). Les héros du pylôme [The pylone heroes, video news report]. Montreal, Canada: Author. Retrieved from: http://archives.radio-canada.ca/emissions/708/

Radler, M., \& Koottungal, L. (2008). OGJ100 group posts improved 2007 results. Oil \& Gas Journal, 106, 34-39.

Ragin, C.. 1987. The comparative method: Moving beyond qualitative and quantitative strategies. Berkeley: University of California Press.

Rayner, S., and Cantor, R. (1987). How fait is safe enough? The cultural approach to societal technology choice. Risk Analysis, 7(1): 3-9.

Reavis, D. J. (1998). The ashes of Waco: An investigation. Syracuse, NY: Syracuse University Press.

Renewable Energy Policy Network for the 21st Century [REN21]. (2010). Renewables 2010 Global status report. Paris, France: REN21 Secretariat.

Renn, O. (1991). Risk communication and the social amplification of risk. In R. E. Kasperson \& P. J. M. Stallen (Eds.), Communicating risks to the public (pp. 287324). Boston, MA: Kluwer Academic. 
Rep. Emerson radio address: Flood immunity. (2005, December 31). US Fed News.

Rewind 2005: The top 10 stories. (2006, January 1). FoxNews.com. Retrieved from http://www.foxnews.com/story/2006/01/01/rewind-2005-top-10-stories/

Riga, A. (1998, January 21). Hydro's future is hotly debated on Net. The Gazette [Montreal, Canada], p. D1.

Robertson, C., \& Krauss, C. (2010, August 3). Gulf spill largest of its kind, scientists say. The New York Times, p. A14.

Rosa, E. A. (2003). The logical structure of the social amplification of risk framework (SARF): Metatheoretical foundations and policy implications. In N. Pidgeon, R. E. Kasperson, \& P. Slovic (Eds.), The social amplification of risk (pp. 47-79). Cambridge, United Kingdom: Cambridge University Press.

Rothman, (2012). Battle for rhetorical dominance: Selective presentations and frames in the climate change debates. Paper presented at the International Studies Association Annual Convention, San Diego, CA.

Rubin, J., \& Smith, M. (2013, August 6). 'I am the shooter,' Nidal Hasan tells Fort Hood $\begin{array}{llll}\text { court-martial. } & C N N . & \text { Retrieved } & \text { from }\end{array}$ http://www.cnn.com/2013/08/06/justice/hasan-courtmartial/index.html?hpt=hp_t2

Rusk, J. (1980, 14 January). Energy issue the great divider when three platforms are compared. The Globe and Mail, p. 9. 
Sabatier, P. A., \& Weible, C. M. (2007). The Advocacy Coalition Framework: Innovations and clarifications. In P. A. Sabatier (Ed.), Theories of the policy process (pp. 189-220). Boulder, CO: Westview Press.

Salter, M. B. (2008). Imagining numbers: Risk, quantification, and aviation security. Security Dialogue, 39(2-3), 243-266.

Sampson, A. (1975). The seven sisters: The great oil companies and the world they made. New York, NY: The Viking Press.

Sarewitz, D. (2004). How science makes environmental controversies worse. Environmental Science \& Policy, 7, 385-403.

Schmidt, M. S. (2013, August 2). F.B.I. said to find it could not have averted Boston attack. The New York Times, p. 13.

Seabrooke, L. (2007a). The everyday social sources of economic crises: From "great frustrations" to "great revelations" in interwar Britain. International Studies Quarterly, 51, 795-810.

Seabrooke, L. (2007b). Varieties of economic constructivism in political economy: Uncertain times call for disparate measures. Review of International Political Economy, 14(2), 371-385.

Shabecoff, P. (1989a, April 7). Balancing need and risk in pursuit of oil. The New York Times.

Shabecoff, P. (1989b, April 20). Oil industry rebuked as Senate hearings begin in Alaska oil spill. The New York Times. 
Skocpol, T., \& Rueschemeyer, D. (1996). Introduction. In D. Rueschemeyer \& T. Skocpol (Eds.), States, social knowledge, and the origins of modern social policies (pp. 3-13). Princeton, NJ: Princeton University Press.

Slovic, P. (2000). Introduction and overview. In P. Slovic (Ed.), The perception of risk (pp. xxi-xxxvii). London, United Kindgom: Earthscan Publications.

Slovic, P., Fischhoff, B., \& Lichtenstein, S. (2000). Cognitive processes and societal risk taking. In P. Slovic (Ed.), The perception of risk (pp. 32-50). London, United Kingdom: Earthscan Publications.

Slovic, P., Kunreuther, H., \& White, G. F. (2000). Decision processes, rationality and adjustment to natural hazards. In P. Slovic (Ed.), The perception of risk (pp. 131). London: Earthscan Publications Ltd.

Smith, C. (1992). Media and apocalypse: News coverage of the Yellowstone forest fires, oil spill, and Loma Prieta earthquake. Westport, CT: Greenwood Press.

Soroka, S. N. (2002). Issue attributes and agenda-setting by media, the public, and policymakers in Canada. International Journal of Public Opinion Research, 14(3), 264-285.

Sovacool, B. K. (2008). The costs of failure: A preliminary assessment of major energy accidents, 1907-2007. Energy Policy, 36, 1802-1820.

Sovacool, B. K., \& Valentine, S. V. (2012). The national politics of nuclear power: Economics, security, and governance: London, United Kingdom: Routledge.

SPD agreed to end nuclear power in West Germany. (1986, May 22). The Times [London, United Kingdom]. 
Starr, C. (1969). Social benefit versus technological risk. Science, New Series, 165(3899), 1232-1238.

Statistics Canada. (1998). The St. Lawrence River Valley 1998 ice storm: Maps and facts. Statistics Canada.

Stevens, W. K. (1989, April 2). Oil exacts a price from the Earth. The New York Times.

Stewart, S. R. (2005). Tropical cyclone report: Hurricane Ivan. National Oceanic and Atmospheric Administration: National Hurricane Center. Retrieved from http://www.nhc.noaa.gov/2004ivan.shtml

Stoffer, P. W. (2005). The San Andreas Fault In The San Francisco Bay Area, California: A Geology Fieldtrip Guidebook To Selected Stops On Public Lands (U.S. Geological Survey Open-File Report 2005-1127). U.S. Department of Interior. Retrieved from http://pubs.usgs.gov/of/2005/1127/

Stone, D. (2012). Policy paradox: The art of political decision making. New York, NY: W. W. Norton \& Company.

Straub, N. (2010, May 20). Interior unveils plan to split MMS into to agencies. The New $\begin{array}{lll}\text { York } & \text { Times. } & \text { Retrieved }\end{array}$ http://www.nytimes.com/gwire/2010/05/20/20greenwire-interior-unveils-plan-tosplit-mms-into-3-agen-72654.html

Sweet, D. M. (2009). The decentralized energy paradigm. In G. Luft \& A. Korin (Eds.), Energy security challenges for the $21^{\text {st }}$ century: A reference handbook (pp. 308317). Santa Barbara, CA: ABC-CLIO. 
Tagliabue, J. (1986, 4 May). In Europe, callers don't ask about weather. New York Times, p. 21.

Talev, Margaret. (2010, May 14). An angry Obama pledges to get tough on offshore drilling. McClatchy Washington Bureau.

Tertzakian, P. (2006). A thousand barrels a second: The coming oil break point and the challenges facing an energy dependent world. New York, NY: McGraw-Hill.

The budget objective is to counter unemployment and inflation, Turner tells the House. (1973, February 20). The Globe and Mail, p. 10.

The White House Office of the Press Secretary. (2010, June 15). Remarks by the President to the Nation on the BP Oil Spill. Retrieve from: http://www.whitehouse.gov/the-press-office/remarks-president-nation-bp-oil-spill

Tilly, C. (1990). Coercion, capital, and European States, AD 990-1990. Cambridge, MA: B. Blackwell.

Tomforde, A. (1986, May 15). Kohl rejects call to close all nuclear power plants/West German Chancellor speaks on impact of Soviet Chernobyl disaster. The Guardian.

Torvanger, A., \& Meadowcroft, J. (2011). The political economy of technology support: Making decisions about carbon capture and storage and low carbon energy technologies. Global Environmental Change, 21(2), 303-312.

True, J. L., Jones, B. D., \& Baumgartner, F. R. (2007). Punctuated-equilibrium theory: Explaining stability and change in public policymaking. In P. A. Sabatier (Ed.), Theories of the policy process (pp. 155-188). Boulder, CO: Westview Press. 
Trueman, M. (1980a, 26 January). Liberals promise two prices for oil. The Globe and Mail, p. 1.

Trueman, M. (1980b, 23 January). Trudeau promises varying price on oil. The Globe and Mail, p. 9.

Turner, J. H. (1988). A theory of social interaction. Stanford, CA: Stanford University Press.

Tversky, A., \& Kahneman, D. (1974). Judgment under uncertainty: Heuristics and Biases. Science, New Series, 185(4157), 1124-1131.

Unemployment, inflation blamed by Bourassa for Liberals defeat. (1977, October 24). The Globe and Mail, p. 8.

Ungar, S. (1992). The rise and (relative) decline of global warming as a social problem. The Sociological Quarterly, 33(4), 483-501.

Ungar, S. (2000). Knowledge, ignorance and the popular culture: climate change versus the ozone hole. Public Understanding of Science, 9, 297-312.

U.S. Department of Homeland Security. (2003). Homeland Security Presidential Directive 7: Critical Infrastructure Identification, Prioritization, and Protection. Retrived from: https://www.dhs.gov/homeland-security-presidential-directive-7\#1

U.S. Environment Protection Agency. (2011). Oil Pollution Act overview. Retrieved from http://www.epa.gov/emergencies/content/lawsregs/opaover.htm

Uslaner, E. M. (1989). Looking Forward and Looking Backward: Prospective and Retrospective Voting in the 1980 Federal Elections in Canada. British Journal of Political Science, 19(4), 495-513. 
Van Loon, J. (2002). Risk and technological culture: Toward a sociology of virulence. London, United Kingdom: Routledge.

Virginia Tech Review Panel. (2007). Mass shootings at Virginia Tech (Report of the Review Panel).

Wald, M. L. (1989, March 28). Exxon may have small liability in spill claims. The New York Times, p. B7.

Wald, M., \& Davey, M. (2008, January 16). States advised to check for a bridge design flaw. The New York Times, p. A17.

Webb, Tim. (2010, May 14). BP boss admits job on the line over Gulf oil spill. The Guardian. Retrived from: http://www.theguardian.com/business/2010/may/13/bpboss-admits-mistakes-gulf-oil-spill

Weber, Max. (2009). Science as a vocation. In H. H. Gerth \& C. W. Mills (Eds.), From Max Weber: Essays in sociology (pp. 129-156). London, United Kingdom: Routledge.

Weingart, P., Engels, A., \& Pansegrau, P. (2000). Risks of communication: Discourses on climate change in science, politics, and the mass media. Public Understanding of Science, 9, 261-283.

Welch, W. M., \& Joyner, C. (2010, May 25). Memorial service honors 11 dead oil rig workers. USA Today.

West Germany issues warning on milk; Radiation levels up in Balkans. (1986, May 2). The Associated Press. 
White, S. (1999, January 2). Ice storm picked top news story of 1998 Storm affected millions in Quebec, Ontario and N.B. The Times [Moncton, Canada].

World Health Organization. (2006). Health effects of the Chernobyl accident and special health care programmes (Report of the UN Chernobyl Forum). Geneva, Switzerland: Author.

Wicker, T. (1989, April 4). Oil can be replaced. The New York Times, p. A27.

Widmaier, W. W. (2004). The social construction of the 'impossible trinity': The intersubjective bases of monetary cooperation. International Studies Quarterly, $48,433-453$.

Widmaier, W. W. (2007). Constructing foreign policy crises: Interpretive leadership in the Cold War and War on Terrorism. International Studies Quarterly, 51, 779794.

Widmaier, W. W., Blyth, M., \& Seabrooke, L. (2007). Exogenous shocks or endogenous constructions? The meanings of wars and crises. International Studies Quarterly, $51,747-759$.

Wilkinson, C., Allan, S., Anderson, A., \& Petersen, A. (2007). From uncertainty to risk? Scientific and news media portrayals of nanoparticle safety. Health, Risk \& Society, 9(2), 145-157.

Williams, P. D. (2008). Security studies: An introduction. In Paul D. Williams (Ed.), Security studies: An introduction (pp. 1-12). London, United Kingdom: Routledge. 
Wilton, K., \& Semenak, S. (1998). 'Help your neighbors,' Bouchard pleads special storm coverage: Plunging temperatures drive Quebecers reluctantly from homes. The Ottawa Citizen, p. A1.

Yablokov, A. V., Nesterenko, V. B., \& Nesterenko, A. V. (2009). Chernobyl: consequences of the catastrophe for people and the environment. Annals of the New York Academy of Sciences, 1181.

Yakabuski, K. (1998, January 20). Critics blast above-ground hydro plan Bouchard defends approval of new transmission line, calling recommended underground option 'horribly costly'. The Globe and Mail, p. A3

Yergin, D. (2008). The prize: The epic quest for oil, money \& power. New York, NY: Free Press.

Youngs, R. (2009). Energy security: Europe's new foreign policy challenge. New York, NY: Routledge.

Zald, M. N. (1996). Culture, ideology, and strategic framing. In D. McAdam, J. D. McCarthy, \& M. N. Zald (Eds.), Comparative perspectives on social movements: Political opportunities, mobilizing structures, and cultural framings (pp. 261274). Cambridge, United Kingdom: Cambridge University Press. 


\section{Appendix}

References for Table 1:

1. 1977 Beverly Hills Supper Club fire: Neitzel (2008)

2. 1979 Three mile island: Sovacool (2008)

3. 1981 Hyatt Regency walkway collapse: Ferrell (1992)

4. 1989 San Francisco earthquake: Palm and (Hodgson, 1992, p. 63); Stoffer (2005)

5. 1989 Exxon Valdez oil spill: "Exxon Valdez damage may hit \$15 billion” (1991)

6. 1993 End of Waco Siege: Reavis (1998)

7. 1993 World Trade Center bombing: Federal Bureau of Investigation (2008)

8. 1995 Oklahoma City bombing: McKee (2014)

9. 1999 Columbine High School massacre: James (2009)

10. 2001 September 11th attacks: National Commission on Terrorist Attacks upon the United States (2004)

11. 2005 Hurricane Katrina: Knabb, Rhome, \& Brown (2005)

12. 2004 Hurricane Ivan: Stewart (2005)

13. 2007 Minnesota bridge collapse: Frommer (2008); Wald \& Davey (2008)

14. 2007 Virginia Tech massacre: Virginia Tech Review Panel (2007)

15. 2007 California wild fires: "Firestorm claims 9th victim" (2007); "Fire deaths, damage come into focus as evacuees cope" (2007)

16. 2008 Hurricane Ike: Berg (2010)

17. 2009 Fort Hood shooting: Rubin and Smith (2013)

18. 2010 BP oil spill: "BP Fighting A Two Front War” (2013); Welch \& Joyner (2010) 
19. 2011 Tucson shooting: Nagourney (2012)

20. 2011 Tornado outbreak: National Oceanic and Atmospheric Administration (2012)

21. 2012 Sandy Hook Elem. school shooting: "Police: Second person injured in Connecticut school shooting survived" (2012)

22. 2012 Hurricane Sandy: National Oceanic and Atmospheric Administration (2013)

23. 2013 Boston marathon bombings: Schmidt (2013) 